Sofia Nascimento dos Santos

\title{
O papel de galectina-3 na via de sinalização Notch, angiogênese tumoral e resistência a quimioterápicos.
}

Tese apresentada à Faculdade de Medicina da Universidade de São Paulo para obtenção do título de Doutor em Ciências

Programa: Oncologia

Orientador: Dr. Emerson Soares Bernardes

São Paulo

2015 


\section{Dados Internacionais de Catalogação na Publicação (CIP)}

Preparada pela Biblioteca da

Faculdade de Medicina da Universidade de São Paulo

Creprodução autorizada pelo autor

\section{Santos, Sofia Nascimento dos}

O papel de galectina-3 na via de sinalização Notch, angiogênese tumoral e resistência a quimioterápicos / Sofia Nascimento dos Santos. -- São Paulo, 2015.

Tese(doutorado)--Faculdade de Medicina da Universidade de São Paulo. Programa de Oncologia.

Orientador: Emerson Soares Bernardes.

Descritores: 1.Galectina-3 2.Receptores Notch 3.Neoplasias da mama 4.Neoplasias gástricas 5.Resistência a medicamentos antineoplásicos 6.Neovascularização patológica

USP/FM/DBD-404/15 
À mes chers parents...

"I don't know anything, but I do know that everything is interesting if you go into it deeply enough" Richard Feynman 


\section{Acknowledgments}

I would like to express my deepest gratitude to my supervisor Dr. Emerson Bernardes for his guidance and encouragement during my $\mathrm{PhD}$ project. His professional leadership, excellent scientific methods, and critical thinking have been, and will still be, a great benefit to my scientific career. He motivated me to not only grow as a biologist but also as an independent thinker.

I am grateful to Prof. Roger Chammas who took me into his lab, and for his guidance in getting my PhD started on the right foot. He was a constant source of encouragement and enthusiasm and provided me an exceptional opportunity to gain a wider breadth of experience.

I would like to express my appreciation to Prof. Adrian Harris for providing me with the opportunity to work in his laboratory and, for his suggestions and help throughout the research. He provided invaluable outsiders perspectives on my research when most needed.

I was fortunate to have the chance to work with Dr. Helen Sheldon who patiently taught me several laboratory techniques and who worked closely with me pursuing the role of galectin-3 in angiogenesis. I am grateful for her tremendous help, useful discussions and continuous support during my stay in Oxford.

To the Coordination for the Improvement of Higher Education Personnel (CAPES) for the PhD scholarship.

I am grateful to everyone who was involved in one way or another in providing the data used in the present thesis, in particular Prof. Celso Reis, Prof. Manuel Vilanova, Prof. Marcelo Baruffi, Prof. Márcia El-Cheikh, Prof. Suely Marie, Dr Sueli Oba and Mara Junqueira.

I would like to thank the various members of the hypoxia and angiogenesis group from the WIMM, the cellular biology group from ICESP, the laboratory of investigation in neurology from FMUSP and the Radiopharmacy center group from 
IPEN with whom I had the opportunity to work. They provided a friendly and cooperative atmosphere at work and also useful feedback and insightful comments on my work.

I also had the opportunity to mentor an exchange student, Inês Rodrigues who with much enthusiasm faced a challenging project over the course of six months.

A special thanks to Sam Oats, Ruud Van Stiphout, Syed Haider, Sheng Yu and Katharina Mondel, who made my time in Oxford a lot more fun. Laís Cardoso, Roseli Silva and Silvina Bustos for their friendship and support in São Paulo.

Last but not the least, I would like to thank my parents Matilde and Baltazar, and my little sister Cindy for unconditional support throughout my life and my studies 
Esta tese está de acordo com as seguintes normas, em vigor no momento desta publicação: Referências: adaptado de International Committee of Medical Journals Editors (Vancouver) Universidade de São Paulo. Faculdade de Medicina. Divisão de Biblioteca e Documentação. Guia de apresentação de dissertações, teses e monografias. Elaborado por Anneliese Carneiro da Cunha, Maria Julia de A. L. Freddi, Maria F. Crestana, Marinalva de Souza Aragão, Suely Campos Cardoso, Valéria Vilhena. 3a ed. São Paulo: Divisão de Biblioteca e Documentação; 2011.

Abreviaturas dos títulos dos periódicos de acordo com List of Journals Indexed in Index Medicus 


\section{Table of contents}

Abbreviations

List of figures

List of tables

Resumo

Abstract

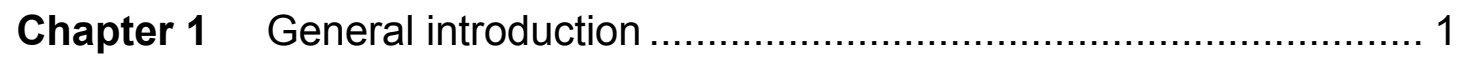

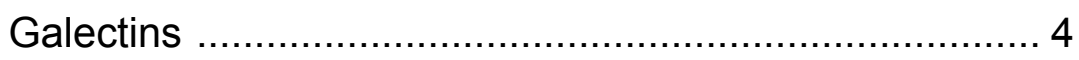

Notch signaling pathway..................................... 14

Tumor glycosylation ........................................... 20

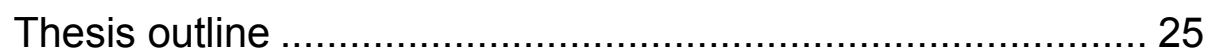

Chapter 2 Galectin-1 and galectin-3 differentially modulate Notch signaling in gastric cancer

Chapter 3 Galectin-3 acts as an angiogenic switch to induce tumor angiogenesis by increasing Jagged1/Notch activation 57

Chapter 4 O-glycan sialylation alters galectin-3 subcellular localization and decreases chemotherapy sensitivity in gastric cancer 103

Chapter 5 General discussion .............................................. 143

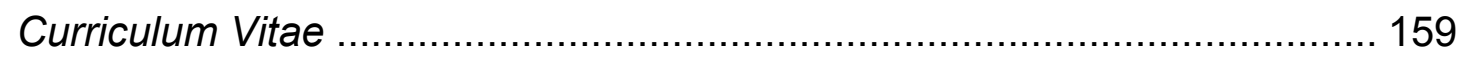

Appendix 161 


\section{Abbreviations}

Asn (Asparagine)

BSA (Bovine serum albumin)

CRD (Carbohydrate recognition domain)

DC (Dendritic cell)

DLL4 (Delta-like-4)

ECM (Extracellular matrix)

FDA (Food and Drug Administration)

Gal-3 (galectin-3)

Gal-3C (N-terminally truncated form of galectin-3)

HIF-1 (Hypoxia-inducible factor 1)

HUVEC (Human umbilical vein endothelial cell)

MRP (Multidrug resistance-associated protein)

MUC1 (Mucin 1)

NADPH (Nicotinamide adenine dinucleotide phosphate)

NICD (Notch intracellular domain)

PBS (Phosphate buffer solution)

PCR (Polymerase chain reaction)

ROS (Reactive oxygen species)

Ser (Serine)

SLex (Sialyl lewis $\mathrm{x}$ )

STn (Sialyl-Tn)

Thr (Threonine)

VEGF (Vascular endothelial growth factor)

VEGFR (Vascular endothelial growth factor receptor)

WT (wild type) 


\section{List of figures}

\section{Chapter 1}

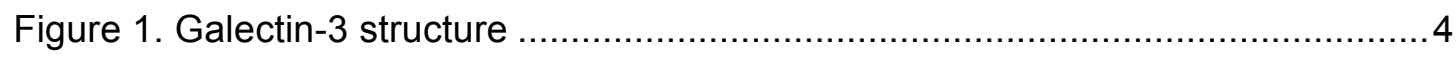

Figure 2. Impact of galectin-3 in the hallmarks of cancer ....................................

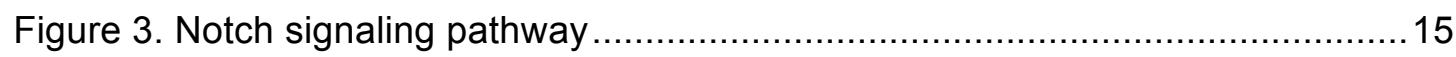

Figure 4. Mechanism of sprouting angiogenesis ............................................... 18

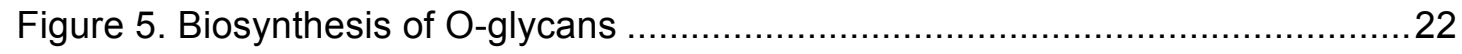

\section{Chapter 2}

Figure 1. Galectin-1 and galectin-3 are positively correlated with Notch ligands in

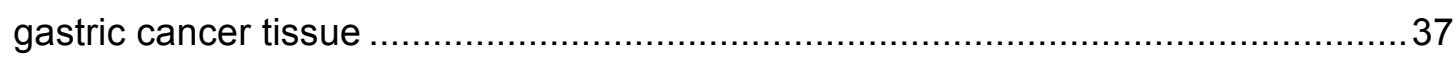

Figure 2. Galectin-1 and galectin-3 bind to Notch-1 receptor .................................. 39

Figure 3. Galectin-1 and galectin-3 modulate ligand-dependent Notch-1 activation .40

Figure 4. Galectin-3 regulates the cell surface expression of Notch components and extracellular gal-3 increases Jagged1/Notch signaling activation............................42

Figure S1. Galectin-3 regulates Notch signaling in U87 cells ................................48

Figure S2. Hypothesis model on Notch signaling modulation by galectin-1 and galectin-3

\section{Chapter 3}

Figure 1. Galectin-3 binds to Notch-1 receptor and Jagged1 and DLL4 ligands, and activates Notch signaling

Figure 2. Galectin-3-induced Notch activation is independent of VEGF/VEGFR2 signaling .65

Figure 3. Galectin-3 proangiogenic functions are mediated by Jagged1-Notch signaling

Figure 4. Galectin-3 promotes the tip cell phenotype 69

Figure 5. Hypoxia increases galectin-3 binding to endothelial cells

Figure 6. Galectin-3 released by cancer cells activates Notch signaling and enhances sprouting angiogenesis

Figure 7. Jagged1 overexpression in tumor cells increases tumor growth

Figure S1. Galectin-3 does not up-regulate Jagged1 mRNA levels, related to Figure 2

Figure S2. Galectin-3 increases Jagged1-mediated Notch signaling, related to Figure 3 
Figure S3. Galectin-3 expression decreases under hypoxic conditions in endothelial cells, related to Figure 5 ..... 89

Figure S4. Immunohistochemical staining of Ki67, related to Figure 7. 91

Figure S5. Galectin-3 knockout mice reduce vessel maturation of LLC-JG1 derived tumors, related to Figure 7 . 92

Figure S6. Proposed model for galectin-3-mediated angiogenesis by modulating Jagged1/Notch signaling .93

\section{Chapter 4}

Figure 1. Sialyl-Tn confers chemotherapeutic resistance 109

Figure 2. Sialyl-Tn inhibits galectin-3 binding to cellular surface 111

Figure 3. Sialyl-Tn increases tumor growth and decreases galectin-3 binding sites in

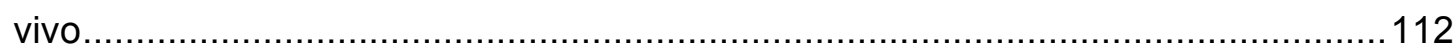

Figure 4. Galectin-3 increases Mock cells susceptibility to cisplatin 114

Figure 5. Intracellular galectin-3 protects cells from chemotherapeutic-induced cytotoxicity 115

Figure 6. Expression of sialyl-Tn and galectin-3 binding sites in human gastric tumors

Figure 7. Galectin-3 in vivo biodistribution 119

Figure 8. Proposed model for sialyl-Tn mediated resistance to cisplatin 123

Figure S1. Total levels of galectin-3 are not altered in Mock and ST6GalNAc-I cells

Figure S2. Galectin-3 increases cisplatin and 5-FU cytotoxicity in Mock cells 132

Figure S3. Intracellular galectin-3 protects cell from 5-FU induced cytotoxicity...... 133

Figure S4. Lactose inhibits hrGal-3/AP binding 134 


\section{List of tables}

\section{Chapter 2}

Table S1. Clinicopathological characteristics of the patients 50

Table S2. Allred score for galectin-1, galectin-3, Jagged1, DLL4 and Notch-1 status in human gastric samples $(0-8)^{*}$ 51

Table S3. Spearman's $\rho$-test correlation between galectin-1, galectin-3, Jagged1, DLL4 and Notch-1 51

\section{Chapter 3}

Table S1. Primer sequences. 94

\section{Chapter 4}

Table S1. Immunohistochemical data. 135

Table S2. Primers sequences 135 


\section{Resumo}

Santos SN. O papel de galectina-3 na via de sinalização Notch, angiogênese tumoral e resistência a quimioterápicos [tese]. São Paulo: Universidade de São Paulo, Faculdade de Medicina; 2015.

A galectina-3, um membro da família das proteínas de ligação a glicanas, tem sido objeto de intensa pesquisa nos últimos anos devido ao seu importante papel na biologia tumoral, como a proliferação, transformação, apoptose, angiogênese, adesão, invasão e metástase tumoral. As diferentes funções de galectina-3 nas células tumorais resultam das suas diversas localizações inter- e subcelulares que lhe permite interagir com diferentes proteínas. Esta tese teve como objetivo identificar um papel específico de galectina-3 na regulação da via de sinalização Notch, que cada vez mais tem sido associada com a progressão tumoral e angiogênese. Inicialmente, demonstramos que galectina-3 interage com o receptor Notch-1 e modula diferencialmente a ativação da via pelos ligantes DLL4 e Jagged1. A galectin-3 regulou a expressão dos ligantes de Notch assim como o receptor Notch-1 e extracelularmente recuperou a ativação de Notch na ausência de galectina-3 endógena. Em câncer gástrico humano, a galectina-3 encontrou-se positivamente correlacionada com a expressão de Jagged1, enquanto que a galectina-1, um outro membro da família das galectinas, foi positivamente correlacionado com DLL4. De seguida estudou-se o papel biológico da regulação da via Notch pela galectina-3 na angiogênese. Demonstramos que nas células endoteliais, galectina-3 liga e aumenta a meia vida de Jagged1 promovendo a ativação preferencial da Jagged1/Notch em vez de DLL4/Notch de uma forma independente de VEGF. Verificamos que condições de hipóxia alteraram a expressão de galectina-3 assim como o status de glicosilação das células endoteliais de forma a promover a ativação de Jagged1/Notch e o aumento de angiogênese. A superexpressão de Jagged1 num modelo de carcinoma de pulmão de Lewis, acelerou o crescimento tumoral in vivo que foi inibido em camundongos Lgals $3^{-/}$. Por fim, avaliou-se o papel de galectina-3 na resistência das células tumorais a quimioterápicos. Observamos que a expressão de sialil-Tn, um produto biossintético da ST6GaINAc-I, diminuiu in vitro como in vivo a presença e os sítios de ligação de galectina-3 na superfície da células levando à sua acumulação no meio intracelular. Extracelularmente, galectina-3 não levou à indução de morte celular, no entanto contribuiu para a morte induzida por quimioterápicos. As células expressando sialil-Tn encontraram-se protegidas. Em amostras de tumor gástrico, 
os sítios de ligação de galectina-3 encontraram-se negativamente correlacionados com a expressão de sialil-Tn. Este conhecimento possui implicações diretas no desenvolvimento de estratégias visando o controle do crescimento tumoral e angiogênese e abre novas perspectivas no combate à resistência tumoral à terapia.

Descritores: Galectina-3; Receptores Notch; Neoplasias da mama; Neoplasias gástricas; Resistência a medicamentos antineoplásicos; Neovascularização patológica 


\section{Abstract}

Santos SN. The role of galectin-3 in Notch signaling activation, tumor angiogenesis and chemotherapy resistance. [tese]. São Paulo: Universidade de São Paulo, Faculdade de Medicina; 2015.

Galectin-3, a member of a family of glycan binding proteins has been the subject of an intense research over the past few years due to its important role in cancer biology, such as cancer cell growth, transformation, apoptosis, angiogenesis, adhesion, invasion and metastasis. The different roles of galectin-3 on cancer cells behavior appears to have originated from its diverse inter- and subcellular localizations where it interacts with several different binding partners. The aim of this thesis was to pinpoint a specific role for galectin-3 in regulating Notch signaling pathway in cancer. Notch signaling has emerged as an important pathway in carcinogenesis, and activated Notch-1 signaling has being associated with cancer progression and angiogenesis. Initially, we found that galectin-3 was able to interact with Notch-1 receptor and to differentially modulate Notch signaling activation by DLL4 and Jagged1 ligands. Galectin-3 was found to regulate the expression of the Notch ligands and Notch-1 receptor and its extracellular form was able to rescue Notch activation in the absence of endogenous galectin-3. In human gastric cancer, galectin-3 was positively correlated with the expression of Jagged1 whereas galectin1 , another member of the galectin family, was positively correlated with DLL4. Furthermore, we studied the biological role of Notch regulation by galectin-3 in angiogenesis. We showed that, in endothelial cells, galectin-3 binds to and increases Jagged1 protein half-life promoting Jagged1/Notch over DLL4/Notch signaling in a VEGF independent way. Hypoxic conditions changed galectin-3 expression and the glycosylation status of endothelial cells, acting in concert to promote Jagged1/Notch activation and sprouting angiogenesis. Jagged1 overexpression in Lewis lung carcinoma accelerated tumor growth in vivo that was prevented in Lgals $3^{-/-}$mice. Finally, we evaluated the role of galectin-3 in cancer cell resistance to therapy. We found that the expression of sialyl-Tn, a biosynthetic product of ST6GaINAc-I, was able to decrease cell surface galectin-3 and galectin-3-binding sites both in vitro and in vivo leading to an intracellular accumulation of this protein. Exogenously added galectin-3 was found to have no effect on cancer cell death but contributed to chemotherapy-induced apoptosis. Sialyl-Tn expressing cells were protected. In human gastric cancer samples, galectin-3 binding sites were negatively correlated with the expression of sialyl-Tn. This knowledge has direct implications for the 
development of strategies aimed at controlling tumor growth and angiogenesis and open novel perspectives to overcome tumor resistance to therapy.

Descriptors: Galetin-3; Receptors, Notch; Breast neoplasms; Stomach neoplasms; Drug resistance, neoplasm; Neovascularization, pathologic. 


\section{Chapter}

\section{General introduction}

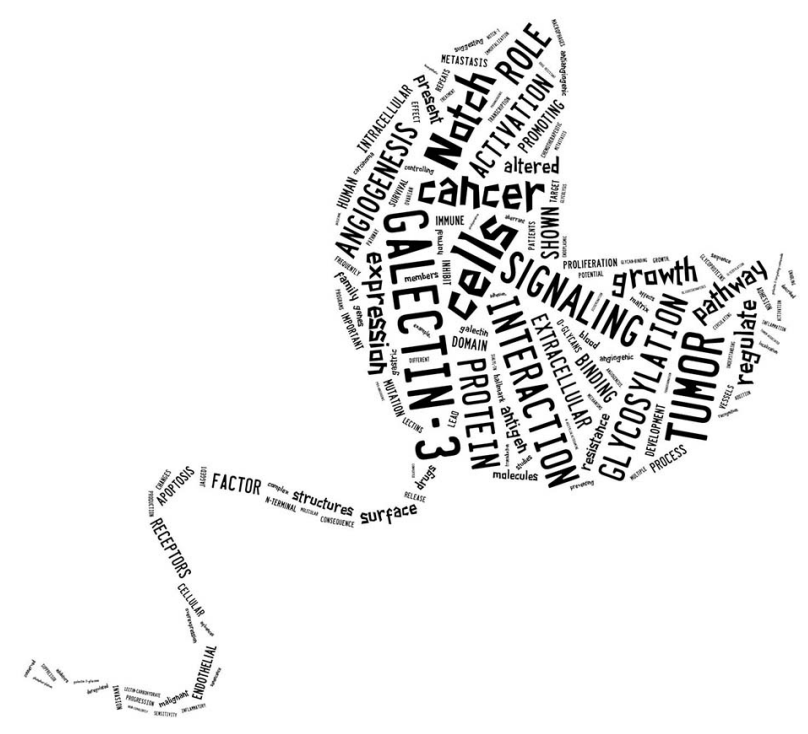



The presence of post-translational modifications such as phosphorylation, ubiquitination or glycosylation, have proven that proteins activity is not specified only by DNA sequences. A layer of glycans linked to proteins or lipids covers the surfaces of all eucaryotic cells and, at the cell surface, glycans are the first point of contact between cells, cells-extracellular matrix and host cells-pathogens $[1,2]$. As a consequence, glycans frequently modulate/regulate various cellular functions in response to changes in the internal and external environment. Therefore, achieving a deeper understanding of the structure-function of glycans in cell biology has been extraordinarily challenging.

Glycan-binding proteins known as "lectins" mediate the major role of glycans in health and diseases. Lectins are a unique group of proteins important for the interpretation of the "sugar code" through their recognition of glycans as ligands [4]. Therefore, the key to understand the functions of glycans is the elucidation of the functions of lectins that recognize them. Several studies have focused in understanding the nature of lectin-carbohydrate interaction and in transferring this biological information to the microbiology, virology, immunology and oncology field. Even though, glycan's role is still underappreciated, altered glycosylation patterns, including under- and overexpression, as well as neoexpression of glycans, are a hallmark of cancer development and progression. Consequently, aberrant glycosylation occurring in cancer cells influences lectin-carbohydrate interactions. Indeed, lectin-carbohydrate interactions play multiple roles in several hallmarks of cancer as defined by Hanahan and Weinberg [3], since they regulate many different aspects of tumor progression, including proliferation, invasion, angiogenesis and metastasis. In the present thesis we studied the interplay between galectin-3, a member of the galectin family of animal lectins, and Notch signaling pathway and its consequences for regulation of tumor angiogenesis. Moreover, we investigated 
whether the overexpression of sialylated O-linked glycans would affect the cellular localization of galectin-3 and its potential impact on cancer drug resistance.

\section{Galectins}

Galectins are defined as an evolutionary conserved family of lectins regarding the structure of their carbohydrate recognition domain (CRD) and their affinity for $\beta$ galactoside-containing glycans [5]. So far, 15 members of the galectin family were found and are divided into three groups according to the number and organization of theirs CRD [6]. The prototype group (galectin-1, -2, -5, -7, -10, -11, -13, -14 and -15) contains one carbohydrate-recognition domain and can be found as a monomer as well as a non-covalent homodimer, each containing an identical CRD. The tandem repeat group (Galectin-4, $-6,-8,-9$ and -12 ) has two distinct CRDs separated by an unconserved linker sequence of up to 70 amino acids. Galectin-3, the only chimeratype galectin, contains one CRD of $\sim 130$ amino acids connected to an unusual long $\mathrm{N}$-terminal proline- and glycine-rich domain $[5,6]$.

\section{Galectin-3}

Galectin-3 (Figure 1), initially identified as Mac-2, a cell surface antigen expressed on murine macrophages [7], is one the most studied members of the galectin family. Galectin-3 has $\sim 30 \mathrm{kDa}$ and can be found both in solution as a monomer or can form oligomers upon binding to multivalent glycoproteins. Besides

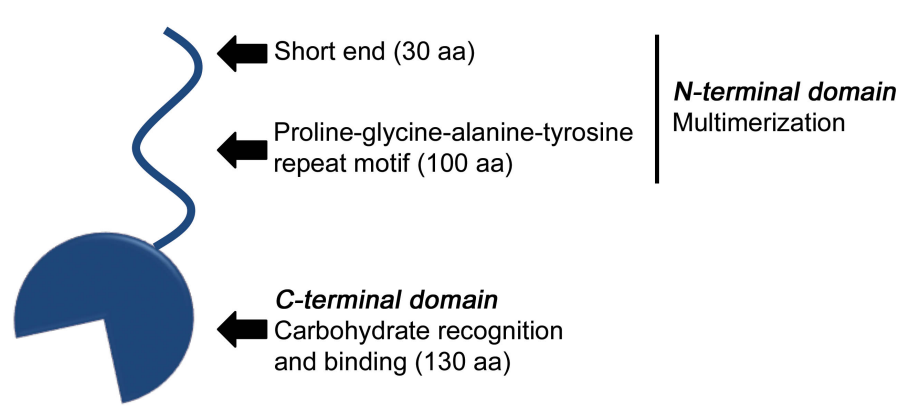

Figure 1. Galectin-3 structure. carbohydrate structures, galectin-3 can bind to nonglycosylated molecules via protein-protein interactions. The N-terminal domain of 
galectin-3, responsible for protein-protein interactions, is a flexible structure composed of $\sim 130$ amino acids and contains multiple homologues repeats of ProGly-Ala-Tyr-Pro-Gly [8]. Although the N-terminal domain was shown to lack carbohydrate-binding activity, it is fundamental for galectin-3 biological functions [9]. The $\mathrm{N}$-terminal domain is also responsible for the ability of galectin-3 to oligomerize allowing it to form lattices upon binding to multivalent oligossacharides [10]. This ability can be biologically regulated by matrix metalloproteinases, such as MMP-2 and MMP-9 that are able to cleave the N-terminal domain, thus reducing galectin- 3 auto association and preventing the biological properties that depend on multimerization [11].

\section{Galectin-3 cellular localization}

Galectin-3 has a ubiquitous expression and plays multiple biological functions, depending on its subcellular localization. It can be found both in the intracellular milieu of cells (nucleus and cytoplasm) as well as bound to the cell surface and in extracellular spaces [12].

\section{Intracellular functions}

Galectin-3 intracellular localization depends on numerous factors such as the cell type, proliferation status, culture conditions, transformation and tumor growth. Several molecules have been identified as galectin-3 binding partners in the cytoplasm. Among them, Bcl-2 recognition by galectin-3 was found to prevent apoptosis by blocking the release of cytochrome c from mitochondria [13]. Moreover, galectin-3 was shown to regulate apoptotic events by interacting with CD95, nucling and Alix/AIP1 cytosoilc proteins [12-14] and to regulate cell proliferation, differentiation and survival by modulating K-Ras, Akt, cyclins E, A and D1, p21 and p27 proteins [15-18]. In the nucleus, galectin-3 is considered as a splicing factor 
because of its interaction with Gemin4 and SMN complexes [19], and was also found to regulate the transcription of cyclin D1 gene [17].

\section{Extracellular functions}

Although galectin-3 lacks a recognizable secretion signal sequence and does not pass across the standard ER/Golgi pathway, this protein can be found on the cell surface and in the extracellular matrix [20]. Extracellular galectin-3 can mediate cell adhesion and cell activation, affecting several biological processes such as maintenance of cellular homeostasis, immune regulation, angiogenesis, tumor development and metastasis. Galectin-3 effect on cell adhesion is mainly based on its ability to cross-link cell surface glycoproteins and components of extracellular matrix. It was reported that galecin-3 could promote cell adhesion of different cell types by interacting with laminin [21], fibronectin [22], elastin [23], collagen IV [24] and the main molecule involved in cell adhesion, $\alpha 1 \beta 1$ integrin [24]. Moreover, by cross-linking cell surface proteins, galectin-3 can trigger signal transduction cascades in the cells, resulting in their activation. For example, galectin-3 was show to potentiate lipopolysaccharide (LPS)-induced production of interleukin-1 in human monocytes [25]. Treatment of Jurkat cells with recombinant galectin-3 led to cellular activation and IL-2 production whereas in B-lymphocytes, exogenously added galectin-3 acted as a mediator of IgE production [26, 27]. Galectin-3 was also shown to induce endothelial cells morphogenesis and angiogenesis both in vitro and in vivo [28] and, to delay EGF and TGF- $\beta$ endocytosis, thus prolonging cell activation [29]. Therefore, considerable observations demonstrated that galectin-3 modulates cellcell and cell-extracellular matrix interactions.

\section{Galectin-3 in cancer biology}

Changes in expression pattern and subcellular localization of galectin-3 have frequently been associated with cancer [30]. Increased galectin-3 expression is 


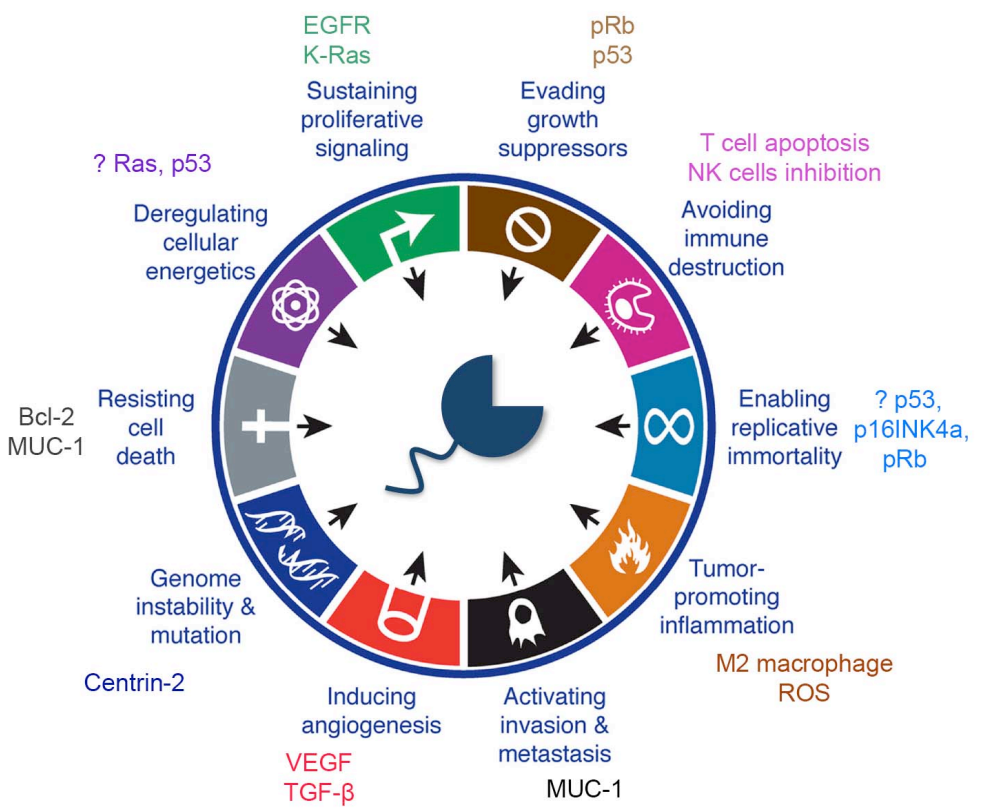

Figure 2. Impact of galectin-3 in the hallmarks of cancer. Schematic representation of the interactions of galectin-3 with different hallmarks of cancer as defined by Hanahan and Weinberg [3]. The question mark indicates an absence of information available in the literature on a direct relation between galectin-3 and cellular energetics and replicative immortality.

usually found in gastric [31], colon [32], bladder [33] and thyroid [34] cancers. On the other hand, in ovarian [35], prostate [36] and cervical [37] tumors galectin-3 expression appears to be predominantly decreased. In brain [38] and skin [39] cancers, galectin-3 has been reported to be either increased or decreased depending on the tumor subtype. Galectin-3 intracellular distribution was also altered in some types of cancer. While nuclear galectin-3 has been correlated with an anti-tumor function, cytoplasmic galectin-3 expression has been shown to have a pro-tumoral role protecting cells against apoptosis [40,41]. Although altered glycosylation is not yet considered an hallmark of cancer, galectin-3-glycans interactions play a key role in orchestrating distinct cell events in tumor cells, which lead to the hallmark characteristics of cancer (Figure 2).

\section{Galectin-3 and "cell death resistance"}

Programmed cell death by apoptosis is a natural barrier to the development of cancer. Intracellular galectin-3 has an important role in protecting cells against apoptosis and was reported to render BT549 human breast carcinoma cells more resistant to cisplatin, anthracycline, adriamycin and 5-FU-induced apoptosis [42]. The interaction of galectin-3 with $\mathrm{Bcl}-2$ seems to be critical for the anti-apoptotic function 
of the $\mathrm{Bcl}-2$ protein against chemotherapeutic drugs [43]. Moreover, the mitogenactivated protein kinase (MAPK) pathway was reported to be increased by phosphorylated galectin-3 and to regulate mitochondrial stability, protecting cells from apoptosis [42]. Galectin-3-MUC1 interaction was shown to participate in the protection of cells against apoptosis induced by loss of anchorage (anoikis) [44]. The present thesis demonstrates that galectin-3-glycans interaction is able to modulate the response of tumor cells to chemotherapeutic drugs-induced apoptosis.

\section{Galectin-3 role in "sustained proliferative signaling"}

Growth-promoting signals are normally carried by growth factors binding to cell surface receptors, which typically contain intracellular tyrosine kinase domains that transmit signals via downstream signaling pathways and control cell cycle, growth and survival. Galectin-3 has been shown to regulate the intracellular trafficking of epidermal growth factor receptor (EGFR) and to modulate the EGFRstimulated cell growth of pancreatic cancer cells $[45,46]$. On the other hand, Akt activation by galectin-3, a signal transduction pathway that promotes survival and growth in response to extracellular signals, was shown to promote in vitro proliferation of leukemic cells [47]. Galectin-3 binding to K-Ras was found to increase cell growth, differentiation and survival of cancer cells [18, 48, 49].

\section{Galectin-3 role in "evading growth suppressors"}

Cancer cells must overcome programs that negatively regulate cell proliferation. These programs depend on the action of tumor suppressor genes that normally govern the decision of cells to proliferate or to undergo programmed cell death [3]. For example, when in a hypophosphorylated state, pRb blocks proliferation by sequestering and altering the function of E2F transcription factors that control the expression of genes essential for progression from $\mathrm{G} 1$ into $\mathrm{S}$ phase of the cell cycle. 
Galectin-3 was shown to prevent premature senescence by directly interacting with the cyclin D1/CDK4 complex, promoting hyperphosphorylation of $\mathrm{Rb}$, thus allowing cell proliferation and rendering them unresponsive to antigrowth factors [50]. P53, another sensor of intracellular stress and DNA damage, was also repressed by galectin-3 [51].

\section{Galectin-3 and "evasion of immune surveillance"}

The immune system is known to recognize and eliminate the vast majority of emerging cancer cells. However, tumors cells have developed a tactic to avoid immune detection and limit immunologic killing [52]. Extracellular galectin-3 has been shown to induce monocytes and $T$ cell apoptosis $[53,54]$ and was described to contribute to immunosuppression during tumorigenesis. Indeed, galectin-3 was able to suppress IL-5, inhibiting B lymphocyte differentiation [55], and to increase phagocytosis of neutrophils and oxidative response of immune cells $[56,57]$. Moreover, galectin-3 was reported to strongly antagonize human NK cells functions against tumors in vivo [58], avoiding cancer cells destruction. Additionally, it was found that galectin-3 drives alternative macrophage activation (M2) that may restrict host immunity against cancers [59]. In fact, galectin-3-targeting compounds, such as GM-CT-01 or GCS-100, were reported to boost human $\mathrm{CD}^{+}$tumor-infiltrating $\mathrm{T}$ lymphocytes cytotoxicity in various cancers $[60,61]$

\section{Galectin-3 and "angiogenesis"}

Angiogenesis, the formation of new blood vessels from pre-existing ones, fuels tumors with nutrients and oxygen and provides a pathway for tumor growth. During tumor growth, the "angiogenic switch" is activated, and several molecules such as vascular endothelial growth factor (VEGF) and fibroblast growth factor (FGF) are released to support the formation of new blood vessels. Galectin-3 has been 
reported to induce endothelial capillary tube formation in vitro and angiogenesis in vivo [28] by interacting with the VEGF and bFGF, enhancing consequently VEGFR2 signaling activation [28, 62, 63]. Accordingly, disruption of galectin-3 in the tumor stroma was found to reduce macrophage induced-angiogenesis dependent on VEGF and TGF- $\beta$ signaling [64]. This angiogenesis-promoting effect of galectin-3 also comprises the interaction of galectin-3 with the endothelial cell surface enzyme aminopeptidase N/CD13, which regulates early steps of angiogenesis [65]. In the present thesis we disclose a novel mechanism by which galectin-3 modulates tumor angiogenesis.

\section{Galectin-3 and "enabling replicative immortality"}

Normal cells undergo a limited number of cell (division) cycles before becoming senescent (alive but non-proliferative). Some cancer cells exhibit unlimited replicative potential and are therefore considered "immortalized". Telomeres are central to limiting the number of division cycles that a normal cell can undergo and, consequently, to the unlimited proliferation capacity of malignant cells [66]. However, an absence of information is available in the literature concerning the correlation between galectin-3 and telomeres functions. Still, inactivation of p53, p16INK4a or $\mathrm{pRb}$ is required for telomere maintenance and for the immortalization process [67]. Since galectin- 3 is able to modulate both $\mathrm{p} 53$ and $\mathrm{pRb}$ functions, it may contribute indirectly to the immortalization process of tumor cells.

\section{Galectin-3 and the "activation of the metastatic potential"}

Tumor metastasis involves the invasion of the tumor cells in the surrounding tissues, dissemination through blood or lymph vessels and growth at distant sites. It has been reported that galectin-3 plays an important role in the metastatic process [68]. In fact, it was described that the levels of circulating galectin-3 in the 
bloodstream of patients with metastasis is significantly higher than those of healthy people [69]. Galectin-3 binding to the oncofoetal Thomsen-Friedenreich antigen present on the mucin MUC1 resulted in increased cancer cell heterotypic adhesion to the blood vascular endothelium, and an increased cancer homotypic aggregation to form a tumor micro-emboli [70, 71]. MUC1-galectin-3 interaction induced a cell surface polarization, exposing smaller adhesion molecules on the cell surface such as E-cadherin, CD44, and E-selectin ligands. Therefore, it has been hypothesized that galectin-3 is able to enhance the survival of disseminating tumor cells in the circulation by preventing initiation of anoikis.

\section{Galectin-3 and the "deregulation of cellular energetics"}

Normal cells are known to generate ATP through glycolysis under anaerobic conditions, and through oxidative phosphorylation under aerobic conditions. Cancer cell however can reprogram glucose metabolism to favor glycolysis even under aerobic conditions. Otto Warburg postulated that these metabolic changes are a fundamental cause of cancer (Warburg hypothesis) [72]. Activated oncogenes, such as Ras and Myc, as well as mutated-p53 are increased during hypoxia and have been found to stimulate the glycolytic flux to lactate [73-75]. Galectin-3 was recently found to increase tumor intracellular metabolites production, such as lactate, free choline, phosphocholine and glycerophosphocholine under hypoxic conditions, suggesting a role in mitochondrial homeostasis [76]. Moreover, galectin-3 was found to interact with K-Ras increasing its activation [49] and could, therefore, indirectly modulate tumor associated-glycolysis. 


\section{Galectin-3 and "Enabling characteristics of cancer"}

It is widely appreciated that the acquisition of hallmarks depends on a succession of alterations in the genomes of neoplastic cells that offer a selective advantage and lead to the outgrowth of the dominant clone.

\section{Genome instability and mutation}

The chance to acquire an enabling mutation can increased due to: (1) increased sensitivity to mutagenic agents or, (2) failure of the surveillance systems that monitor genomic integrity and force damaged cells into senescence or apoptosis [3]. Centrossomal aberrations are a potential source of genetic instability and are frequently observed in early steps of carcinogenesis [77-79]. Galectin-3 was found to be associated with basal bodies and centrosomes, where it closely interacted with core proteins, such as centrin-2. Moreover, galectin-3 directly interfered with the regulation in number, size, and shape of the centrosomes suggesting a direct role for galectin-3 in centrosomal biology [80].

\section{Tumor promoting inflammation}

Cells of the immune system typically infiltrate tumor cells in order to eradicate the tumor. However, tumor-associated inflammation may instead promote tumor growth by supplying growth factors, pro-angiogenic factors, matrix-modifying enzymes that facilitate angiogenesis, invasion and metastasis. Moreover, inflammatory cells can release chemicals, particularly reactive oxygen species (ROS) that are mutagenic, accelerating malignant progression [3]. Since galectin-3 is expressed by several inflammatory cells and can regulate their functions [81], it is conceivable that it can affect the inflammatory responses developed against tumors. Galectin-3 was reported to have proinflammatory activity both in vitro and in vivo. It was shown to stimulate superoxide production from peripheral blood leukocytes and to activate NAPDH-oxidase in neutrophils that experienced extravasation $[82,83]$. Additionally, peritoneal macrophages from Lgals $^{-/-}$mice were more prone to undergo apoptosis than those from wild-type mice upon treatment with apoptotic 
stimuli, suggesting that expression of galectin-3 in peritoneal cavity inflammatory cells may lead to longer cell survival, thus prolonging inflammation [84]. Indeed, several reports showed that the inflammatory response is diminished in galectin-3deficient mice $[85,86]$

\section{Galectin-3 concluding remarks}

Therefore, galectin-3 is undoubtedly involved in tumorigenesis, tumor growth and metastasis. Consequently, several efforts are being made to develop galectin-3targeting-compouds and have proved to be effective in pre-clinical models of multiple myeloma, lymphoma, leukemia and solid tumors [61, 87-89]. However, galectin-3 inhibitors are not expected to be a miracle drug to cure cancer. In several types of cancer (ovarian and cervical), the inhibition of galectin-3 does not seem to be favorable for patients since galectin-3 induces apoptosis of these tumor cells $[35,37]$. Thus, a continuous investigation on how galectin-3-glycans interaction support cancer cells growth in the tumor microenvironment is still required. In this thesis, we study the interplay between galectin-3 Notch signaling pathway and how it affects angiogenesis and tumor growth. Then, we describe a novel mechanism by which Oglycosylation modulates both tumor drug-resistance and intracellular galectin-3 content. 


\section{Notch signaling pathway}

Notch signaling is a highly evolutionally conserved molecular pathway that plays an important role in cell fate determination, proliferation, differentiation and survival during development, neurogenesis and homeostasis [90]. Several evidences have pointed out that Notch signaling is deregulated in human hematological malignancies and solid tumors [91]. Mutations of the components of Notch signaling pathway have been show to be responsible for congenital disorders such as Alagille syndrome and Spondylocostal dysostosis, and adult onset diseases such as CADASIL [92]. Moreover, activating and inactivating mutations in Notch can lead to a variety of hematopoietic and solid tumors, showing that Notch can function either as a tumor suppressor or as a tumor promoter depending on the cell type [92]. As a result, Notch signaling has emerged as a potential molecular target for treating a variety of cancers [93]

The term Notch signaling refers to a specific molecular mechanism conserved in many organisms. This mechanism is also referred as the "canonical" Notch signaling in order to distinguish it from the atypical (ligand-independent) signaling pathways that have been described $[94,95]$. The canonical Notch signaling pathway involves the activation of Notch receptors on cell surface by a direct interaction with ligands present in a neighboring cell. Notch receptors (N1-N4) are synthesized in the endoplasmic reticulum as an inactive single peptide precursor, which is subsequently proteolytically cleaved (S1) by a furin-like convertase in the trans-Golgi network producing a non-covalently bound heterodimer that subsequently reaches the plasma membrane (Figure 3). There are four Notch receptors (Notch1-4) and five ligands including delta-like ligand (DLL) 1, 3, and 4, and Jagged (JAG) 1 and 2 in mammals. All Notch receptors and their ligands are transmembrane glycoproteins containing multiple epidermal growth factor (EGF)-like repeats in the extracellular region. The Ofucosyltransferase (POFUT1) enzyme is responsible to add a fucose to the EGF-like 
repeats on Notch receptor. O-linked fucose can be further elongated by members of the Fringe family (Lunatic Fringe, Radical Fringe and Manic Fringe), which determines the affinity strength between the receptors and their ligands [96]. The activation of Notch signaling is initiated by the binding of Notch receptor to a Notch ligand expressed on an adjacent cell. Upon binding, Notch receptor undertakes a conformational change that allows a second cleavage (S2) on its extracellular domain, which is catalyzed by a member of the disintegrin and metalloproteases (ADAM) family (ADAM17 or ADAM10). This cleavage dissociates the extracellular domain, which is internalized with the ligand in the adjacent cell. The third cleavage (S3) is mediated by a presenilin-dependent $y$-secretase protease complex [97] and results in the release of a soluble fragment, NICD (Notch intracellular domain), which translocates to the nucleus where it binds to the transcription factor CSL (CBF1/Suppressor of Hairless), and activates the transcription of Notch target genes (including genes encoding Hairy Enhancer of Split (HES) family proteins and HES-

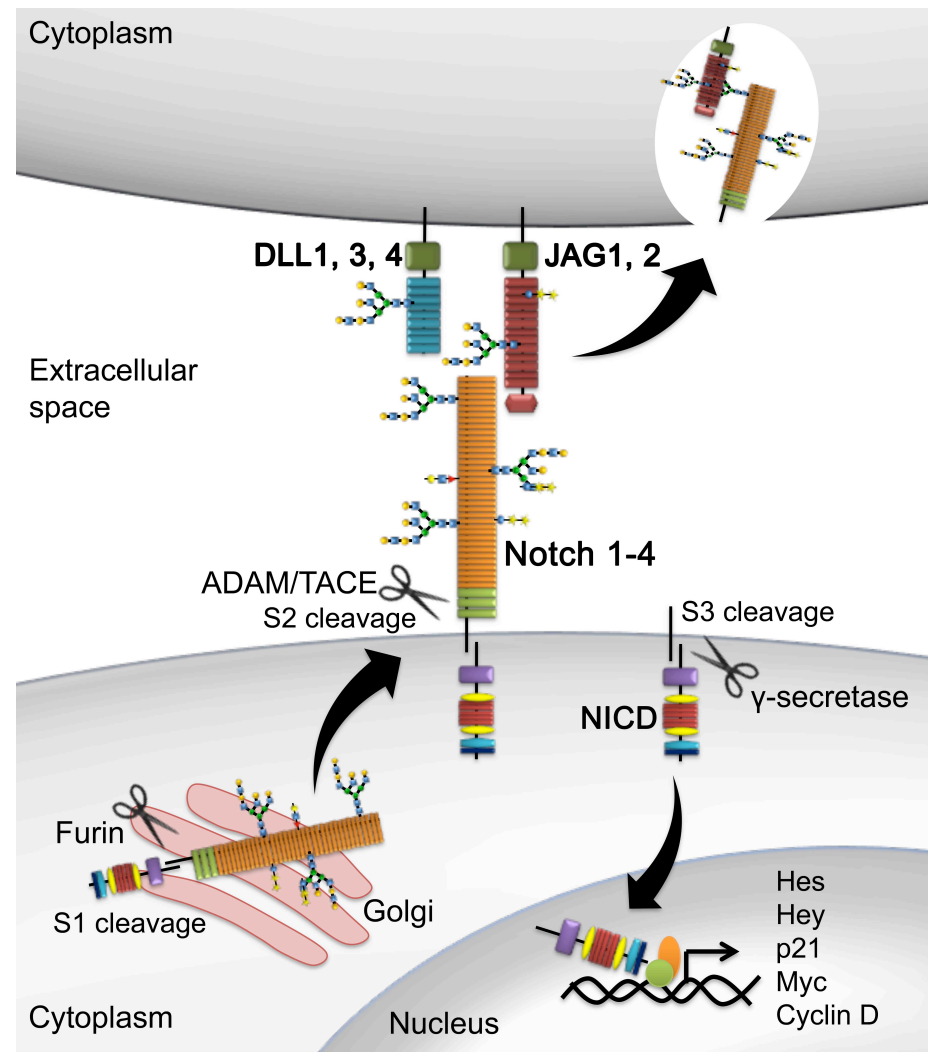

Figure 3. Notch signaling pathway. The intracellular and extracellular domains of the Notch receptor are synthesized as a single protein (preNotch). A Furin-like convertase cleaves pre-Notch into the extracellular and intracellular domain (S1 cleavage). This results in a heterodimeric receptor with non-covalently associated domains that is transported to the plasma membrane. Ligand binding initiates two successive proteolytic cleavages (S2 and S3). The first, mediated by an ADAM (a disintegrin and metalloproteinase domain) proteinase, occurs in the extracellular domain. S2 cleavage allows access of the secretase complex, which is responsible for the second proteolytic cleavage (S3), which occurs within the transmembrane domain and liberates the intracellular domain (NICD). NICD then translocates to the nucleus, where it interacts with the CSL transcription factor converting it from a transcriptional repressor to an activator. A few transcriptional targets of Notch have been identified and include Hes, Hey, p21, Myc or cyclin D. 
related proteins (HEY), as well as p21cip1/waf1, c-myc, HER2, members of NF-KB family and PPAR family and DLL4 and Notch-1 itself [98].

\section{Notch signaling in cancer}

The role of Notch signaling in the regulation of tumor behavior depends on its function in a given tissue. Notch signaling is primarily oncogenic in many cellular contexts by maintaining cells in an undifferentiated state or inducing them to retain a stem cell-like characteristic. However, Notch can also be tumor-suppressive by inducing keratinocyte growth arrest in the skin [99]. The role of Notch signaling in human malignancy was first identified in T-cell acute lymphoblastic leukemia/lymphoma (T-ALL/T-LL) and Notch-1 gain-of-function mutations were subsequently found in approximately $50 \%$ of T-ALL [100]. However, in solid tumors, mutations of the Notch family members are infrequent and the mutation rates are only $4.7 \%$ for Notch-1, $1.5 \%$ for Notch-2 and $1.3 \%$ for Notch-3. Notch-4 and Notch ligand genes are rarely mutated [101]. Yet, an overexpression of Notch receptors and ligands is frequently found, independently of mutation, in human solid tumors including gastric, pancreatic, prostate, breast, lung, glioblastoma, sarcomas, cervical, melanoma or head and neck tumors [101-108], suggesting a role for upstream signals in controlling Notch signaling activation. Deregulation of the Notch pathway may result in increased intracellular levels of NICD, which in turn modulate several cellular functions associated with tumorigenesis such as cell cycle progression, cell metabolism, apoptosis, adhesion, transition epithelial-mesenchyme and angiogenesis $[92,109]$. In the second and third chapters of this thesis, the specific role of galectin-3 in Notch signaling and angiogenesis will be addressed. 


\section{Notch signaling in angiogenesis}

Angiogenesis is a fundamental process by which new blood vessels are formed from pre- existing ones and is a requisite not only for continued tumor growth, but also for metastasis [110]. The sprouting of new blood vessels initiates after degradation of the extracellular matrix allowing endothelial cells (ECs) migration, invasion, proliferation and tube formation. The balance of angiogenesis-promoting factors and angiogenesis inhibitors tightly regulates the angiogenic switch, the transition from a nonangiogenic to an angiogenic phenotype in tumors [111]. Therefore, in tumors, the angiogenic switch may occur when tumors expand, causing some cells to become hypoxic. The response of tumor cells to hypoxia activates the hypoxia-inducible factor (HIF-1) that directly transactivates genes involved in the process of angiogenesis, such as vascular endothelial growth factor (VEGF) [112]. VEGF is probably the best characterized and among the first identified proangiogenic proteins involved in all stages of angiogenesis. The current model of angiogenesis centers on the interplay between tips and stalk cells (Figure 4). Accordingly, when extracellular VEGF-A binds VEGF receptor 2 (VEGFR-2) on an endothelial cell it causes an up-regulation of DLL4 ligand (tip cell). DLL4 is then able to interact with Notch receptors on adjacent endothelial cells (stalk cell), leading to the downregulation of VEGFR-2 in those cells. As a consequence, the tip cells express high levels of VEGFR-2 and DLL4, are nonproliferative and undergo chemotaxis toward angiogenic factors. Stalk cells neighbors are rendered less sensitive to VEGF-A signaling, are proliferative and contribute to the elongation of the nascent sprout. These stalk cells ultimately lumenize to form functional blood vessels [113]. Recent work has suggested that DLL4 and Jagged1 signaling may have opposing effect in angiogenesis $[114,115]$. Indeed Notch ligand Jagged1 was described to be a potent proangiogenic regulator and to antagonize Dll4-Notch signaling in endothelial cells, allowing the integration of different pro- and antiangiogenic stimuli 
into a single coordinated biological process of tip cell formation. Moreover Jagged1 expression in tumor cells promotes the growth of tumor vessels, suggesting a proangiogenic role of Jagged1 in tumors [116]. Since DLL4 and Jagged1 have opposing roles in angiogenesis, the identification of upstream signals controlling the expression of one or the other ligand might modulate angiogenesis positively or negatively and have a direct impact in the development of strategies aimed at controlling tumor angiogenesis.

A

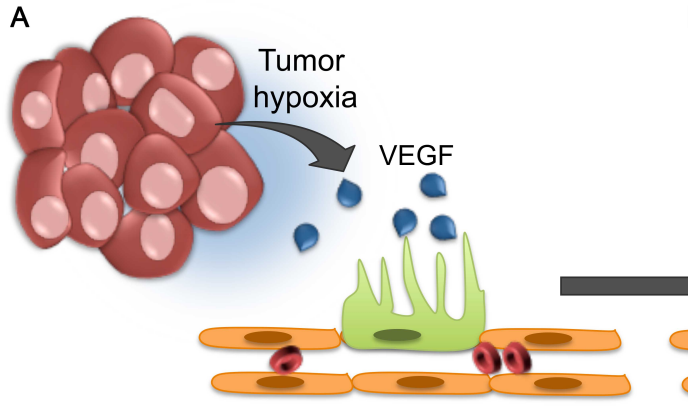

C

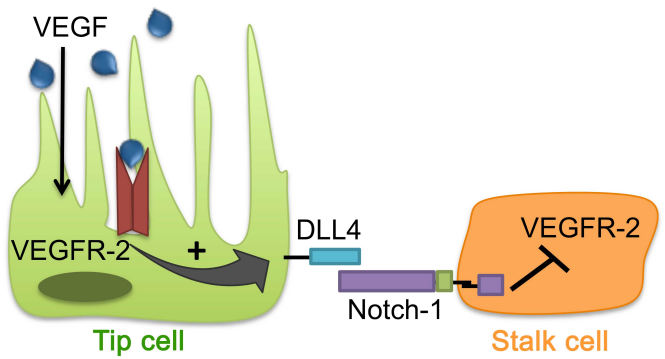

B

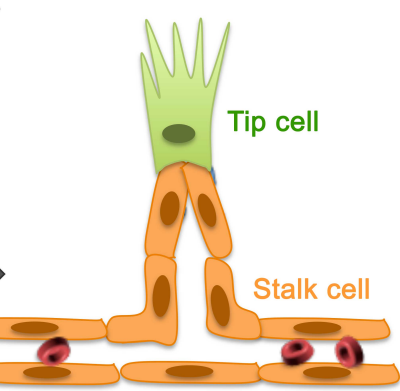

Figure 4. Mechanism of sprouting angiogenesis. A) Vascular endothelial growth factor (VEGF) from hypoxic tumor cells and surrounding tissue activates quiescent endothelial cells (ECs). Responsive ECs should take the lead to prevent ECs moving as a sheet instead of forming a branch. B) The tip cell gains a competitive advantage and is induced to migrate acquiring its tip position in the growing sprout. Tip cells activate Notch signaling in neighboring stalk cells preventing them from becoming a new tip cell. C) This endothelial fate specification is achieved by distinct molecular mechanisms: after VEGFinduced selection of the tip cell, VEGFR2 activation leads to upregulation of the Notch ligand DII4 by the tip cell. Dll4 activates Notch in the neighboring cell, which results in VEGFR2 and down-modulation on the neighboring cell. The latter cell will adapt a stalk phenotype, because the VEGF-induced migratory response is minimized.

\section{Agents targeting Notch signaling}

The use of antiangiogenics agents still holds promise for future cancer treatment. However, after over two decades of antiangiogenic therapy, only modest benefits in increasing overall survival of cancer patients have been reached. 
Numerous mechanisms of resistance to antiangiogenic therapy have been proposed so far [117] [118]. Among them, prolonged VEGF inhibition increases the secretion of hypoxia-induced factors with proangiogenic properties, which can bypass the initial requirement of VEGF for inducing angiogenesis. Therefore, such redundancy of angiogenic molecules may limit the efficacy of anti-VEGF-based therapy.

Targeting the Notch pathway with either small molecule inhibitors of $\mathrm{y}$ secretase (GSIs) or large molecule monoclonal antibodies (mAbs) to Notch ligands and Notch receptors are currently in clinical development [93]. However, several challenges have been encountered due to the dose limiting intestinal adverse events. Indeed, disruption of Notch in the intestinal crypt stem cells (that rely on Notch signaling for daughter cell fate determination) leads to overpopulation of mucussecreting globet cells, leading to malnutrition and diarrhea $[119,120]$. Recently, a competitive Notch-1 decoy inhibitor protein was developed. This protein, consisting of the 36 EGF-like repeats of the Notch-1 extracellular domain was able to competitively inhibit Notch signaling in mouse model of tumor angiogenesis [121, 122]. However, further work will be necessary to characterize the behavior of this construct. Therefore, the search for novel angiogenic mechanisms may lead to a rational design of more effective antiangiogenic combination therapies.

Galectin-3 interaction with the Notch signaling pathway has recently been identified to inhibit osteoblast differentiation [123]. Furthermore, Deleted in Malignant Brain Tumors 1 protein was shown to interact with galectin-3 and modulate Notch signaling pathway [124]. Galectin-1 on the other hand, was reported to promote AKT activation by potentiating integrin $\alpha 6 \beta 4$ and Notch1/Jagged2 in lung cancer [125]. However, the precise role by which galectins affects Notch signal transduction remains elusive. The present thesis demonstrates that galectin-3 regulates Jagged1/Notch signaling activation making it an attractive target for antiangiogenic therapy. 


\section{Tumor glycosylation}

The characterization of the biological functions of glycan-binding proteins, such as galectins, has led to important contributions to the oncology field. As an example, the aberrant glycosylation of VEGFR-2 has been shown to modulate its interaction with galectins and to increase tumor angiogenesis [126]. Indeed, tumor cells display a wide range of glycosylation alterations compared with their nontransformed counterparts. Several evidences support the notion that aberrant glycosylation presented on the cell-surface correlates with cancer progression and affects tumor cell growth, invasion and metastasis [127]. Malignant transformation was shown to lead to the expression of cancer specific antigens, such as oncofetal antigens (epitopes that are present on embryonic tissues and tumor cells but are absent in healthy adult cells), via neo-synthesis or incomplete synthesis [128]. Interestingly though, some of the most-common clinically utilized serological biomarkers for cancer diagnosis as well as prognostic biomarkers, are glycoproteins $[129,130]$. For example, biomarkers that are widely used in patients include prostate cancer (prostate-specific antigen (PSA)) [131], ovarian cancer (carcinoma antigen 125 (CA125) [132], colon cancer (SLea, CA19-9 and carcinoembryonic antigen (CEA)) [130, 133], breast cancer (aberrantly glycosylated MUC1) [134] and gastric cancer (SLea, CA19-9) [130, 135].

The glycans found in human cells, typically undergo glycosylation in the endoplasmic reticulum-Golgi pathway, and are mainly attached to the protein via an Asn residue within a consensus peptide sequence of Asn-X-Ser/Thr (where $X$ can be any amino acid except proline) for N-glycans; or they can be attached by a GalNAc residue in the hydroxyl group of a Ser or Thr residue on the peptide sequence for Oglycans [136]. Altered glycosylation of N-linked glycans in cancer is typically associated with enhanced $\beta 1,6-$ branching by the $\beta 1,6-N-$ acetylglucosaminyltransferase-5 (GnT5) enzyme, which was shown to favor tumor 
growth and metastasis [137, 138]. Regarding O-glycans, shortened or truncated glycans, such as antigens $\mathrm{T}, \mathrm{Tn}$ and their sialylated forms (sT/Tn) seem to be a consistent feature commonly increased in O-glycans attached to mucins. These truncated glycans have been reported to be present at elevated levels in breast, colorectal, ovarian and gastric cancer [139-142].

\section{Glycosylation and tumor resistance to therapy}

Despite the significant clinical success of platinum-based therapies, drug resistance is still the principal cause of treatment failure. Several studies have reported that alterations in the glycosylation status of tumor cells are associated with chemoresistance. In ovarian cancer, increased levels of multidrug resistanceassociated protein (MRP) 1 and MRP4 in resistant cells were associated with a glycosylation defect involving $\mathrm{N}$-linked oligosaccharides [143]. Moreover, altered glycosylation of MRP1 was found in epidermoid carcinoma cells selected for resistance to platinum drugs [144]. N-glycan alterations were also associated with epirubucin and mitoxantrone drugs resistance in human hepatocellular carcinoma [145]. On the other hand, inhibition of N-linked glycosylation of P-glycoprotein by tunicamycin, which inhibits the biosynthesis of glycan precursors, resulted in a reduced multidrug resistance phenotype in a human colorectal carcinoma model [146]. In a different study, alterations in the N-glycan profile of human breast cancer cells correlated with tumor sensitivity to chemotherapeutic drugs such as paclitaxel, vincristine and Adriamycin [147]. All the above studies have proved the importance of altered-N-linked glycans in inducing resistance to chemotherapy. However, the role of O-linked glycans in drug-resistant cells has not been elucidated so far. The present thesis explores for the first time the role of O-glycans in cancer drug resistance. 


\section{Alteration of O-glycans in cancer}

O-linked glycosylation is one of the most abundant forms of protein glycosylation at the cell surface. The O-glycan synthesis is initiated by the addition of a GalNAc to the Ser or Thr residue of a protein. The simplest O-glycan Tn antigen can be further converted to a core 1 structure ( $T$ antigen) by the addition of a $\beta 1,3$ galactose extension or to a core 3 structure by the addition of $\beta 1,3-G I c N A c$. Core 1 structure can be further branched by $\mathrm{C} 2 \mathrm{GnT} 1$ to form core 2 that can be further modified to poly-N-acetyllactosamine structures carrying sialyl-Lewisx/a (Figure 5).
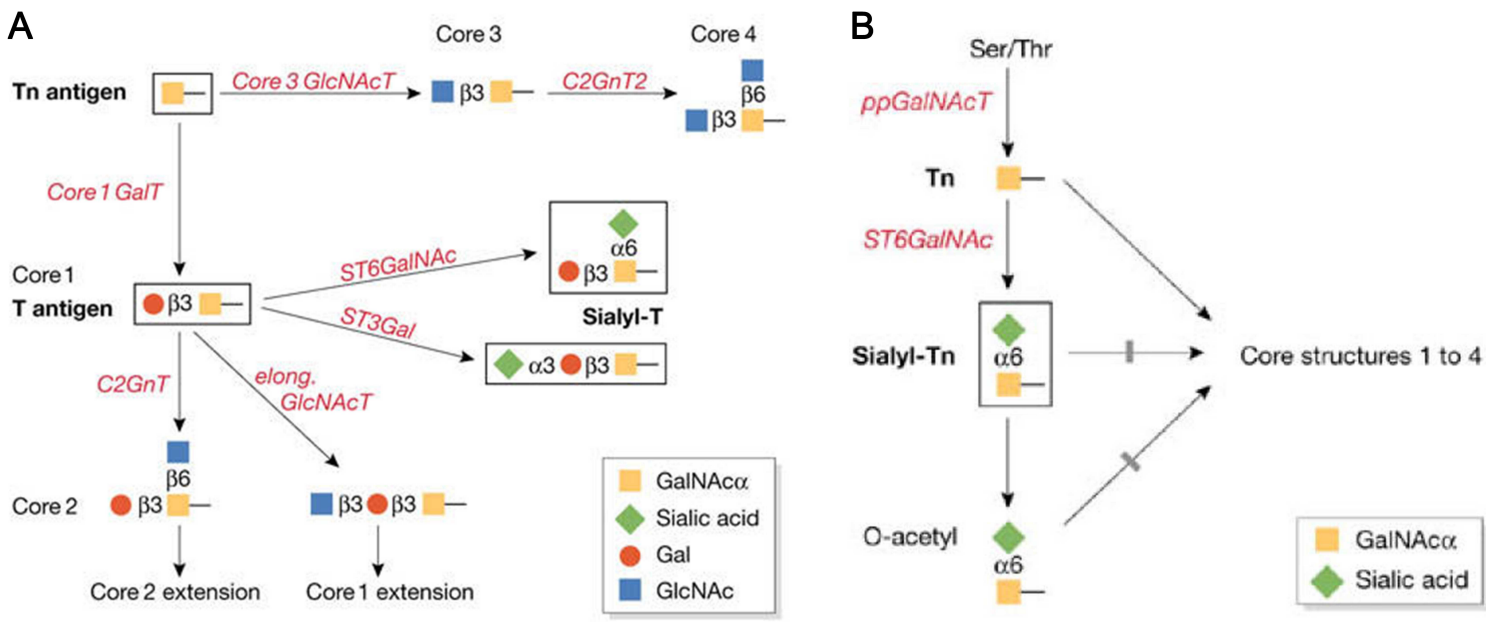

Figure 5. Biosynthesis of O-glycans.

A) N-acetylgalactosamine (GalNAc; Tn antigen) can be converted to core 1 ( $\mathrm{T}$ antigen) by core $1 \beta 3$ Gal-transferase (core $1 \mathrm{GalT}$ ) or to core 3 structures by core $3 \beta 3-\mathrm{N}$-acetylglucosamine (GIcNAc)transferase (core 3 GlcNAcT), which can be branched by C2GnT2 to form core 4 . Core 1 can be converted to sialyl-T antigens by $\alpha 3$-sialyltransferases (ST3Gal) or by $\alpha 6$-sialyltransferases (ST6GalNAc). Alternatively, core 1 can be elongated by a $\beta 3$-GlcNAc-transferase (elong. GlcNAcT) or can be branched by $\mathrm{C} 2 \mathrm{GnT}$ to form core 2. All core structures can be further extended to form complex O-glycans.

B) In the biosynthetic pathway that forms the sialyl-Tn (STn) antigen, a family of polypeptide $\mathrm{N}$ acetylgalactosamine (GalNAc)-transferases (ppGalNAcT) initially adds a GalNAc residue to Ser or Thr of the peptide. This is followed by the addition of sialic acid in $\alpha 2-6$ linkage to GalNAc, catalysed by a family of a6-sialyltransferases (ST6GaINAc), and produces the STn antigen. Bars across the arrows indicate a block in the biosynthetic pathway [148].

During tumor progression, mucins of intestine, colon, liver, stomach or pancreas can present a reduced expression of core 1 GalT and core 3 GIcNAcT correlated with an increased formation of sialyl-Tn and sialyl-T antigens [148]. Moreover, an enhanced expression of sLEx on O-glycans in colorectal and lung carcinomas was found to be associated with strong binding to E-selectin and metastasis compared to normal tissues [149, 150]. Additionally, reduced expression 
of C2GnT1 in mammary cancer was associated with enhanced presence of Tn and STn $[151,152]$.

Sialyl-Tn overexpression has been reported to be a consequence of ST6GalNAc-I upregulation or re-localization from the Golgi to the endoplasmic reticulum $[126,153]$. Since STn is not a normal biosynthetic precursor, its expression is necessarily pathologic. No other oligossacharides are known to be further added to STn antigen. STn expression has been shown to reduce tumor cell-cell aggregation and increase extracellular matrix adhesion, migration and invasion in breast and gastric cancer [154, 155]. Moreover, STn antigen was found in circulating CD44 protein in serum from patients with gastric cancer and has also been found in plasminogen in the serum from patients with intestinal metaplasia and gastric carcinoma $[156,157]$. STn-expressing tumor cells were reported to impair dendritic cells (DC) maturation, rendering DCs with a tolerogenic function and limiting their capacity to trigger protective anti-tumour $\mathrm{T}$ cell responses [158]. Therefore, targeting tumor-associated changes in glycosylation represents an attractive opportunity for novel therapeutic interventions. In the present thesis, we explore the role of Oglycans sialylation in modulating the galectin-3 binding sites on the cell surface and its consequences for chemotherapy resistance. 
Chapter 1 


\section{Thesis outline}

Galectin-3 has been the subject of an intense research over the past few years due to its important role in cancer biology. In Chapter 1 we provide an overview on the state of the art with regard to the role of galectin-3 in tumor biology. Moreover, we discuss about the role of Notch signaling pathway in cancer and its particular role in tumor angiogenesis. Finally, we present an overview of the impact of tumor altered-glycosylation in cancer progression and resistance to chemotherapeutic drugs.

In Chapter 2 we address how galectin-3 and galectin-1 differentially modulate Notch activation by Jagged1 or DLL4 ligands in tumor cells.

The Chapter 3 describes how galectin-3 acts as angiogenic switch to promote tumor angiogenesis via Jagged1-Notch signaling activation.

The Chapter 4 describes how sialylated O-linked glycans influence galectin-3 subcellular localization, which in turn confers tumor cells resistance to chemotherapeutics.

In Chapter 5, we discuss how the knowledge obtained from the present thesis may contribute to our understanding of the role of galectin-3 in Notch signaling regulation, tumor angiogenesis and chemotherapeutic resistance. Moreover, we discuss about the potential use of galectin- 3 inhibitors and its combination with conventional drugs as a strategy to overcome both platinum and antiangiogenic therapy resistance. 


\section{References}

1. Davicino RC, Elicabe RJ, Di Genaro MS, Rabinovich GA. Coupling pathogen recognition to innate immunity through glycan-dependent mechanisms. International immunopharmacology. 2011 Oct;11(10):1457-63.

2. Dennis JW, Lau KS, Demetriou M, Nabi IR. Adaptive regulation at the cell surface by Nglycosylation. Traffic. 2009 Nov;10(11):1569-78.

3. Hanahan D, Weinberg RA. Hallmarks of cancer: the next generation. Cell. 2011 Mar 4;144(5):646-74.

4. Elola MT, Blidner AG, Ferragut F, Bracalente C, Rabinovich GA. Assembly, organization and regulation of cell-surface receptors by lectin-glycan complexes. The Biochemical journal. 2015 Jul 1;469(1):1-16.

5. Barondes $\mathrm{SH}$, Castronovo V, Cooper DN, Cummings RD, Drickamer K, Feizi T, et al. Galectins: a family of animal beta-galactoside-binding lectins. Cell. 1994 Feb 25;76(4):597-8.

6. Liu FT, Rabinovich GA. Galectins as modulators of tumour progression. Nature reviews Cancer. 2005 Jan;5(1):29-41.

7. Ho MK, Springer TA. Mac-2, a novel 32,000 Mr mouse macrophage subpopulation-specific antigen defined by monoclonal antibodies. Journal of immunology. 1982 Mar;128(3):1221-8.

8. Hsu DK, Zuberi RI, Liu FT. Biochemical and biophysical characterization of human recombinant IgE-binding protein, an S-type animal lectin. The Journal of biological chemistry. 1992 Jul 15;267(20):14167-74.

9. Barboni EA, Bawumia S, Henrick K, Hughes RC. Molecular modeling and mutagenesis studies of the N-terminal domains of galectin-3: evidence for participation with the C-terminal carbohydrate recognition domain in oligosaccharide binding. Glycobiology. 2000 Nov;10(11):1201-8.

10. Garner OB, Baum LG. Galectin-glycan lattices regulate cell-surface glycoprotein organization and signalling. Biochemical Society transactions. 2008 Dec;36(Pt 6):1472-7.

11. Ochieng J, Green B, Evans S, James O, Warfield P. Modulation of the biological functions of galectin-3 by matrix metalloproteinases. Biochimica et biophysica acta. 1998 Jan 8;1379(1):97-106.

12. Openo KP, Kadrofske MM, Patterson RJ, Wang JL. Galectin-3 expression and subcellular localization in senescent human fibroblasts. Experimental cell research. 2000 Mar 15;255(2):278-90.

13. Yu F, Finley RL, Jr., Raz A, Kim HR. Galectin-3 translocates to the perinuclear membranes and inhibits cytochrome $c$ release from the mitochondria. A role for synexin in galectin- 3 translocation. The Journal of biological chemistry. 2002 May 3;277(18):15819-27.

14. Fukumori T, Takenaka Y, Oka N, Yoshii T, Hogan V, Inohara H, et al. Endogenous galectin-3 determines the routing of CD95 apoptotic signaling pathways. Cancer research. 2004 May 15;64(10):3376-9.

15. Wang Y, Balan V, Kho D, Hogan V, Nangia-Makker P, Raz A. Galectin-3 regulates p21 stability in human prostate cancer cells. Oncogene. 2013 Oct 17;32(42):5058-65.

16. Oka N, Nakahara S, Takenaka Y, Fukumori T, Hogan V, Kanayama HO, et al. Galectin-3 inhibits tumor necrosis factor-related apoptosis-inducing ligand-induced apoptosis by activating Akt in human bladder carcinoma cells. Cancer research. 2005 Sep 1;65(17):7546-53

17. Lin HM, Pestell RG, Raz A, Kim HR. Galectin-3 enhances cyclin D(1) promoter activity through SP1 and a cAMP-responsive element in human breast epithelial cells. Oncogene. 2002 Nov $14 ; 21(52): 8001-10$

18. Elad-Sfadia G, Haklai R, Balan E, Kloog Y. Galectin-3 augments K-Ras activation and triggers a Ras signal that attenuates ERK but not phosphoinositide 3-kinase activity. The Journal of biological chemistry. 2004 Aug 13;279(33):34922-30.

19. Park JW, Voss PG, Grabski S, Wang JL, Patterson RJ. Association of galectin-1 and galectin-3 with Gemin4 in complexes containing the SMN protein. Nucleic acids research. 2001 Sep 1;29(17):3595-602.

20. Ochieng J, Furtak V, Lukyanov P. Extracellular functions of galectin-3. Glycoconjugate journal. 2004;19(7-9):527-35.

21. Kuwabara I, Liu FT. Galectin-3 promotes adhesion of human neutrophils to laminin. Journal of immunology. 1996 May 15;156(10):3939-44.

22. Sato S, Hughes RC. Binding specificity of a baby hamster kidney lectin for $\mathrm{H}$ type I and II chains, polylactosamine glycans, and appropriately glycosylated forms of laminin and fibronectin. The Journal of biological chemistry. 1992 Apr 5;267(10):6983-90.

23. Ochieng J, Warfield P, Green-Jarvis B, Fentie I. Galectin-3 regulates the adhesive interaction between breast carcinoma cells and elastin. Journal of cellular biochemistry. 1999 Dec 1;75(3):505-14.

24. Ochieng J, Leite-Browning ML, Warfield P. Regulation of cellular adhesion to extracellular matrix proteins by galectin-3. Biochemical and biophysical research communications. 1998 May 29;246(3):788-91.

25. Jeng KC, Frigeri LG, Liu FT. An endogenous lectin, galectin-3 (epsilon BP/Mac-2), potentiates IL-1 production by human monocytes. Immunology letters. 1994 Oct;42(3):113-6. 
26. Kimata H. Enhancement of $\mathrm{IgE}$ production in $\mathrm{B}$ cells by neutrophils via galectin-3 in $\mathrm{IgE}$ associated atopic eczema/dermatitis syndrome. International archives of allergy and immunology. 2002 Jun;128(2):168-70.

27. Hsu DK, Hammes SR, Kuwabara I, Greene WC, Liu FT. Human T Iymphotropic virus-I infection of human $\mathrm{T}$ lymphocytes induces expression of the beta-galactoside-binding lectin, galectin-3. The American journal of pathology. 1996 May;148(5):1661-70.

28. Nangia-Makker P, Honjo Y, Sarvis R, Akahani S, Hogan V, Pienta KJ, et al. Galectin-3 induces endothelial cell morphogenesis and angiogenesis. The American journal of pathology. 2000 Mar;156(3):899-909.

29. Partridge EA, Le Roy C, Di Guglielmo GM, Pawling J, Cheung P, Granovsky M, et al. Regulation of cytokine receptors by Golgi N-glycan processing and endocytosis. Science. 2004 Oct 1;306(5693):120-4.

30. Balan V, Nangia-Makker P, Raz A. Galectins as cancer biomarkers. Cancers. 2010 Apr 20;2(2):592-610.

31. Cheng D, Liang B, Li Y. Serum galectin-3 as a potential marker for gastric cancer. Medical science monitor : international medical journal of experimental and clinical research. 2015;21:755-60.

32. Dawson H, Andre S, Karamitopoulou E, Zlobec I, Gabius HJ. The growing galectin network in colon cancer and clinical relevance of cytoplasmic galectin-3 reactivity. Anticancer research. 2013 Aug;33(8):3053-9.

33. Canesin G, Gonzalez-Peramato P, Palou J, Urrutia M, Cordon-Cardo C, Sanchez-Carbayo M. Galectin-3 expression is associated with bladder cancer progression and clinical outcome. Tumour biology : the journal of the International Society for Oncodevelopmental Biology and Medicine. 2010 Aug;31(4):277-85.

34. de Matos LL, Del Giglio AB, Matsubayashi CO, de Lima Farah M, Del Giglio A, da Silva Pinhal MA. Expression of CK-19, galectin-3 and HBME-1 in the differentiation of thyroid lesions: systematic review and diagnostic meta-analysis. Diagnostic pathology. 2012;7:97.

35. Cortesi L, Rossi E, Della Casa L, Barchetti A, Nicoli A, Piana S, et al. Protein expression patterns associated with advanced stage ovarian cancer. Electrophoresis. 2011 Aug;32(15):1992-2003.

36. Pacis RA, Pilat MJ, Pienta KJ, Wojno K, Raz A, Hogan V, et al. Decreased galectin-3 expression in prostate cancer. The Prostate. $2000 \mathrm{Jul}$ 1;44(2):118-23.

37. Lee JW, Song SY, Choi JJ, Choi CH, Kim TJ, Kim J, et al. Decreased galectin-3 expression during the progression of cervical neoplasia. Journal of cancer research and clinical oncology. 2006 Apr;132(4):241-7.

38. Park SH, Min HS, Kim B, Myung J, Paek SH. Galectin-3: a useful biomarker for differential diagnosis of brain tumors. Neuropathology : official journal of the Japanese Society of Neuropathology. 2008 Oct;28(5):497-506.

39. Larsen L, Chen HY, Saegusa J, Liu FT. Galectin-3 and the skin. Journal of dermatological science. 2011 Nov;64(2):85-91.

40. Sanjuan X, Fernandez PL, Castells A, Castronovo V, van den Brule F, Liu FT, et al. Differential expression of galectin 3 and galectin 1 in colorectal cancer progression. Gastroenterology. 1997 Dec;113(6):1906-15

41. Califice S, Castronovo V, Bracke M, van den Brule F. Dual activities of galectin-3 in human prostate cancer: tumor suppression of nuclear galectin-3 vs tumor promotion of cytoplasmic galectin-3. Oncogene. 2004 Sep 30;23(45):7527-36.

42. Takenaka Y, Fukumori T, Yoshii T, Oka N, Inohara H, Kim HR, et al. Nuclear export of phosphorylated galectin-3 regulates its antiapoptotic activity in response to chemotherapeutic drugs. Molecular and cellular biology. 2004 May;24(10):4395-406.

43. Akahani S, Nangia-Makker P, Inohara H, Kim HR, Raz A. Galectin-3: a novel antiapoptotic molecule with a functional BH1 (NWGR) domain of Bcl-2 family. Cancer research. 1997 Dec 1;57(23):5272-6.

44. Zhao Q, Barclay M, Hilkens J, Guo X, Barrow H, Rhodes JM, et al. Interaction between circulating galectin-3 and cancer-associated MUC1 enhances tumour cell homotypic aggregation and prevents anoikis. Molecular cancer. 2010;9:154.

45. Liu W, Hsu DK, Chen HY, Yang RY, Carraway KL, 3rd, Isseroff RR, et al. Galectin-3 regulates intracellular trafficking of EGFR through Alix and promotes keratinocyte migration. The Journal of investigative dermatology. 2012 Dec;132(12):2828-37.

46. Merlin J, Stechly L, de Beauce S, Monte D, Leteurtre E, van Seuningen I, et al. Galectin-3 regulates MUC1 and EGFR cellular distribution and EGFR downstream pathways in pancreatic cancer cells. Oncogene. 2011 Jun 2;30(22):2514-25.

47. Yamamoto-Sugitani M, Kuroda J, Ashihara E, Nagoshi H, Kobayashi T, Matsumoto Y, et al. Galectin-3 (Gal-3) induced by leukemia microenvironment promotes drug resistance and bone marrow lodgment in chronic myelogenous leukemia. Proceedings of the National Academy of Sciences of the United States of America. 2011 Oct 18;108(42):17468-73.

48. Levy R, Grafi-Cohen M, Kraiem Z, Kloog Y. Galectin-3 promotes chronic activation of K-Ras and differentiation block in malignant thyroid carcinomas. Molecular cancer therapeutics. 2010 Aug;9(8):2208-19. 
49. Shalom-Feuerstein R, Cooks T, Raz A, Kloog Y. Galectin-3 regulates a molecular switch from N-Ras to K-Ras usage in human breast carcinoma cells. Cancer research. 2005 Aug 15;65(16):7292300 .

50. Kim SJ, Lee HW, Gu Kang H, La SH, Choi IJ, Ro JY, et al. Ablation of galectin-3 induces p27(KIP1)-dependent premature senescence without oncogenic stress. Cell death and differentiation. 2014 Nov;21(11):1769-79.

51. Cecchinelli B, Lavra L, Rinaldo C, lacovelli S, Gurtner A, Gasbarri A, et al. Repression of the antiapoptotic molecule galectin-3 by homeodomain-interacting protein kinase 2-activated p53 is required for p53-induced apoptosis. Molecular and cellular biology. 2006 Jun;26(12):4746-57.

52. Vinay DS, Ryan EP, Pawelec G, Talib WH, Stagg J, Elkord E, et al. Immune evasion in cancer: Mechanistic basis and therapeutic strategies. Seminars in cancer biology. 2015 Mar 25.

53. Stillman BN, Hsu DK, Pang M, Brewer CF, Johnson P, Liu FT, et al. Galectin-3 and galectin-1 bind distinct cell surface glycoprotein receptors to induce T cell death. Journal of immunology. 2006 Jan $15 ; 176(2): 778-89$.

54. Dhirapong A, Lleo A, Leung P, Gershwin ME, Liu FT. The immunological potential of galectin-1 and -3 . Autoimmunity reviews. 2009 Mar;8(5):360-3.

55. Cortegano I, del Pozo V, Cardaba B, de Andres B, Gallardo S, del Amo A, et al. Galectin-3 down-regulates IL-5 gene expression on different cell types. Journal of immunology. 1998 Jul 1;161(1):385-9.

56. Feuk-Lagerstedt E, Jordan ET, Leffler H, Dahlgren C, Karlsson A. Identification of CD66a and $\mathrm{CD} 66 \mathrm{~b}$ as the major galectin-3 receptor candidates in human neutrophils. Journal of immunology. 1999 Nov 15;163(10):5592-8.

57. Fernandez GC, Ilarregui JM, Rubel CJ, Toscano MA, Gomez SA, Beigier Bompadre M, et al. Galectin-3 and soluble fibrinogen act in concert to modulate neutrophil activation and survival: involvement of alternative MAPK pathways. Glycobiology. 2005 May;15(5):519-27.

58. Wang W, Guo H, Geng J, Zheng X, Wei H, Sun R, et al. Tumor-released Galectin-3, a soluble inhibitory ligand of human NKp30, plays an important role in tumor escape from NK cell attack. The Journal of biological chemistry. 2014 Nov 28;289(48):33311-9.

59. MacKinnon AC, Farnworth SL, Hodkinson PS, Henderson NC, Atkinson KM, Leffler H, et al. Regulation of alternative macrophage activation by galectin-3. Journal of immunology. 2008 Feb $15 ; 180(4): 2650-8$.

60. Demotte N, Bigirimana R, Wieers G, Stroobant V, Squifflet JL, Carrasco J, et al. A short treatment with galactomannan GM-CT-01 corrects the functions of freshly isolated human tumorinfiltrating lymphocytes. Clinical cancer research : an official journal of the American Association for Cancer Research. 2014 Apr 1;20(7):1823-33.

61. Demotte N, Wieers G, Van Der Smissen P, Moser M, Schmidt C, Thielemans K, et al. A galectin-3 ligand corrects the impaired function of human CD4 and CD8 tumor-infiltrating lymphocytes and favors tumor rejection in mice. Cancer research. 2010 Oct 1;70(19):7476-88.

62. Markowska Al, Jefferies KC, Panjwani N. Galectin-3 protein modulates cell surface expression and activation of vascular endothelial growth factor receptor 2 in human endothelial cells. The Journal of biological chemistry. 2011 Aug 26;286(34):29913-21.

63. Markowska AI, Liu FT, Panjwani N. Galectin-3 is an important mediator of VEGF- and bFGFmediated angiogenic response. The Journal of experimental medicine. 2010 Aug 30;207(9):1981-93.

64. Machado CM, Andrade LN, Teixeira VR, Costa FF, Melo CM, dos Santos SN, et al. Galectin-3 disruption impaired tumoral angiogenesis by reducing VEGF secretion from TGFbeta1-induced macrophages. Cancer medicine. 2014 Apr;3(2):201-14.

65. Yang E, Shim JS, Woo HJ, Kim KW, Kwon HJ. Aminopeptidase N/CD13 induces angiogenesis through interaction with a pro-angiogenic protein, galectin-3. Biochemical and biophysical research communications. 2007 Nov 16;363(2):336-41.

66. Martinez P, Blasco MA. Replicating through telomeres: a means to an end. Trends in biochemical sciences. 2015 Sep;40(9):504-15.

67. Reddel RR. The role of senescence and immortalization in carcinogenesis. Carcinogenesis. 2000 Mar;21(3):477-84.

68. Takenaka Y, Fukumori T, Raz A. Galectin-3 and metastasis. Glycoconjugate journal. 2004;19(7-9):543-9.

69. lurisci I, Tinari N, Natoli C, Angelucci D, Cianchetti E, lacobelli S. Concentrations of galectin-3 in the sera of normal controls and cancer patients. Clinical cancer research : an official journal of the American Association for Cancer Research. 2000 Apr;6(4):1389-93.

70. Yu LG, Andrews N, Zhao Q, McKean D, Williams JF, Connor LJ, et al. Galectin-3 interaction with Thomsen-Friedenreich disaccharide on cancer-associated MUC1 causes increased cancer cell endothelial adhesion. The Journal of biological chemistry. 2007 Jan 5;282(1):773-81.

71. Zhao Q, Guo X, Nash GB, Stone PC, Hilkens J, Rhodes JM, et al. Circulating galectin-3 promotes metastasis by modifying MUC1 localization on cancer cell surface. Cancer research. 2009 Sep 1;69(17):6799-806.

72. Weber GF. Metabolism in cancer metastasis. International journal of cancer Journal international du cancer. 2015 Sep 10. 
73. Chesney J, Telang S. Regulation of glycolytic and mitochondrial metabolism by ras. Current pharmaceutical biotechnology. 2013;14(3):251-60.

74. Dang CV. c-Myc target genes involved in cell growth, apoptosis, and metabolism. Molecular and cellular biology. 1999 Jan;19(1):1-11.

75. Puzio-Kuter AM. The Role of p53 in Metabolic Regulation. Genes \& cancer. 2011 Apr;2(4):385-

91.

76. Bacchi PS, Bloise AC, Bustos SO, Zimmermann L, Chammas R, Rabbani SR. Metabolism under hypoxia in Tm1 murine melanoma cells is affected by the presence of galectin-3, a metabolomics approach. SpringerPlus. 2014;3:470.

77. Fukasawa K. Centrosome amplification, chromosome instability and cancer development. Cancer letters. 2005 Dec 8;230(1):6-19.

78. Basto R, Brunk K, Vinadogrova T, Peel N, Franz A, Khodjakov A, et al. Centrosome amplification can initiate tumorigenesis in flies. Cell. 2008 Jun 13;133(6):1032-42.

79. Nigg EA. Origins and consequences of centrosome aberrations in human cancers. International journal of cancer Journal international du cancer. 2006 Dec 15;119(12):2717-23.

80. Koch A, Poirier F, Jacob R, Delacour D. Galectin-3, a novel centrosome-associated protein, required for epithelial morphogenesis. Molecular biology of the cell. 2010 Jan 15;21(2):219-31.

81. Henderson NC, Sethi T. The regulation of inflammation by galectin-3. Immunological reviews. 2009 Jul;230(1):160-71.

82. Karlsson A, Follin P, Leffler $H$, Dahlgren C. Galectin-3 activates the NADPH-oxidase in exudated but not peripheral blood neutrophils. Blood. 1998 May 1;91(9):3430-8.

83. Yamaoka A, Kuwabara I, Frigeri LG, Liu FT. A human lectin, galectin-3 (epsilon bp/Mac-2), stimulates superoxide production by neutrophils. Journal of immunology. 1995 Apr 1;154(7):3479-87.

84. Correa M, Machado J, Jr., Carneiro CR, Pesquero JB, Bader M, Travassos LR, et al. Transient inflammatory response induced by apoptotic cells is an important mediator of melanoma cell engraftment and growth. International journal of cancer Journal international du cancer. 2005 Apr 10;114(3):356-63.

85. Breuilh L, Vanhoutte F, Fontaine J, van Stijn CM, Tillie-Leblond I, Capron M, et al. Galectin-3 modulates immune and inflammatory responses during helminthic infection: impact of galectin-3 deficiency on the functions of dendritic cells. Infection and immunity. $2007 \mathrm{Nov} ; 75(11): 5148-57$.

86. Saegusa J, Hsu DK, Chen HY, Yu L, Fermin A, Fung MA, et al. Galectin-3 is critical for the development of the allergic inflammatory response in a mouse model of atopic dermatitis. The American journal of pathology. 2009 Mar;174(3):922-31.

87. Chauhan D, Li G, Podar K, Hideshima T, Neri P, He D, et al. A novel carbohydrate-based therapeutic GCS-100 overcomes bortezomib resistance and enhances dexamethasone-induced apoptosis in multiple myeloma cells. Cancer research. 2005 Sep 15;65(18):8350-8.

88. Clark MC, Pang M, Hsu DK, Liu FT, de Vos S, Gascoyne RD, et al. Galectin-3 binds to CD45 on diffuse large B-cell lymphoma cells to regulate susceptibility to cell death. Blood. 2012 Nov 29;120(23):4635-44.

89. Streetly MJ, Maharaj L, Joel S, Schey SA, Gribben JG, Cotter FE. GCS-100, a novel galectin-3 antagonist, modulates MCL-1, NOXA, and cell cycle to induce myeloma cell death. Blood. 2010 May 13;115(19):3939-48.

90. Ranganathan P, Weaver KL, Capobianco AJ. Notch signalling in solid tumours: a little bit of everything but not all the time. Nature reviews Cancer. 2011 May;11(5):338-51.

91. Nickoloff BJ, Osborne BA, Miele L. Notch signaling as a therapeutic target in cancer: a new approach to the development of cell fate modifying agents. Oncogene. 2003 Sep 29;22(42):6598-608.

92. Penton AL, Leonard LD, Spinner NB. Notch signaling in human development and disease. Seminars in cell \& developmental biology. 2012 Jun;23(4):450-7.

93. Takebe N, Nguyen D, Yang SX. Targeting notch signaling pathway in cancer: clinical development advances and challenges. Pharmacology \& therapeutics. 2014 Feb;141(2):140-9.

94. Hu QD, Ang BT, Karsak M, Hu WP, Cui XY, Duka T, et al. F3/contactin acts as a functional ligand for Notch during oligodendrocyte maturation. Cell. 2003 Oct 17;115(2):163-75.

95. Miyamoto A, Lau R, Hein PW, Shipley JM, Weinmaster G. Microfibrillar proteins MAGP-1 and MAGP-2 induce Notch1 extracellular domain dissociation and receptor activation. The Journal of biological chemistry. 2006 Apr 14;281(15):10089-97.

96. Rampal R, Arboleda-Velasquez JF, Nita-Lazar A, Kosik KS, Haltiwanger RS. Highly conserved O-fucose sites have distinct effects on Notch1 function. The Journal of biological chemistry. 2005 Sep 16;280(37):32133-40.

97. Fortini ME. Gamma-secretase-mediated proteolysis in cell-surface-receptor signalling. Nature reviews Molecular cell biology. 2002 Sep;3(9):673-84.

98. Wang H, Zang C, Liu XS, Aster JC. The role of Notch receptors in transcriptional regulation. Journal of cellular physiology. 2015 May;230(5):982-8.

99. Rangarajan A, Talora C, Okuyama R, Nicolas M, Mammucari C, Oh $\mathrm{H}$, et al. Notch signaling is a direct determinant of keratinocyte growth arrest and entry into differentiation. The EMBO journal. 2001 Jul 2;20(13):3427-36. 
100. Weng AP, Ferrando AA, Lee W, Morris JPt, Silverman LB, Sanchez-Irizarry C, et al. Activating mutations of NOTCH1 in human $\mathrm{T}$ cell acute lymphoblastic leukemia. Science. 2004 Oct 8;306(5694):269-71.

101. Egloff AM, Grandis JR. Molecular pathways: context-dependent approaches to Notch targeting as cancer therapy. Clinical cancer research : an official journal of the American Association for Cancer Research. 2012 Oct 1;18(19):5188-95.

102. De La OJ, Murtaugh LC. Notch and Kras in pancreatic cancer: at the crossroads of mutation, differentiation and signaling. Cell cycle. 2009 Jun 15;8(12):1860-4.

103. Hendrix MJ, Seftor RE, Seftor EA, Gruman LM, Lee LM, Nickoloff BJ, et al. Transendothelial function of human metastatic melanoma cells: role of the microenvironment in cell-fate determination. Cancer research. 2002 Feb 1;62(3):665-8.

104. Lee HW, Kim SJ, Choi IJ, Song J, Chun KH. Targeting Notch signaling by gamma-secretase inhibitor I enhances the cytotoxic effect of 5-FU in gastric cancer. Clinical \& experimental metastasis. 2015 Aug;32(6):593-603.

105. Reedijk M, Odorcic S, Chang L, Zhang H, Miller N, McCready DR, et al. High-level coexpression of JAG1 and NOTCH1 is observed in human breast cancer and is associated with poor overall survival. Cancer research. 2005 Sep 15;65(18):8530-7.

106. Santagata S, Demichelis F, Riva A, Varambally S, Hofer MD, Kutok JL, et al. JAGGED1 expression is associated with prostate cancer metastasis and recurrence. Cancer research. 2004 Oct 1;64(19):6854-7.

107. Xu K, Moghal N, Egan SE. Notch signaling in lung development and disease. Advances in experimental medicine and biology. 2012;727:89-98.

108. Zagouras P, Stifani S, Blaumueller CM, Carcangiu ML, Artavanis-Tsakonas S. Alterations in Notch signaling in neoplastic lesions of the human cervix. Proceedings of the National Academy of Sciences of the United States of America. 1995 Jul 3;92(14):6414-8.

109. Espinoza I, Pochampally R, Xing F, Watabe K, Miele L. Notch signaling: targeting cancer stem cells and epithelial-to-mesenchymal transition. OncoTargets and therapy. 2013;6:1249-59.

110. Hofmann JJ, Iruela-Arispe ML. Notch signaling in blood vessels: who is talking to whom about what? Circulation research. 2007 Jun 8;100(11):1556-68.

111. Yadav L, Puri N, Rastogi V, Satpute P, Sharma V. Tumour Angiogenesis and Angiogenic Inhibitors: A Review. Journal of clinical and diagnostic research : JCDR. 2015 Jun;9(6):XE01-XE5.

112. Liu Z, Fan F, Wang A, Zheng S, Lu Y. DII4-Notch signaling in regulation of tumor angiogenesis. Journal of cancer research and clinical oncology. 2014 Apr;140(4):525-36.

113. Jakobsson L, Franco CA, Bentley K, Collins RT, Ponsioen B, Aspalter IM, et al. Endothelial cells dynamically compete for the tip cell position during angiogenic sprouting. Nature cell biology. 2010 Oct;12(10):943-53.

114. Benedito R, Roca C, Sorensen I, Adams S, Gossler A, Fruttiger M, et al. The notch ligands DII4 and Jagged1 have opposing effects on angiogenesis. Cell. 2009 Jun 12;137(6):1124-35.

115. Pedrosa AR, Trindade A, Fernandes AC, Carvalho C, Gigante J, Tavares AT, et al. Endothelial Jagged1 antagonizes DII4 regulation of endothelial branching and promotes vascular maturation downstream of DII4/Notch1. Arteriosclerosis, thrombosis, and vascular biology. 2015 May;35(5):113446.

116. Dufraine J, Funahashi Y, Kitajewski J. Notch signaling regulates tumor angiogenesis by diverse mechanisms. Oncogene. 2008 Sep 1;27(38):5132-7.

117. Bergers G, Hanahan D. Modes of resistance to anti-angiogenic therapy. Nature reviews Cancer. 2008 Aug;8(8):592-603.

118. Krock BL, Skuli N, Simon MC. Hypoxia-induced angiogenesis: good and evil. Genes \& cancer. 2011 Dec;2(12):1117-33.

119. Barten DM, Meredith JE, Jr., Zaczek R, Houston JG, Albright CF. Gamma-secretase inhibitors for Alzheimer's disease: balancing efficacy and toxicity. Drugs in R\&D. 2006;7(2):87-97.

120. Searfoss GH, Jordan WH, Calligaro DO, Galbreath EJ, Schirtzinger LM, Berridge BR, et al. Adipsin, a biomarker of gastrointestinal toxicity mediated by a functional gamma-secretase inhibitor. The Journal of biological chemistry. 2003 Nov 14;278(46):46107-16.

121. Funahashi Y, Hernandez SL, Das I, Ahn A, Huang J, Vorontchikhina M, et al. A notch1 ectodomain construct inhibits endothelial notch signaling, tumor growth, and angiogenesis. Cancer research. 2008 Jun 15;68(12):4727-35.

122. Kangsamaksin T, Murtomaki A, Kofler NM, Cuervo H, Chaudhri RA, Tattersall IW, et al. NOTCH decoys that selectively block DLL/NOTCH or JAG/NOTCH disrupt angiogenesis by unique mechanisms to inhibit tumor growth. Cancer discovery. 2015 Feb;5(2):182-97.

123. Nakajima K, Kho DH, Yanagawa T, Harazono Y, Gao X, Hogan V, et al. Galectin-3 Inhibits Osteoblast Differentiation through Notch Signaling. Neoplasia. 2014 Nov;16(11):939-49.

124. Muller H, Hu J, Popp R, Schmidt MH, Muller-Decker K, Mollenhauer J, et al. Deleted in malignant brain tumors 1 is present in the vascular extracellular matrix and promotes angiogenesis. Arteriosclerosis, thrombosis, and vascular biology. 2012 Feb;32(2):442-8.

125. Hsu YL, Wu CY, Hung JY, Lin YS, Huang MS, Kuo PL. Galectin-1 promotes lung cancer tumor metastasis by potentiating integrin alpha6beta4 and Notch1/Jagged2 signaling pathway. Carcinogenesis. 2013 Jun;34(6):1370-81. 
126. Croci DO, Cerliani JP, Dalotto-Moreno T, Mendez-Huergo SP, Mascanfroni ID, Dergan-Dylon $\mathrm{S}$, et al. Glycosylation-dependent lectin-receptor interactions preserve angiogenesis in anti-VEGF refractory tumors. Cell. 2014 Feb 13;156(4):744-58.

127. Stowell SR, Ju T, Cummings RD. Protein glycosylation in cancer. Annual review of pathology. 2015;10:473-510

128. Kim YJ, Varki A. Perspectives on the significance of altered glycosylation of glycoproteins in cancer. Glycoconjugate journal. 1997 Aug;14(5):569-76.

129. Cummings RD. The repertoire of glycan determinants in the human glycome. Molecular bioSystems. 2009 Oct;5(10):1087-104.

130. Locker GY, Hamilton S, Harris J, Jessup JM, Kemeny N, Macdonald JS, et al. ASCO 2006 update of recommendations for the use of tumor markers in gastrointestinal cancer. Journal of clinical oncology : official journal of the American Society of Clinical Oncology. 2006 Nov 20;24(33):5313-27.

131. Gilgunn S, Conroy PJ, Saldova R, Rudd PM, O'Kennedy RJ. Aberrant PSA glycosylation--a sweet predictor of prostate cancer. Nature reviews Urology. 2013 Feb;10(2):99-107.

132. Zurawski VR, Jr., Orjaseter H, Andersen A, Jellum E. Elevated serum CA 125 levels prior to diagnosis of ovarian neoplasia: relevance for early detection of ovarian cancer. International journal of cancer Journal international du cancer. 1988 Nov 15;42(5):677-80.

133. Goldstein MJ, Mitchell EP. Carcinoembryonic antigen in the staging and follow-up of patients with colorectal cancer. Cancer investigation. 2005;23(4):338-51.

134. Kumpulainen EJ, Keskikuru RJ, Johansson RT. Serum tumor marker CA 15.3 and stage are the two most powerful predictors of survival in primary breast cancer. Breast cancer research and treatment. 2002 Nov;76(2):95-102.

135. Safi F, Schlosser W, Kolb G, Beger HG. Diagnostic value of CA 19-9 in patients with pancreatic cancer and nonspecific gastrointestinal symptoms. Journal of gastrointestinal surgery : official journal of the Society for Surgery of the Alimentary Tract. 1997 Mar-Apr;1(2):106-12.

136. Moremen KW, Tiemeyer M, Nairn AV. Vertebrate protein glycosylation: diversity, synthesis and function. Nature reviews Molecular cell biology. 2012 Jul;13(7):448-62.

137. Dennis JW, Laferte S, Waghorne C, Breitman ML, Kerbel RS. Beta 1-6 branching of Asn-linked oligosaccharides is directly associated with metastasis. Science. 1987 May 1;236(4801):582-5.

138. Lau KS, Dennis JW. N-Glycans in cancer progression. Glycobiology. 2008 Oct;18(10):750-60.

139. Imada T, Rino Y, Hatori S, Takahashi M, Amano T, Kondo J, et al. Sialyl Tn antigen expression is associated with the prognosis of patients with advanced colorectal cancer. Hepato-gastroenterology. 1999 Jan-Feb;46(25):208-14

140. Imai J, Ghazizadeh M, Naito Z, Asano G. Immunohistochemical expression of T, Tn and sialylTn antigens and clinical outcome in human breast carcinoma. Anticancer research. 2001 MarApr;21(2B):1327-34.

141. Ogawa $\mathrm{H}$, Ghazizadeh M, Araki T. Tn and sialyl-Tn antigens as potential prognostic markers in human ovarian carcinoma. Gynecologic and obstetric investigation. 1996;41(4):278-83.

142. Pinto R, Carvalho AS, Conze T, Magalhaes A, Picco G, Burchell JM, et al. Identification of new cancer biomarkers based on aberrant mucin glycoforms by in situ proximity ligation. Journal of cellular and molecular medicine. 2012 Jul;16(7):1474-84.

143. Beretta GL, Benedetti V, Cossa G, Assaraf YG, Bram E, Gatti L, et al. Increased levels and defective glycosylation of MRPs in ovarian carcinoma cells resistant to oxaliplatin. Biochemical pharmacology. 2010 Apr 15;79(8):1108-17.

144. Liang XJ, Shen DW, Garfield S, Gottesman MM. Mislocalization of membrane proteins associated with multidrug resistance in cisplatin-resistant cancer cell lines. Cancer research. 2003 Sep 15;63(18):5909-16.

145. Kudo T, Nakagawa H, Takahashi M, Hamaguchi J, Kamiyama N, Yokoo H, et al. N-glycan alterations are associated with drug resistance in human hepatocellular carcinoma. Molecular cancer. 2007;6:32.

146. Kramer R, Weber TK, Arceci R, Ramchurren N, Kastrinakis WV, Steele G, Jr., et al. Inhibition of $\mathrm{N}$-linked glycosylation of $\mathrm{P}$-glycoprotein by tunicamycin results in a reduced multidrug resistance phenotype. British journal of cancer. 1995 Apr;71(4):670-5

147. Ma H, Miao X, Ma Q, Zheng W, Zhou H, Jia L. Functional roles of glycogene and N-glycan in multidrug resistance of human breast cancer cells. IUBMB life. 2013 May;65(5):409-22.

148. Brockhausen I. Mucin-type O-glycans in human colon and breast cancer: glycodynamics and functions. EMBO reports. 2006 Jun;7(6):599-604.

149. Machida E, Nakayama J, Amano J, Fukuda M. Clinicopathological significance of core 2 beta1,6-N-acetylglucosaminyltransferase messenger RNA expressed in the pulmonary adenocarcinoma determined by in situ hybridization. Cancer research. 2001 Mar 1;61(5):2226-31.

150. Shimodaira K, Nakayama J, Nakamura N, Hasebe O, Katsuyama T, Fukuda M. Carcinomaassociated expression of core 2 beta-1,6-N-acetylglucosaminyltransferase gene in human colorectal cancer: role of O-glycans in tumor progression. Cancer research. 1997 Dec 1;57(23):5201-6.

151. Brockhausen I, Yang JM, Burchell J, Whitehouse C, Taylor-Papadimitriou J. Mechanisms underlying aberrant glycosylation of MUC1 mucin in breast cancer cells. European journal of biochemistry / FEBS. 1995 Oct 15;233(2):607-17. 
152. Solatycka A, Owczarek T, Piller F, Piller V, Pula B, Wojciech L, et al. MUC1 in human and murine mammary carcinoma cells decreases the expression of core 2 beta1,6-Nacetylglucosaminyltransferase and beta-galactoside alpha2,3-sialyltransferase. Glycobiology. 2012 Aug;22(8):1042-54.

153. Vazquez-Martin C, Cuevas E, Gil-Martin E, Fernandez-Briera A. Correlation analysis between tumor-associated antigen sialyl-Tn expression and ST6GalNAc I activity in human colon adenocarcinoma. Oncology. 2004;67(2):159-65.

154. Julien S, Adriaenssens E, Ottenberg K, Furlan A, Courtand G, Vercoutter-Edouart AS, et al. ST6GaINAc I expression in MDA-MB-231 breast cancer cells greatly modifies their O-glycosylation pattern and enhances their tumourigenicity. Glycobiology. 2006 Jan;16(1):54-64.

155. Pinho S, Marcos NT, Ferreira B, Carvalho AS, Oliveira MJ, Santos-Silva F, et al. Biological significance of cancer-associated sialyl-Tn antigen: modulation of malignant phenotype in gastric carcinoma cells. Cancer letters. 2007 May 8;249(2):157-70.

156. Campos D, Freitas D, Gomes J, Magalhaes A, Steentoft C, Gomes C, et al. Probing the Oglycoproteome of gastric cancer cell lines for biomarker discovery. Molecular \& cellular proteomics : MCP. 2015 Jun;14(6):1616-29.

157. Gomes C, Almeida A, Ferreira JA, Silva L, Santos-Sousa H, Pinto-de-Sousa J, et al. Glycoproteomic analysis of serum from patients with gastric precancerous lesions. Journal of proteome research. 2013 Mar 1;12(3):1454-66.

158. Carrascal MA, Severino PF, Guadalupe Cabral M, Silva M, Ferreira JA, Calais F, et al. Sialyl Tn-expressing bladder cancer cells induce a tolerogenic phenotype in innate and adaptive immune cells. Molecular oncology. 2014 May;8(3):753-65. 


\section{Chapter}

Galectin-1 and galectin-3 differentially modulate Notch

signaling in gastric cancer 



\section{Abstract}

Notch signaling pathway has emerged as an important pathway in maintaining the balance between cell proliferation, differentiation and apoptosis in cancer cells. Galectin-3, a glycan-binding protein, was recently reported to regulate Notch signaling activation. Still, the precise mechanism by which this regulation is accomplished is not fully understood. Here we demonstrate that galectin-1-DLL4 and galectin-3-Jagged1 expressions are positively correlated in human gastric cancer. Moreover, galectin-1 and galectin-3 interact with Notch-1 receptor and preferentially activate Notch signaling by DLL4 or Jagged1 ligands, respectively. Galectin-3, which is mainly found in tumor cells, regulates the cell surface expression of Notch ligands and Notch-1 receptor and, when present extracellularly, can rescue Notch-1 activation in the absence of endogenous galectin-3. This knowledge open novel perspectives for future combined Notch-targeted therapy. 


\section{Introduction}

Notch receptors are cell surface glycoproteins whose interaction with ligands (Jagged/Delta-like) present on an adjacent cell initiates the proteolytic cleavage of the receptor and the subsequent release of its intracellular domain (NICD) that initiates the transcription of Notch target genes [1]. Notch signaling has emerged as an attractive pathway for cancer therapy because of its central role in regulating differentiation, proliferation, apoptosis and angiogenesis in a broad types of cancer [2]. Although strategies targeting Notch pathway are currently being tested in clinical trials [3], several challenges have been encountered due to the dose limiting intestinal adverse event [3]. Therefore, the identification of novel molecules, which can interfere with Notch signaling activation, will be of great importance for Notchtargeted therapy.

Galectins, a family of glycan binding proteins, have emerged as promising molecular targets for cancer therapy since they are overexpressed in a wide range of tumor and can contribute to neoplastic transformation, growth, angiogenesis and metastasis [4]. Recently, Nakajima et al [5], reported that galectin-3 was able to binds and activate Notch-1 receptor in a ligand-independent way, thus inhibiting osteoblast differentiation. Moreover, Deleted in Malignant Brain Tumors 1 protein was shown to interact with galectin-3 and indirectly modulate Notch signaling pathway [6]. In addition, galectin-1 was reported to promote AKT activation which potentiating integrin $\alpha 6 \beta 4$ and Notch1/Jagged2 in lung cancer [7]. Therefore, changes in galectin-1 and -3 expression levels during cancer progression suggest that galectins may modulate Notch signaling during malignant transformation. Here we found that galectin- 1 and -3 differentially modulate Notch activation by Delta- 4 and Jagged-1 ligands, respectively, in gastric carcinoma cells. 


\section{Results}

\section{Galectin-1 and galectin-3 have a positive correlation with Jagged-1 and DLL4 protein expression in gastric cancer tissues}

To study the correlation between galectin- 1 and -3 protein expressions with Notch-1 receptor and Jagged1, DLL4 ligands, we analyzed by immunohistochemistry 58 gastric tumor samples (Table S1) and quantified the intensity and proportion staining of the different proteins with the Allred score (Table S2). Galectin-1 expression was mostly expressed in tumor-associated stroma cells with a negative/weak reaction in tumor cells (Figure 1A-E) whereas gal-3 was mainly found in tumor cells (Figure 1F-J). Jagged1 and Notch-1 were typically present in tumor cells whereas DLL4 was found both in tumor as well as in cancer-associated stroma

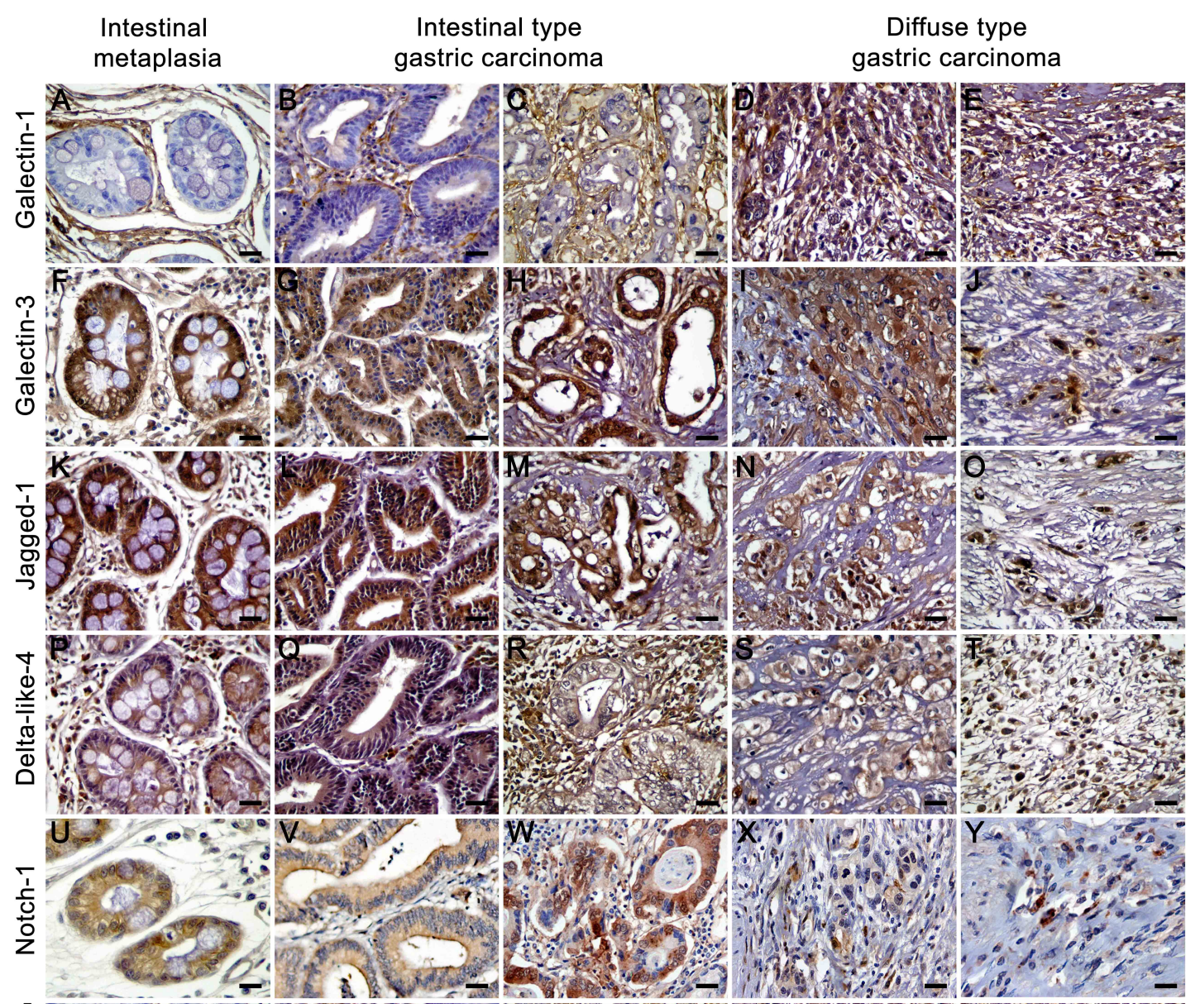

Figure 1. Galectin-1 and galectin-3 are positively correlated with Notch ligands.

Representative immunostaining of galectin-1 (A-E), galectin-3 (F-J), Jagged-1 (K-O), Delta-like-4 (P-T) and Notch-1 (U-Y) in intestinal metaplasia, intestinal type gastric carcinoma and diffuse type gastric carcinoma. Scale bars, $50 \mu \mathrm{m}$. 
cells (Figure $1 \mathrm{~K}-\mathrm{Y}$ ). Spearman's $\rho$-test gave a positive correlation between the expression levels of gal-1 and DLL4 and, between the levels of gal-3 with Jagged1 and DLL4 ligands (Table S3). No correlation was found between both galectins and Notch-1 receptor.

\section{Galectin-1 and galectin-3 bind to Notch-1 receptor}

We next used AGS and MKN45 gastric carcinoma cells as a model to study galectins interaction with Notch-1 receptor. Both cell lines presented similar levels of cell surface expression of galectin-1 (Figure 2A) as evaluated by flow cytometry analysis, though, gal-3 cell surface expression (Figure 2B), as well as gal-1 and gal-3 cell surface-binding sites (Figure 2C and 2D) were significantly higher in AGS cell in comparison with MKN45. The total levels of gal-1 and gal-3 (Figure 2E-G) were increased in AGS cells in comparison to MKN45. Using AGS and MKN45 cells lysates we observed that both gal-1 (Figure $2 \mathrm{H}$ ) and gal-3 (Figure 2I) were coimmunoprecipitated with Notch-1 receptor.

\section{Galectin-1 and galectin-3 activate ligand-dependent Notch} signaling

We further investigated the effect of gal-1 and gal-3 in Notch signaling activation by culturing AGS cells, which presented the highest levels of gal-1 and gal3, with immobilized BSA (control), Jagged1 or DLL4. We found, as expected, that DLL4 is a more potent activator of the Notch signaling than Jagged1 in scrambledAGS cells (Figure 3A). Upon galectin-1 dsRNA inhibition, Jagged1 was found to upregulate NICD1 protein levels while DLL4 induced a downregulation of NICD1 levels (Figure 3A and 3B) and, Hes-1 (Figure 3C) and Hey-1 (Figure 3D) Notch target genes in comparison to scrambled cells. On the other hand, galectin-3 dsRNA inhibition led to NICD1 (Figure 3E and 3F), Hes-1, (Figure 3G) and Hey-1 (Figure 


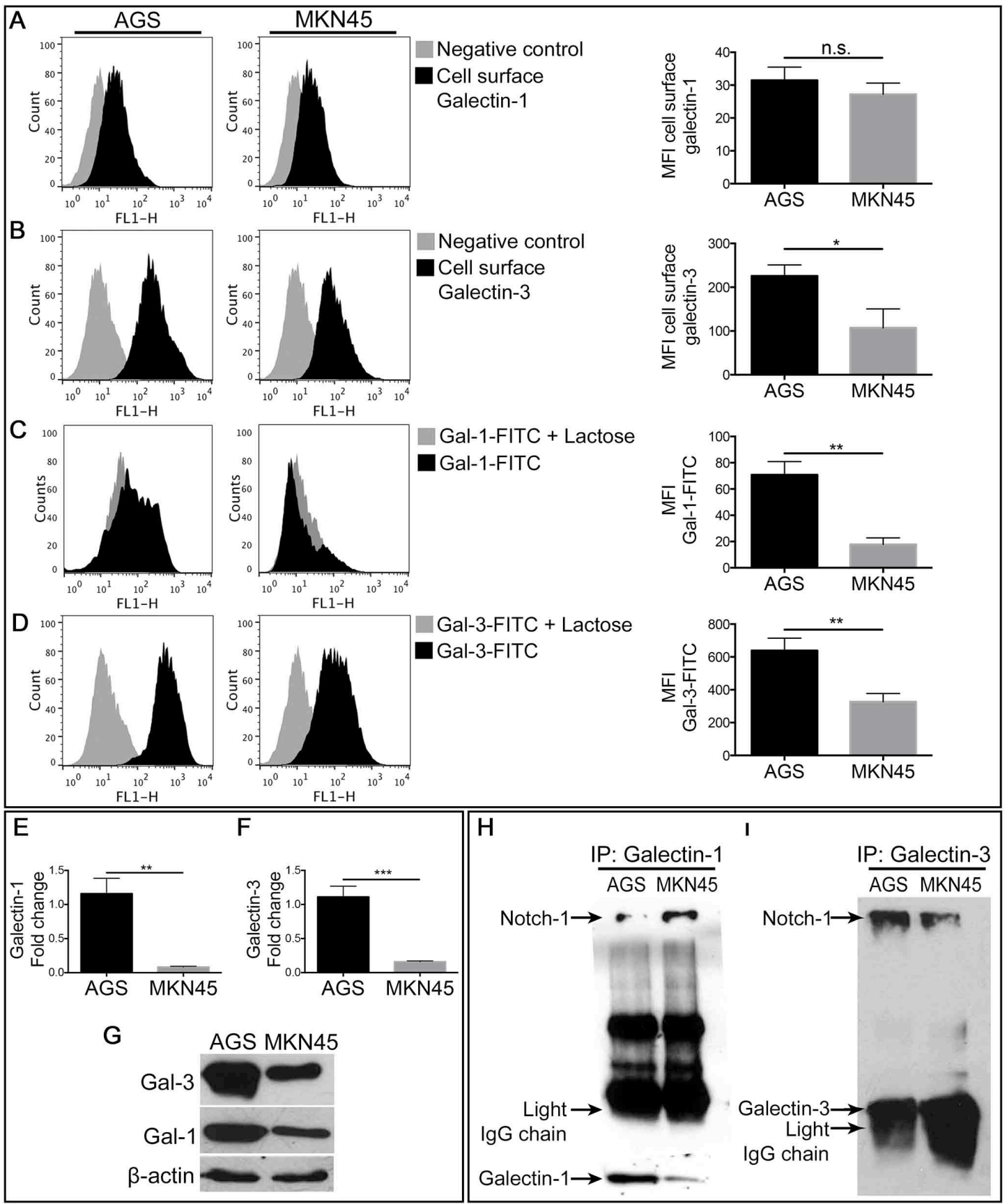

Figure 2. Galectin-1 and galectin-3 from AGS and MKN45 gastric cancer cells bind to Notch-1 receptor.

(A-D) Flow cytometry histogram and mean fluorescence intensity quantification of cell surface (A) galectin-1, (B) galectin-3, (C) galectin-1-FITC and (D) galectin-3-FITC in AGS and MKN45 cells.

(E) Galectin-1 and (F) galectin-3 mRNA levels of AGS and MKN45 cells. The relative levels of expression were normalized to the level of $\beta$-actin mRNA expression.

(G) Immunoblot of galectin-1, galectin-3 and Notch-1 in (G) total AGS and MKN45 lysates or in the immunoprecipitation of $(\mathrm{H})$ galectin-1 and $(\mathrm{I})$ galectin-3. $\beta$-actin was used as a loading control.

Data are representative of three independent experiments (A-D and $G-I)$, or are the mean \pm SEM, $n=3$ (E and F). ${ }^{* *} p<0.01 ;{ }^{* *} p<0,001$.

$3 \mathrm{H})$ downregulation in the presence of Jagged-1 but to NICD1 upregulation in the presence of DLL4 compared to scramble cells (Figure 3C and 3D). Altogether, these results show that gal-1 preferentially activates Notch-1 signaling by the DLL4 ligand whereas gal-3 enhances Jagged1-mediated Notch-1 activation. 

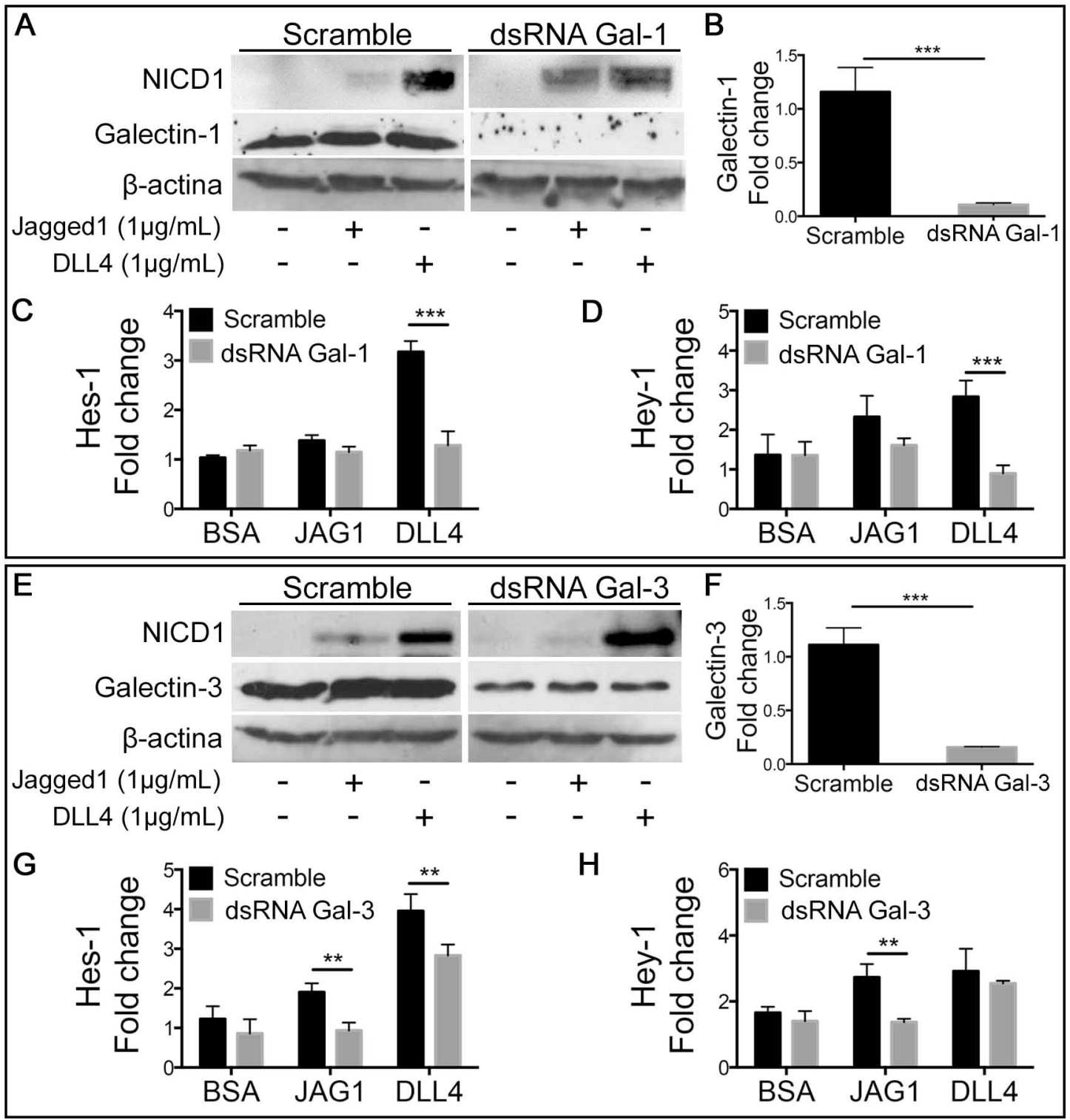

Figure 3. Galectin-1 and galectin-3 modulate ligand-dependent Notch-1 signaling activation. AGS-scramble or AGS-dsRNA-Gal-1 cells seeded for 6 hours in a BSA-, DLL4- or Jagged1-coated plate were (A) immunoblotted against NICD1 and galectin-1 or, evaluated for (B) galectin-1, (C) Hes-1 and (D) Hey-1 mRNA levels. $\beta$-actin was used as loading control and (B-D) were normalized to $\beta$-actin mRNA expression.

AGS-scramble or AGS-dsRNA-Gal-3 cells seeded for 6 hours in a BSA-, DLL4- or Jagged1-coated plate were (E) immunoblotted against NICD1 and galectin-3 or, evaluated for (F) galectin-3, $(G)$ Hes-1 and $(\mathrm{H}) \mathrm{Hey}-1$ mRNA levels. $\beta$-actin was used as loading control and $(\mathrm{F}-\mathrm{H})$ were normalized to $\beta$-actin mRNA expression.

Data are representative of three independent experiments ( $A$ and $E$ ), or are the mean $\pm S E M, n=3$. ${ }^{* *} p<0.01 ;{ }^{* * *} p<0,001$.

\section{Galectin-3 regulates Notch ligands and Notch-1 receptor}

\section{expression}

Unlike galectin-1, galectin-3 was predominantly found in tumor cells of gastric cancer. Therefore, we additionally observed that gal-3-silenced AGS cells showed 
decreased levels of cell surface galectin-3 (Figure 4A) and total galectin-3 (Figure 4B), that led to a downregulation of cell surface DLL1, DLL4 and Jagged1 ligands and Notch-1 receptor in comparison to scrambled AGS cells (Figure 4C-4F, respectively). Moreover, human glioblastoma cells overexpressing the Notch ligands Jagged1 (U87-JG1) or DLL4 (U87-DLL4) presented increased cell surface levels of galectin-3 (Figure S1A) and galectin-3 binding sites (Figure S1B) in comparison with the control empty vector U87-EV. These data suggest that galectin-3 regulates the expression levels of the Notch ligands and Notch-1 receptor through direct binding to Notch components.

\section{Extracellular galectin-3 can rescue Jagged1-Notch signaling activation}

We subsequently incubated AGS-scramble cells with $2 \mu \mathrm{M}$ of recombinant human galectin-3 and observed an upregulation of NICD1 and Jagged-1 protein levels in the presence of immobilized Jagged-1 compared to control BSA (Figure $4 G$ ). Exogenously added gal-3 was able to further upregulate NICD1 and Jagged1 protein levels. In gal-3-silenced cells, NICD1 and Jagged1 levels were decreased in comparison to scrambled cells and immobilized Jagged1 was not able to activate Notch signaling nor Jagged1 protein. Surprisingly, exogenously added gal-3 was able to rescue NICD1 and Jagged1 expression in gal-3-silenced AGS cells (Figure 4G). No differences were found in DLL4 protein expression in all tested conditions.

Exogenously added gal-3 also increased NICD1 levels in U87-EV, -JG1 and -DLL4 scrambled cells, though this increase was higher in Jagged1-overexpressing cells (Figure S1C). In gal-3-silenced cells, exogenously added gal-3 rescued Notch-1 activation to the basal scrambled levels in U87-JG1 cells, but no effect was found in U87-EV or U87-DLL4. Our results demonstrate that extracellular galectin-3 has an important role in modulating Jagged1/Notch-1 activation in cancer cells. 


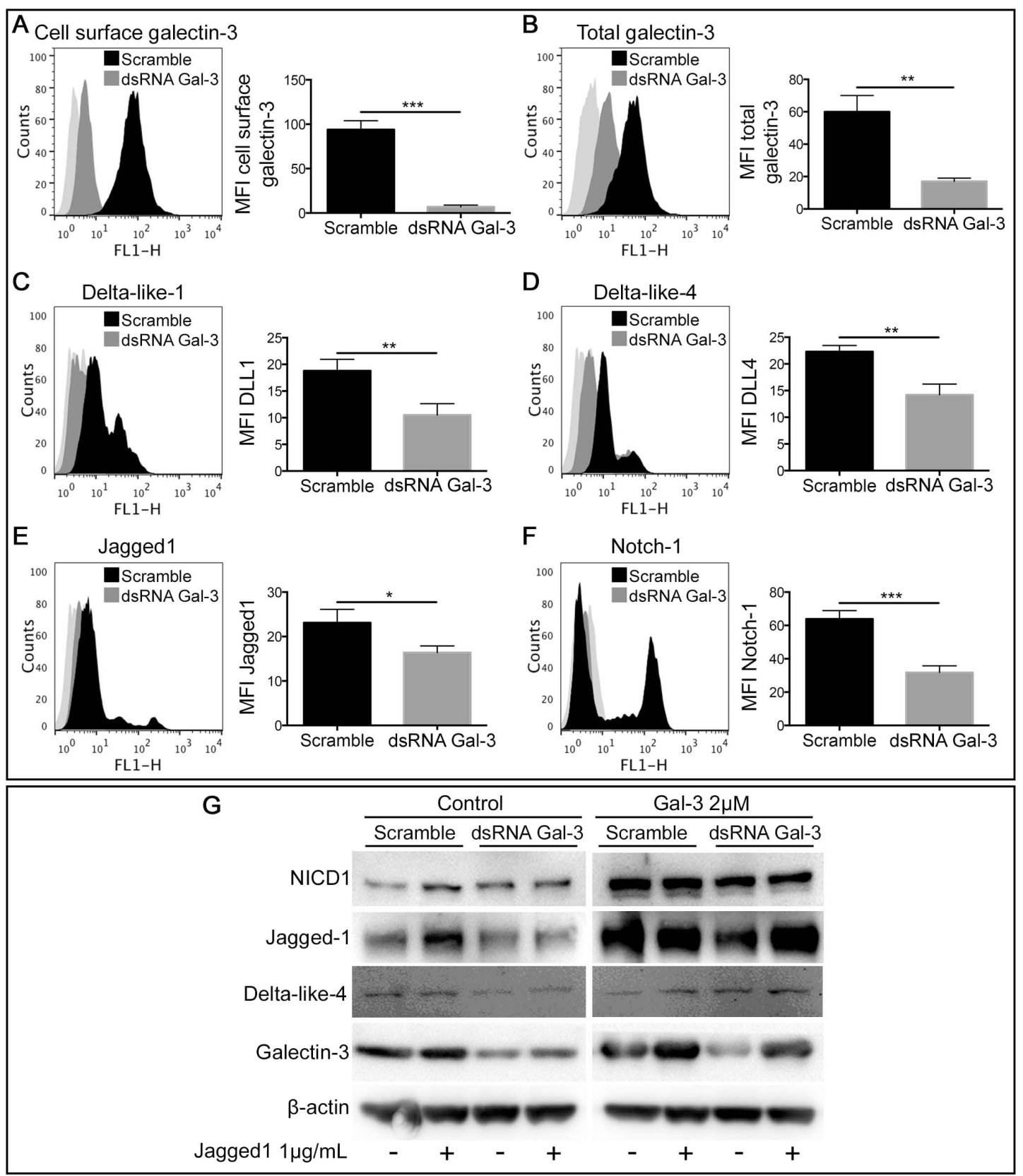

Figure 4. Galectin-3 regulates the cell surface expression of Notch components and extracellular gal-3 increases Jagged1/Notch signaling activation.

(A-F) Flow cytometry histogram and the mean fluorescence intensity (MFI) of cell surface (A), total galectin-3 (B), Delta-like-1 (C), Delta-like-4 (D), Jagged1 (E) and Notch-1 (F) in AGS-scramble or AGSdsRNA-Gal3.

(G) Immunoblot of NICD1, Jagged1, Delta-like-4 and galectin-3 in AGS-scramble or AGS-dsRNA-Gal-3 cultured for 6 hours with immobilized Jagged1 and/or gal-3. $\beta$-actin was used as a loading control.

Data are representative of three independent experiments or are the mean \pm SEM, $n=3 .{ }^{*} p<0.05$; ${ }^{* *} p<0.01 ;{ }^{* * *} p<0,001$. 


\section{Discussion}

Galectin-1 and galectin-3 have been the subject of an intense research due to their increased expression in cancer tissue comparing to normal tissues and their role in tumor biology. Here we demonstrate that (1) galectin-1 has a positive correlation with DLL4 protein whereas galectin-3 preferentially positively correlates with Jagged1 expression in gastric cancer tissues; (2) galectin-1 and -3 bind and activate Notch-1 signaling in a ligand-dependent manner; (3) Particularly, galectin-3 was found to regulate Notch ligands and Notch-1 receptor expression; (4) Extracellular gal-3 was able to rescue Notch signaling activation in a Jagged1dependent manner in cells gal-3 depleted.

Galectin-1 expression in tumor tissues has been mainly associated to the stroma surrounding tumor cells and endothelial cells [8]. Likewise DLL4 is preferentially overexpressed in tumor and stromal/endothelilal-associated tumor cells [9]. Galectin-3 and Jagged1 on the other hand have been mainly found overexpressed in the tumor cells $[10,11]$. Therefore, gal-1-DLL4 and gal-3-Jagged1 related localizations may explain the preferential Notch-dependent ligand signaling activation by galectins. Moreover, both Notch receptor and ligands are glycoproteins bearing $\beta 1-4$-galactose glycans that are potentially recognized by galectins. Therefore, the ability of galectins to crosslink glycosylated proteins could promote Notch receptor and ligand interaction between different cells, thus initiating the Notch signaling activation cascade. Furthermore, galectin-1 was reported to form homogenous and organized lattices whereas galectin-3 forms heterogeneous and disorganized structures when cross-linking multivalent carbohydrates [12]. The differences in the lattice formation could also explain why galectin-1 preferentially activates Notch via DLL4, whereas galectin-3 preferentially activates Notch via Jagged1. Additionally, it has been demonstrated that galectins have the ability to control cell surface receptors half-life [4]. Since endocytosis is a fundamental feature 
of the Notch signaling pathway [2], we can also hypothesize that extracellular galectins may regulate Notch receptor or ligands endocytosis, thus modulating Notch activation.

In addition to binding extracellular glycoproteins, galectin-1 and galectin-3 are also engaged in protein-protein interactions and can be found intracellularly [4]. Therefore, we cannot discard a direct interaction between galectins and NICD in Notch signaling modulation. Interestingly, gal-1 has been reported to inhibit glycogen synthase kinase (GSK)-3 $\alpha / \beta$ phosphorylation, increasing its activity [13] whereas gal-

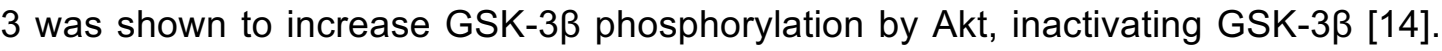
Since conflicting results about GSK-3 $\beta$ have shown that this protein can increase NICD phosphorylation protecting it from proteasome degradation, or, on the other hand, downregulate Notch activity $[15,16]$, one can hypothesize that intracellular galectins may also modulate intracellularly Notch signaling activation indirectly via GSK-3ß.

We then propose a new mechanism by which galectin-1 and galectin-3 may modulate Notch signaling activation in cancer cells (Figure S2). Since the status of Notch signaling activation can be altered by galectin-1 and -3 expression during malignant transformation, the interference with galectin-1 or galectin-3 in the tumor microenvironment may represent a novel therapeutic intervention strategy against Notch signaling in cancer. 


\section{Experimental Procedures}

\section{Cell culture}

MKN45 cells (American Type Culture Collection, Manassas, VALLC [17]) and AGS cells (ATCC CRL-1739) were cultured in RPMI (Gibco, Life technologies, MD, USA) Both cell lines were supplemented with $10 \%$ of fetal bovine serum (Gibco, Life technologies, MD, USA) and $50 \mu \mathrm{g} / \mathrm{mL}$ of gentamicin (Gibco, Life technologies, MD, USA). Mycoplasma contamination in cultured cells was excluded using Lonza Mycoplasma Detection Kit.

\section{Flow cytometry}

For flow cytometry, cells were incubated with anti-galectin-3, -galectin-1, DLL4, -Jagged1, -DLL1 or -Notch-1 antibodies and detected with Alexa488 conjugated secondary antibodies (Invitrogen). Alternatively, cells were incubated with $2 \mu \mathrm{M}$ of gal-1-FITC or gal-3-FITC in the presence or absence of lactose $(50 \mathrm{mM})$. For detailed protocol see supplemental experimental procedures.

\section{Gene expression analysis}

Total RNA from cell cultures was isolated with Tri-Reagent (Sigma) according to the manufacturer's instructions. Complementary DNA (cDNA) was synthesized using the High capacity cDNA RT kit (Applied Biosystems), according to the manufacturer's protocols. Quantitative PCR analysis of galectin-1, galectin-3, Hes-1 and Hey-1 were performed in triplicate using the SensiMix SYBR No-ROX kit (Bioline). Relative quantification was done using the $\Delta \Delta$ Ct method normalizing to $\beta$ actin gene expression. 
Chapter 2

\section{Immunostaining}

Sections from cancer specimens were fixed in $10 \%$ formaldehyde and embedded in paraffin. Serial sections of $3 \mu \mathrm{m}$ were cut and used for immunostaining with anti-galectin-1, anti-galectin-3, anti-Notch-1, anti-DLL4 or anti-Jagged1 followed by secondary biotinylated antibodies (DAKO). For detailed protocol see supplemental experimental procedures.

\section{Statistical Analysis}

All data are expressed as the mean \pm SEM of at least three independent experiments. Statistical analysis including spearman correlation, t-test and one-way ANOVA were done using GraphPad Prism 6.0 software. $p<0.05$ was considered statistically significant. 


\section{References}

1. Kopan R, llagan MX. The canonical Notch signaling pathway: unfolding the activation mechanism. Cell. 2009 Apr 17;137(2):216-33.

2. Tien AC, Rajan A, Bellen HJ. A Notch updated. The Journal of cell biology. 2009 Mar 9;184(5):621-9.

3. Takebe N, Nguyen D, Yang SX. Targeting notch signaling pathway in cancer: clinical development advances and challenges. Pharmacology \& therapeutics. 2014 Feb;141(2):140-9.

4. Liu FT, Rabinovich GA. Galectins as modulators of tumour progression. Nature reviews Cancer. 2005 Jan;5(1):29-41.

5. Nakajima K, Kho DH, Yanagawa T, Harazono Y, Gao X, Hogan V, et al. Galectin-3 Inhibits Osteoblast Differentiation through Notch Signaling. Neoplasia. 2014 Nov; 16(11):939-49.

6. Muller H, Hu J, Popp R, Schmidt MH, Muller-Decker K, Mollenhauer J, et al. Deleted in malignant brain tumors 1 is present in the vascular extracellular matrix and promotes angiogenesis. Arteriosclerosis, thrombosis, and vascular biology. 2012 Feb;32(2):442-8.

7. Hsu YL, Wu CY, Hung JY, Lin YS, Huang MS, Kuo PL. Galectin-1 promotes lung cancer tumor metastasis by potentiating integrin alpha6beta4 and Notch1/Jagged2 signaling pathway. Carcinogenesis. 2013 Jun;34(6):1370-81.

8. Demydenko D, Berest I. Expression of galectin-1 in malignant tumors. Experimental oncology. 2009 Jun;31(2):74-9.

9. Kuhnert F, Chen G, Coetzee S, Thambi N, Hickey C, Shan J, et al. DII4 Blockade in Stromal Cells Mediates Antitumor Effects in Preclinical Models of Ovarian Cancer. Cancer research. 2015 Sep 16.

10. Cay T. Immunhistochemical expression of galectin-3 in cancer: a review of the literature. Turk patoloji dergisi. 2012;28(1):1-10.

11. Li D, Masiero M, Banham AH, Harris AL. The notch ligand JAGGED1 as a target for anti-tumor therapy. Frontiers in oncology. 2014;4:254.

12. Ahmad N, Gabius HJ, Andre S, Kaltner H, Sabesan S, Roy R, et al. Galectin3 precipitates as a pentamer with synthetic multivalent carbohydrates and forms heterogeneous cross-linked complexes. The Journal of biological chemistry. 2004 Mar 19;279(12):10841-7.

13. Fischer I, Weber M, Kuhn C, Fitzgerald JS, Schulze S, Friese K, et al. Is galectin-1 a trigger for trophoblast cell fusion?: the MAP-kinase pathway and syncytium formation in trophoblast tumour cells BeWo. Molecular human reproduction. $2011 \mathrm{Dec} ; 17(12): 747-57$.

14. Song S, Mazurek N, Liu C, Sun Y, Ding QQ, Liu K, et al. Galectin-3 mediates nuclear beta-catenin accumulation and Wnt signaling in human colon cancer cells by regulation of glycogen synthase kinase-3beta activity. Cancer research. 2009 Feb 15;69(4):1343-9.

15. Guha S, Cullen JP, Morrow D, Colombo A, Lally C, Walls D, et al. Glycogen synthase kinase 3 beta positively regulates Notch signaling in vascular smooth muscle cells: role in cell proliferation and survival. Basic research in cardiology. 2011 Sep;106(5):773-85.

16. Espinosa L, Ingles-Esteve J, Aguilera C, Bigas A. Phosphorylation by glycogen synthase kinase-3 beta down-regulates Notch activity, a link for Notch and Wnt pathways. The Journal of biological chemistry. 2003 Aug 22;278(34):32227-35.

17. Tamura G, Sakata K, Nishizuka S, Maesawa C, Suzuki Y, Iwaya T, et al. Inactivation of the E-cadherin gene in primary gastric carcinomas and gastric carcinoma cell lines. Japanese journal of cancer research : Gann. 1996 Nov;87(11):1153-9. 


\section{Supplemental Information}

\section{Supplemental Figures and Legends}
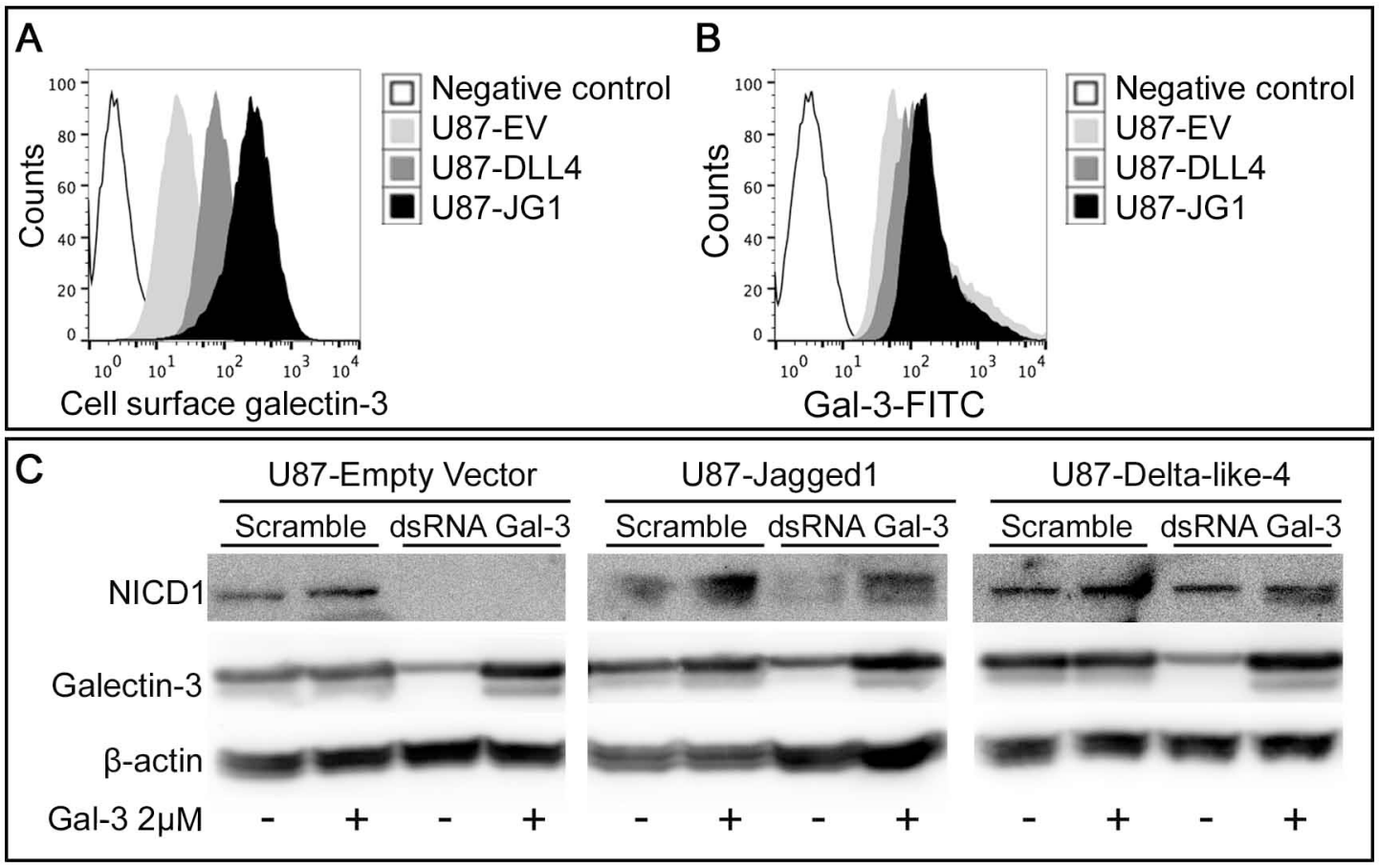

Figure S1. Galectin-3 regulates Notch signaling in U87 cells.

(A and B) Flow cytometry histogram of cell surface galectin-3 $(G)$ and galectin-3 binding sites, Gal-3-FITC (H) in U87-EV, U87-DLL4 and U87-JG1.

(C) Immunoblot of NICD1 and galectin-3 in U87-EV, U87-DLL4 or U87-JG1cultured for 6 hours in the presence or absence of Gal-3 $(2 \mu \mathrm{M})$.

Data are representative of three independent experiments. 


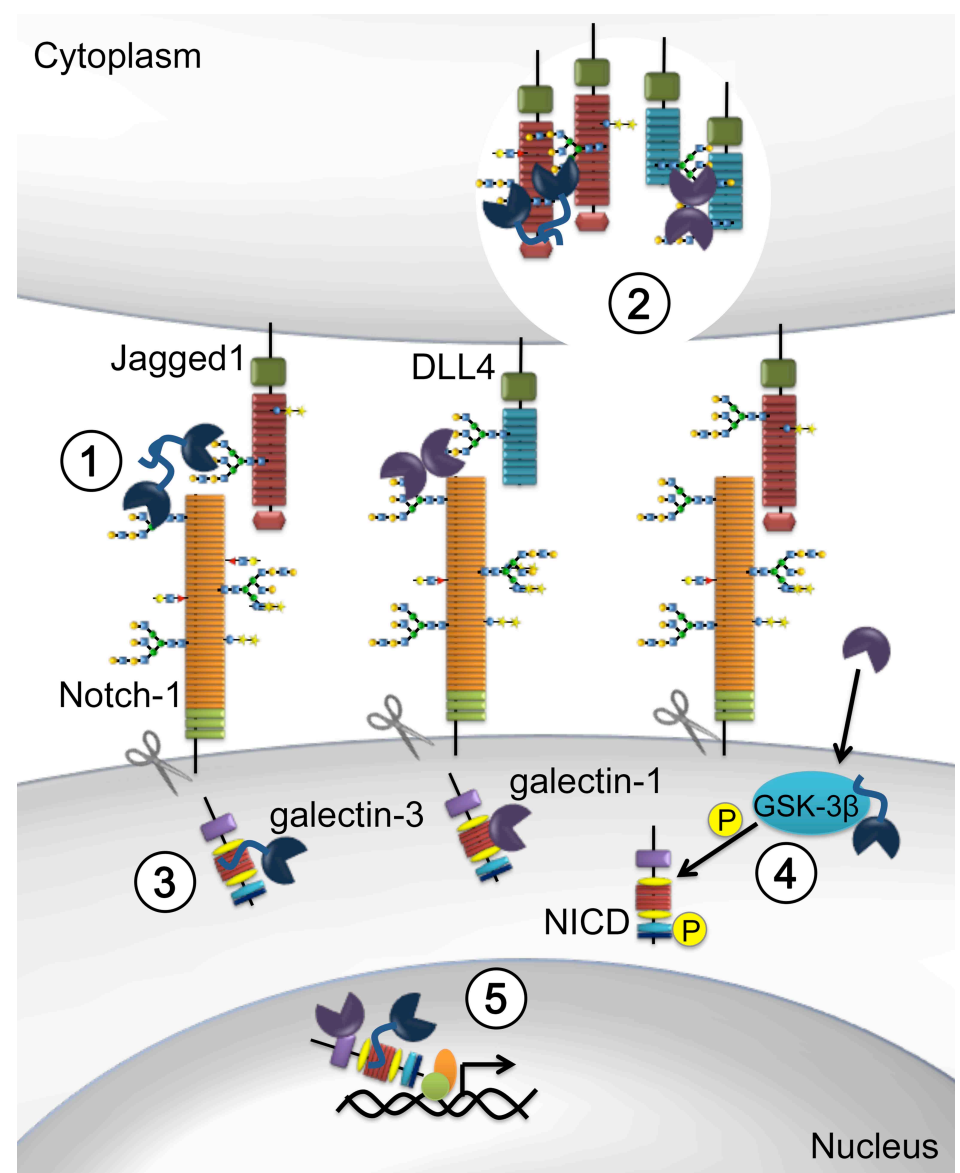

Figure S2. Hypothesis model on Notch signaling modulation by galectin-1 and galectin-3.

(1) Extracellular galectin-1 and galectin-3 may interact with glycans present on Notch-1 and DLL4/Jagged-1 ligands, thus promoting their crosslink and facilitating cleavage and Notch activation; (2) Galectin-1 and galectin-3 may induce DLL4/Jagged-1 endocytosis important for the production of active ligands; (3) Alternatively, intracellular galectin-1 and galectin-3 may also directly interact with Notch intracellular domain (NICD) by protein-protein interaction and facilitate its migration to the nucleus; (4) Indirectly, both galectins can increase NICD phosphorylation thus increasing NICD stability; (5) In the nucleus, galectin-1 and galectin-3 can modulate NICD binding to DNA. 


\section{Supplemental Table}

Table S1. Clinicopathological characteristics of the patients

\begin{tabular}{|c|c|}
\hline Number of patients & N (\%) \\
\hline \multicolumn{2}{|l|}{ Gender } \\
\hline Male & $37(63.8)$ \\
\hline Female & $21(36.2)$ \\
\hline \multicolumn{2}{|l|}{ Age (years) } \\
\hline$\leq 50$ & $11(18.9)$ \\
\hline$>50$ & $47(81.1)$ \\
\hline \multicolumn{2}{|l|}{ Lauren } \\
\hline Intestinal & $32(57.2)$ \\
\hline Diffuse & $26(44.8)$ \\
\hline \multicolumn{2}{|l|}{ TMN stage } \\
\hline I & $7(12.1)$ \\
\hline II & $7(12.1)$ \\
\hline III & $43(74.1)$ \\
\hline IV & $1(1.7)$ \\
\hline
\end{tabular}


Table S2. Allred score for galectin-1, galectin-3, Jagged1, DLL4 and Notch-1 status in human gastric samples $(0-8)^{*}$.

\begin{tabular}{|c|c|c|c|c|c|c|c|c|c|c|c|}
\hline \multirow{2}{*}{ Categories } & \multirow{2}{*}{$\begin{array}{l}\text { Allred } \\
\text { scoring }\end{array}$} & \multicolumn{2}{|c|}{ Galectin-1 } & \multicolumn{2}{|c|}{ Galectin-3 } & \multicolumn{2}{|c|}{ Jagged1 } & \multicolumn{2}{|c|}{ DLL4 } & \multicolumn{2}{|c|}{ Notch-1 } \\
\hline & & $\bar{N}$ & $\%$ & $\mathbf{N}$ & $\%$ & $\mathbf{N}$ & $\%$ & $\mathbf{N}$ & $\%$ & $\mathbf{N}$ & $\%$ \\
\hline \multirow{2}{*}{ Negative } & 0 & 7 & \multirow{2}{*}{30} & 0 & \multirow{2}{*}{1.7} & 0 & \multirow{2}{*}{0} & 0 & \multirow{2}{*}{14.6} & 8 & \multirow{2}{*}{25} \\
\hline & 2 & 5 & & 1 & & 0 & & 6 & & 0 & \\
\hline \multirow{6}{*}{ Positive } & 3 & 9 & \multirow{6}{*}{70} & 0 & \multirow{6}{*}{98.3} & 0 & \multirow{6}{*}{100} & 1 & \multirow{6}{*}{85.4} & 5 & \multirow{6}{*}{75} \\
\hline & 4 & 5 & & 4 & & 0 & & 3 & & 6 & \\
\hline & 5 & 2 & & 1 & & 0 & & 13 & & 4 & \\
\hline & 6 & 8 & & 3 & & 3 & & 10 & & 7 & \\
\hline & 7 & 2 & & 12 & & 19 & & 7 & & 2 & \\
\hline & 8 & 2 & & 37 & & 19 & & 1 & & 0 & \\
\hline Total & & 40 & 100 & 58 & 100 & 41 & 100 & 41 & 100 & 32 & 100 \\
\hline
\end{tabular}

${ }^{*}$ Allred score $=\%$ staining score + intensity score

Table S3. Spearman's p-test correlation between galectin-1, galectin-3, Jagged1, DLL4 and Notch-1.

\begin{tabular}{lcccc}
\hline & \multicolumn{2}{c}{ Galectin-1 } & \multicolumn{2}{c}{ Galectin-3 } \\
\hline & $r$ & $P$-value & $r$ & $P$-value \\
Jagged1 & 0.1947 & 0.2225 & 0.4459 & 0.0035 \\
DLL4 & 0.404 & 0.0088 & 0.3415 & 0.0289 \\
Notch-1 & -0.4359 & 0.0624 & -0.1378 & 0.4520 \\
\hline
\end{tabular}




\section{Supplemental Experimental Procedures}

\section{Cell culture}

U87 cells (ATCC, HTB-14) and AGS cells (ATCC CRL-1739) were cultured in DMEM (Gibco, Life technologies, MD, USA) and were supplemented with $10 \%$ of fetal bovine serum (Gibco, Life technologies, MD, USA) and $50 \mu \mathrm{g} / \mathrm{mL}$ of gentamicin (Gibco, Life technologies, MD, USA). Mycoplasma contamination in cultured cells was excluded using Lonza Mycoplasma Detection Kit.

\section{Recombinant human galectin-3 and galectin-1 preparation}

Galectin-3 and galectin-1 were produced in Escherichia coli BI21/DE3 containing the pET11a plasmid with the human galectin-3 coding DNA or the human galectin-1 coding DNA and purified by affinity chromatography on lactosyl-Sepharose (Sigma) as previously described [18, 19]. Lactose was removed by gel-filtration chromatography on desalting columns and contaminating LPS was eliminated by affinity chromatography on detoxi-gel beads (Pierce). The endotoxin levels were less than $0,1 \mathrm{EU}$ per $\mu \mathrm{g}$ of protein as determined by the LAL method (Lonza). Conjugation of galectin-1 and galectin-3 with FITC was performed accordingly to manufacturer's instructions (Thermo Fischer Scientific).

\section{Immunoprecipitation and Western Blotting}

Cells were lysed in RIPA buffer (Sigma). For immunoprecipiattion studies, $100 \mu \mathrm{g}$ of total protein was incubated O.N. with anti-galectin-1 or anti-galectin-3 antibodies and then incubated with Protein G-coupled beads (Sigma) for 2 hours. Beads were washed and bound proteins were applied in Novex NuPAGE SDSPAGE gel system (Invitrogen). Alternatively $50 \mu \mathrm{g}$ of protein extract was separated by NuPAGE SDS-PAGE gel and then transferred overnight to a PVDF membrane (Invitrogen). The membrane was incubated with anti-galectin-1 (Abcam, ab25138), 
anti-galectin-3 (M3/38, ATCC TIB166), anti-Notch-1 (Santa Cruz, sc-6014), NICD1 (Cell signaling, D3B8), anti-DLL4 (Santa Cruz, sc-18640) or anti-Jagged1 (Santa Cruz, sc-6011). Anti- $\beta$-actin-peroxidase (Sigma) was used as a loading control. Horseradish peroxidase (HRP)-conjugated secondary antibodies (Dako) were detected using the enhanced chemiluminescence (ECL) reagent (GE Healthcare) and images were acquired using ImageQuant (GE HealthCare).

\section{Flow cytometry}

For flow cytometry, $1 \times 10^{6}$ cells were harvested, blocked with $1 \%$ BSA/PBS and then incubated with anti-galectin-3 (M3/38, ATCC TIB166), anti-galectin-1 (Abcam, ab25138), anti-DLL4 (Santa Cruz, sc-18640), anti-Jagged1 (Santa Cruz, sc6011), anti-DLL1 (Santa Cruz, sc-8155) or anti-Notch-1 (Santa Cruz, sc-6014) for 1 hour. Primary antibodies were detected with Alexa488 conjugated secondary antibodies (Invitrogen). For intracellular staining of galectin-3 cells were treated as described above and permeabilized with saponin 0.5\%/PBS in the presence of antigalectin-3 antibody. Alternatively, cells were incubated with $2 \mu \mathrm{M}$ of gal-1-FITC or gal3-FITC in the presence or absence of lactose $(50 \mathrm{mM})$. Analyses were made using the flow cytometer CyAn ${ }^{\mathrm{TM}}$ ADP Analyzer from Beckman Coulter. Data were subsequently evaluated with FlowJo vX 0.7 software.

\section{Galectin-1 and galectin-3 dsRNA transfection}

AGS cells were transfected at $60 \%$ of confluency with galectin- 1 or galectin-3 specific siRNAs and negative control (scramble) IDT (TriFECTa Kit) at a final concentration of 20nM using RNAiMAX reagent (Invitrogen) in Opti-MEM I reduced serum medium (Invitrogen). After $6 \mathrm{~h}$, transfection medium was replaced by complete RPMI medium. 48h post-transfection, cells were cultured for additional 6 hours in a plate previously coated with $1 \mu \mathrm{g} / \mathrm{ml}$ rhJagged1 (R\&D system) or $1 \mu \mathrm{g} / \mathrm{ml} \mathrm{rhDLL4}$ (R\&D system) or $1 \mu \mathrm{g} / \mathrm{ml}$ BSA (Sigma). 


\section{Generation of DLL4 and Jagged1 overexpressing U87 cells}

Stable U87 control (EV) or overexpressing the full length Delta-like-4 (DLL4) or Jagged1 (JG1), were generated after co-transfection of $30 \mu \mathrm{g}$ of empty vectorcontaining pLenti6.2-V5 plasmid or full length DLL4 cDNA or Jagged1 cDNAcontaining pLenti6.2-V5 plasmid with $15 \mu \mathrm{g}$ pPAX2 and $5 \mu \mathrm{g}$ of pMDG.2 (Addgene) into HEK293t packaging cell line utilizing $\mathrm{CaCl}_{2}$ method. The viral supernatant was recovered and the transduced cells were generated by infection with $6 \mathrm{MOI}$ (multiplicity of infectious units) of lentiviral particles. On the next day, cells were replaced with fresh medium, and a day later, cells were selected with $5 \mu \mathrm{g} / \mathrm{mL}$ of Blasticidin for 1 week. DLL4 and Jagged1 expression were confirmed by Western blot.

\section{Immunostaining}

Sections from cancer specimens were obtained from patients with muci- nous adenocarcinomas undergoing surgery at Hospital S. João, Medical Faculty (Porto, Portugal) between 1991 and 2009. Tissue fragments were fixed in $10 \%$ formaldehyde and embedded in paraffin. Serial sections of $3 \mu \mathrm{m}$ were cut and used for immunostaining with anti-galectin-1 (Abcam, ab25138), anti-galectin-3 (M3/38, ATCC TIB166), anti-Notch-1 (Santa Cruz, sc-6014), anti-DLL4 (Santa Cruz, sc18640) or anti-Jagged1 (Santa Cruz, sc-6011) followed by a secondary biotinylated antibodies (DAKO). Next, streptavidin-peroxidase (DAKO) was added and color development was done with DAB (DAKO). Nuclei were counterstained with hematoxylin and mounted in Vectashield (Vector Laboratories, Inc). Representative areas of gastric adenocarcinomas were digitalized by digital camera (axioskop Plus, Zeiss, germany) and the immunohistochemical expression of the proteins was semiquantitatively measured by estimating the proportion and intensity of positively stained tumor cells [20]. The proportion score (PS) was given using a 0-to-4 scale: 0 for $0-5 \%$ positive tumor cells, 1 for $6-25 \%$ positive tumor cells, 2 for $26-50 \%$ positive 
tumor cells, 3 for $51-75 \%$ positive tumor cells and 4 for $>75 \%$ positive tumor cells.

The intensity score (IS) was based on a 4-point system: 0, 1, 2 and 3 (for no, light, medium or dark staining, respectively). The proportion and intensity scores were added to obtain the total score (Allred scoring system). The Spearman correlation was used to analyze the significance of the correlation between galectin-1 or galectin-3 proteins expression and Jagged1, DLL4 or Notch-1 expressions.

\section{Statistical Analysis}

All data are expressed as the mean \pm SEM of at least three independent experiments. Statistical analysis including spearman correlation, t-test, one-way ANOVA and two-way ANOVA were done using GraphPad Prism 6.0 software. $p<0.05$ was considered statistically significant.

\section{Supplemental references}

1. Hsu DK, Zuberi RI, Liu FT. Biochemical and biophysical characterization of human recombinant IgE-binding protein, an S-type animal lectin. The Journal of biological chemistry. 1992 Jul 15;267(20):14167-74.

2. Pace KE, Hahn HP, Baum LG. Preparation of recombinant human galectin-1 and use in T-cell death assays. Methods in enzymology. 2003;363:499-518.

3. Allred DC, Harvey JM, Berardo M, Clark GM. Prognostic and predictive factors in breast cancer by immunohistochemical analysis. Modern pathology : an official journal of the United States and Canadian Academy of Pathology, Inc. 1998 Feb;11(2):155-68. 
Chapter 2 


\section{Chapter}

Galectin-3 acts as an angiogenic switch to induce tumor angiogenesis by increasing Jagged1/Notch activation 



\section{Abstract}

Angiogenesis is a coordinated process tightly regulated by the balance between DLL4 and Jagged1 in endothelial cells. Here we show that galectin-3, a glycan binding protein, binds to and increases Jagged1 protein half-life promoting Jagged1/Notch signaling over DLL4/Notch in endothelial cells. Although important for angiogenesis, VEGF signaling is not required for galectin-3-promoted Notch activation. Hypoxic conditions changed galectin-3 expression and the glycosylation status of endothelial cells, acting in concert to promote Jagged1/Notch-1 activation and sprouting angiogenesis. Jagged1 overexpression in Lewis lung carcinoma accelerated tumor growth in vivo that was prevented in Lgals $3^{-/-}$mice. Our findings establish galectin-3 as a molecular regulator of the Jagged1/Notch-1 signaling pathway that has direct implications for the development of strategies aimed at controlling tumor angiogenesis. 


\section{Introduction}

In tumors, the angiogenic switch occurs when a tumor expands, causing some cells to become hypoxic. An insufficient supply of nutrients and oxygen trigger tumor cells to release hypoxia-dependent, and tissue-derived proangiogenic signals, such as vascular endothelial growth factor (VEGF) [1], which stimulate quiescent endothelial cells (ECs) to become migratory and invasive. The current widely accepted angiogenic model describes that VEGF/VEGFR2 up regulates the Notch ligand DLL4 in responsive endothelial tip cells [2,3]. This tip cell is rapidly selected and can signal Notch1 receptor in an adjacent endothelial cell to acquire a stalk cell characteristics inducing HES and HEY transcription factor families [4]. HES and HEY proteins in stalk cells, are able to repress VEGFR2 expression, preventing the excess of sprout formation [5]. Still, this crosstalk between Notch and VEGFR2 is complex. VEGFR2 has been reported not to be essential for DLL4 expression in tip cells $[6,7]$ and, Notch inhibition also had no significant impact on VEGFR2 expression inducing deregulated endothelial sprouting and proliferation even in the absence of VEGFR2 [8]. Adding further complexity, a growing body of evidence has demonstrated that remodeling of cell-surface glycans through the action of glycosyltransferases, regulates the angiogenic process and determines the selective activation of Notch signaling by DLL4 or Jagged1 in endothelial tip cells [9]. Here, we investigated how a secreted glycan-binding protein affects the balance of Jagged1 and DLL4 expression in ECs and, consequently tumor angiogenesis.

Recently, much attention has been given to galectins and their role in tumor angiogenesis [10-12]. Galectin-3 (Gal-3), a glycan-binding protein, is one of the most studied galectins and unique for having an N-terminal nonlectin domain of about 100 aminoacids, in addition to the usual C-terminal carbohydrate recognition domain (CRD). Once Gal-3 binds to cell surface glycans by its CRD, Gal-3 molecules can form oligomers (in a concentration dependent manner) through the $\mathrm{N}$-terminal 
domain and promote crosslinks of its ligands, thus modulating several cellular signaling pathways [13]. Galectin-3 has been reported as a proangiogenic molecule that is induced during hypoxia $[14,15]$ and increases the chemotaxis and differentiation of human umbilical vein endothelial cells (HUVECs) by enhancing VEGFR2 signaling activation [16-18]. Accordingly, disruption of galectin-3 in the tumor stroma reduces macrophage induced-angiogenesis dependent on VEGF and TGF- $\beta$ signaling [19].

Taking into account both the role of galectin-3 in inducing VEGFR2 activation and the interplay between VEGFR2 and DLL4/Notch in regulating angiogenesis, we investigated the role of galectin-3 in integrating the VEGF-A-VEGFR2-DLL4-Notch signaling axis. We identified galectin-3 as a novel interaction partner of DLL4 and Jagged1 ligands, capable of inducing angiogenesis through enhancing Jagged1/Notch-1 activation in endothelial cells. This novel mechanism of regulation should allow the development of new approaches to inhibit angiogenesis. 


\section{Results}

\section{Galectin-3 binds to Jagged1 and DLL4 ligands and promotes} Notch-1 activation in a dose-dependent manner in endothelial cells

Since both Notch receptors and Notch ligands are cell surface glycoproteins that display terminal $\beta$-galactose [20], we first investigated the interaction between galectin-3, the Notch-1 receptor and Jagged1 and DLL4 ligands. For this assay, the recombinant human Notch-1, Jagged1 and DLL4 proteins were immobilized in a 96 well plate and subsequently incubated with the human recombinant galectin-3 (Gal3 ) or its truncated form, galectin-3C (Gal-3C, retains its carbohydrate binding ability but lacks the N-terminal domain). The bound Gal-3 and Gal-3C were detected by ELISA. Gal-3 was able to bind Notch-1 (Figure 1A), Jagged1 (Figure 1B) and DLL4 (Figure 1C). In the presence of $\beta$-lactose (a competitive inhibitor of the galectin-3 CRD), galectin-3 binding to Notch ligands was only partially inhibited, suggesting a role for Gal-3 N-terminal protein binding domain in such interaction. Gal-3C interaction with Notch components was completely blocked by $\beta$-lactose. Sucrose, a non-competitive saccharide, was used as a control and had no effect on Gal-3 and Gal-3C binding.

We next investigated whether galectin-3 modulated Notch-1 signaling activation in HUVECs. Initially, we demonstrated that both DyLight488-labeled galectin-3 (Figure 1D) and galectin-3C (Figure 1E) were able to bind to HUVECs in a dose dependent manner and the binding did not reach saturation at the highest dose used. Subsequently, HUVECs in suspension were incubated with recombinant human galectin-3 $(37 \mathrm{nM}, 370 \mathrm{nM}, 0,925 \mu \mathrm{M}$ and $1,85 \mu \mathrm{M})$ for $15 \mathrm{~min}$ and then plated on BSA-, Jagged1- or DLL4-coated plates for an additional 6 hours. We found that low doses of galectin-3 in the bovine serum albumin control (BSA), up-regulated the expression of DLL4 and increased Notch-1 cleavage (NICD1), with $10 \mu \mathrm{g}$ being the concentration that led to the highest level of Notch-1 activation (Figure 1F). 

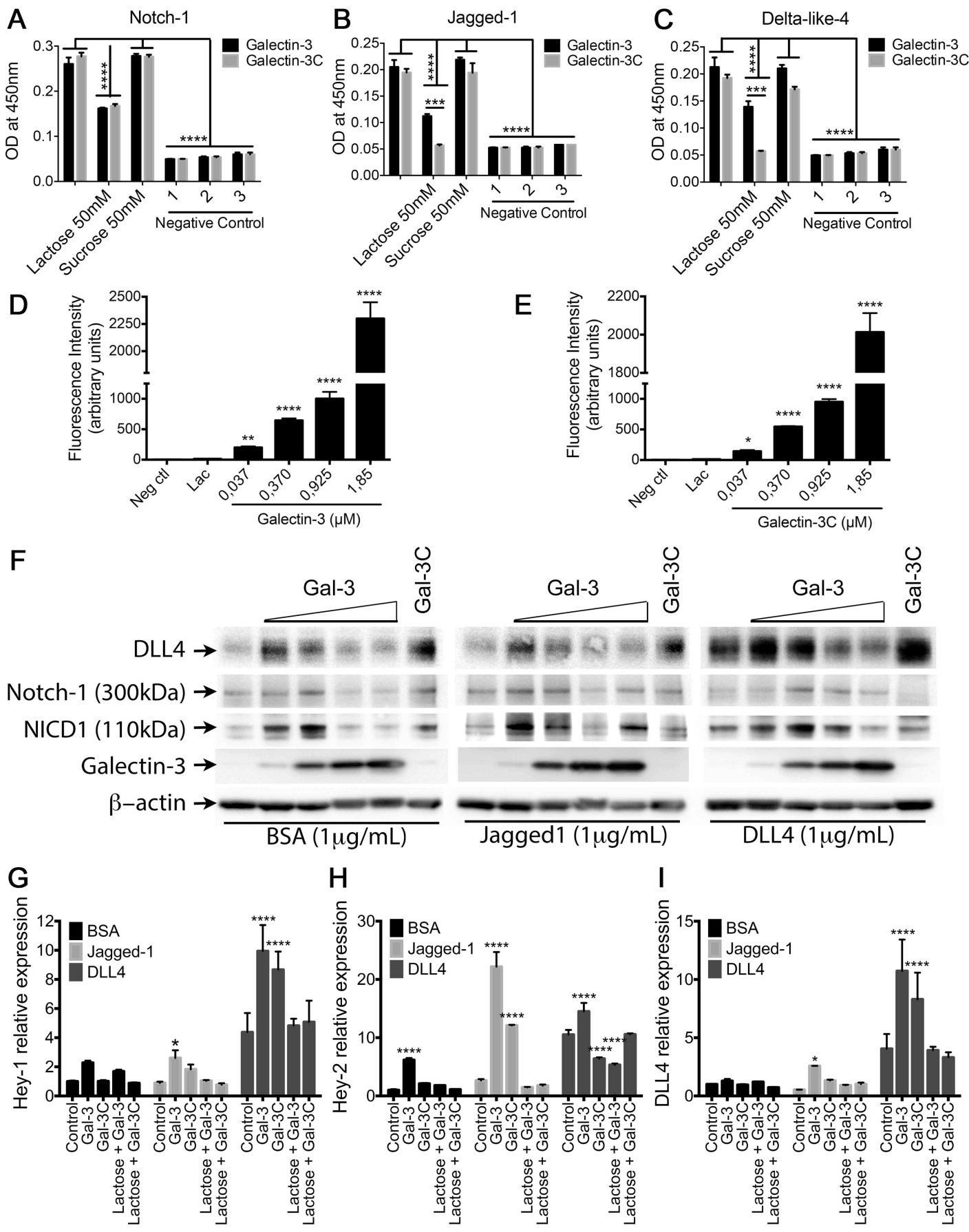

Figure 1. Galectin-3 binds to Notch-1 receptor and Jagged1 and DLL4 ligands, and activates Notch signaling.

(A-C) ELISA detection of galectin-3 or galectin-3C in a 96 well plate previously coated with human Notch-1, Jagged1 or DLL4 proteins in the presence or absence of lactose or sucrose.

( $D$ and E) Binding of DyLigth488 labeled-Gal-3 (D) or Gal-3C (E) to HUVECs in the presence or absence of lactose followed by flow cytometry analyses.

(F) Immunoblot of galectin-3, NICD1, Notch-1 and DLL4 following treatment of HUVECs with 1, 10, 25 and $50 \mu \mathrm{g}$ of Gal-3 or $50 \mu \mathrm{g} \mu \mathrm{g}$ of Gal-3C prior to seeding on BSA-, Jagged1- or DII4-coated plates for additional 6 hours. $\beta$-actin was used as a loading control.

(G-I) HUVECs were incubated with $1 \mu \mathrm{g}$ of Gal-3 or $50 \mu \mathrm{g}$ of Gal-3C in the presence or absence of lactose $(50 \mathrm{mM})$ prior to seeding on BSA, DII4 or Jagged 1 coated plate for $6 \mathrm{~h}$. RT-PCR was carried out for the Notch target genes $(G)$ Hes1, $(H)$ Hey2 and (I) DLL4 and normalized to GAPDH.

Data are the mean \pm SEM $(A-E, G-I)$ or are representative $(F)$ of three experiments. ${ }^{*} p<0.05,{ }^{* *} p<$ $0.01,{ }^{* * *} p<0.001,{ }^{* * * *} p<0.0001$. 
In the presence of immobilized Jagged1, the lowest dose of galectin-3 (37nM) was more effective at increasing NICD1 levels than higher doses. In the presence of immobilized DLL4, galectin-3 was more efficient at increasing Notch signaling at a dose of $370 \mathrm{nM}$.

Treatment with higher doses of galectin-3 $(0.925 \mu \mathrm{M}$ and $1.85 \mu \mathrm{M})$ resulted in significant inhibition of Notch-1 signaling. In face of these results, all the subsequent experiments were performed using the dose of $37 \mathrm{nM}$ of galectin-3. The influence of Gal-3C on Notch activation was also assessed and we observed that even at the highest dose $(1.85 \mu \mathrm{M})$, Gal-3C was able to increase NICD1 and DLL4 protein levels. We also measured the expression of downstream Notch targets. As expected, DLL4 is a more potent activator of the Notch signaling pathway than Jagged1, as observed from the basal expression levels. Yet, HUVECs treated with galectin-3 (37 nM) and cultured on Jagged1-coated plates displayed a significantly increased transcription of the Notch target genes HEY-1 (by $\sim 3$ fold) (Figure $1 \mathrm{G}$ ), HEY-2 ( 8 fold) (Figure 1H) and DLL4 ( 5 fold) in comparison to galectin-3 untreated cells on Jagged1 plates (Figure 1I). On DLL4-coated plates, galectin-3 led to a significant up-regulation of HEY-1 ( 2 fold), HEY-2 ( 1,4 fold) and DLL4 ( 2,7 fold) although to a lower extent in comparison with Jagged1-coated plates. The effect of galectin-3 in Notch signaling was lactose inhibitable and thus, dependent on its carbohydrate-binding domain. Overall our results demonstrate that galectin- 3 binds to Jagged1 and Delta-like- 4 ligands by both carbohydrate-dependent and independent mechanisms and galectin3 preferentially increases the Notch signaling activation in endothelial cells by Jagged1 more than DLL4. 


\section{Galectin-3 induced-Notch signaling activation is independent of VEGF/VEGFR2 signaling}

It is well known that VEGFR2 signaling induces the expression of the Notch

A

B

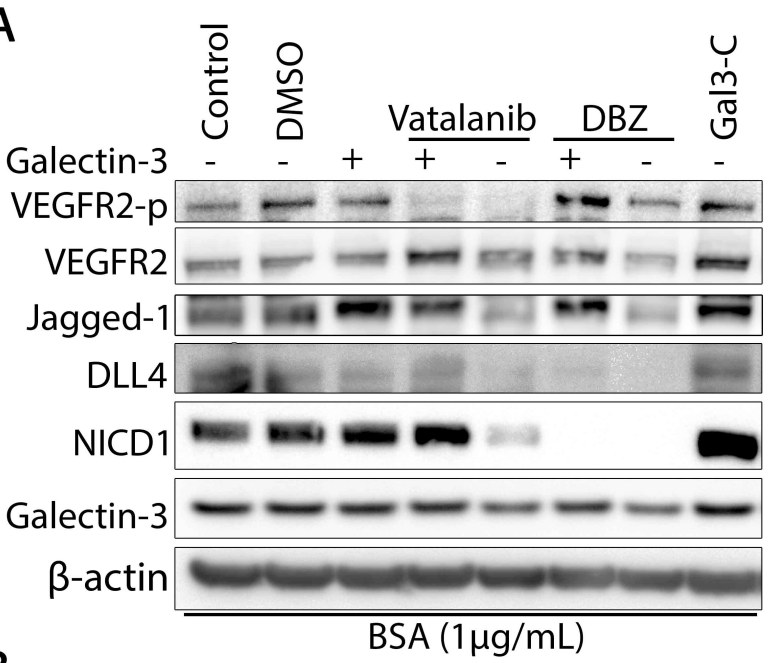

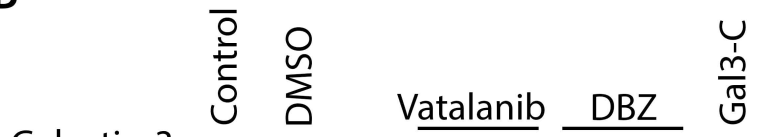

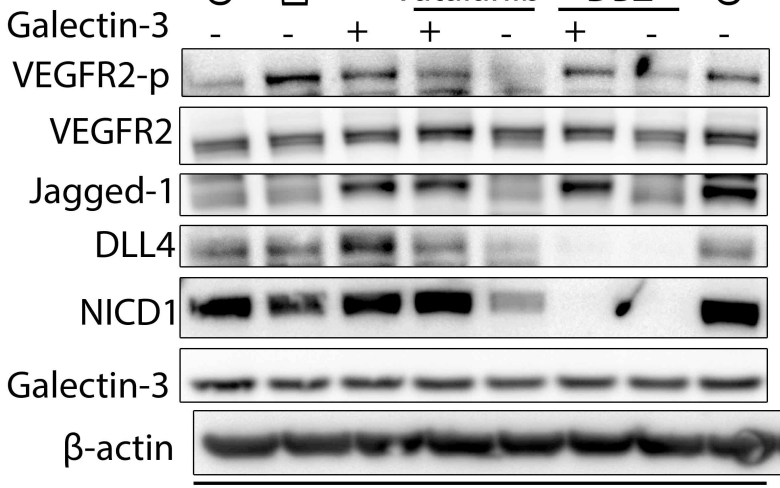

hrJagged1 $(1 \mu \mathrm{g} / \mathrm{mL})$

C
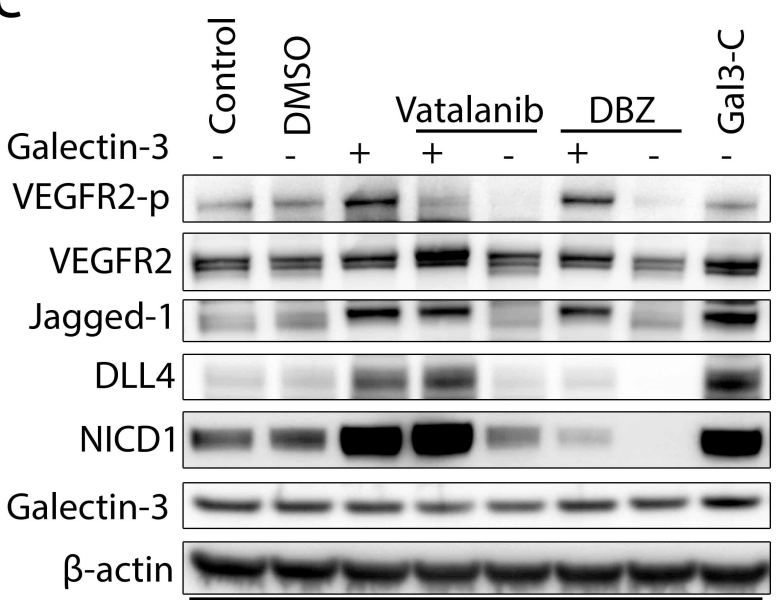

$\operatorname{hrDLL4}(1 \mu \mathrm{g} / \mathrm{mL})$ ligand DLL4 in endothelial cells

and consequently increases

Notch signaling [2, 3]. Since galectin-3 binds to VEGFR2 receptor and modulates VEGFand

bFGF-mediated

angiogenesis [17, 18], we

evaluated whether galectin-3

induces Notch signaling

activation directly, or indirectly via

VEGFR2. HUVECs were then

cultured in the presence of 100

$\mathrm{nM}$ of Vatalanib, (an inhibitor of

VEGF receptor kinase) and

plated on BSA-, Jagged1- or

DLL4-coated plates in the presence or absence of Gal-3.

Galectin-3 treatment alone was

Figure 2. Galectin-3-induced Notch activation is independent of VEGF/VEGFR2 signaling.

(A-C) Immunoblot of galectin-3, NICD1, DLL4, Jagged1, VEGFR2 and VEGFR2-p in HUVECs treated for $15 \mathrm{~min}$ with galectin-3 $(37 \mathrm{nM})$ in the presence or absence of Vatalanib (100nM) or DBZ $(10 \mathrm{nM})$ and seeded for $6 \mathrm{~h}$ in a (A) BSA, (B) Jagged1 or (C) DLL4 coated plate. $\beta$ actin was used as a loading control. Representative of three experiments. See also Figure S1. 
able to induce VEGFR2 phosphorylation, as described previously [17], and increased the level of cleaved-Notch-1 intracellular domain (NICD1) in all the three assay conditions (Figure 2A-2C). As expected, in the presence of Vatalanib alone, we observed a reduction of VEGFR2 phosphorylation and Notch activation. Remarkably, in the presence of exogenously added Gal-3, Vatalanib was not able to inhibit Notch1 activation, suggesting that Notch-1 activation by galectin-3 is independent of VEGFR2 signaling. Surprisingly, disruption of Notch signaling pathway using DBZ prevented galectin-3-induced Notch-1 cleavage and its target DLL4 expression, but not Jagged1 up-regulation of signaling in all the three assay conditions (Figure 2A2C).

Besides VEGFR2 signaling, DLL4-Notch signaling also stimulates HUVECs to produce more DLL4 [21]. In the presence of Vatalanib, Gal-3 enhanced DLL4 expression level in HUVECS cultured on DLL4-coated plates i.e. independently from VEGF (Figure 2B). Finally, with Vatalanib and DBZ, the addition of Gal-3 increased Jagged 1 protein levels in all the assay conditions (Figure $2 \mathrm{~A}-2 \mathrm{C}$ ). Surprinsingly, Jagged1 upregulation induced by Gal-3 was not associated with an increase in Jagged1 mRNA levels (Figure S1). All together, our results suggest that galectin-3induced Notch signaling activation does not depend on VEGFR2 signaling and modulates the level of Jagged1 protein expression.

\section{Galectin-3 proangiogenic functions are mediated through Jagged1}

It is well known that galectin-3 affects the cellular distribution and turnover rate of cell surface glycoproteins $[17,22]$. Therefore, HUVECs were treated with cyclohexamide in order to inhibit protein synthesis and the expression levels of Jagged1 and DLL4 were monitored over time by western blot analysis. Cycloheximide treatment revealed that galectin-3 increased the half-life of Jagged1 
protein from $\sim 240$ min to $\sim 400$ min (Figure $3 \mathrm{~A}$ and $3 \mathrm{~B}$ ). On the other hand, galectin-3 decreased DLL4 protein half-life from $\sim 150 \mathrm{~min}$ to $\sim 60 \mathrm{~min}$ (Figure $3 \mathrm{~A}$ and $3 \mathrm{C}$ ).

A

A $\frac{\text { Control }}{\text { Oh } 1 \mathrm{~h} 2 \mathrm{~h} 4 \mathrm{~h} 6 \mathrm{~h} 8 \mathrm{~h}} \frac{\text { Galectin-3 }}{\text { oh } 2 \mathrm{~h} 4 \mathrm{~h} 6 \mathrm{~h} 8 \mathrm{~h}}$

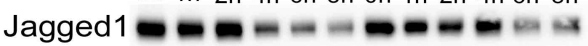

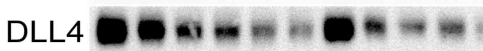

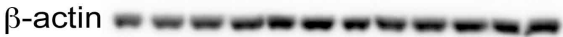

B

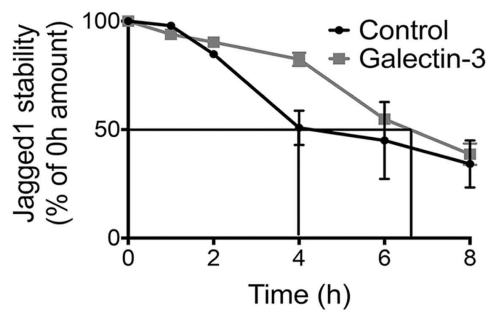

C

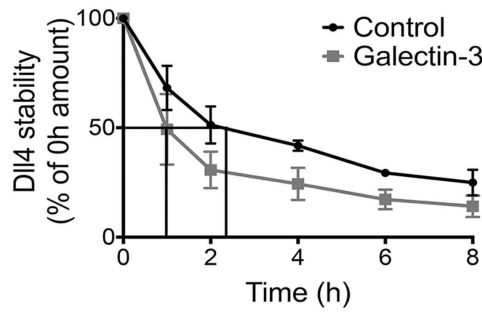

D

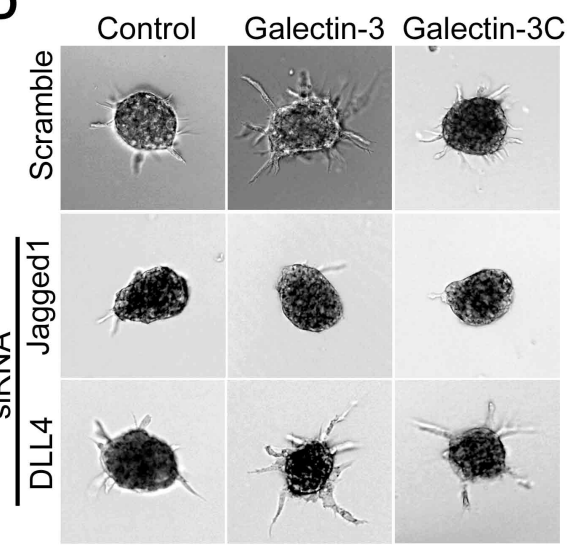

E

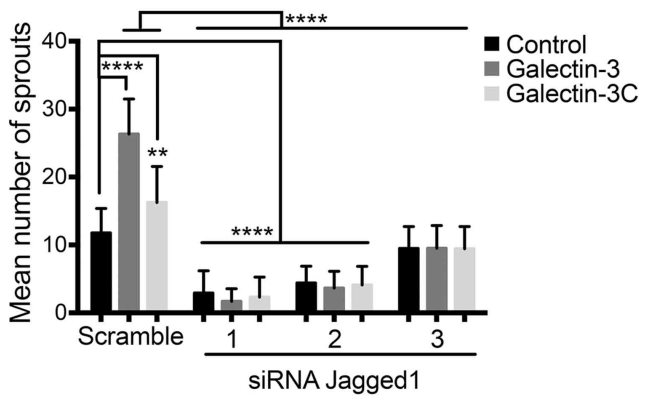

$\mathbf{F}$

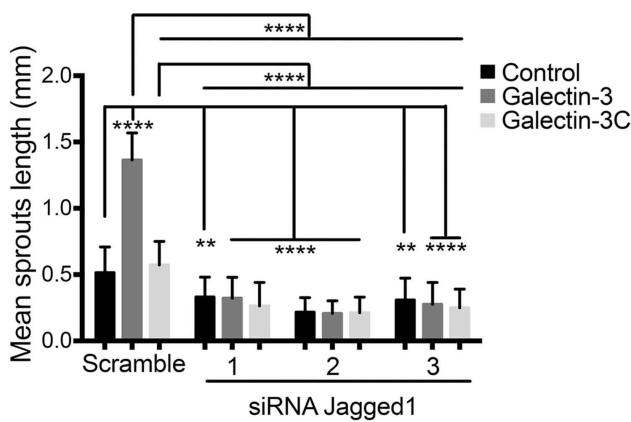

$\mathbf{G}$

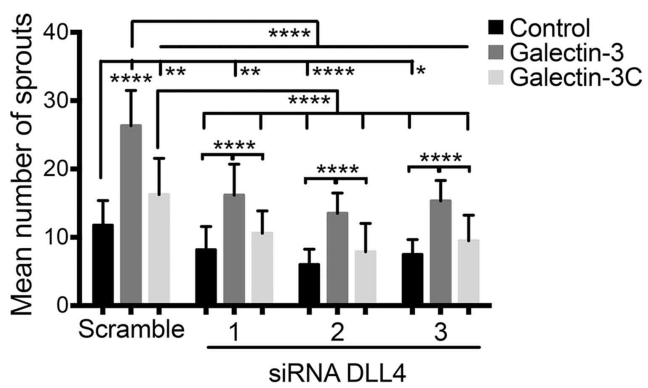

$\mathrm{H}$

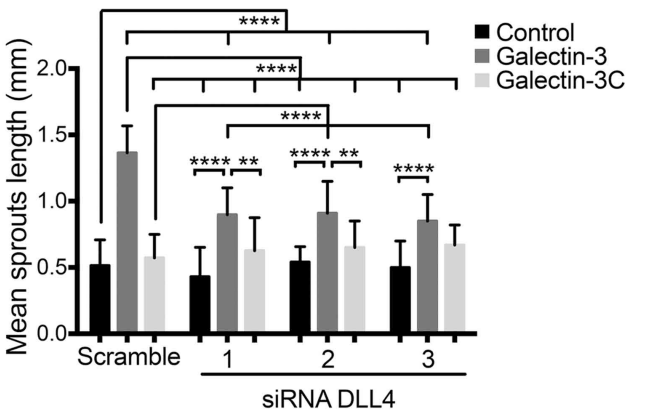

Figure 3. Galectin-3 proangiogenic functions are mediated by Jagged1-Notch signaling.

(A) Immunoblot of Jagged1 and DLLL4 in HUVECs treated with $37 \mathrm{nM}$ of Gal-3 and cultured in the presence of $0.1 \mathrm{mM}$ cycloheximide (time point $0-8 \mathrm{~h}$ ).

(B and C) Quantification of western blot bands showed a prolonged half-life of (B) Jagged1 protein (240min to $400 \mathrm{~min}$ ) and an increased degradation rate of (C) DLL4 (150min to 60min) (mean \pm SEM, $n=3 ;{ }^{* *} p<0.01$ ). See also Figure $\mathrm{S} 2$.

(D-F) HUVECs previously transfected with Jagged1 or DLL4 siRNA were grown into spheroids and treated \pm Gal-3 or Gal-3C for 24hrs (D) representative images are shown. (E and G) Mean number of sprouts and $(F$ and $H)$ sprouts length of HUVECs spheroids were measured (mean $\pm S E M, n=3$; $\left.{ }^{* \star} p<0.01,{ }^{* * *} p<0.0001\right)$. See also Figure S2.

Additionally, HUVECs were treated with 37 nM of DyLigth488 labeled-hrGal-3

for 1 hour and Jagged1 or DLL4 protein were analyzed by immunofluorescence. We 
observed that DyLight 488-labeled-galectin-3 co-localized with Jagged1 in the cytoplasm, while DLL4 staining revealed virtually no co-localization with galectin-3 (Figure S2A).

These results indicate that galectin-3 prolong Jagged1 half-life in HUVECs, which may favor Notch activation induced by this Notch ligand. Therefore, we next investigated whether the proangiogenic functions of galectin-3 are Jagged1- or DLL4-dependent. We used siRNA-mediated silencing of Jagged1 or DLL4 in HUVECs with three different siRNAs for each ligand and monitored the endothelial sprouting capacity, using a fibrin gel-embedded spheroid-based in vitro angiogenesis assay. We firstly observed that all three individual siRNAs targeting Jagged1 or DLL4 led to significant downregulation of Jagged1 and DLL4 proteins levels respectively (Figure S2B). As predicted from notch activation, when endothelial sprouting was analyzed, galectin-3 induced a significant increase both in sprout number (Figure 3D and 3E) and length (Figure 3D and 3F). However, the galectin-3-induced effect was completely abrogated in Jagged1-silenced HUVECs in comparison with the scramble control (Figure 3D-3F). Galectin-3 treatment was still able to increase the number and the extension of sprout in DLL4-silenced HUVECs, although at a reduced level (Figure 3D, 3G and 3H, respectively). In contrast to Gal3 , Gal-3C did not increase the sprout length and the number of sprouts in all assay conditions (Figure 3D-3H), which demonstrates the importance of oligomerization for galectin-3 proangiogenic functions.

Since Jagged1/Notch signaling acts in a proangiogenic manner, we examined whether galectin-3-induced angiogenesis could be a consequence of increased Jagged1/Notch signaling. To test the transmission of Notch signaling by Jagged 1 expressing cells as opposed to tethered proteins, we co-cultured (1:1) Jagged1overexpressing HUVECs with murine endothelial cells (sEnd) in the presence or absence of Gal-3. Extracellularly added galectin-3 increased the murine Hes-1, Hey1, Hey-2 and Hey-L mRNA levels in response to Jagged1 overexpressing HUVECS 
(Figure S2C-S2F). All together, our findings demonstrate that galectin-3 requires Jagged1-induced Notch activation to mediate its proangiogenic function.

\section{Galectin-3 promotes the endothelial tip-cell phenotype}

Some of the Jagged1/Notch signaling features positively control ECs proliferation, sprouting [9] and induce an EC tip cell phenotype [16]. Likewise, galectin-3 plays an important role in HUVECs proliferation (Figure 4A) and in sprouting angiogenesis (Figure 4B). These effects were lactose inhibitable and thus dependent on galectin-3 carbohydrate binding domain.

A

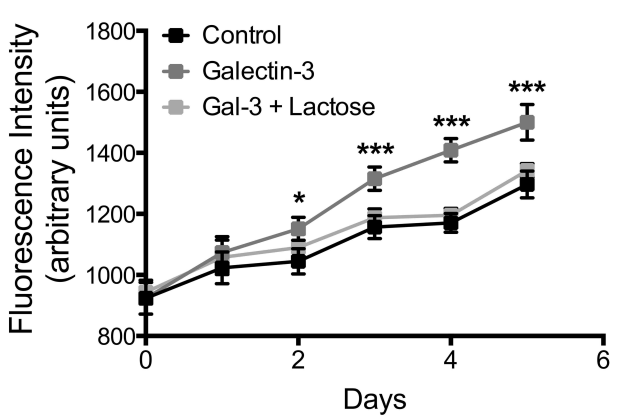

C
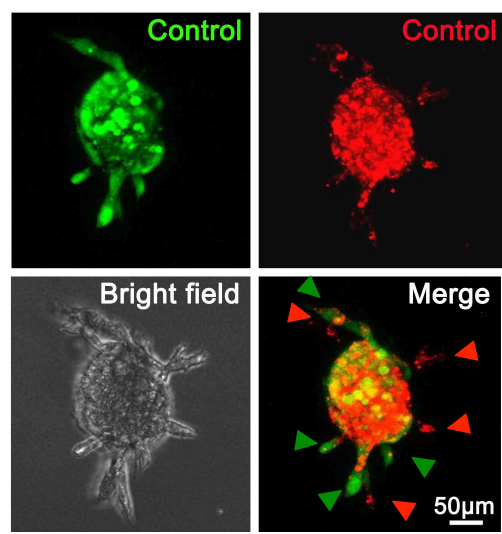

B

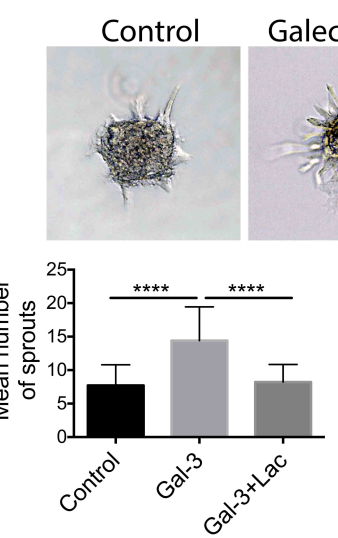

Galectin-3

Gal-3 + Lactose
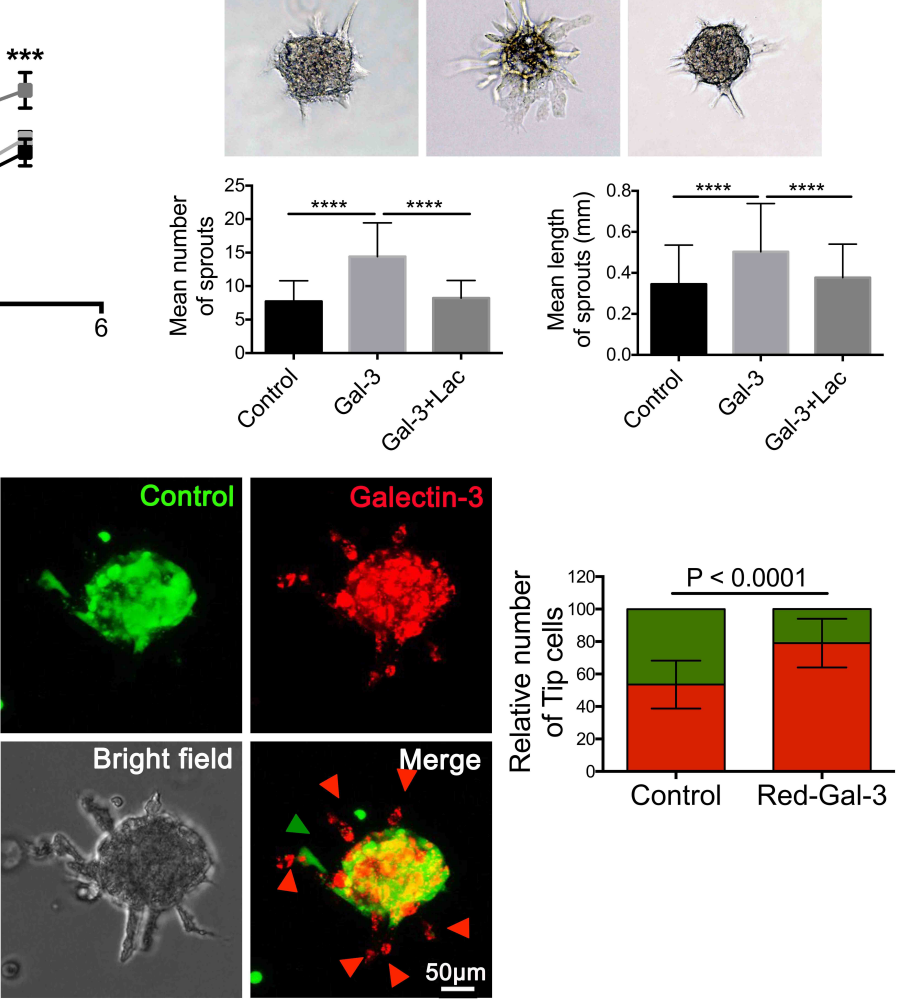

Figure 4. Galectin-3 promotes the tip cell phenotype.

(A) Fluorescent intensity of HUVECs treated for 5 days with $37 \mathrm{nM}$ of Gal-3 \pm lactose, measured by CyQuant assay (mean \pm SEM, $n=3$; ${ }^{*} p<0.05$ ).

(B) Top panel, representative figures of HUVECs spheroids in the presence of Gal- $3 \pm$ lactose. (bottom left) The average number and (bottom right) sprouts length were quantified (mean $\pm S E M, n=3$; $* * * * 0<0.0001$ ).

(C) HUVECs spheroids composed of a 1:1 ratio between prelabeled control (green) and galectin-3treated cells (red). Arrowheads indicate the tip cells position (mean \pm SEM, $n=3$ ).

Next we studied the role of galectin-3 in tip cell selection. HUVECs were labeled with a green or a red fluorescent probe. Red and green-labeled HUVECs 
were mixed in a 1:1 ratio for spheroid formation and subsequently embedded in fibrinogen gel. As expected, we found that approximately $50 \%$ of endothelial cell at the growing tip position was red or green in the control group. However, when redlabeled HUVECs were treated with Gal-3 prior to embedding, the probability of detecting a red-labeled cell at the tip growing position increased significantly, from $50 \pm 13.75 \%$ to $79 \pm 14.76 \%(P<0,0001)$ (Figure $4 C)$. Therefore, the proangiogenic functions of galectin-3 fit well with the described role of Jagged1/Notch signaling as a positive regulator of tip cell formation and endothelial cell proliferation.

\section{Tumor-released galectin-3 induces Notch signaling activation and sprouting angiogenesis}

It has been well described that hypoxia is the primary physiological trigger of the angiogenic switch in tumors [23] and elicit the production of several proangiogenic factors [24], including galectin-3 [14]. We initially evaluated the protein (Figure S3A), mRNA (Figure S3B) expression levels, and the secretion (Figure 5A) of galectin-3 by MCF7, MDA-MB-231 and HUVECs in response to hypoxia. We found that hypoxia increased galectin-3 protein and mRNA levels as well as its secretion in the MCF7 and MDA-MB-231 breast cancer cells but did not significantly change its expression or secretion by endothelial cells. Using a panel of lectins that recognize specific glycans that are important for galectin-3 binding (Figure S3C), we found that under normoxic conditions MCF7, MDA-MB-231 and HUVECs showed a substantial reactivity to Erythrina cristagalli lectin (ECA) and Phaseolus vulgaris lectin (L-PHA), thus showing galectin-3-binding sites at the cell surface (Figure 5B and 5C). However, under hypoxic conditions, we observed a reduction in galectin-3-binding sites (decreased ECA and L-PHA reactivity) in MCF7 and MDA-MB-231 cells, whereas an increase in HUVECs (Figure 5B and 5C). Accordingly, we observed higher binding of DyLight-labeled-Gal-3 to HUVECs cultured under hypoxic 
conditions than to the breast cancer cells MCF7 and MDA-MB-231 under the same conditions (Figure 5D).

\section{A}

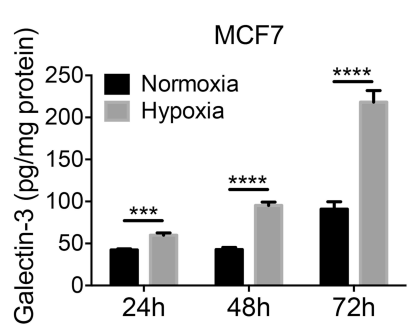

B

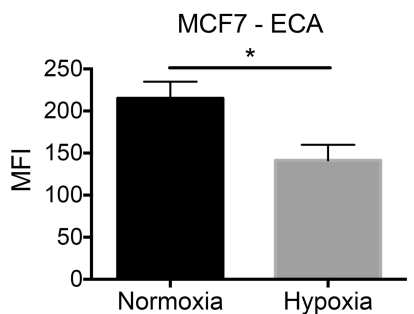

C

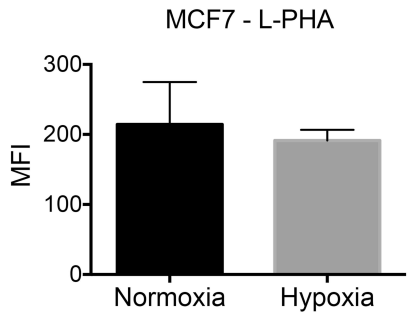

D

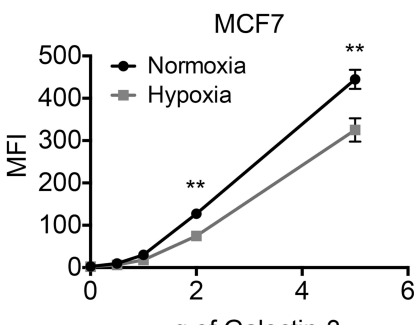

$\mu \mathrm{g}$ of Galectin-3

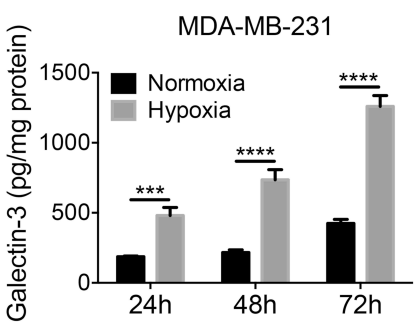

MDA-MB-231 - ECA

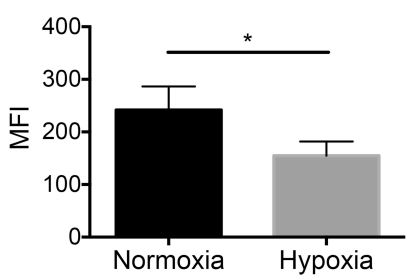

MDA-MB-231 - L-PHA

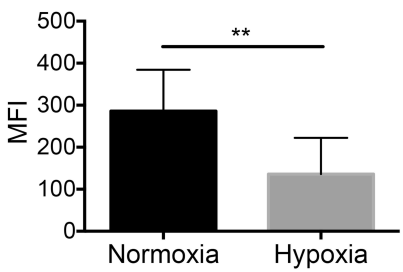

MDA-MB-231

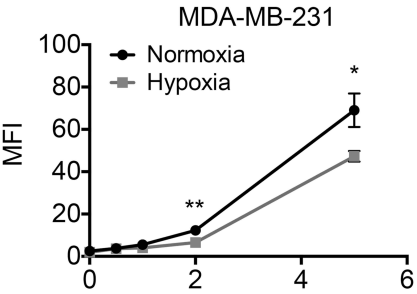

ug of Galectin-3

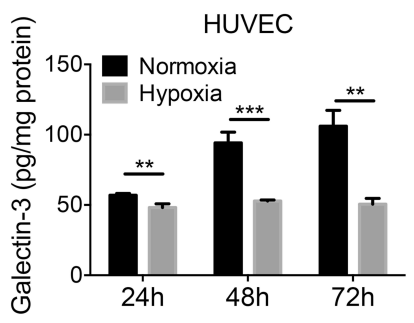

HUVEC - ECA

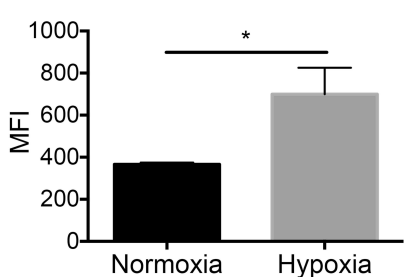

HUVEC - L-PHA
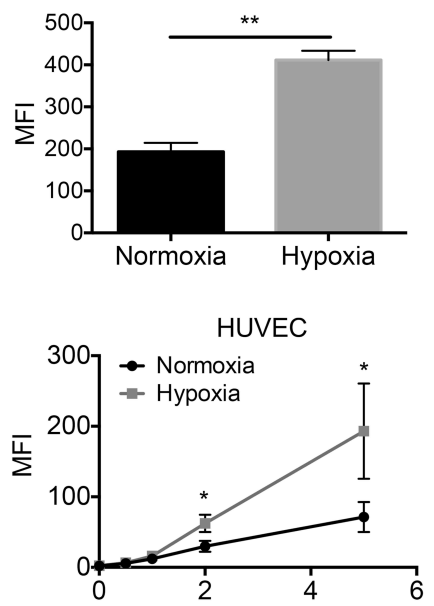

ug of Galectin-3

Figure 5. Hypoxia increases galectin-3 binding to endothelial cells.

(A) ELISA of galectin-3 secretion by MCF7, MDA-MB-231 and HUVECs after culture under normoxic or hypoxic conditions.

(B-D) Flow cytometry of (B) ECA, (C) L-PHA and (D) DyLigth488 labeled-Gal-3 in MCF7, MDA-MB-231 and HUVEC cultured under normoxic or hypoxic conditions for $48 \mathrm{~h}$. See also Figure S3.

Data are the mean \pm SEM, $n=3 ;{ }^{*} p<0.05,{ }^{* *} p<0.01,{ }^{* * *} p<0.001,{ }^{* * * *} p<0.0001$. See also Figure S3.

We next tested whether galectin- 3 secreted by cancer cells would induce Notch signaling activation and angiogenic sprouting. Thus, MCF7 breast cancer cells and HUVECs were used in a co-culture experiment. HUVEC spheroids were embedded in fibrin gel and were co-cultured with galectin-3-shRNA silenced MCF7 cells, which showed reduced levels of galectin-3 protein and mRNA levels (Figure 6A and $6 \mathrm{~B}$ ), or scramble shRNA control. In the presence of galectin-3-silenced MCF7 
cells, both the number of sprouts and sprout length were significantly lower in comparison with spheroids growing with MCF7-scramble cells (Figure 6C).

We evaluated whether galectin-3 released by cancer cells was able to induce Notch signaling in HUVEC cells. We treated HUVECs with the conditioned medium obtained from scrambled or galectin-3-silenced MCF7 cells cultured under normoxic or hypoxic conditions (Figure 6D). The effect was compared to control HUVECs \pm tethered DLL4, but without MCF7 conditioned medium.

A

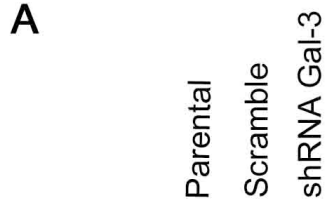

Galectin-3

$\beta$-actin

D

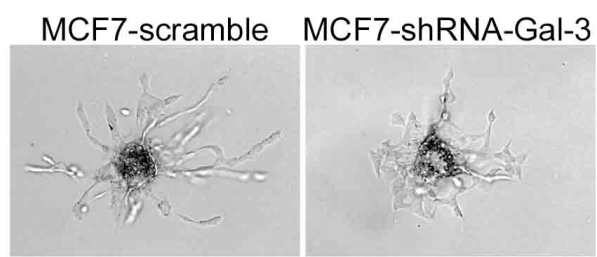

B

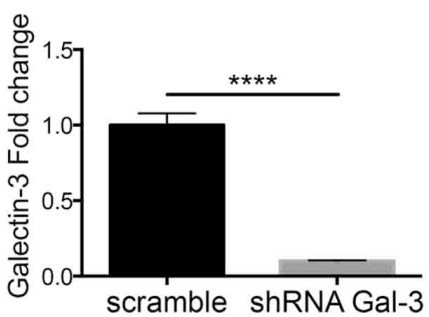

$\mathrm{E}$

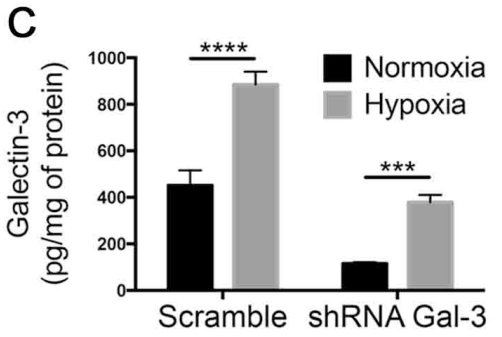

F

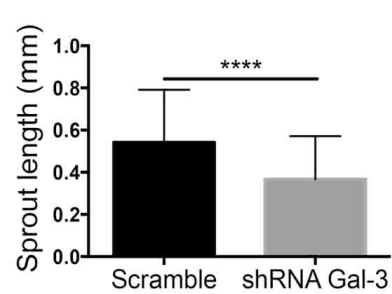

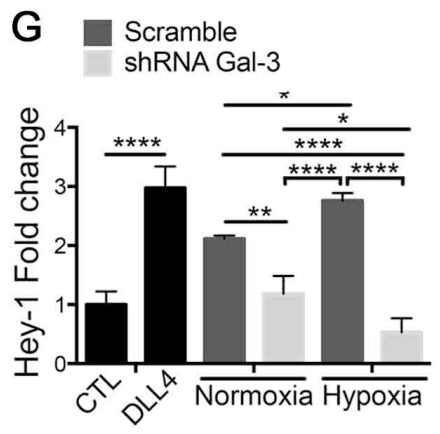
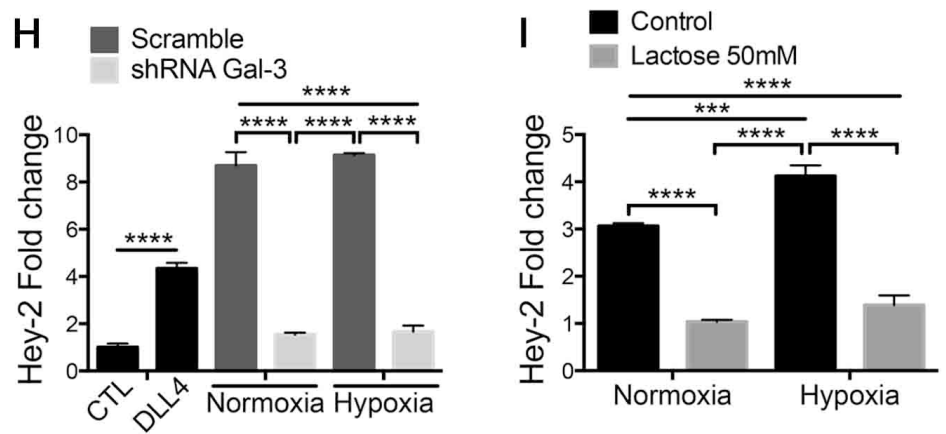

Figure 6. Galectin-3 released by cancer cells activates Notch signaling and enhances sprouting angiogenesis.

(A) Immunoblot and mRNA levels (B) of galectin-3 in MCF7 cells transduced with scramble or shRNAGal-3 lentiviral particles.

(C) ELISA of galectin-3 secretion by MCF7-scramble or shRNA-Gal-3.

(D-F) Representative figures of HUVECs spheroids cultured on the presence of MCF7-scramble or shRNA-Gal-3 cells for $24 \mathrm{hrs}$. (E) The average number and $(F)$ sprouts length was quantified.

( $\mathrm{G}$ and $\mathrm{H}$ ) Hey-1 and $(\mathrm{H}) \mathrm{Hey}-2$ mRNA levels of HUVECs cultured on DLL4-coated plated, or in the presence of conditioned medium from MCF7-scramble and shRNA-Gal-3 cells previously grown in normoxic or hypoxic conditions.

(I) Hey-2 mRNA levels of HUVECs cultured in the presence of conditioned medium from MCF7 cells previously grown in normoxic or hypoxic conditions \pm Lactose $(50 \mathrm{mM})$.

Data are the mean \pm SEM $(B-C, E-I)$, or are representative of $n=3 ;{ }^{*} p<0.05,{ }^{* *} p<0.01,{ }^{* * *} p<0.001$, ${ }^{* * * *} \mathrm{p}<0.0001$ 
Up regulation of Notch target genes Hey-1 and Hey-2 in HUVECs were induced by the culture supernatant from hypoxic and normoxic cells control MCF7 cells. However Notch signaling activation remained at control levels, without MCF7 conditioned medium, when HUVECs were treated with conditioned medium from normoxic or hypoxic galectin-3-silenced MCF7 cells (Figure 6E and 6F). This suggests that even the basal level of conditioned medium contains a soluble activator of Notch signaling, which is lost by galectin-3 knockdown. Hey-2 followed a similar pattern, although it was more strongly induced then Hey-1 and did not increase further with hypoxic conditioned medium. We further studied whether Notch activation by the conditioned medium from normoxic or hypoxic MCF7 cells was dependent on galectin-3 carbohydrate-binding domain. We found that tumorreleased galectin-3 activates the Notch target Hey-2 in a lactose inhibitable manner (Figure 6G). Altogether, these findings suggest that galectin-3 released by tumor cells has an important role in modulating angiogenic sprouting via Notch signaling activation.

\section{The growth rate of Jagged1 overexpressing tumor cells is prevented in galectin-3 knock out mice}

Both Jagged1 $[25,26]$ and DII4 [27, 28] are up regulated in several cancer cells and can control neovascularization and stimulate tumor growth in mice. Therefore we tested the ability of galectin-3 to interfere with Jagged1 and DLL4induced tumor growth. LLC cells were transduced with empty vector retrovirus (LLCEV), Jagged1-encoded retrovirus (LLC-JG1) or DLL4-encoded retrovirus (LLC-DLL4) (Figure 7A) and implanted subcutaneously into C57black/6 Lgals $^{+/+}$or Lgals3 $^{-/}$ mice. LLC-JG1 and LLC-DLL4 tumor growth were increased in Lgals $3^{+/+}$mice in comparison with LLC-EV tumors while LLC-JG1 tumor growth was higher than LLCDLL4 (Figure 7B and 7D). Surprisingly, we found a significant reduction in the tumor 
growth of LLC-JG1 but not LLC-DLL4 and LLC-EV when grown in Lgals $3^{-1-}$ mice (Figure 7C and 7D). At the end of the experiment, tumors were collected for immunohistochemical and mRNA analysis. Although there was no correlation between tumor size and Ki67 antigen expression (Figure S4A and S4B), we found that Jagged1 overexpressing tumors (LLC-JG1) presented a significantly higher necrotic area than overexpressing DLL4 (LLC-DLL4) or empty vector (LLC-EV) tumors regardless of the mouse background (Figure S5A and S5B). We also observed that LLC-DLL4 and LLC-JG1 derived tumors grown in Lgals $3^{+/+}$mice had

A

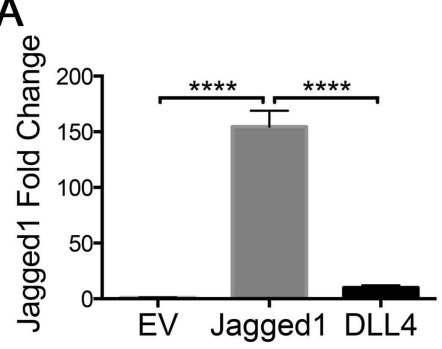

B

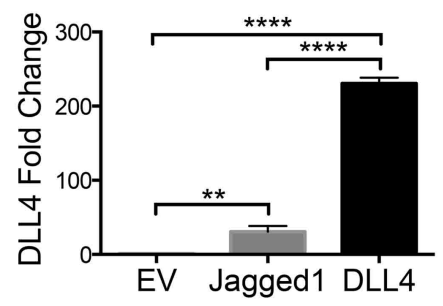

C

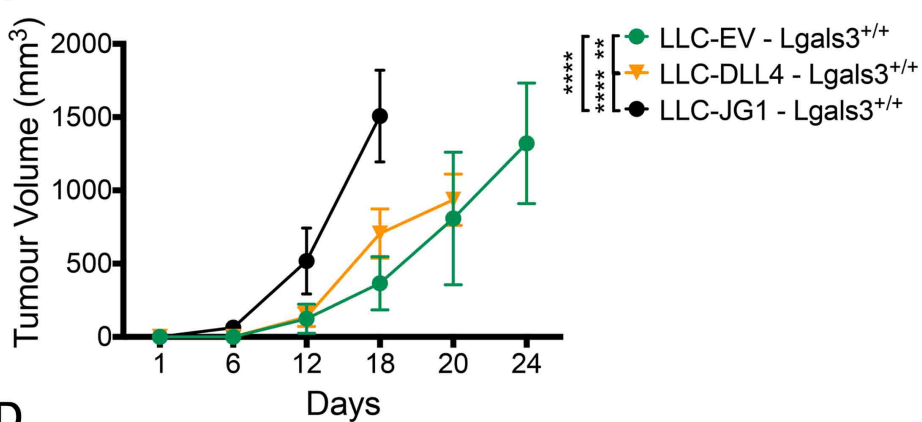

D

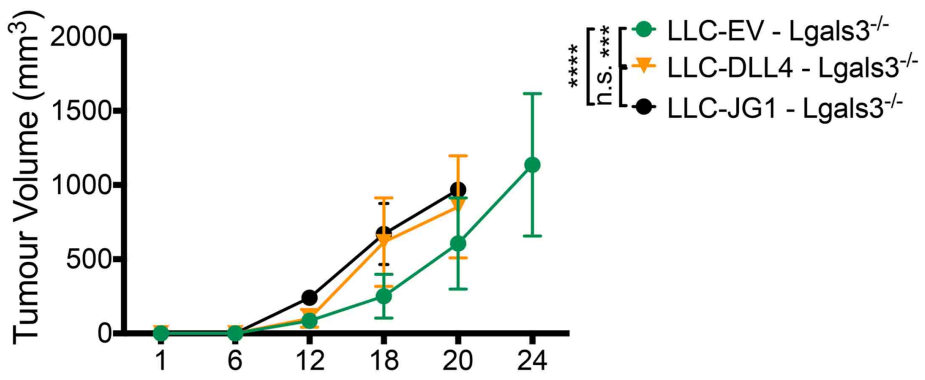

E

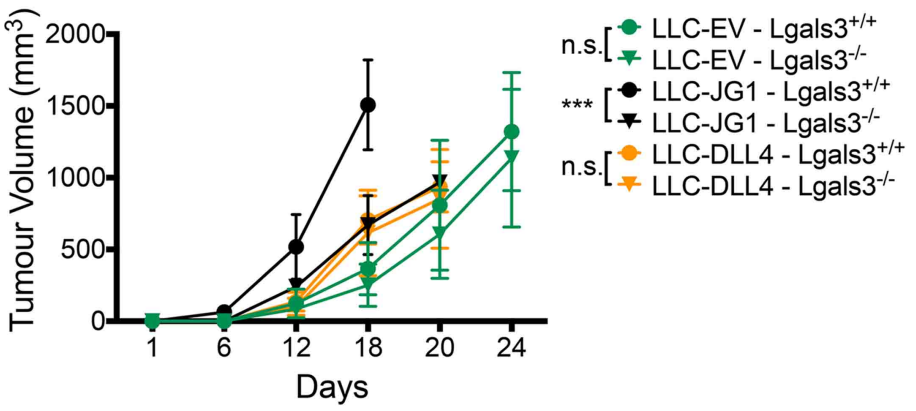

higher levels of CD31

mRNA comparing to Lgals3 $^{-/-}$mice (Figure S5C). Moreover, after staining tumors by $\mathrm{H} \& \mathrm{E}$ (Figure S5D), we found that LLC-JG1 tumors grown in Lgals $^{+/+}$mice had significantly fewer blood vessel numbers per $0,16 \mathrm{~mm}^{2}$ (Figure S5E) but increased vascular lumen area (Figure S5F) in

Figure $7 . \quad$ Jagged1 overexpression in tumor cells increases tumor growth.

(A and B) mRNA levels of (A) Jagged1 and (B) DLL4 of LLC cells overexpressing the full length of murine Jagged1 or DLL4.

(C-E) Tumor growth of LLC-EV, LLC-JG1 or LLC-DLL4 in (C, E) C57black/6 Lgals3+/+, (D, E) Lgals3-/- mice.

Mean \pm SEM, $n=3$, five animals per group; ${ }^{* *} p<0.01,{ }^{* * *} p<0.001$, ${ }^{* * * *} p<0.0001$. See also Figure S5 and S6. 
comparison to LLC-JG1 tumors in Lgals $3^{-/-}$mice. No significant changes were found in LLC-DLL4 and LLC-EV tumors. These data suggest that galectin-3 is responsible not only for the increased growth rate of Jagged1 expressing tumors but also for blood vessel maturation in Jagged1 overexpressing tumors.

\section{Discussion}

Galectin-3 binds to many cell surface glycoproteins and thus, it has been a challenge to determine which glycoproteins recognized by galectin-3 are responsible for the pro-angiogenic functions exerted on endothelial cells, and the conditions under which galectin-3 can affect this function. The molecular mechanisms for galectin-3-induced angiogenesis described so far include the binding and activation of VEGFR2 in endothelial cells, $\alpha_{\mathrm{v}} \beta_{3}$ integrin clustering and activation of signaling pathways that influence bFGF, VEGF and neuron-glial antigen 2 (NG2) angiogenic activities [16-19].

The current study describes a novel mechanism by which galectin-3 promotes angiogenesis that is independent of the VEGFR2 pathway. Galectin-3 induced angiogenic sprouting by increasing the proangiogenic activity of Jagged1/Notch-1 signaling and by changing the ratio of Jagged 1 and DLL4 expression in endothelial cells. In addition, our findings suggest that Jagged1/Notch1 signaling might be triggered by galectin-3 released from hypoxic tumor assisted with changes in the glycosylation status of tumor and endothelial cells under hypoxic conditions.

Most of the galectin-3 functions can be explained by its capacity to form oligomers in a concentration-dependent equilibrium, which accounts for its ability to crosslink cell surface proteins. Since Notch activation requires that the Jagged1/DLL4 ligands expressed on a signal-sending cell to interact with Notch receptor on a neighboring signal-receiving cell (trans-interaction) [29], we can 
hypothesize that galectin-3 may help bring receptor and ligand together. Indeed, galectin-3 is known to behave as a monomer in concentration < 50nM [30], however, we cannot disregard that HUVECs already display galectin-3 on the cell surface (data not shown). Therefore, the addition of $37 \mathrm{nM}$ of exogenous galectin-3 may have led to oligomer formation through self-association with endogenous galectin-3 present on the cell surface, thus increasing Notch/ligand interaction and further signaling. The concentration of galectin-3 used is also in agreement with the galectin3 levels found in the serum of cancer patients (that are increased in comparison with healthy individuals), with values ranging from $20-620 \mathrm{ng} / \mathrm{mL}(0.74-22 \mathrm{nM})$ in breast cancer; $20-950 \mathrm{ng} / \mathrm{mL}(0.74-35 \mathrm{nM})$ in gastrointestinal tumors; $20-807 \mathrm{ng} / \mathrm{mL}(0.74-29$ $\mathrm{nM})$ in lung cancer; and 35-366 ng/mL (1.3-12.4 nM) in ovarian cancer [31].

At higher concentrations $(>25 \mu \mathrm{g} / \mathrm{mL}(>925 \mathrm{nM})$ galectin-3 is described to multimerize, creating a rigid structure called a lattice, which restrains the lateral movement of membrane glycoproteins [30] and can result in cell adhesion inhibition $[32,33]$. Thus, a high concentration of galectin-3 might restrain Notch receptor interaction with the ligands present on an opposite cell inhibiting Notch signaling. In agreement with this, we observed that Gal-3C, which lacks the N-terminal domain responsible for oligomerization, was able to induce NICD1 cleavage and DLL4 up regulation, even at the highest concentration $(1,85 \mu \mathrm{M})$. In a very recent study, Nakajima K e cols. 2014 [34] reported that galectin-3 induces Notch signaling activation in a dose-dependent manner at concentrations ranging from $0.4 \mu \mathrm{M}$ to 1.6 $\mu \mathrm{M}$ in human fetal osteoblasts. Although we found in our model that higher concentration of galectin-3 (> $925 \mathrm{nM}$ ) have an inhibitory effect on Notch signaling, galectin-3 effect on Notch activation may depend on the cellular type, on the endogenous level of galectin-3 present on the cell surface and on the expression level of Notch ligands (Jagged1/DLL4) in a particular cell.

Our data also demonstrated that Notch signaling activation by galectin-3 was independent of VEGFR2. This is of particular importance since most antiangiogenic 
therapies are designed to disrupt VEGF-VEGFR interactions [35]. Our result suggests the induction of a compensatory angiogenic pathway by galectin-3, particularly via Jagged1/Notch pathway, that may contribute to limit the efficacy of anti-VEGF treatment. Jagged1 has been identified as a critical component in the process of tip cell selection, and, unlike DLL4 it has been considered as proangiogenic $[36,37]$. Loss of Jagged1 has been seen to significantly decrease the number of tips and filopodia as well as ECs proliferation. On the other hand, Jagged1 overexpression increased vessel branching, ECs density and downregulated DLL4Notch signaling decreasing Hes-1 and Hey-1 levels [9]. Here we reported that extracellular galectin-3 phenocopied the role of Jagged1 in angiogenesis by increasing HUVECs proliferation and the tip cell number. Moreover, in the presence of galectin-3, Jagged1 ligand present on HUVECs was able to induce Notch signaling activation in murine endothelial receiving cells (sEnd). Therefore, we suggest that the proangiogenic functions of extracellular galectin-3 might be mediated by the activation of Jagged1/Notch-1 signaling in endothelial cells.

Although not yet explored, galectin-3 and Jagged1/Notch signaling play similar biological roles in multiple cellular processes. It was previously published that $\mathrm{T}$ regulatory cells from Lgals $^{-/-}$mice displayed higher expression of Jagged1 associated with an increase in immunosuppressive capacity [38]. Jagged1/Notch-3 has been shown to be essential for TREG expansion and immunosuppressive phenotype [39]. Another example is the role of galectin-3 in epithelial to mesenchymal transition, which leads to an increase in phosphorylation and nuclear translocation of $\beta$-catenin [40]. Similarly, Jagged1/Notch signaling induces epithelialto-mesenchymal transition through Slug-induced repression of E-cadherin, resulting in $\beta$-catenin activation [41]. Additionally, galectin-3 has been associated with several aspects of allergic inflammation such as the development of a Th2 phenotype [42]; likewise, Jagged1/Notch signaling is implicated in Th2 differentiation [43] . Thus, our results have a wider significance that extends to other cell types and biological 
processes that are regulated by the Notch signaling pathway.

Our findings also showed that under hypoxic conditions, galectin-3 is be more prone to bind to endothelial cells rather than tumor cells, reinforcing the role of extracellular galectin-3 in the integration of signals from the tumor microenvironment. Indeed, it is well know that both galectin-3 and Jagged1 are overexpressed in several malignancies such as prostate cancer, breast cancer, glioma and head and neck cancers and are largely appreciated as potential targets for cancer therapy, including antiangiogenic therapy $[44,45]$. Jagged1-induced Notch signaling plays an important role in tumor biology affecting both proliferation and metastasis of tumor cells and also activating neighboring endothelial cells to promote neovascularization and growth of experimental tumors in mice $[46,47]$. Similarly, galectin-3 has been associated with tumor growth and cells invasion [48, 49]. Therefore, circumstances that lead to the up-regulation of galectin-3 in the tumor microenvironment may influence Jagged1 activity both in cancer and endothelial cells. For instance tumor necrosis factor- $\alpha$ (TNF- $\alpha)$, a proinflammatory cytokine, as be seen to induce the expression of galectin-3 [50] together with Jagged1 [37]. Moreover, in response to hypoxia, HIF-1 $\alpha$ activates several genes, including galectin-3 [14, 51, 52].

Besides regulating Jagged1/Notch proangiogenic functions in vitro, this study also showed that galectin-3 has an essential role in regulating the tumor growth of Jagged1 expressing tumors. We observed that in Lgals $3^{-/-}$mice, LLC-JG1 cells had a significant reduced growth rate comparing to LLC-JG1 grown Lgals $3^{+/+}$mice while DLL4 and EV-derived tumors were not affected. Since Jagged1 can increase cancer progression because of its pro-proliferative functions [46, 53], our findings suggest that Jagged1 role in cancer progression can be regulated by microenvironmental galectin-3 possibly via modulation of Jagged1/Notch signaling. Additionally, we identified that Jagged1-expressing tumors were associated with increased necrosis in comparison with LLC-DLL4 and LLC-EV. This may be due to the increased growth rate observed in LLC-JG1 tumors in comparison to DLL4 and EV expressing tumors. 
This finding is of particular importance since increased hypoxia is often associated with resistance to radiotherapy and chemotherapy [54]. Therefore, the development of strategies aimed to target Jagged1 (such as galectin-3 inhibition) is also important to overcome resistance to therapy. The present study furthermore demonstrates that galectin-3 is able to increase the proangiogenic role of Jagged1 in vivo. Indeed, we observed that in the absence of galectin-3, Jagged1 expressing tumors presented a decreased vascular lumen area and CD31 mRNA levels than in the presence of microenvironmental galectin-3. Taking into account our overall results, we can suggest that galectin-3 positively regulates Jagged1 biological role in inducing endothelial sprouts, blood vessel maturation and the formation of luminal structures [55, 56]. Thus, and in agreement with our in vitro findings, microenvironmental galectin-3 seems to regulate vessels formation in tumors via modulation of Jagged1/Notch signaling.

We then propose a new mechanism by which tumor released-galectin-3 increases angiogenesis by influencing Jagged1/Notch-1 signaling in endothelial cells (Figure S6). In this context, the coordinated expression of Jagged1 and DLL4 modulated by gal-3 seems to be a key determinant to proper and functional neovascularization. Therefore, targeting galectin-3 may open novel perspectives to interfere with angiogenesis, and potentiating radiotherapy, and may provide novel experimental strategies to overcome anti-VEGF resistance. 


\section{Experimental Procedures}

\section{Jagged1, DII4 and Notch1 binding assay}

$1 \mu \mathrm{g}$ of the recombinant human Jagged1 or DII4 or Notch1 were diluted in PBS, and incubated overnight in a 96-well plate. The next day, the plate was washed and blocked with $1 \%$ BSA/PBS and $1 \mu \mathrm{g}$ of recombinant human galectin- 3 or galectin$3 \mathrm{C}$ in the presence or absence of lactose $(50 \mathrm{mM})$ and sucrose $(50 \mathrm{mM})$ was added to the plate. Galectin-3 binding was detected after addition of a detection antibody according to the manufacturer's procedure (ELISA galectin-3 Duo Set, R\&D Systems). Detection assay without galectin-3 or galectin-3C (1), without the primary antibody (2) or blank (3) were used as a negative control.

\section{Gene expression analysis}

Total RNA from cell cultures was isolated with Tri-Reagent (Sigma) according to the manufacturer's instructions. Complementary DNA (cDNA) was synthesized using the High capacity cDNA RT kit (Applied Biosystems), according to the manufacturer's protocols. Quantitative PCR analysis was performed in triplicate using the SensiMix SYBR No-ROX kit (Bioline). Relative quantification was done using the $\triangle \Delta \mathrm{Ct}$ method normalizing to GAPDH gene expression (See Supplemental Data for primer detail, Table S1).

\section{CyQuant proliferation assay}

HUVEC proliferation in response to galectin-3 and galectin-3C were performed by plating cells in quadruplicate (2000 cells/well) in 96-well plates, followed by incubation with CyQUANT (Invitrogen) as described by manufacturer. 


\section{Sprouting angiogenesis assay}

HUVEC spheroids were generated by the hanging-drop method [57]. In a set of experiments, HUVEC were previously transfected with 3 different siRNA against Jagged1 or DLL4 or scrambled prior to spheroid generation. In another set of experiments, after spheroids formation, MCF7 scramble or shRNA-Gal-3 silenced was cultured on the top of the gel. Alternatively, HUVECs were pre-labeled with viable fluorescent dyes (cell tracker green and red, Invitrogen) prior to spheroid generation. Angiogenesis was quantified by counting the number and the length of sprouts for each spheroid. (See Supplemental Experimental Procedures).

\section{Determination of Jagged1 and DLL4 half-life}

To assess protein stability, HUVECs were incubated with $37 \mathrm{nM}$ of galectin- 3 for $15 \mathrm{~min}$. After that period, the growth medium was replaced with medium containing $0.1 \mathrm{mM}$ of cycloheximide to stop protein biosynthesis. Cells were treated for 0 to 8 hours and then collected for Western blotting. ImageJ software was used to quantify western blot bands.

\section{Treatment of HUVECs with MCF7 cells conditioned medium}

Scrambled or shRNA-Gal-3 MCF7 cells were cultured under normoxic or hypoxic conditions for $48 \mathrm{~h}$. After this period, the conditioned medium was incubated with HUVECs $\left(10^{6}\right)$ for $6 \mathrm{hrs}$ and mRNA levels were analyzes. Galectin-3 from the conditioned medium was quantified by ELISA (ELISA galectin-3 Duo Set, R\&D Systems).

\section{In vivo studies}

Six- to 8-week-old male wild type (WT) or Lgals3 $^{-1-}$ C57BL/6 mice were implanted subcutaneously with $10^{6}$ LLC-EV or LLC-JG1 or LLC-DLL4 cells. Each group consisted of five mice. When tumors reached the size $1-1.5 \mathrm{~cm}^{3}$ volume, mice 
Chapter 3

were sacrificed and tumors were excised. Each animal experiment was repeated at least 3 times.

\section{Statistical Analysis}

All data are expressed as the mean \pm SEM of at least three independent experiments. Statistical analysis including t-test, one-way ANOVA and two-way ANOVA were done using GraphPad Prism 6.0 software. $p<0.05$ was considered statistically significant. 


\section{References}

1. Sakurai T, Kudo M. Signaling pathways governing tumor angiogenesis. Oncology. 2011;81 Suppl 1:24-9.

2. Hellstrom M, Phng LK, Hofmann JJ, Wallgard E, Coultas L, Lindblom P, et al. DII4 signalling through Notch1 regulates formation of tip cells during angiogenesis. Nature. 2007 Feb 15;445(7129):776-80.

3. Lobov IB, Renard RA, Papadopoulos N, Gale NW, Thurston G, Yancopoulos GD, et al. Deltalike ligand 4 (DII4) is induced by VEGF as a negative regulator of angiogenic sprouting. Proceedings of the National Academy of Sciences of the United States of America. 2007 Feb 27;104(9):3219-24.

4. Herbert SP, Stainier DY. Molecular control of endothelial cell behaviour during blood vessel morphogenesis. Nature reviews Molecular cell biology. 2011 Sep;12(9):551-64.

5. Phng LK, Gerhardt H. Angiogenesis: a team effort coordinated by notch. Developmental cell. 2009 Feb;16(2):196-208.

6. Stenzel D, Franco CA, Estrach S, Mettouchi A, Sauvaget D, Rosewell I, et al. Endothelial basement membrane limits tip cell formation by inducing DII4/Notch signalling in vivo. EMBO reports. 2011 Nov;12(11):1135-43.

7. Estrach S, Cailleteau L, Franco CA, Gerhardt $H$, Stefani C, Lemichez E, et al. Laminin-binding integrins induce DII4 expression and Notch signaling in endothelial cells. Circulation research. $2011 \mathrm{Jul}$ 8;109(2):172-82.

8. Benedito R, Rocha SF, Woeste M, Zamykal M, Radtke F, Casanovas O, et al. Notchdependent VEGFR3 upregulation allows angiogenesis without VEGF-VEGFR2 signalling. Nature. 2012 Apr 5;484(7392):110-4.

9. Benedito R, Roca C, Sorensen I, Adams S, Gossler A, Fruttiger M, et al. The notch ligands DII4 and Jagged1 have opposing effects on angiogenesis. Cell. 2009 Jun 12;137(6):1124-35.

10. Funasaka T, Raz A, Nangia-Makker P. Galectin-3 in angiogenesis and metastasis. Glycobiology. 2014 Oct;24(10):886-91.

11. Rabinovich GA, Thijssen VL. Introduction to special issue: Galectins go with the flow. Glycobiology. 2014 Oct;24(10):885.

12. Thijssen VL, Griffioen AW. Galectin-1 and -9 in angiogenesis: a sweet couple. Glycobiology. 2014 Oct;24(10):915-20.

13. Hirabayashi J, Kasai K. The family of metazoan metal-independent beta-galactoside-binding lectins: structure, function and molecular evolution. Glycobiology. 1993 Aug;3(4):297-304.

14. Zeng Y, Danielson KG, Albert TJ, Shapiro IM, Risbud MV. HIF-1 alpha is a regulator of galectin-3 expression in the intervertebral disc. Journal of bone and mineral research : the official journal of the American Society for Bone and Mineral Research. 2007 Dec;22(12):1851-61.

15. Neder L, Marie SK, Carlotti CG, Jr., Gabbai AA, Rosemberg S, Malheiros SM, et al. Galectin-3 as an immunohistochemical tool to distinguish pilocytic astrocytomas from diffuse astrocytomas, and glioblastomas from anaplastic oligodendrogliomas. Brain pathology. 2004 Oct;14(4):399-405.

16. Nangia-Makker P, Honjo Y, Sarvis R, Akahani S, Hogan V, Pienta KJ, et al. Galectin-3 induces endothelial cell morphogenesis and angiogenesis. The American journal of pathology. 2000 Mar;156(3):899-909.

17. Markowska Al, Jefferies KC, Panjwani N. Galectin-3 protein modulates cell surface expression and activation of vascular endothelial growth factor receptor 2 in human endothelial cells. The Journal of biological chemistry. 2011 Aug 26;286(34):29913-21.

18. Markowska Al, Liu FT, Panjwani N. Galectin-3 is an important mediator of VEGF- and bFGFmediated angiogenic response. The Journal of experimental medicine. 2010 Aug 30;207(9):1981-93.

19. Machado CM, Andrade LN, Teixeira VR, Costa FF, Melo CM, dos Santos SN, et al. Galectin-3 disruption impaired tumoral angiogenesis by reducing VEGF secretion from TGFbeta1-induced macrophages. Cancer medicine. 2014 Apr;3(2):201-14.

20. Haines N, Irvine KD. Glycosylation regulates Notch signalling. Nature reviews Molecular cell biology. 2003 Oct;4(10):786-97.

21. Harrington LS, Sainson RC, Williams CK, Taylor JM, Shi W, Li JL, et al. Regulation of multiple angiogenic pathways by DIl4 and Notch in human umbilical vein endothelial cells. Microvascular research. 2008 Mar;75(2):144-54

22. Furtak V, Hatcher F, Ochieng J. Galectin-3 mediates the endocytosis of beta-1 integrins by breast carcinoma cells. Biochemical and biophysical research communications. 2001 Dec 14;289(4):845-50.

23. Giordano FJ, Johnson RS. Angiogenesis: the role of the microenvironment in flipping the switch. Current opinion in genetics \& development. $2001 \mathrm{Feb} ; 11(1): 35-40$.

24. Ferrara N. VEGF and the quest for tumour angiogenesis factors. Nature reviews Cancer. 2002 Oct;2(10):795-803.

25. Jubb AM, Browning L, Campo L, Turley H, Steers G, Thurston G, et al. Expression of vascular Notch ligands Delta-like 4 and Jagged-1 in glioblastoma. Histopathology. 2012 Apr;60(5):740-7. 
26. Lu C, Bonome T, Li Y, Kamat AA, Han LY, Schmandt R, et al. Gene alterations identified by expression profiling in tumor-associated endothelial cells from invasive ovarian carcinoma. Cancer research. $2007 \mathrm{Feb}$ 15;67(4):1757-68.

27. Patel NS, Li JL, Generali D, Poulsom R, Cranston DW, Harris AL. Up-regulation of delta-like 4 ligand in human tumor vasculature and the role of basal expression in endothelial cell function. Cancer research. 2005 Oct 1;65(19):8690-7.

28. Mailhos C, Modlich U, Lewis J, Harris A, Bicknell R, Ish-Horowicz D. Delta4, an endothelial specific notch ligand expressed at sites of physiological and tumor angiogenesis. Differentiation; research in biological diversity. $2001 \mathrm{Dec} ; 69(2-3): 135-44$.

29. Cordle J, Johnson S Fau - Tay JZY, Tay Jz Fau - Roversi P, Roversi P Fau - Wilkin MB, Wilkin Mb Fau - de Madrid BH, de Madrid Bh Fau - Shimizu H, et al. A conserved face of the Jagged/Serrate DSL domain is involved in Notch trans-activation and cis-inhibition. 20080805 DCOM- 20080902(15459985 (Electronic)).

30. Nieminen J, Kuno A, Hirabayashi J, Sato S. Visualization of galectin-3 oligomerization on the surface of neutrophils and endothelial cells using fluorescence resonance energy transfer. The Journal of biological chemistry. 2007 Jan 12;282(2):1374-83.

31. Iurisci I, Tinari N, Natoli C, Angelucci D, Cianchetti E, lacobelli S. Concentrations of galectin-3 in the sera of normal controls and cancer patients. Clinical cancer research : an official journal of the American Association for Cancer Research. 2000 Apr;6(4):1389-93.

32. Kariya Y, Kawamura C, Tabei T, Gu J. Bisecting GlcNAc residues on laminin-332 downregulate galectin-3-dependent keratinocyte motility. The Journal of biological chemistry. 2010 Jan 29;285(5):3330-40

33. Bao Q, Hughes RC. Galectin-3 expression and effects on cyst enlargement and tubulogenesis in kidney epithelial MDCK cells cultured in three-dimensional matrices in vitro. Journal of cell science. 1995 Aug;108 ( Pt 8):2791-800.

34. Nakajima K, Kho DH, Yanagawa T, Harazono Y, Gao X, Hogan V, et al. Galectin-3 inhibits osteoblast differentiation through notch signaling. Neoplasia. 2014 Nov;16(11):939-49.

35. Loges $S$, Mazzone M, Hohensinner $P$, Carmeliet $P$. Silencing or fueling metastasis with VEGF inhibitors: antiangiogenesis revisited. Cancer cell. 2009 Mar 3;15(3):167-70.

36. Pedrosa AR, Trindade A, Fernandes AC, Carvalho C, Gigante J, Tavares AT, et al. Endothelial Jagged1 antagonizes DII4 regulation of endothelial branching and promotes vascular maturation downstream of DIl4/Notch1. Arteriosclerosis, thrombosis, and vascular biology. 2015 May;35(5):113446.

37. Sainson RC, Johnston DA, Chu HC, Holderfield MT, Nakatsu MN, Crampton SP, et al. TNF primes endothelial cells for angiogenic sprouting by inducing a tip cell phenotype. Blood. 2008 May 15;111(10):4997-5007.

38. Fermino ML, Dias FC, Lopes CD, Souza MA, Cruz AK, Liu FT, et al. Galectin-3 negatively regulates the frequency and function of CD4(+) CD25(+) Foxp3(+) regulatory T cells and influences the course of Leishmania major infection. European journal of immunology. 2013 Jul;43(7):1806-17.

39. Gopisetty A, Bhattacharya P, Haddad C, Bruno JC, Jr., Vasu C, Miele L, et al. OX40L/Jagged1 cosignaling by GM-CSF-induced bone marrow-derived dendritic cells is required for the expansion of functional regulatory T cells. Journal of immunology. 2013 Jun 1;190(11):5516-25

40. Mackinnon AC, Gibbons MA, Farnworth SL, Leffler H, Nilsson UJ, Delaine T, et al. Regulation of transforming growth factor-beta1-driven lung fibrosis by galectin-3. American journal of respiratory and critical care medicine. 2012 Mar 1;185(5):537-46.

41. Leong KG, Niessen K, Kulic I, Raouf A, Eaves C, Pollet I, et al. Jagged1-mediated Notch activation induces epithelial-to-mesenchymal transition through Slug-induced repression of E-cadherin. The Journal of experimental medicine. 2007 Nov 26;204(12):2935-48.

42. Gao P, Simpson JL, Zhang J, Gibson PG. Galectin-3: its role in asthma and potential as an anti-inflammatory target. Respiratory research. 2013;14:136.

43. Okamoto M, Matsuda H, Joetham A, Lucas JJ, Domenico J, Yasutomo K, et al. Jagged1 on dendritic cells and Notch on CD4+ T cells initiate lung allergic responsiveness by inducing IL-4 production. Journal of immunology. 2009 Sep 1;183(5):2995-3003.

44. Li D, Masiero M, Banham AH, Harris AL. The notch ligand JAGGED1 as a target for anti-tumor therapy. Frontiers in oncology. 2014;4:254.

45. Fortuna-Costa A, Gomes AM, Kozlowski EO, Stelling MP, Pavao MS. Extracellular galectin-3 in tumor progression and metastasis. Frontiers in oncology. 2014;4:138.

46. Dai Y, Wilson G, Huang B, Peng M, Teng G, Zhang D, et al. Silencing of Jagged1 inhibits cell growth and invasion in colorectal cancer. Cell death \& disease. 2014;5:e1170.

47. Zeng Q, Li S, Chepeha DB, Giordano TJ, Li J, Zhang H, et al. Crosstalk between tumor and endothelial cells promotes tumor angiogenesis by MAPK activation of Notch signaling. Cancer cell. 2005 Jul;8(1):13-23.

48. Honjo $\mathrm{Y}$, Nangia-Makker $\mathrm{P}$, Inohara $\mathrm{H}$, Raz A. Down-regulation of galectin-3 suppresses tumorigenicity of human breast carcinoma cells. Clinical cancer research : an official journal of the American Association for Cancer Research. 2001 Mar;7(3):661-8. 
49. Zhang D, Chen ZG, Liu SH, Dong ZQ, Dalin M, Bao SS, et al. Galectin-3 gene silencing inhibits migration and invasion of human tongue cancer cells in vitro via downregulating beta-catenin. Acta pharmacologica Sinica. 2013 Jan;34(1):176-84.

50. Nishi Y, Sano H, Kawashima T, Okada T, Kuroda T, Kikkawa K, et al. Role of galectin-3 in human pulmonary fibrosis. Allergology international : official journal of the Japanese Society of Allergology. 2007 Mar;56(1):57-65.

51. Brocato J, Chervona Y, Costa M. Molecular responses to hypoxia-inducible factor 1alpha and beyond. Molecular pharmacology. 2014 May;85(5):651-7.

52. Tsai YP, Wu KJ. Hypoxia-regulated target genes implicated in tumor metastasis. Journal of biomedical science. 2012;19:102.

53. Steg AD, Katre AA, Goodman B, Han HD, Nick AM, Stone RL, et al. Targeting the notch ligand JAGGED1 in both tumor cells and stroma in ovarian cancer. Clinical cancer research : an official journal of the American Association for Cancer Research. 2011 Sep 1;17(17):5674-85.

54. Rockwell S, Dobrucki IT, Kim EY, Marrison ST, Vu VT. Hypoxia and radiation therapy: past history, ongoing research, and future promise. Current molecular medicine. 2009 May;9(4):442-58.

55. High FA, Lu MM, Pear WS, Loomes KM, Kaestner KH, Epstein JA. Endothelial expression of the Notch ligand Jagged1 is required for vascular smooth muscle development. Proceedings of the National Academy of Sciences of the United States of America. 2008 Feb 12;105(6):1955-9.

56. Scheppke L, Murphy EA, Zarpellon A, Hofmann JJ, Merkulova A, Shields DJ, et al. Notch promotes vascular maturation by inducing integrin-mediated smooth muscle cell adhesion to the endothelial basement membrane. Blood. 2012 Mar 1;119(9):2149-58.

57. Korff T, Augustin HG. Integration of endothelial cells in multicellular spheroids prevents apoptosis and induces differentiation. The Journal of cell biology. 1998 Nov 30;143(5):1341-52. 


\section{Supplemental Information}

Supplemental Figures and Legends

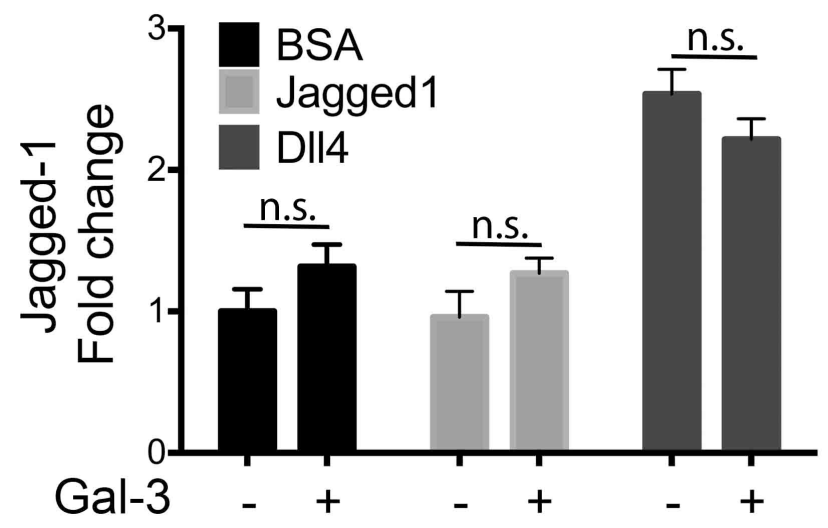

Figure S1. Galectin-3 does not up-regulate Jagged1 mRNA levels, related to Figure 2.

HUVECs were treated for 15 min with galectin-3 and then seeded onto BSA, Jagged1 or DLL4 coated plates for $6 \mathrm{~h}$. Total RNA was extracted and the mRNA level of Jagged1 were evaluated. The relative level of expression was normalized to the level of GAPDH mRNA expression (mean \pm SEM, $n=3$ ). 


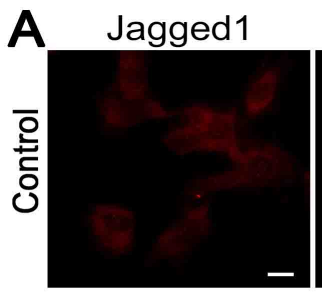

DAPI

Merge

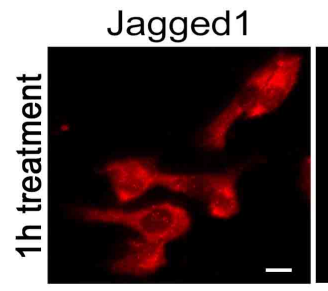

DAPI Gal-3-DyLight488

Merge
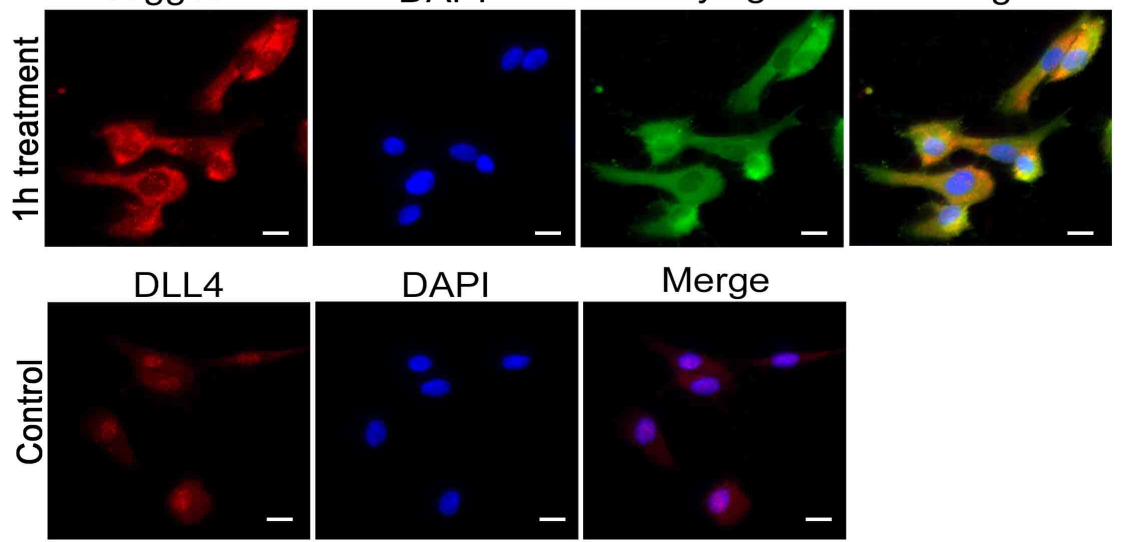

Merge

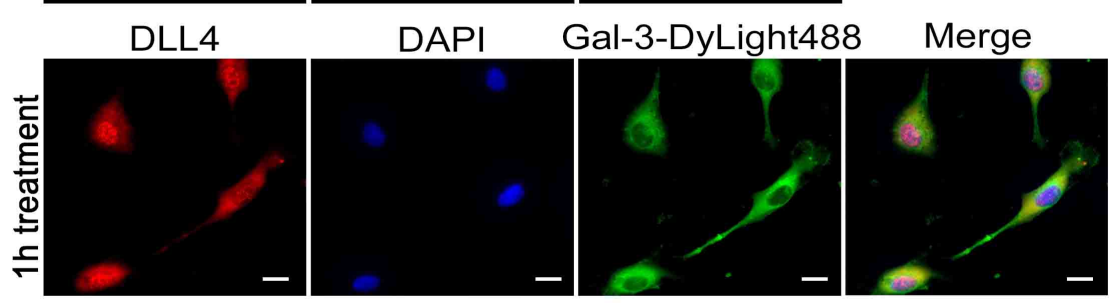

B

$$
P \text { Scr } \overline{123} \overline{123}
$$

Jagged1

DLL4

$\beta$-actin

C

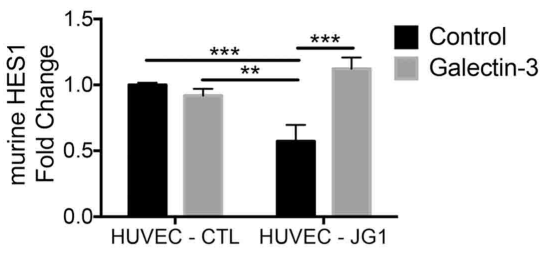

D

$E$

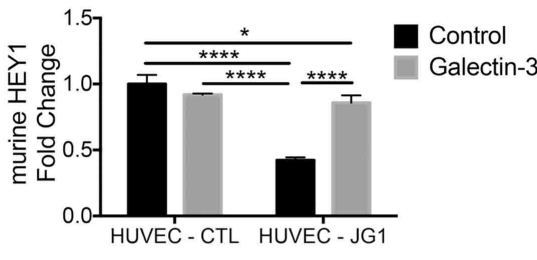

F
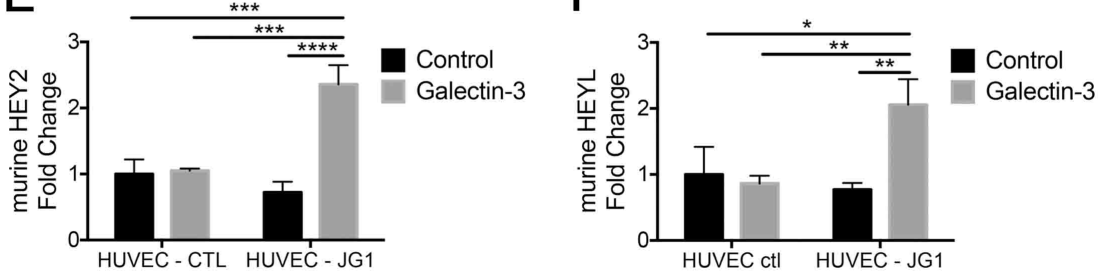

Figure S2. Galectin-3 increases Jagged1-mediated Notch signaling, related to Figure 3. 
(A) HUVECs were treated with DyLigth-488 labeled-hrGal-3 for $1 \mathrm{~h}$ and stained for Jagged1 and DLL4 proteins. Representative immunofluorescence images showing Jagged1 (red), DLL4 (red), hrGal3-DyLigth (green) and nucleus (blue) staining. Scale bar, $50 \mu \mathrm{m}$.

(B) Immunoblot of Jagged1 and DLL4 after $48 \mathrm{~h}$ of Jagged1 or DLL4 siRNA inhibition in HUVECs. $\beta$-actin was used as a loading control. Representative of three experiments.

(C-F) Relative quantification of murine (C) Hes-1, (D) Hey-1, (E) Hey-2, (F) Hey-L mRNA levels after co-culture (1:1) of sEnd-1 cells with HUVEC-CTL or HUVEC-JG1 in the presence or absence of galectin-3 (37 nM). Relative mRNA expression was normalized to GAPDH. (mean \pm SEM, $\left.n=3 ;{ }^{*} p<0.05,{ }^{* *} p<0.01,{ }^{* * *} p<0.001,{ }^{* * * *} p<0.0001\right)$. 
A
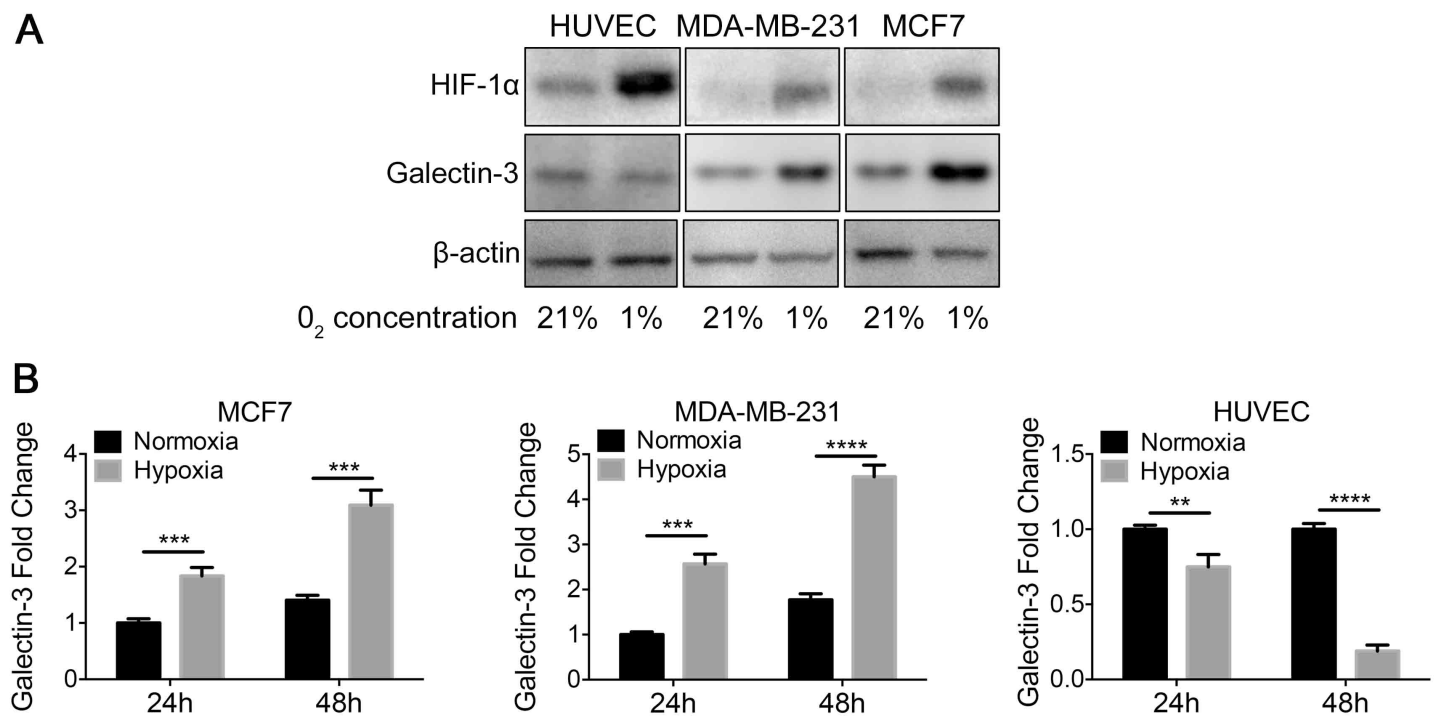

C

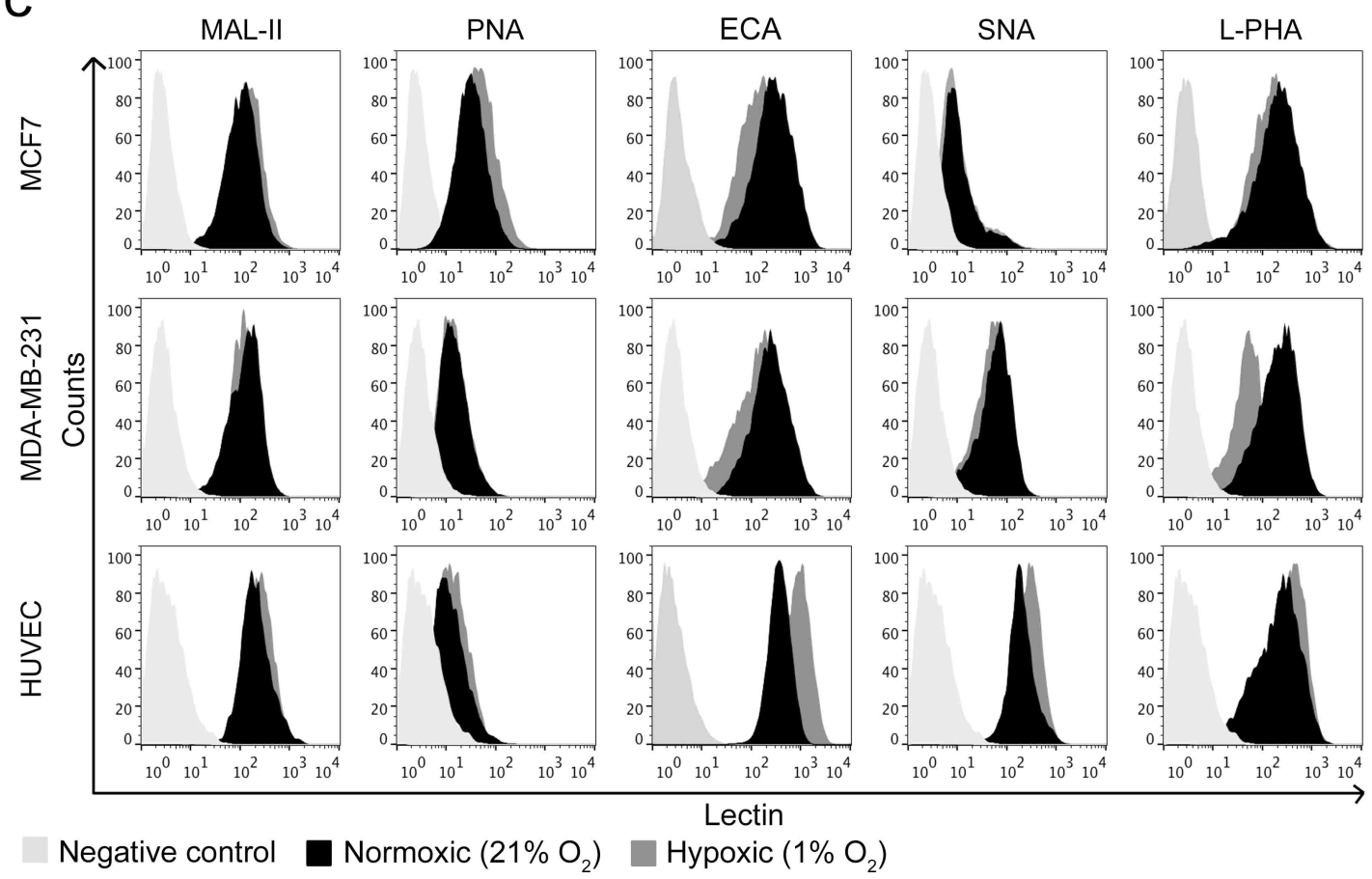

Figure S3. Galectin-3 expression decreases under hypoxic conditions in endothelial cells, related to Figure 5.

(A) Immunoblot of HIF-1a and galectin-3 following culture of HUVECs, MDA-MB-231 and MCF7 cells under normoxic $(21 \%$ O2) or hypoxic ( $1 \%$ O2) conditions for $48 \mathrm{~h}$. Representative of three experiments.

(B) mRNA relative expression of galectin-3 from MCF7, MDA-MB-231 and HUVECs cultured under normoxic $\left(21 \% \mathrm{O}_{2}\right)$ or hypoxic $\left(1 \% \mathrm{O}_{2}\right)$ conditions for $24 \mathrm{~h}$ and $48 \mathrm{~h}$ (mean $\pm \mathrm{SEM}, \mathrm{n}=3$; $\left.{ }^{* *} p<0.01,{ }^{* * *} p<0.001,{ }^{* * * *} p<0.0001\right)$. 
Chapter 3

(C) Flow cytometry of MCF7, MDA-MB-231 and HUVECs detected with the biotinylated lectins MAL-II, PNA, ECA, SNA and L-PHA or with Cy5-conjugated streptavidin alone after culture under normoxic or hypoxic concidtions. Representative of four experiments. 
A

Lgals $3^{-1}$

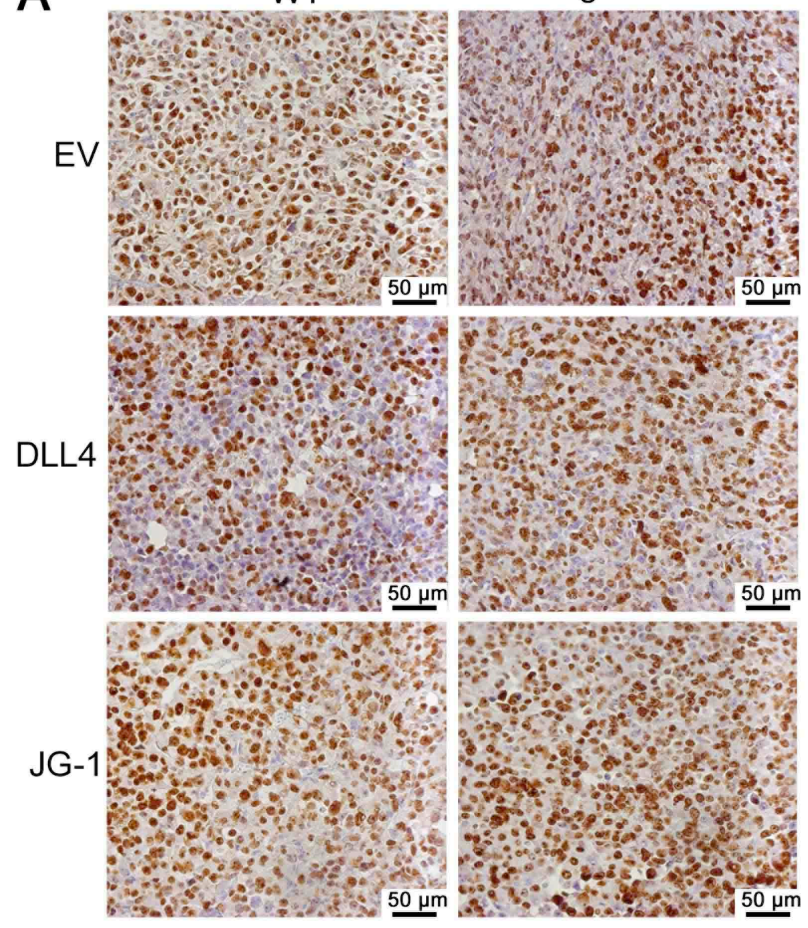

B

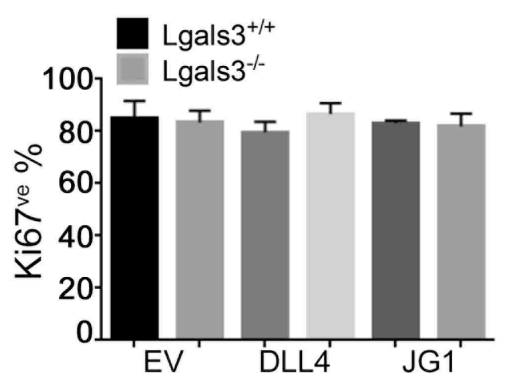

Figure S4. Immunohistochemical staining of Ki67, related to Figure 7.

(A) Immunohistochemical staining and (B) quantification of Ki67 in LLC-EV, LLC-JG1 or LLCDLL4 tumors inoculated in C57black/6 Lgals $3^{+/+}$or Lgals ${ }^{-/-}$mice. 

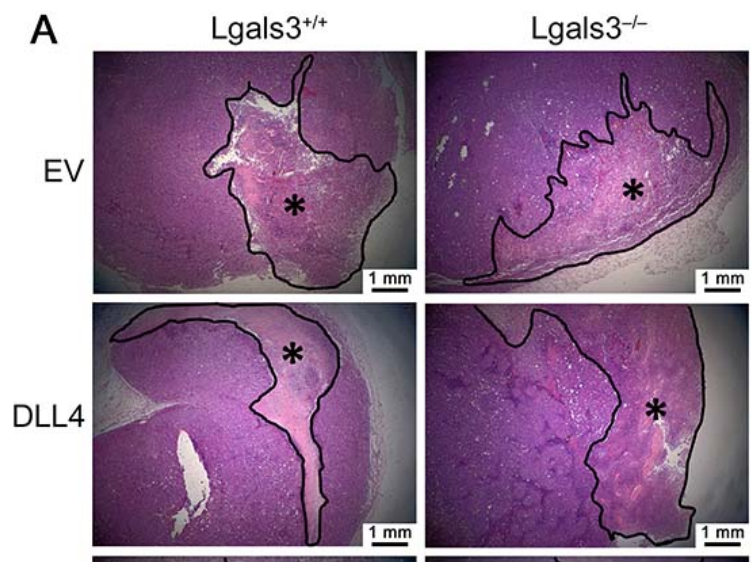

\section{B \\ C}
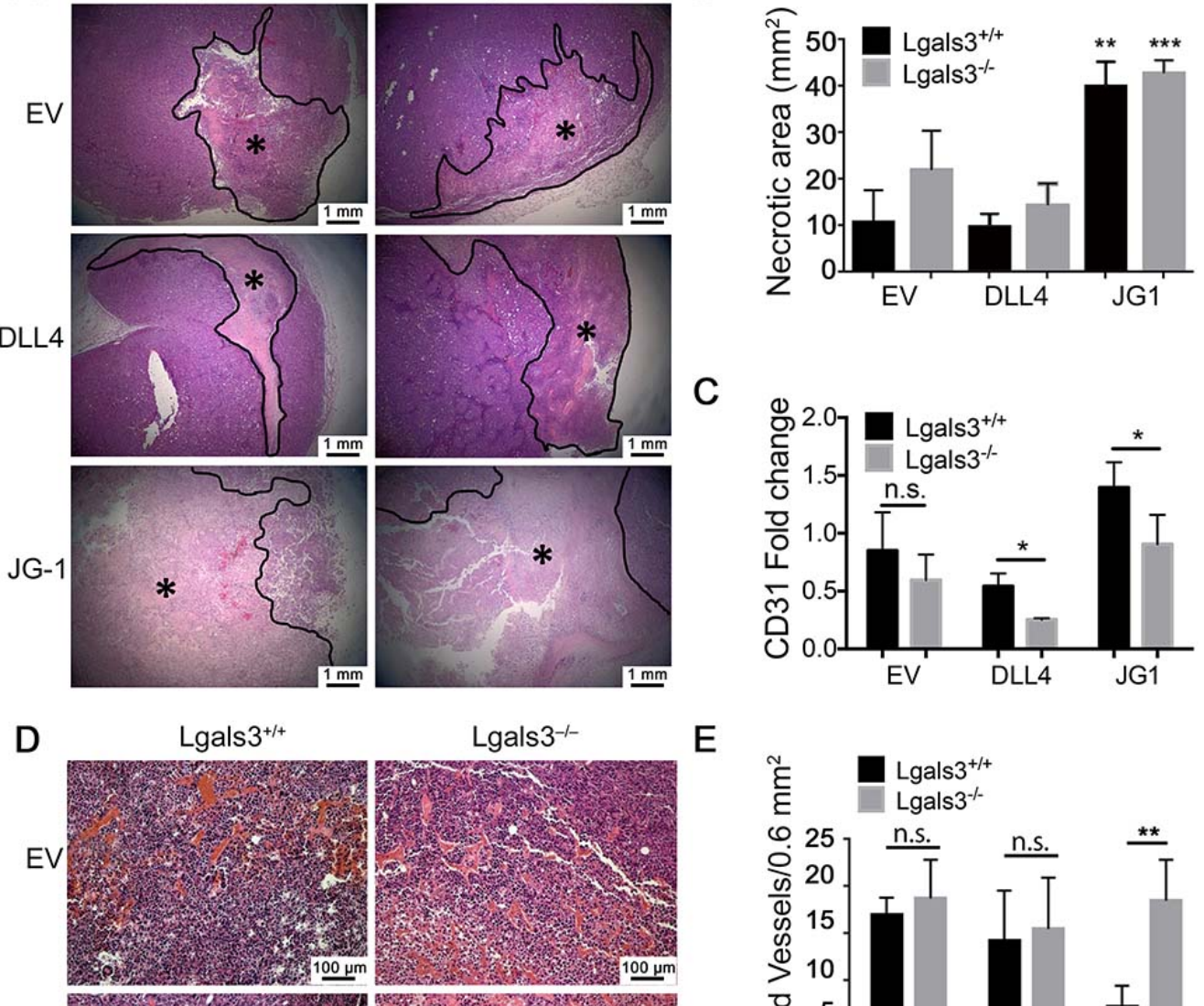

E
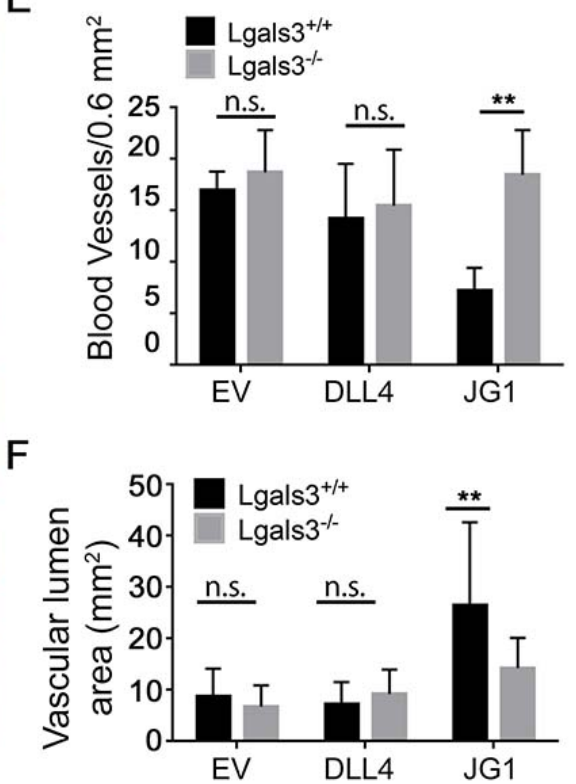

Figure S5. Galectin-3 knockout mice reduce vessel maturation of LLC-JG1 derived tumors, related to Figure 7.

(A and B) Hematoxylin and eosin staining and (B) quantification of the necrotic area in LLC-

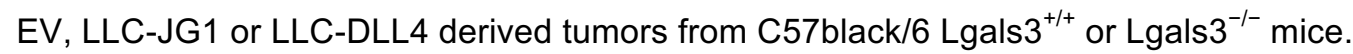

(C) CD31 mRNA levels in tumors of LLC-EV, LLC-JG1 or LLC-DLL4 derived tumors.

(D-F) Hematoxylin and eosin staining of LLC-EV, LLC-JG1 or LLC-DLL4 derived tumors and quantification of $(E)$ blood vessels number and $(F)$ vascular lumen area.

Data are the mean \pm SEM (B and C, E and F), or are representative of $n=4 ;{ }^{*} p<0.05,{ }^{* *} p<$ 0.01 . 


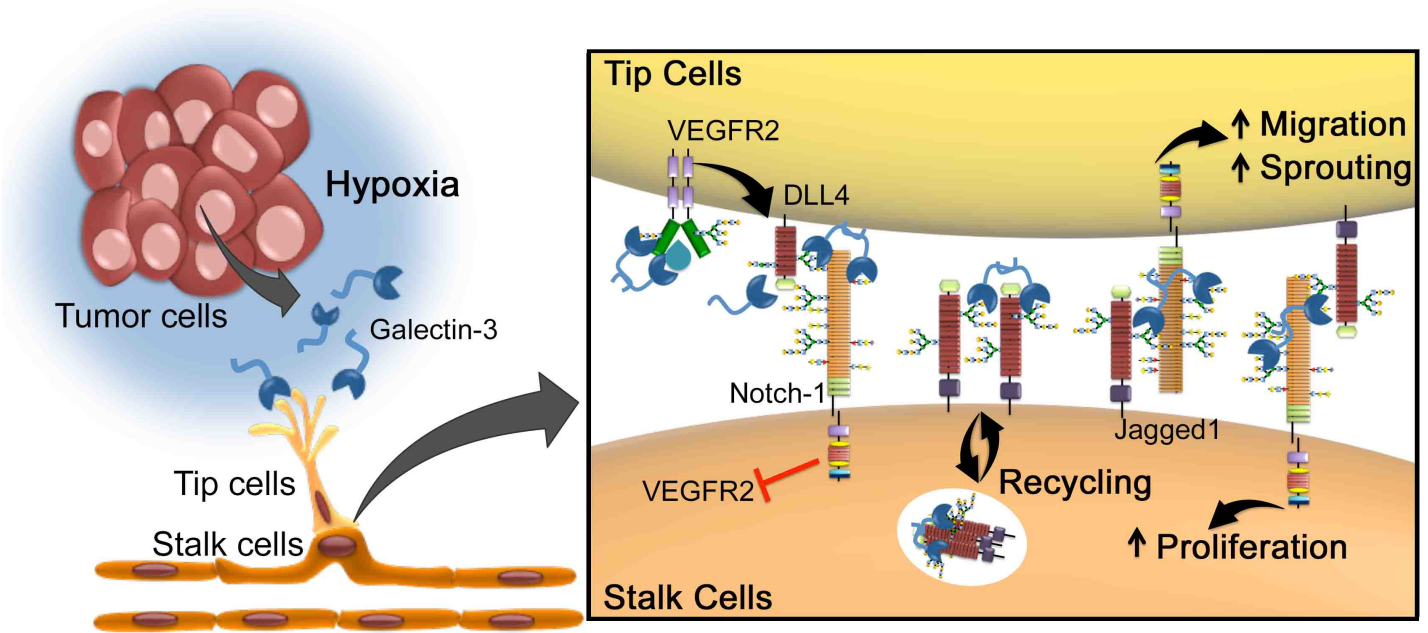

Figure S6. Proposed model for galectin-3-mediated angiogenesis by modulating Jagged1/Notch signaling.

Tumor environmental signals such as hypoxia stimulates cancer cells to release the proangiogenic galectin-3, in order to increase the formation of new blood vessels. Due to changes in the glycosylation status triggered by hypoxia, galectin-3 secreted by cancer cells binds to endothelial cells and activates glycan-dependent circuits, including activation of VEFGR2 and the stabilization of Jagged1 over DLL4. Once sprouting begins, while VEGFR2 induces the expression of DLL4 in endothelial tip cells, galectin-3 limits DLL4-Notch signaling by decreasing DLL4 protein and increasing Jagged1-Notch1 interaction. Jagged1/Notch signaling then induces (1) migration of tip cells and (2) proliferation of stalk cells. This mechanism is in contrast to another mechanism of regulating the ratio of DLL4 over Jagged1 signaling via fringe, but both processes may be involved [1]. Mechanistically, galectin-3 can modulate this highly dynamic process: (1) by interfering with DLL4 and Jagged1 ratio; (2) enhancing Notch-ligand interaction and consequently Notch signaling activation; (3) inducing Jagged-1 endocytosis in order to make it a more effective ligand; or (4) stabilizing Jagged1 on the cell surface making it more available to interact with Notch receptor. 


\section{Supplemental Table}

\section{Table S1. Primer sequences}

\begin{tabular}{|c|c|c|}
\hline Primer & Forward 5' $-3^{\prime}$ & Reverse 5' $-3^{\prime}$ \\
\hline hGAPDH & AGCCACATCGCTCAGACAC & GCCCAATACGACGAAATCC \\
\hline hJagged-1 & GGAACCTAGAGCCGAACTCA & AGCCTTGTCGGCAAATAGC \\
\hline hHEY-1 & CGAGCTGGACGAGCCCAT & GGAACCTAGAGCCGAACTCA \\
\hline hHEY-2 & GTACCATCCAGCAGTGCATC & AGAGAATTCAGGGCATTT \\
\hline hDELTA-4 & CCCTGGCAATGTACTTGTGAT & TGGTGGGTGCAGTAGTTGAG \\
\hline hHES-1 & AGTGAAGCACCTCCGGAAC & CGTTCATGCACTCGCTGA \\
\hline hGAL-3 & TGTTTGCAATACAAAGCTGGA & GCAACCTTGAAGTGGTCAGG \\
\hline mACTIN & CTAAGGCCAACCGTGAAAAG & ACCAGAGGCATACAGGGACA \\
\hline mHEY-1 & CATGAAGAGAGCTCACCCAGA & CGCCGAACTCAAGTTTCC \\
\hline mHES-1 & ACACCGGACAAACCAAAGAC & CGCCTCTTCTCCATGATAGG \\
\hline mHEY-L & CTGAATTGCGACGATTGGT & GCAAGACCTCAGCTTTCTCC \\
\hline mHEY-2 & GTGGGGAGCGAGAACAATTA & GTTGTCGGTGAATTGGACCT \\
\hline mCD31 & CGGTGTTCAGCGAGATCC & ACTCGACAGCATGGAAATCAC \\
\hline
\end{tabular}




\section{Supplemental Experimental Procedures}

\section{Reagents}

Recombinant human Jagged1-His tagged protein (rhJagged1) was purchased from Sino Biological and recombinant human DIl4-His tagged (rhDLL4) and recombinant human Notch1-Fc tagged were obtained from R\&D Systems. To activate Notch signaling by rhJagged1, rhDLL4 or BSA (Sigma) 6 well plate were coated with $1 \mu \mathrm{g} / \mathrm{ml}$ rhJagged 1 or $1 \mu \mathrm{g} / \mathrm{ml}$ rhDLL4 or $1 \mu \mathrm{g} / \mathrm{ml} \mathrm{BSA}$ in PBS for $16 \mathrm{~h}$ at $4{ }^{\circ} \mathrm{C}$. The VEGFR inhibitor Vatalanib (Selleckchem) was dissolved in water and used at a concentration of $100 \mathrm{nM}$. The $\mathrm{y}$-secretase inhibitor dibenzazepine (Calbiochem) was dissolved in dimethyl sulfoxide and used at a concentration of $10 \mathrm{nM}$. Cycloheximide (Sigma) was dissolved in water and used at a concentration of 100nM. Biotinylated lectins Erythrina cristagalli (ECA), Phaseolus vulgaris (L-PHA), Sambucus nigra (SNA) and Maackia amurensis (MAL) were purchased from Vector Laboratories. Arachis hypogaea (PNA) was purchased from Sigma. Anti-cleaved Val1744 (NICD1), anti-Jagged1, anti-DLL4, anti-Notch1, anti-VEGFR2, anti-VEGFR$\mathrm{p}$ and anti-HIF1- $\alpha$ were from Cell Signaling; anti- $\beta$-actin-peroxidase from SigmaAldrich. Horseradish peroxidase (HRP)-conjugated secondary antibodies were purchased from DAKO. Anti-rabbit-Alexa-488 and streptavidin-Cy5 were from Invitrogen. DyLight-488 mAb labelling kit (catalogue no. 53025) was purchased from Thermo Fisher Scientific.

\section{Cell culture}

HUVECs (Lonza) were cultured in EGM-2 media supplemented with growth factors and $5 \%$ of fetal bovine serum (FBS) as provided in the EGM-2 Bullet Kit (Lonza). The cells between passages 2 and 6 were used. LLC (ATCC CRL-1642), MCF7 (ATCC HTB-22), MDA-MB-231 (ATCC HTB-26) tumor cells and sEnd-1 cell line, murine endothelial cells transformed by middle $T$ antigen of polyoma virus [2], 
were cultured in Dulbecco modified Eagle medium (DMEM, Gibco) supplemented with $10 \%$ of fetal bovine serum (FBS). For virus production, HEK293t cells (ATCC CRL-3216) and Phoenix amphotropic cells (ATCC CRL-3213TM) were used and cultured in DMEM and supplemented with 10\% FBS. Mycoplasma contamination in cultured cells was excluded by using Lonza Mycoplasma Detection Kit.

\section{Recombinant human galectin-3 and galectin-3C preparation}

Galectin-3 and galectin-3C were produced in Escherichia coli BI21/DE3 containing the pET11a plasmid with the human galectin-3 (hrGal-3) coding DNA or the C-terminal domain fragment of galectin-3 (hrGal-3C) (gift from Dr. Nozomu Nishi, Kagawa University, Japan) and purified by affinity chromatography on lactosylSepharose (Sigma) as previously described [3]. Lactose was removed by gelfiltration chromatography on desalting columns and contaminating LPS was eliminated by affinity chromatography on detoxi-gel beads (Pierce). The endotoxin levels were less than $0,1 \mathrm{EU}$ per $\mu \mathrm{g}$ of protein as determined by the $\mathrm{LAL}$ method (Lonza). Conjugation of hrGal-3 and hrGal-3C with DyLight488 was performed accordingly to manufacturer's instructions.

\section{Western Blotting}

Cells were lysed in RIPA buffer and $50 \mu \mathrm{g}$ of proteins were separated by Novex NuPAGE SDS-PAGE gel system (Invitrogen) and then transferred overnight to a PVDF membrane (Invitrogen). The membrane was incubated with Anti-cleaved Val1744 (NICD1) (1:1000), anti-Jagged1 (1:1000), anti-DLL4 (1:1000), anti-Notch1 (1:1000), anti-VEGFR2 (1:1000), anti-VEGFR-p (1:1000) and HIF1- $\alpha$ (1:1000). Anti$\beta$-actin-peroxidase $(1: 20,000)$ was used as a loading control. Horseradish peroxidase (HRP)-conjugated secondary antibodies were detected using the enhanced chemiluminescence $(E C L)$ reagent (GE Healthcare). 


\section{Flow cytometry}

For flow cytometry, MCF7, MDA-MB-231 and HUVEC cells were harvested and $1 \times 10^{6}$ cells were incubated with $1 \%$ BSA/PBS for 1 hour in at $4^{\circ} \mathrm{C}$. Next, cells were incubated with $1 \mu \mathrm{g}$ of the biotinylated lectins MAL-II, PNA, ECA, SNA or L-PHA for 1 hour. Subsequently cells were washed with PBS, and biotinylated lectins were detected with streptavidin-Cy5 for 45 min. After final washing, cells were fixed with $4 \%$ paraformaldehyde. Alternatively, cells were incubated with different doses ( $37 n M$, $370 \mathrm{nM}, 925 \mathrm{nM}, 1.85 \mu \mathrm{M})$ of DyLigth 488 labelled-hrGal-3 or DyLigth 488 labeledhrGal-3C in the presence or absence of lactose $(50 \mathrm{mM})$ for 1 hour and fixed in $4 \%$ paraformaldeyde. Analysis was made using the flow cytometer CyAn TM ADP Analyzer from Beckman Coulter. Data were subsequently evaluated with FlowJo vX 0.7 software

\section{Generation of Jagged1 overexpressing HUVECs}

Stable HUVEC control or overexpressing the full length Jagged1, were generated after co-transfection of $30 \mu \mathrm{g}$ of empty vector-containing pLenti6.2-V5 plasmid or full length Jagged1 cDNA-containing pLenti6.2-V5 plasmid with $15 \mu \mathrm{g}$ pPAX2 and 5 $\mu \mathrm{g}$ of pMDG.2 (Addgene) into HEK293t packaging cell line utilizing $\mathrm{CaCl}_{2}$ method. The viral supernatant was recovered and the transduced cells were generated by infection with $6 \mathrm{MOI}$ (multiplicity of infectious units) of lentiviral particles. On the next day, cells were replaced with fresh medium, and a day later, cells were selected with $5 \mu \mathrm{g} / \mathrm{mL}$ of Blasticidin for 1 week. Jagged1 expression was confirmed by Western blot and Real-time PCR.

\section{Sprouting angiogenesis assay}

HUVEC spheroids (500 cells) were generated by the hanging-drop method [4]. Alternatively, $24 \mathrm{~h}$ after transfection of 3 different siRNA against Jagged1 or DLL4 
or scrambled, HUVEC spheroids were generated. Briefly, cells were harvested and resuspended in culture medium containing $0.20 \%(\mathrm{wt} / \mathrm{vol})$ methylcellulose and seeded on the inside face of the lid of a $150 \mathrm{~mm}$ culture dish (Corning). $16 \mathrm{~h}-24 \mathrm{~h}$ later, spheroids were collected and embedded into $500 \mu \mathrm{L}$ of $2,5 \mathrm{mg} / \mathrm{mL}$ fibrinogen solution (Sigma) containing 0,15 Units $/ \mathrm{mL}$ of aprotinin (Sigma). After polymerization, spheroids were cultured for $24 \mathrm{~h}$ in the presence of EGM2 medium and growth supplements. In a set of experiments, after polymerization, MCF7 scramble and galectin-3 silenced were cultured on the top of the gel. Afterward, angiogenesis was quantified by counting the number of sprouts and the length of sprouts for each spheroid ( 30-50 spheroids). Additionally, cells were pre-labeled with viable fluorescent dyes according to manufacturer's protocol (cell tracker green and red, Invitrogen). Spheroids were generated after mixing control and galectin-3 (370nM) treated cells in a 1:1 ratio and both color combinations were analyzed. Spheroids were then embedded into $200 \mu$ l of fibrinogen solution and plated on a glass-bottom dishes (MatTek). After 24h, spheroids were fixed over night at $4^{\circ} \mathrm{C}$ in $4 \%$ formaldehyde/PBS and pictures of the sprouts were taken using an inverted microscope (Zeiss Axiovert 200M). The number of tip cells of each color was counted.

\section{Generation of MCF7 galectin-3 knockdown cells}

Stable shRNA MCF7 cell line targeting galectin-3 (TRCN0000029305, Sigma) and negative control (SHC016, Sigma) were generated after co-transfection of $30 \mu \mathrm{g}$ of shRNA-containing plasmids with $15 \mu \mathrm{g}$ pPAX2 and $5 \mu \mathrm{g}$ of pMDG.2 (Addgene) into HEK293t packaging cell line utilizing $\mathrm{CaCl}_{2}$ method. The viral supernatant was recovered and the transduced cells were generated by infection with $2 \mathrm{MOI}$ (multiplicity of infectious units) of shRNA lentiviral particles. On the next day, cells were replaced with fresh medium, and a day later, cells were selected with $2 \mu \mathrm{g} / \mathrm{mL}$ of puromycin for 1 week. Galectin-3 knockdown (shRNA-Gal-3) and negative control 
(scramble) cells were generated and subjected to Western blot and mRNA quantification to investigate galectin-3 expression.

\section{Immunofluorescence analysis}

HUVEC cells were plated in a 24 well glass bottom plate at a density of $2 \times 10^{4}$ overnight. The next day, control cells were fixed with methanol. The remaining cells were incubated with hrGal-3-DyLight488-label for 1 hour. Unbound galectin-3 was washed away with PBS and cells were fixed with methanol. Fixed cells were hydrated with PBS and blocked with $1 \%$ of bovine serum albumin (BSA, Sigma) for 1 hour and incubated with the indicated primary antibody (1:100) in BSA for 1 hour. After washing, primary antibodies were detected with anti-rabbit-Alexa-488 (1:200) in BSA for 1 hour and pictures of the cells were taken using an inverted microscope (Zeiss Axiovert 200M).

\section{Determination of Jagged1 and DLL4 half-life}

To assess protein stability, HUVECs were incubated with $37 \mathrm{nM}$ of hrGal-3 for 15 min. After that period, the growth medium was replaced with medium containing $0.1 \mathrm{mM}$ of cycloheximide to stop protein biosynthesis. Cells were treated for 0 to 8 hours and then collected for western blotting. ImageJ software was used to quantify western blot bands.

\section{Jagged1 and DLL4 siRNA transfection}

HUVECs were transfected at $60 \%$ of confluency with Jagged1 or DLL4 specific siRNAs and negative control (scramble) (Ambion, Life Technologies) at a final concentration of $20 \mathrm{nM}$ using RNAiMAX reagent (Invitrogen) in Opti-MEM I reduced serum medium (Invitrogen). After 6h, transfection medium was replaced by complete EGM-2 medium. Cells were collected for western blot and Real-time analysis after $48 \mathrm{~h}$ of inhibition. 


\section{Treatment of HUVECs with MCF7 cells conditioned medium}

MCF7 cells previously transduced with lentiviral particles containing shRNA against galectin-3 or scrambled, were cultured under normoxic or hypoxic conditions for $48 \mathrm{~h}$. After this period, the conditioned medium was incubated with HUVECs $\left(10^{6}\right)$ for 6 hrs. Total RNA was extracted for real time PCR analysis. Galectin-3 from the conditioned medium was quantified by ELISA.

\section{In vivo studies}

Lgals $3^{+/+}$and Lgals $^{-/-}$mice were bred at the animal facility of FMUSP and all experiments complied with the relevant laws and were approved by local animal ethics committees. Empty vector (LLC-EV), murine Jagged-1 overexpressing (LLCJG1) or murine DLL4 overexpressing (LLC-DLL4) Lewis Lung carcinoma cells (LLC) were kindly provided by $\mathrm{Dr}$ Ji-Liang Li (University of Oxford, UK). Briefly, the murine Lewis Lung carcinoma cells (LLC) were transduced with retrovirus containing fulllength mouse Jagged-1 or Dll4 or empty vector as previously described [5]. Retroviral supernatants were prepared using the bicistronic pLZRS-IRES-GFP plasmid with the Phoenix amphotropic packaging cell line.

Six- to 8-week-old male wild type (WT) or Lgals $3^{-1-}$ C57BL/6 mice were implanted subcutaneously with $10^{6}$ LLC-EV or LLC-JG1 or LLC-DLL4 cells. Each group consisted of five mice. When tumors reached the size $1-1.5 \mathrm{~cm}^{3}$ volume, mice were sacrificed and tumors were excised for immunohistochemical analysis and for RNA extraction. Each animal experiment was repeated at least 3 times.

\section{Immunostaining}

Tissue sections were deparaffinized in xylene and rehydrated in serial alcohol dilutions. Tissue sections were stained with hematoxylin and eosin or with Ki67 rabbit anti-Ki67 antibody (Vector Laboratories) followed by a secondary anti-rabbit biotinylated antibody (Vector Laboratories). Next, streptavidin-peroxidase (Sigma) 
was added and color development was done with DAB (DAKO). Nuclei were counterstained with hematoxylin. Percentage of Ki-67 expressing cells was determined by counting using TMARKER software at a magnification of 200-fold [6].

\section{Statistical Analysis}

All data are expressed as the mean \pm SEM of at least three independent experiments. Statistical analysis including t-test, one-way ANOVA and two-way ANOVA were done using GraphPad Prism 6.0 software. $p<0.05$ was considered statistically significant.

\section{Supplemental references}

1. Benedito R, Roca C, Sorensen I, Adams S, Gossler A, Fruttiger M, et al. The notch ligands DII4 and Jagged1 have opposing effects on angiogenesis. Cell. 2009 Jun 12;137(6):1124-35

2. Williams RL, Courtneidge SA, Wagner EF. Embryonic lethalities and endothelial tumors in chimeric mice expressing polyoma virus middle T oncogene. Cell. 1988 Jan 15;52(1):121-31.

3. Hsu DK, Zuberi RI, Liu FT. Biochemical and biophysical characterization of human recombinant IgE-binding protein, an S-type animal lectin. The Journal of biological chemistry. 1992 Jul 15;267(20):14167-74.

4. Korff T, Augustin HG. Integration of endothelial cells in multicellular spheroids prevents apoptosis and induces differentiation. The Journal of cell biology. 1998 Nov 30;143(5):1341-52.

5. Raval RR, Lau KW, Tran MG, Sowter HM, Mandriota SJ, Li JL, et al. Contrasting properties of hypoxia-inducible factor 1 (HIF-1) and HIF-2 in von Hippel-Lindau-associated renal cell carcinoma. Molecular and cellular biology. $2005 \mathrm{Jul} ; 25(13): 5675-86$.

6. $\quad$ Schuffler PJ, Fuchs TJ, Ong CS, Wild PJ, Rupp NJ, Buhmann JM. TMARKER: A free software toolkit for histopathological cell counting and staining estimation. Journal of pathology informatics. 2013;4(Suppl):S2. 
Chapter 3 


\section{Chapter}

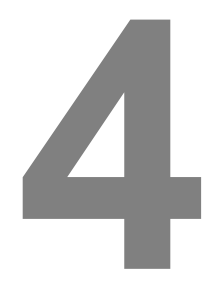

O-glycan sialylation alters galectin-3 subcellular

localization and decreases chemotherapy sensitivity

in gastric cancer 



\section{Abstract}

ST6GaINAc-I, the sialyltransferase responsible for Sialyl-Tn (STn) synthesis, has been previously reported to increase motility and invasion of cancer cells. However, the mechanisms by which aberrant expression of STn affect tumor progression remain elusive. Using a human gastric carcinoma cell line transfected with the full length of ST6GalNAc-I we found that STn expression protected gastric cancer cells against chemotherapeutic-induced cell death and increased xenograft tumor growth. Overexpression of STn decreased cell surface galectin-3-binding sites both in vitro and in vivo, leading to a decrease in galectin-3 cell surface levels and to an increase in galectin-3 intracellular accumulation. Exogenously added galectin-3 potentiated chemotherapeutics-induced cytotoxicity, which was dependent on galectin-3 carbohydrate recognition domain and its ability to form oligomers. STn overexpressing cells were protected from the enhancing effect of galectin-3-mediated cell death, which was associated, at least in part, to the intracellular accumulation of galectin-3 in STn-expressing cells. Corroborating our in vitro data, the expression of galectin-3 binding sites was negatively correlated with the sialyl-Tn levels in human gastric cancer samples. Our results clearly demonstrate an association between Oglycosylation changes and resistance to chemotherapeutic drugs, thus highlighting a need for the development of novel strategies to target intracellular galectin-3. 


\section{Introduction}

Modification of cell surface glycosylation is a common feature of cancer cells, including gastric cancer [1] and comprises one of the first steps in progression, invasion and the metastatic processes [2, 3]. The overexpression of tumorassociated carbohydrate antigens and the expression of new carbohydrate antigens (oncofetal antigens) are commonly used in the clinic as tumor markers [4, 5]. The synthesis of highly sialylated glycans is the most frequent alteration associated with tumor development and originates premature termination of the biosynthesis and expression of incomplete glycans forms (truncated) [6]. These modifications are frequently associated with changes in sialyltransferase expression. ST6GalNAc-I is the sialyltransferase responsible for the synthesis of sialyl-Tn (STn) [7], a glycan structure that cannot be further processed, and blocks the posterior elongation of the O-glycan chains [8].

The STn antigen is highly expressed in most gastric[9], colorectal [10], ovarian [11], breast [12] and pancreatic carcinomas [13] whereas no expression is observed in the respective normal tissues. The positive correlation of STn with carcinoma aggressiveness and poor prognosis has motivated the research on sialylTn role in cancer cell biology. Indeed, it was found that STn antigen is able to induce a more aggressive cell behavior, such as decreased cell-cell aggregation and increased ECM adhesion, migration and invasion [9]. Sialyl-Tn was also found to be responsible for morphological changes, impaired proliferation, and decreased migration on fibronectin and hyaluronic acid strata in a mouse mammary carcinoma cell line [14]. Furthermore, in a murine model, the overexpression of STn in gastric cancer cells increased their intraperitoneal metastatic ability resulting in shortened survival time of the mice [15]. Although the exact mechanism is not known, the aberrant expression of STn may favor tumor progression by modulating the interaction of glycan receptors with glycan-binding proteins. 
Galectin-3 (gal-3) belongs to a family of glycan-binding proteins that binds a wide array of glycan-containing glycoproteins expressed on the cell surface, thus regulating the activation status of the cell [16]. Similar to ST6GalNAc-I, gal-3 plays an important role in cancer biology. It has been reported that gal-3 expression is upregulated in tumor cells including breast [17], colon [18], pancreatic [19], thyroid [20] and gastric [21] when compared to normal cells. The alteration of gal-3 expression is correlated with tumor aggressiveness and acquisition of a metastatic phenotype, indicating that gal-3 is able to modulate tumor development and influence the progression of the disease.

Galectin-3 functions through both intracellular and extracellular mechanisms. Intracellularly, gal-3 protects cells against apoptosis through carbohydrateindependent mechanisms. On the other hand, upon binding to cell surface glycans gal-3 has a pro-apoptotic role and modulates cell signaling and cell-matrix interactions [22]. It has been described that gal-3 binds preferentially to unsialylated proteins in comparison with $\alpha 2-6$-sialylated present on $\mathrm{N}$-glycans, which provides a mechanism for blocking the pro-apoptotic effects of secreted gal-3 [23]. However, no studies addressing the role of O-glycans sialylation on gal-3 binding and function have been described so far. In the present study we demonstrated that the overexpression of STn led to a decrease in gal-3 binding sites in cancer cells and an increase in the intracellular levels of gal-3, which can account for the chemotherapeutic resistance observed in STn-expressing tumor cells. Although exogenously add gal-3 did not induce tumor cell death, it shows a potentiating effect on drug-induced cell death. These findings were further validated in human gastric cancer samples, showing that gal-3 binding sites expression correlated negatively with sialyl-Tn levels. Our results suggest that STn aberrant expression in O-glycans increases gastric carcinoma cells drug resistance by shifting gal-3 localization. 


\section{Results}

\section{Overexpression of ST6GalNAc-I leads to Sialyl-Tn expression and confers resistance to chemotherapeutic drugs in MKN45 gastric cancer cells}

In order to evaluate the susceptibility of STn-expressing tumor cells to chemotherapeutic drugs, we used a human gastric carcinoma cell line (MKN45), transfected with the full length of ST6GalNAc-I or empty vector (Mock) [8]. First, we confirmed that only ST6GalNAc-I-transfected cells and not Mock displayed STn antigen as observed by western blot analysis (Figure 1A). Mock and STnoverexpressing cells were then treated with $12.5 \mu \mathrm{M}$ of cisplatin and flow cytometry analysis showed that Mock cells exhibited increased activation of caspase-3/7 in response to cisplatin in comparison with STn-expressing cells (Figure 1B). Mock or STn-expressing cells were treated with increasing doses of cisplatin or 5-fluorouracil (5-FU) and we found that STn-expressing cells were more resistant to the cytotoxic effect of cisplatin and 5-FU than Mock cells, with IC50 values of $5.8 \mu \mathrm{M}$ (cisplatin) and $152 \mu \mathrm{M}$ (5-FU) for STn-expressing cells and $3.5 \mu \mathrm{M}$ (cisplatin) and $25 \mu \mathrm{M}(5-\mathrm{FU})$ for Mock cells (Figures 1C-1F). Additionally, Mock or STn-expressing cells were grown into spheroids, which replicate important features of tumors in vivo, and treated with cisplatin once spheroids reached approximately a volume of $0.5 \mathrm{~mm}^{3}$. Although Mock cells formed significantly bigger spheroids than STn-expressing cells, Mock spheroids presented a significant volume reduction in the presence of cisplatin compared to STn-expressing spheroids (Figures $1 \mathrm{G}$ and $1 \mathrm{H}$ ). These results suggest that STn-expressing cells are more resistant to chemotherapeutic drugs (Cisplatin and 5-FU) than Mock cells. 
A

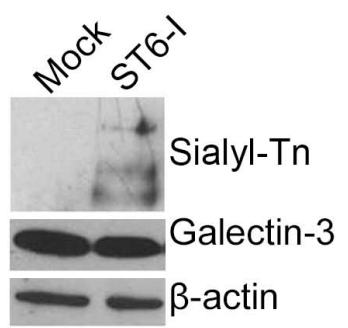

C

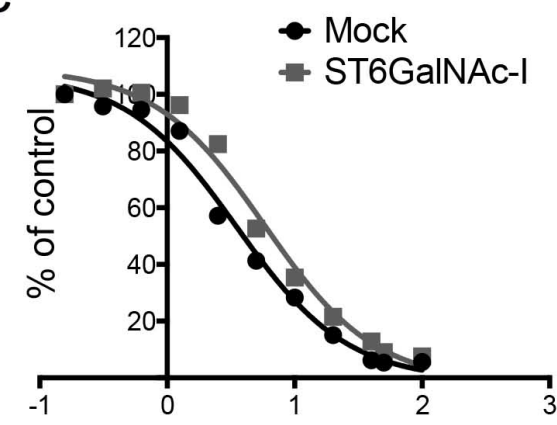

E

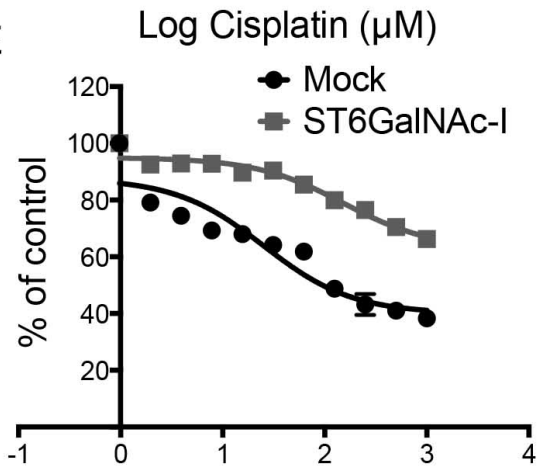

$\log 5-\mathrm{FU}(\mu \mathrm{M})$

G

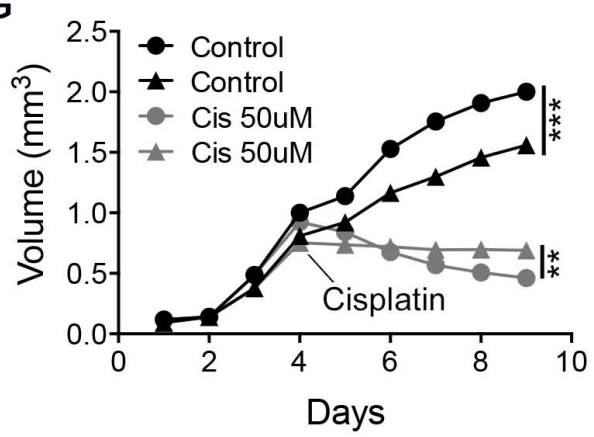

Mock

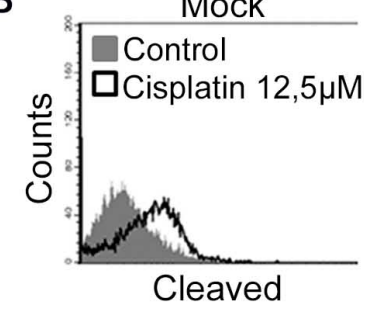

Caspase 3/7

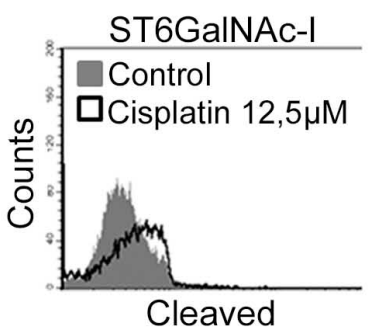

Caspase 3/7
D

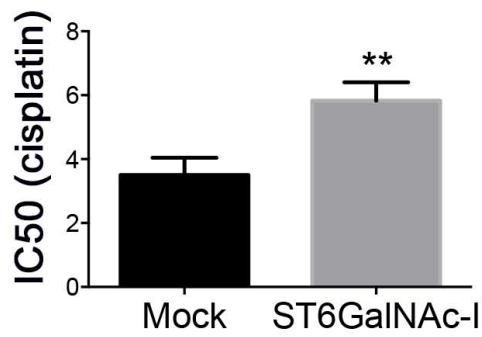

$\mathrm{F}$

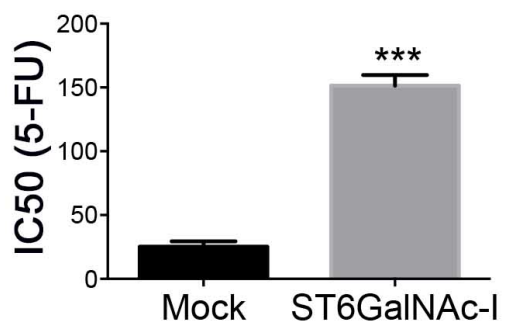

$\mathrm{H}$

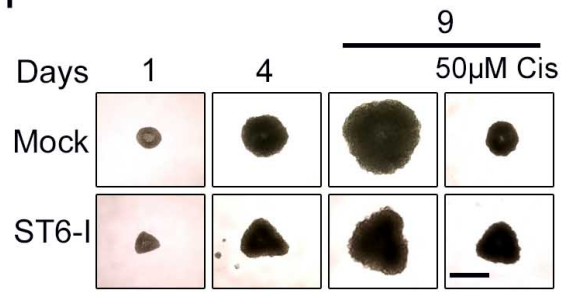

Figure 1. Sialyl-Tn confers chemotherapeutic resistance.

(A) Immunoblot of sialyl-Tn and galectin-3 in Mock and STn-expressing cells. $\beta$-actin was used as a loading control.

(B) Flow cytometry analysis of caspase 3/7 activation in Mock and STn-expressing cells undergoing apoptosis by treatment with cisplatin $(12.5 \mu \mathrm{M})$.

(C-F) SRB assay showing the cells viability under the treatment of cisplatin (C) or 5-FU (E) and determined as a percentage of viable cells relative to control (cells with no drug treatment). ( $D$ and $F$ ) Average of IC50 values.

( $G$ and $H$ ) (G) Growth curve of Mock (circule) or STn-expressing (triangule) cells spheroids. Cisplatin $(50 \mu \mathrm{M})$ was added to spheroid culture and day 4 and the spheroid volume was measured until day 9 . (H) Representative images of MKN45 spheroids at day 1, 4 and 9, Bar=400 $\mu \mathrm{m})$.

Data are representative $(A, B$ and $H)$ or are the mean \pm SEM $(C-G)$ of three experiments, ${ }^{* *} p<0.01$, ${ }^{* * *} p<0.001$. 


\section{Sialyl-Tn expression reduces the availability of galectin-3 binding sites on the cell surface}

Interestingly, Mock cells treated with cisplatin displayed increased cell surface and supernatants levels of galectin-3 (Figures 2A-2D and Figures S1A an S1B) in comparison with STn-expressing cells. Moreover, by immunofluorescence microscopy we observed that Mock cells presented gal-3 mainly on the cell surface and cytoplasm whereas in STn-expressing cells, gal-3 was localized preferentially in the cytoplasm (Figure 2E). Since cell surface gal-3 has been reported to have a proapoptotic role [23], we next evaluated the mechanism by which the expression of STn could reduce gal-3 binding sites on the cell surface. After incubating Mock or STn-expressing cells with Gal-3-Dy488 in the presence or absence of lactose (a competitive gal-3 CRD inhibitor), we found that STn-expressing cells displayed a substantial reduction in gal-3-binding sites compared to Mock cells as observed by flow cytometry analysis (Figure 2F) and immunofluorescence microscopy (Figure $2 \mathrm{G})$. Surprisingly, no changes in the total level of endogenous gal-3 were observed between Mock and STn-expressing cells by flow cytometry analysis (Figure S1C) or RT-PCR (Figure S1D). Taken together, these data indicate that the overexpression of STn reduces the availability of gal-3 binding sites in vitro and results in a cell surface to intracellular shift of gal-3 expression. 

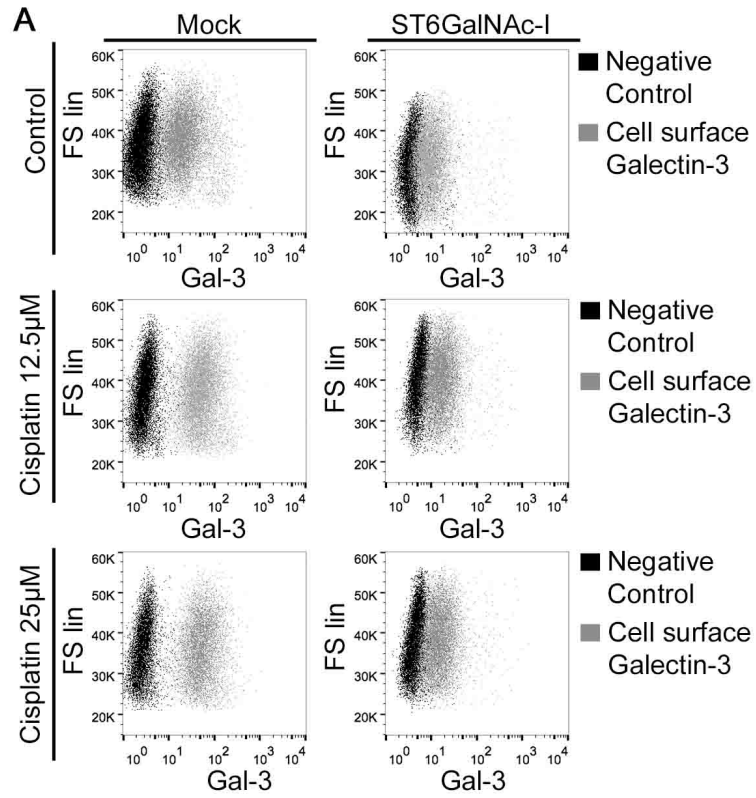

D

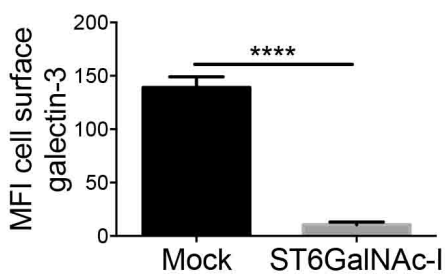

$\mathrm{F}$

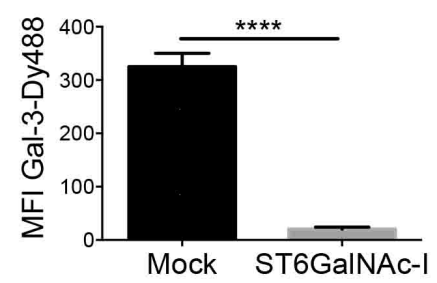

$\mathrm{E}$

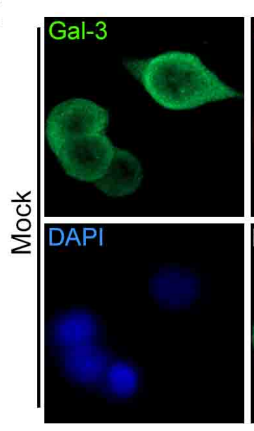

G
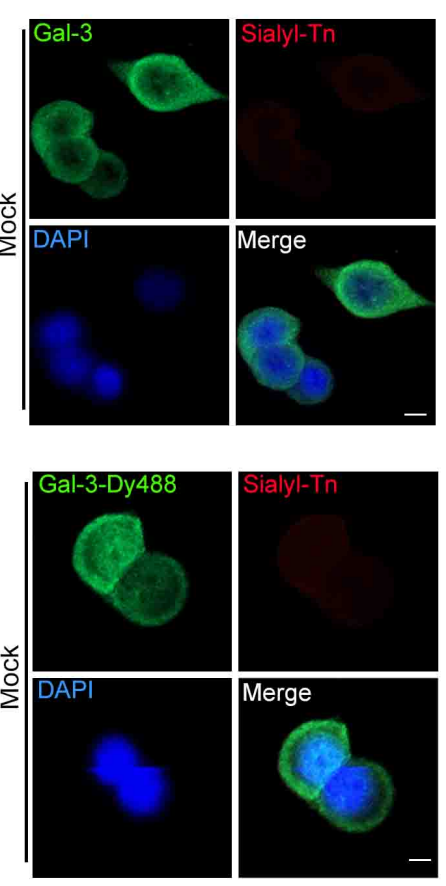

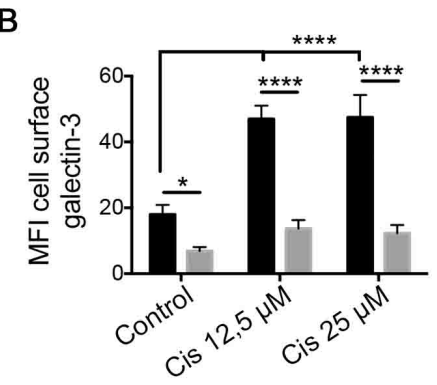

-Mock

- ST6GalNAc-I
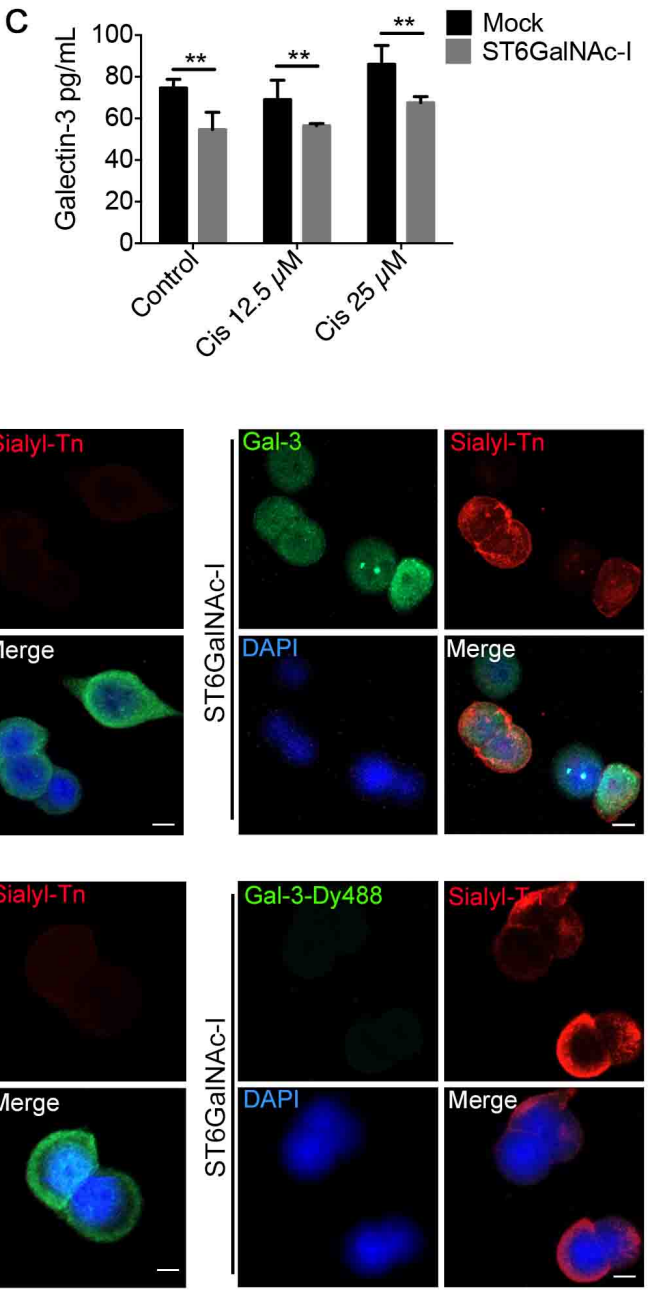

Figure 2. Sialyl-Tn inhibits galectin-3 binding to cellular surface.

(A and B) (A) Flow cytometry analysis of Mock and STn-expressing cells stained with anti-galectin-3 antibody after cultured in the presence of cisplatin $(12.5 \mu \mathrm{M}$ and $25 \mu \mathrm{M})$ and $(B)$ mean fluorescence intensity (MFI) due to galectin-3 staining.

(C) Quantification by ELISA of galectin-3 in culture supernatants of Mock and STn-expressing cells treated with cisplatin ( $12.5 \mu \mathrm{M}$ and $25 \mu \mathrm{M}$, as indicated) for $48 \mathrm{~h}$.

(D) Mean fluorescence intensity (MFI) of cell surface galectin-3 in Mock and STn-expressing cells.

(E) Representative immunofluorescence images of Mock and STn-expressing cells stained with antigalectin-3 and anti-sialyl-Tn antibodies (Bar=5 $\mu \mathrm{m}$ ).

(F) Mean fluorescence intensity (MFI) of galectin-3 binding sites by using Gal-3Dy488 staining in Mock and STn-expressing cells.

(G) Representative immunofluorescence images of Mock and STn-expressing cells stained with Gal-3Dy488 and anti-sialyl-Tn antibody (Bar=5 $\mu \mathrm{m})$.

Data are representative of three independent experiments (A, D-G), or are the mean \pm SEM (B and $C$ ), ${ }^{*} p<0.05 ;{ }^{* *} p<0.01 ;{ }^{* * *} p<0.0001$. See also Figure S1. 


\section{Sialyl-Tn-expressing tumor xenografts have an increased growth}

\section{rate and reduced galectin-3 binding sites}

We subsequently explored whether the inverse correlation between STn and galectin-3 binding sites was maintained when tumor cells are subjected to microenvironment variations. We thus inoculated Mock or STn-expressing cells subcutaneously in Balb/c nude mice and observed that STn-expressing tumors had a significantly higher growth rate than Mock-derived tumors (Figure 3A). At the end of the experiment (day 20) tumors were collected and no differences were found between Mock and STn-derived tumors with regard to gal-3 mRNA levels (Figure 3B) or protein expression assessed by immunohistochemical staining (Figure 3C).

A

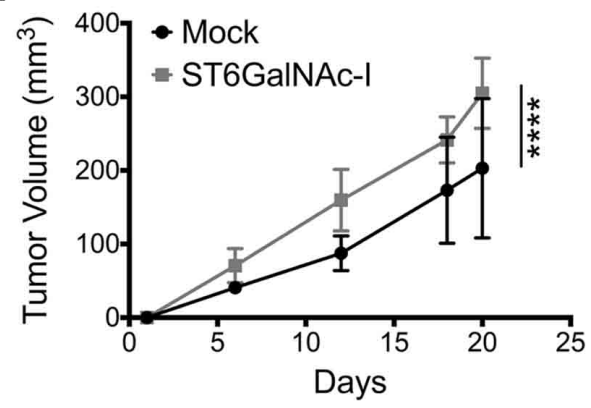

B

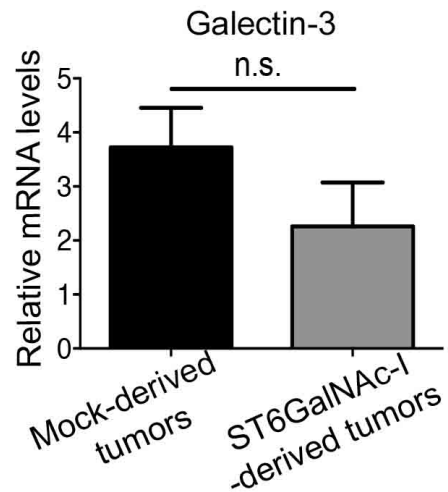

C
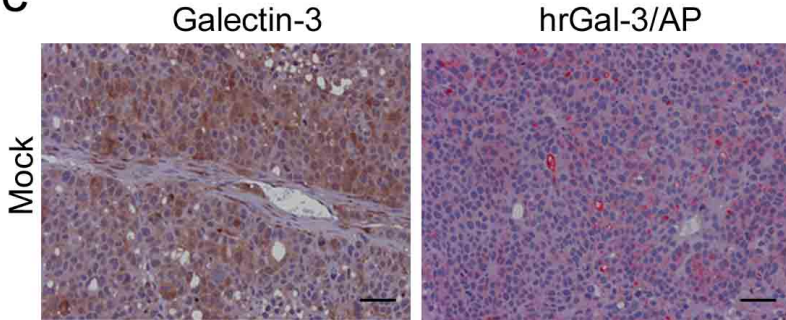

Sialyl-Tn

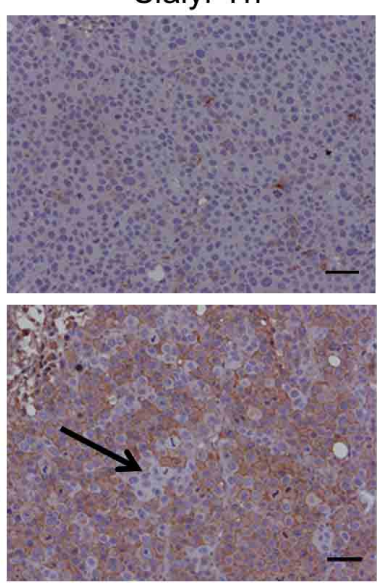

Figure 3. Sialyl-Tn increases tumor growth and decreases galectin-3 binding sites in vivo.

(A) Tumor growth of Mock and ST6GalNAc-I overexpressing cells in Balb/c nude mice.

(B) mRNA levels of galectin-3 in Mock and ST6GalNAc-I derived tumors. Values are normalized to $\beta$ actin mRNA expression.

(C) Immunohistochemical staining of galectin-3, galectin-3 binding sites (hrGal-3/AP) and sialyl-Tn in Mock and ST6GalNAc-I-derived tumors. Black arrows show no co-localization of galectin-3 binding sites with sialyl-Tn. Representative images are shown, bar $=20 \mu \mathrm{m}$.

Data are the mean + SEM (A and B), $n=3$, or are representative of three independent experiments, five animals per group $(C) .{ }^{* * *} p<0.0001$. 
Furthermore, using a human recombinant gal-3 protein fusioned with bacterial alkaline phosphatase (hrGal3/AP) we found that gal-3-binding sites were lower in STn-derived tumors in comparison to Mock (Figure 3C). Interestingly, we observed that cells expressing STn were unable to bind hrGal-3/AP and the opposite was also true (shown by arrows in Figure 3C). Thus, STn expression confers a selective growth advantage to the tumors, which was associated to a reduced availability of gal-3 binding sites in vivo.

\section{Cell surface galectin-3 increases the anticancer activity of chemotherapeutic drugs}

Subsequently, we treated Mock and STn-expressing cells with recombinant human gal-3 $(2 \mu \mathrm{M})$ and found that gal-3 treatment alone had no effect on cell viability (Figure 4A), the ability to form colonies (Figure 4B) or on the cleavage of PARP and phosphorylation of $\mathrm{H} 2 \mathrm{AX}(\mathrm{Y}-\mathrm{H} 2 \mathrm{AX})$ (Figure $4 \mathrm{C})$ in Mock and STnexpressing cells. However, the combination of both gal-3 and cisplatin led to a significant increase in the percentage of cell death (Figure 4A), reduction in the number colonies (Figure 4B) and increased PARP cleavage and $\mathrm{y}-\mathrm{H} 2 \mathrm{AX}$ phosphorylation (Figure 4C), in Mock cells in comparison to cisplatin alone, whereas no changes were observed in STn-expressing cells. The potentiating effect of galectin-3 on cellular death was inhibited by lactose and therefore, dependent on gal3 carbohydrate binding domain. We next evaluated the survival of Mock or STnexpressing cells treated with cisplatin or $5-\mathrm{FU}$ in the presence of gal-3 or its $\mathrm{N}$ terminally truncated form (gal-3C). Mock cells incubated with gal-3 displayed a higher susceptibility to the cytotoxic effect of cisplatin (Figure 4D and Figures S2A and S2B) or 5-FU (Figure 4E and Figures S2C and S2D) as compared to cisplatin treatment alone. Contrastingly, gal-3C did not affect cisplatin or 5-FU cytotoxic effect in Mock cells. Neither gal-3 nor gal-3C had any influence on the cytotoxic effect of cisplatin 
and 5-FU in STn-expressing cells (Figure 4D and 4E). Our results demonstrate that although extracellular gal-3 does not directly induce cells death, it increases chemotherapeutic treatment induced effects in cells bearing gal-3 binding sites.

A

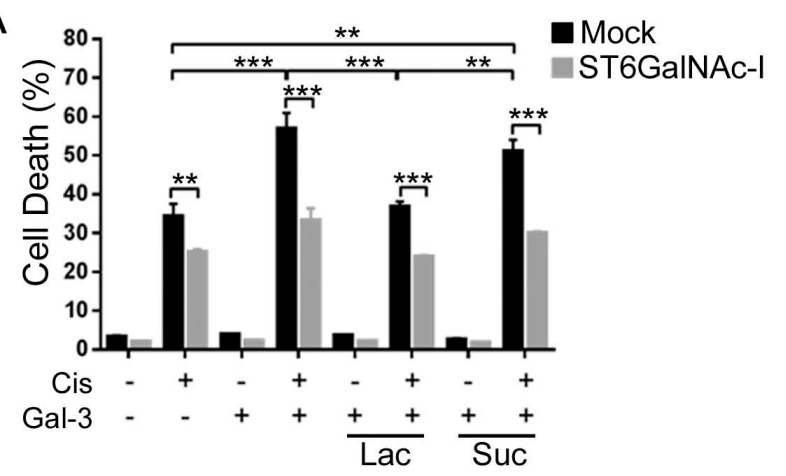

C

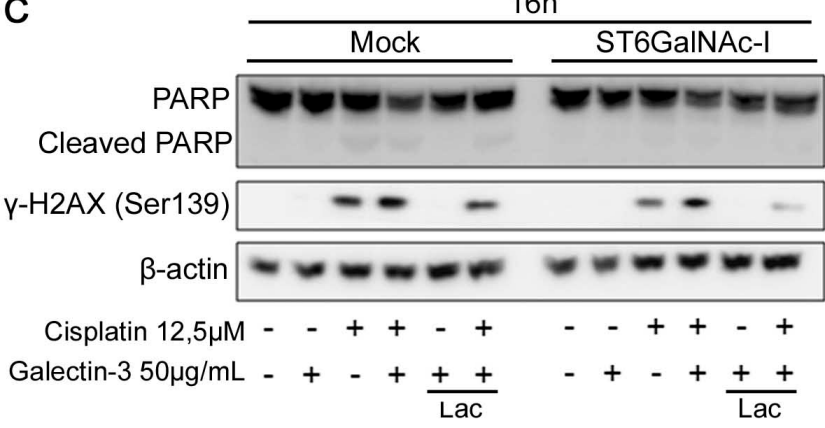

B

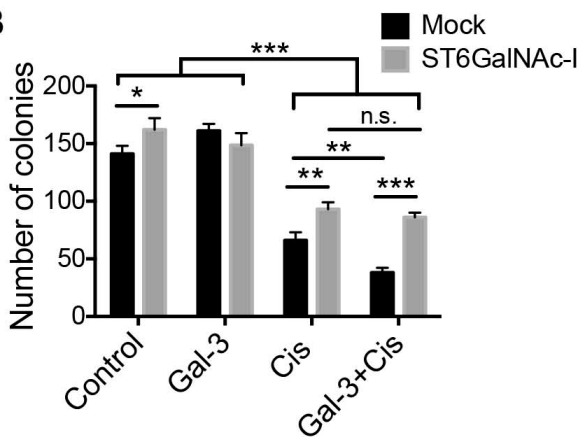

D

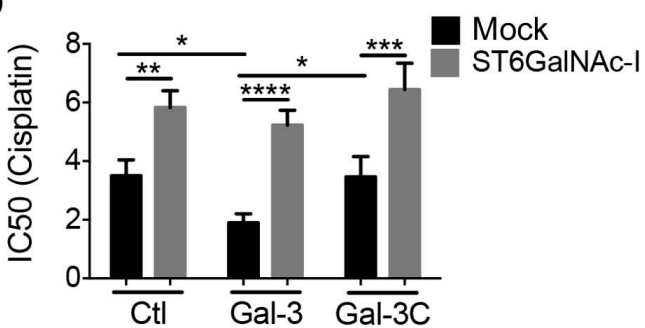

E

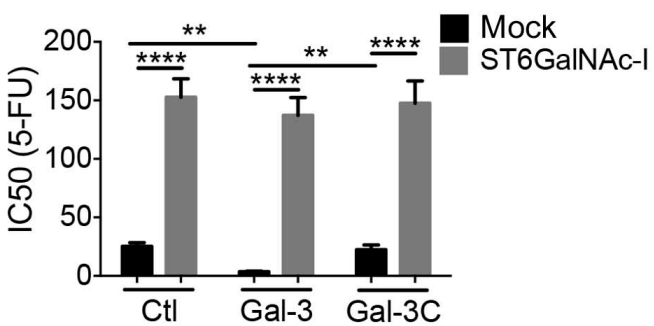

Figure 4. Galectin-3 increases Mock cells susceptibility to cisplatin.

(A) Quantification of \% of cell death by measuring propidium iodide incorporation, assessed by flow cytomety, in Mock and STn-expressing cells cultured for $48 \mathrm{~h}$ with cisplatin and galectin-3 in the presence or absence of lactose.

(B) Clonogenic assay of Mock and STn-expressing cells after cultured for $48 \mathrm{~h}$ with cisplatin and galectin-3.

(C) Immunoblot of PARP, cleaved PARP and $\mathrm{y}-\mathrm{H} 2 \mathrm{AX}$, as indicated, in Mock and STn-expressing cells cultured with cisplatin and galectin-3 in the presence or absence of lactose for $16 \mathrm{~h}$ and $24 \mathrm{~h}$. $\beta$-actin was used as a loading control.

(D and E) IC50 values for Mock and STn-expressing cells cultured 48h with (D) cisplatin or (E) 5-FU in the presence or absence of gal-3 or gal-3C.

Data are the mean $\pm S E M, n=3(A, B, D$ and $E)$ or are representative of three independent experiments (C). ${ }^{*} p<0.05,{ }^{* *} p<0.01,{ }^{* * *} p<0.001,{ }^{* * *} p<0.0001$. See also Figure S2. 


\section{Intracellular galectin-3 protects cells from cisplatin induced cell}

\section{death}

Since cytoplasmic galectin-3 has an important role in protecting cells against apoptosis [22], we subsequently downregulated gal-3 in Mock and STn-expressing cells using shRNA for gal-3 (Figure 5A). Downregulation of gal-3 had no effect on cisplatin-induced cell death in Mock cells (Figure 5B). On the other hand,

A
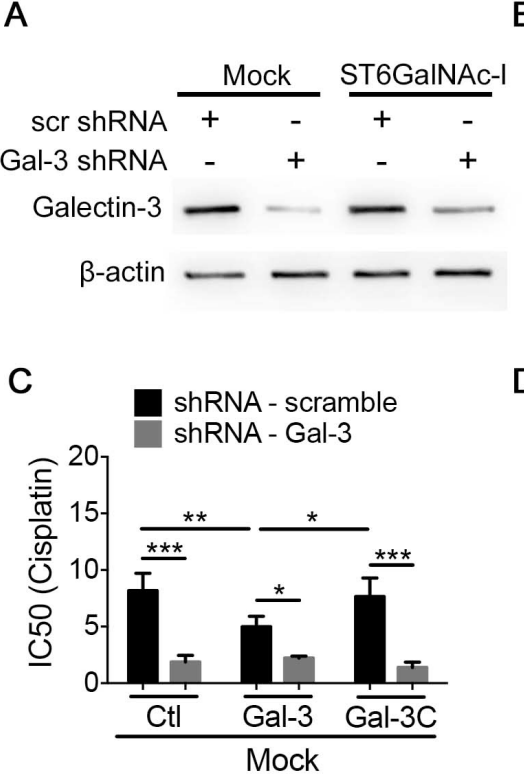

E

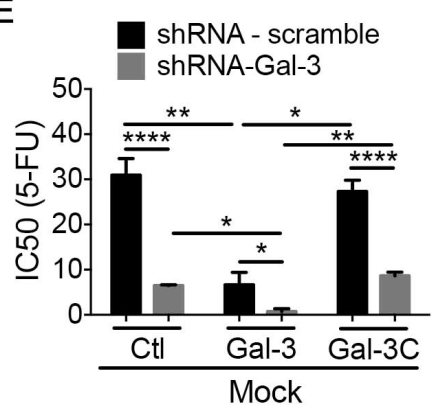

B

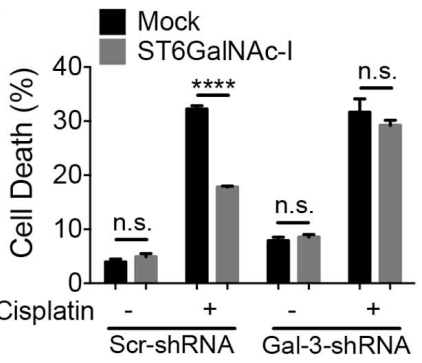

D

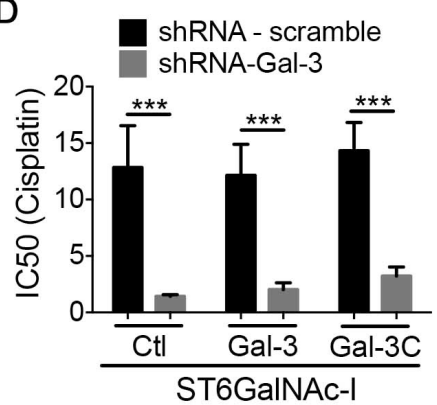

F

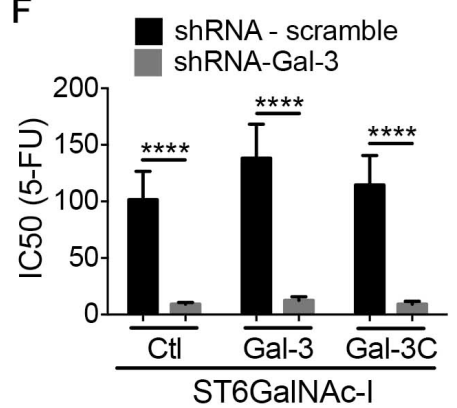

ST6GaINAc-I-shRNA-

Gal-3 cells presented an increased percentage of cell death, similar to Mock levels, when treated with cisplatin. We further evaluated cisplatin and 5-FU cytotoxicity in the presence of gal-3 or gal$3 \mathrm{C}$ and showed that gal3 inhibition significantly increased cisplatin (Figures 5C-5D and S3)

Figure 5. Intracellular galectin-3 protects cells from and 5-FU (Figures 5Echemotherapeutic-induced cytotoxicity.

(A) Immunoblot of galectin-3 in Mock and STn-expressing cells transduced with viral particles containing scrambled or shRNA-Gal-3. $\beta$-actin was used as a loading control.

(B) Quantification of \% of cell death after culturing Mock and ST6GalNAc-I with cisplatin $(12.5 \mu \mathrm{M})$ for $48 \mathrm{~h}$. Cells were assayed by propidium iodide and flow cytometry.

(C-F) IC50 values for Mock and STn-expressing cells transduced with viral particles containing scrambled or shRNA-Gal-3 after culture with cisplatin $(C$ and $D)$ or $5-F U(E$ and $F)$ and galectin-3 or galectin-3C.

Data are representative of three independent experiments $(\mathrm{A})$, or are the mean \pm SEM, $n=3(B-F) .{ }^{*} p<0.05,{ }^{* * *} p<0.001,{ }^{* * * *} p<0.0001$. See also Figure $\mathrm{S} 3$.

combination of gal-3 with cisplatin or 5-FU led to an IC50 reduction in Mock- 
Chapter 4

scrambled cells in comparison to chemotherapeutic treatment alone, whereas no effect was observed in gal-3-silenced cells. Galectin-3C had no effect on both scrambled-or gal-3-silenced Mock cells. Gal-3 or gal-3C did not alter the IC50 dose of cisplatin or 5-FU in STn-expressing cells (Figures 5D-5F). Collectively, our results suggest that overexpression of STn leads to an increase in cytoplasmic galectin-3 expression, which results in resistance to drug-induced apoptosis.

\section{Expression of sialyl-Tn is associated with a reduction in galectin-3} binding sites in human gastric tumors

We further evaluated whether the negative correlation between STn expression and galectin-3 binding sites could be found in the normal adjacent mucosa, intestinal metaplasia (IM), tumor and associated metastasis in human gastric samples. Gastric samples were classified according to the histological types [24] and the percentage of positive galectin-3, STn and galectin-3-binding sites stained tumor cells were quantified (Table S1). Galectin-3 expression was found to be strongly expressed in IM and moderately expressed in normal adjacent mucosa (Figure 6A). In the tumor, gal-3 was found to be expressed in $39 / 40(97.5 \%)$ of the samples and to be present in all 6 gastric cancer-derived metastasis samples. Galectin-3-binding sites were detected in normal adjacent mucosa but not in IM (Figure 6A) and were inhibited by lactose, a gal-3 inhibitor (Figure S4). On the contratry, STn was completely absent in normal adjacent mucosa and expressed in IM. In the tumor, gal-3-binding sites were detected in $40 / 40(100 \%)$ of samples and STn was expressed in 31/40 (77.5\%) of gastric cancer cases, however, gal-3binding sites and STn were never co-localized with each other. Also, a negative correlation between gal-3-binding sites and STn expression was also observed in gastric cancer-derived metastasis, (Figure 6A) that was further confirmed in a double immunofluorescence assay using anti-STn antibody and human recombinant 
gal-3 previously labeled with -Dy488 (Gal-3-Dy488) (Figure 6B). These results

strongly suggest an important role for sialyl-Tn in reducing galectin-3-binding sites in gastric tumor samples.

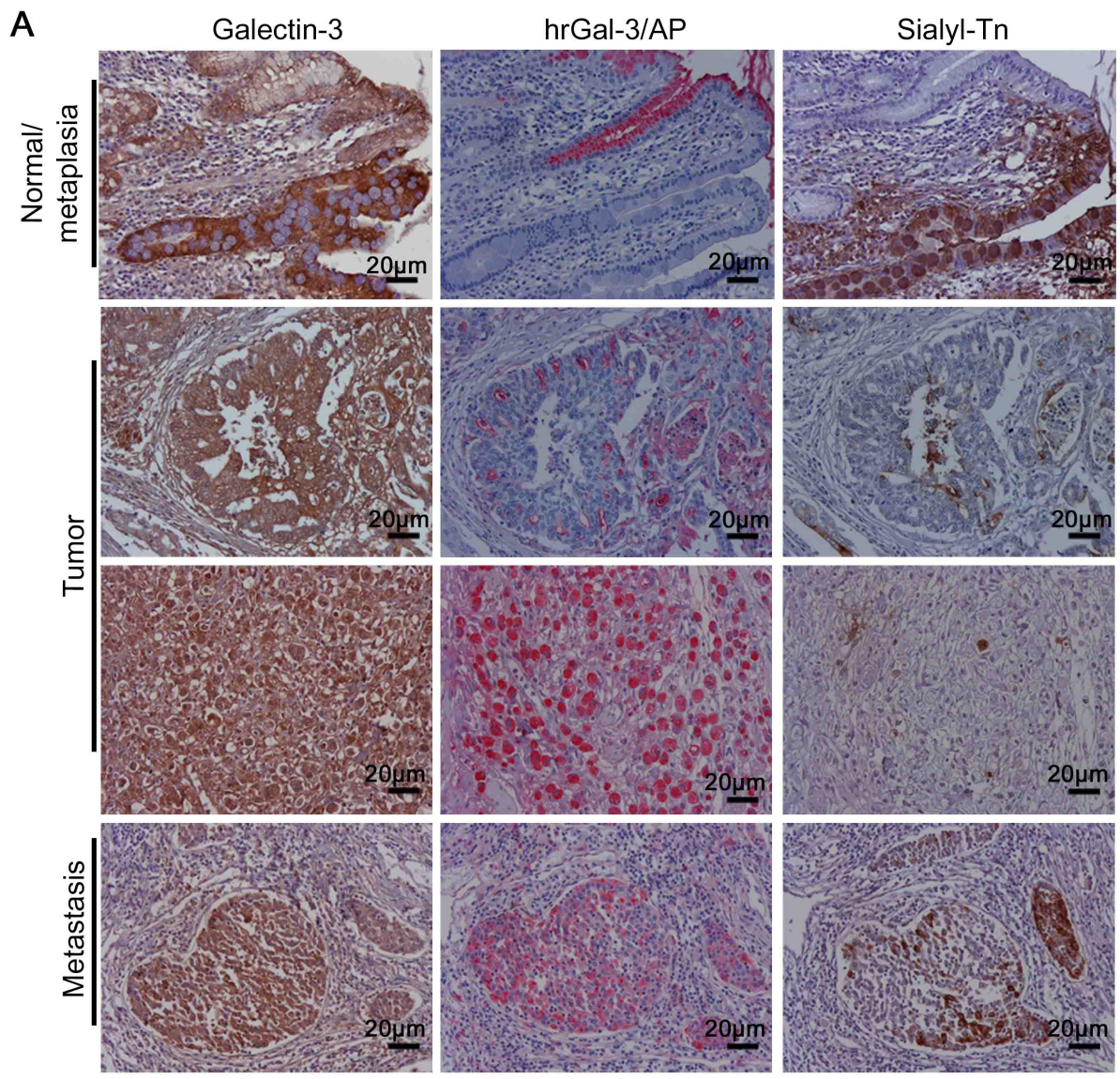

B
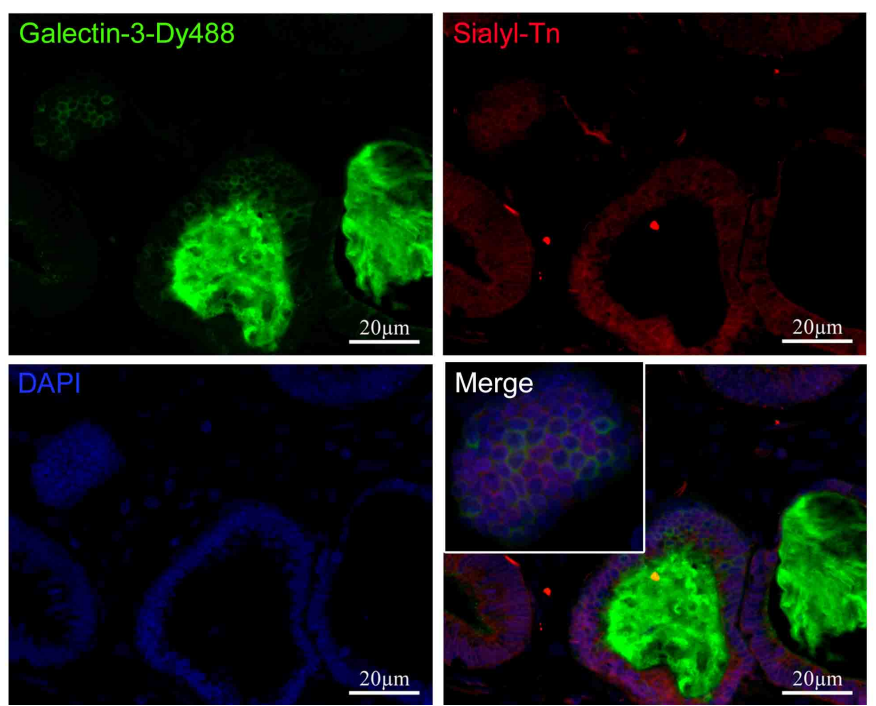

Figure 6. Expression of sialyl-Tn and galectin-3 binding sites in human gastric tumors

(A) Immunohistochemical staining of galectin-3, galectin-3 binding sites (hrGal-3/AP) and sialyl-Tn in human gastric tissue samples.

(B) Immunofluorescence of gastric tumor samples with galectin-3-FITC, sialyl-Tn and DAPI staining. (A and B) Representative images are shown, bar=20 $\mu \mathrm{m}$. See also Fig. S4. 


\section{In vivo biodistribution of galectin-3}

Taking into account our previous results showing that non-sialylated cells could benefit from chemotherapy in combination with galectin-3 we tested whether exogenously added gal-3 could reach the tumor microenvironment in a murine model of gastric cancer. Gal-3 was labeled with a near-infrared fluorofore (VivoTag 680XL) and then injected intravenously into Balb/c nude mice bearing tumors of Mock cells. Despite the fact that Mock cell display gal3-binding sites in vitro, we were not able to detect any uptake of gal-3-680XL by the tumor microenvironment in all time points assessed (Figure 7A and 7B). Surprisingly, gal-3-680XL was mostly found in the kidneys of the nude mice (Figure $7 \mathrm{~B}$ and Figure $7 \mathrm{C}$ ). To exclude a non-specific binding of gal-3 to kidneys, we next mixed lactose with gal-3-680XL prior to intravenous injection and observed a reduction in the total fluorescent signal (Figure 7D) and in the kidneys (Figure 7E and 7F) in comparison to mice injected with Gal-3$680 \mathrm{XL}$ alone. These results showed that intravenously administered fluorescent gal-3 did not reach the tumor mass in a murine model of gastric cancer. 
A
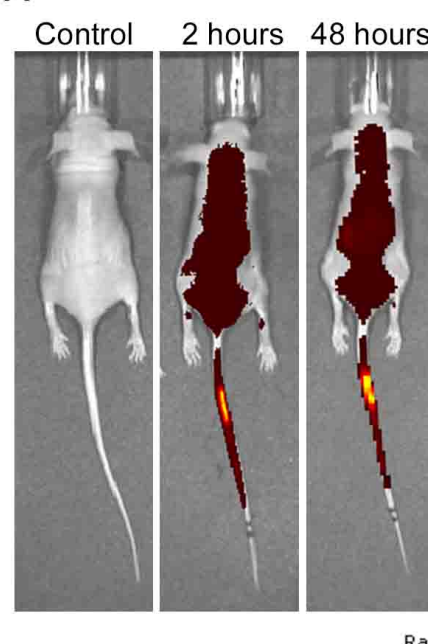

96 hours

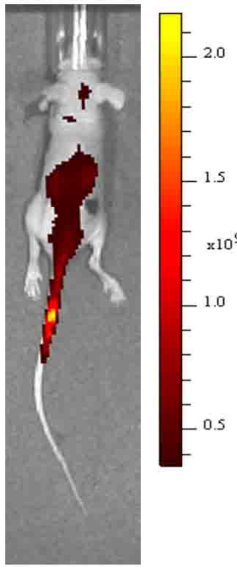

Radiant Efficiency $\left(\frac{\mathrm{P} / \mathrm{sec} / \mathrm{cm}^{2} / \mathrm{sr}}{\mu \mathrm{W} / \mathrm{cm}^{2}}\right)$

B

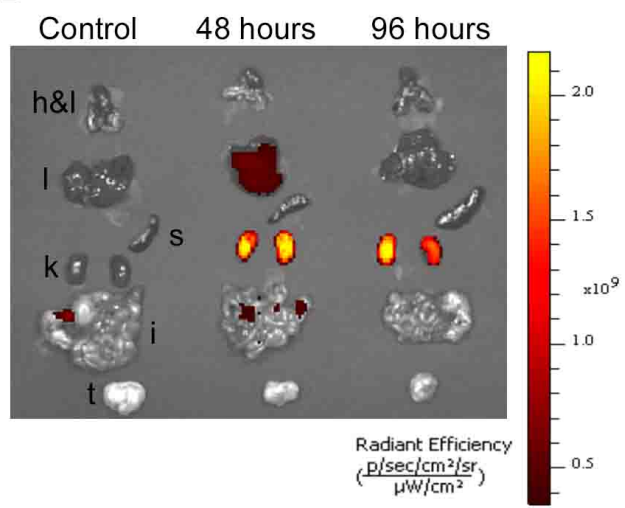

C

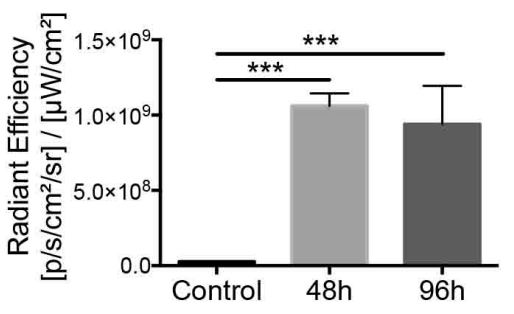

D

Gal-3-680XL Gal-3-680XL

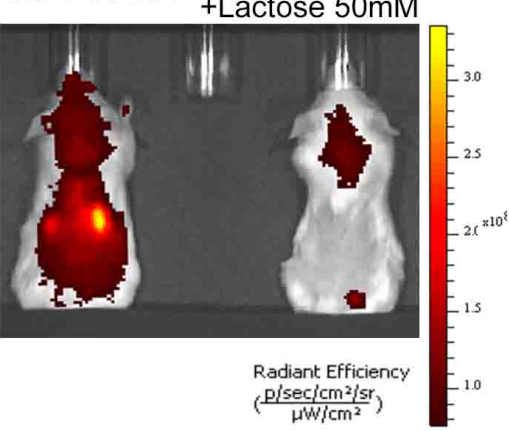

$E$

Gal-3-680XL $\begin{gathered}\text { Gal-3-680XL } \\ + \text { Lactose } 50 \mathrm{mM}\end{gathered}$

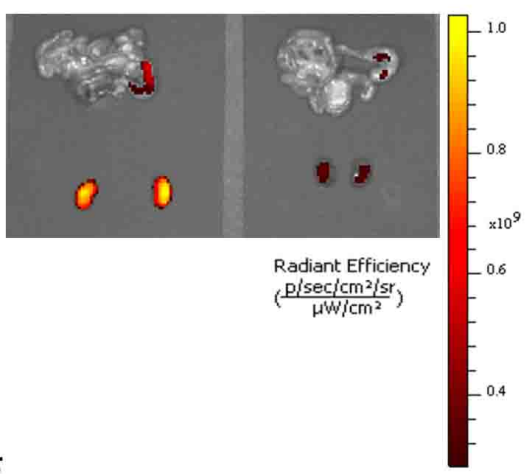

$\mathrm{F}$

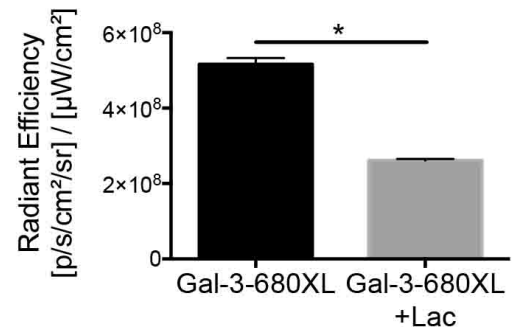

Figure 7. Galectin-3 in vivo biodistribution.

(A) Mock-tumor bearing Balb/c nude mice were injected intravenously with 150 $\mathrm{gg}$ of Gal-3-680XL and imaged with IVIS Spectrum at $2 \mathrm{hrs}, 48 \mathrm{hrs}$ and $96 \mathrm{hrs}$ post injection. Ideal filter set for imaging was 640 $\mathrm{nm}$ excitation and $680 \mathrm{~nm}$ emission. Mice were imaged dorsally at all time points.

(B) Hearth and lungs (h\&e), liver (l), spleen (s), kidneys (k), intestine (i) and Mock-derived tumor (t) were harvested for ex vivo imaging 48 and 96 hrs post Gal-3-680XL injection.

(C) Radiant efficiency quantification in kidneys harvested 48h and 96hrs post Gal-3-680XL injection.

(D) Balb/c mice were injected intravenously with 150 $\mathrm{gg}$ of Gal-3-680XL in the presence or absence of lactose $50 \mathrm{mM}$ and imaged with IVIS Spectrum after 2 hrs post injection. Ideal filter set for imaging is 640 $\mathrm{nm}$ excitation and $680 \mathrm{~nm}$ emission. Mice were imaged dorsally.

(E) Intestine (I) and kidneys (K) were harvested for ex vivo imaging $2 \mathrm{hrs}$ post Gal-3-680XL injection in the presence or absence of lactose $50 \mathrm{mM}$.

(F) Radiant efficiency quantification in kidneys harvested 2 hrs post Gal-3-680XL injection in the presence or absence of lactose $50 \mathrm{mM}$.

Data are representative of two experiments ( $A-B$ and $D-E)$, or are the mean $\pm S E M, n=2(C$ and $F)$. ${ }^{*} p<$ $0.05,{ }^{* * *} p<0.001$. 


\section{Discussion}

Resistance to chemotherapy is the major obstacle to the clinical treatment of cancer. Platinum-based drugs have been widely used in the treatment of solid cancers, however, tumor resistance to these drugs has compromised their long-term efficacy and besides the attempts to describe the multifactorial mechanisms responsible for this resistance, they are still incompletely understood.

In this study we demonstrated that: (1) ST6GalNAc-I overexpression confers chemotherapy resistance in gastric cancer cells; (2) STn expression, a biosynthetic product of ST6GalNAc-I, leads to decreased expression of gal-3 binding sites on the cell surface and modulates gal-3 subcellular localization both in vitro and in vivo; (3) Although exogenously added gal-3 does not induce gastric cancer cells death, it increases the chemotherapy-induced apoptosis in Mock cells, while STn-expressing cells are protected due to a reduction in gal-3-binding sites; (4) Intracellular gal-3 protects cells from chemotherapy-induced apoptosis.

These data illustrate a new mechanism of chemoresistance and demonstrate the importance of cellular glycosylation machinery in response to drugs. Platinum chemotherapy resistant cells are known to possess an abnormal glycosylation, and treatment with cisplatin can increase the sialic acid content of $\mathrm{N}$-linked glycans on tumor cells [24]. However, too little attention has been given to the role of O-linked glycans in chemotherapy resistance. Taking into account the biological role of STn in tumors, ST6GaINAc-I enzyme seems to be an effective therapeutic target for cancer treatment. In fact, it was recently demonstrated that transfection of human gastric cancer cells with ST6GalNAc-I siRNA inhibited the expression of STn and resulted in several antitumor activities such as inhibition of cell growth, migration, and invasion both in vitro and in vivo [25]. Still, a link between ST6GalNAc-I overexpression and chemotherapeutic resistance has not been demonstrated so far. 
Several cell surface receptors such as mucins glycoproteins [8, 9], integrins [14], CD44 [26], among others, are O-linked sialylated. In fact it is known that mucin MUC1 attenuates the apoptotic response to DNA damage conferring resistance to chemotherapeutic drugs such as cisplatin [27]. Similarly, integrin $\beta 1$ has been shown to block apoptosis induced by cisplatin via ERK and MAP kinase $[28,29]$ and CD44 molecule has been show to promote $\mathrm{Pl}-3$ kinase-mediated oncogenic signaling and cisplatin resistance in cancer cells [30]. Since gal-3 has been shown to favor MUC1 [31], integrin $\beta 1$ [27] and CD44 [32] endocytosis, increased STn expression on these proteins may impair gal-3-mediated endocytosis and consequently increase chemotherapy resistance in tumor cells.

In this study we also showed that exogenously added gal-3 alone did not induce tumor cell death. Several previous studies have supported the concept that extracellular gal-3 alone promote cell apoptosis. Extracellular galectin-3 has been reported to stimulate apoptosis in human leukemia $T$ cell lines [33], human B cell lymphoma [34] and neutrophils [35]. However the majority of studies are focused on cells from the immune system and only one study reported that gal-3 treatment alone was a pro-apoptotic molecule in epithelial tumor cells [23]. Therefore, the exact role of cell surface gal-3 on apoptosis depends not only on the cell type, but also on which receptors are present and its glycosylation status in a given cell.

Moreover, the N-terminally truncated form of galectin-3 (gal-3C) was previously reported to inhibit human tumor growth, motility, invasion and angiogenesis [36]. Additionally, gal-3C in combination with bortezomib significantly reduced tumor development in human multiple myeloma [36]. In our model however, gal-3C alone or in combination with cisplatin or 5-FU had no effect on gastric cancer cells viability. Since most of gal-3 functions are mediated by its ability to oligomerize and crosslink cell surface proteins one can assume that the sensitizing effect of gal-3 to chemotherapy may be dependent on gal-3-induced crosslink of cell surface receptors. 
Our data also demonstrated that intracellular gal-3 increased cell resistance to chemotherapy-induced cell death. Indeed, intracellular gal-3 has been previously described to protect cells against apoptotic stimuli in response to chemotherapeutic drugs. Intracellular gal-3 is thought to mediate anti-apoptotic activity by interacting with $\mathrm{Bcl}-2$ family members, synexin, modulating the expression of survivin, cyclin D1, and XIAP and activating Ras signaling [37]. Our data showed that STn expression, which decreases gal-3 binding sites at the cell surface, might be responsible for the intracellular accumulation of gal-3 in ST6GalNAc-I-overexpressing cells, thus providing a resistance mechanism to chemotherapy. Therefore, we propose a new mechanism by which sialyl-Tn influences tumor cell resistance to chemotherapeutic drugs (Figure 8).

A few studies have demonstrated that injection of truncated gal-3 is able to inhibit tumor cell proliferation in vivo possibly by its direct binding to the tumor [36]. Despite the importance of these reports and to the best of our knowledge, the present study is the first addressing whether gal-3 could reach the tumor site upon in vivo administration. Although gal-3 was not able to reach the tumor site, we cannot discard that: (1) gal-3 binding to other organs and cells could indirectly benefit tumor growth inhibition. Indeed, gal-3 has been shown to have an important role in the modulation of immune responses to tumors affecting for instance, maturation of cytotoxic NK cells and their cytotoxic activity [38], enhancing the number of Treg cells [39] and suppressing $\mathrm{CD}^{+} \mathrm{T}$ cells [40]; (2) MKN45 gastric cancer cells were implanted in an anatomical site different from the original tumor in this study that could influence galectin-3 tropism for tumor; (3) only one model of gastric carcinoma was tested and others types of tumors could be recognized by galectin-3.

Thus, the knowledge obtained from this study may open news perspectives in the way we diagnose and treat cancer. Indeed, a careful evaluation o STn expression and galectin-3 binding sites in tumors may be important to predict patient's response to a specific therapy. Tumor expressing galectin-3 binding sites 
will probably benefit from a cisplatin or 5-FU therapy in comparison with tumors expressing STn. Even though a combination of chemotherapeutic drug with galectin3 do not seem to be promising (taking into account our biodistribution studies of gal3) to treat gastric cancer, we cannot rule out that not only tumor cells, but also other cells within the tumor microenvironment such as macrophages [41] or dendritic cells [42], are able to locally produce and release gal-3 to the tumor. Consequently, in the presence of extracellular gal-3, tumors bearing galectin-3-binding sites could benefit from chemotherapeutic drug treatment.
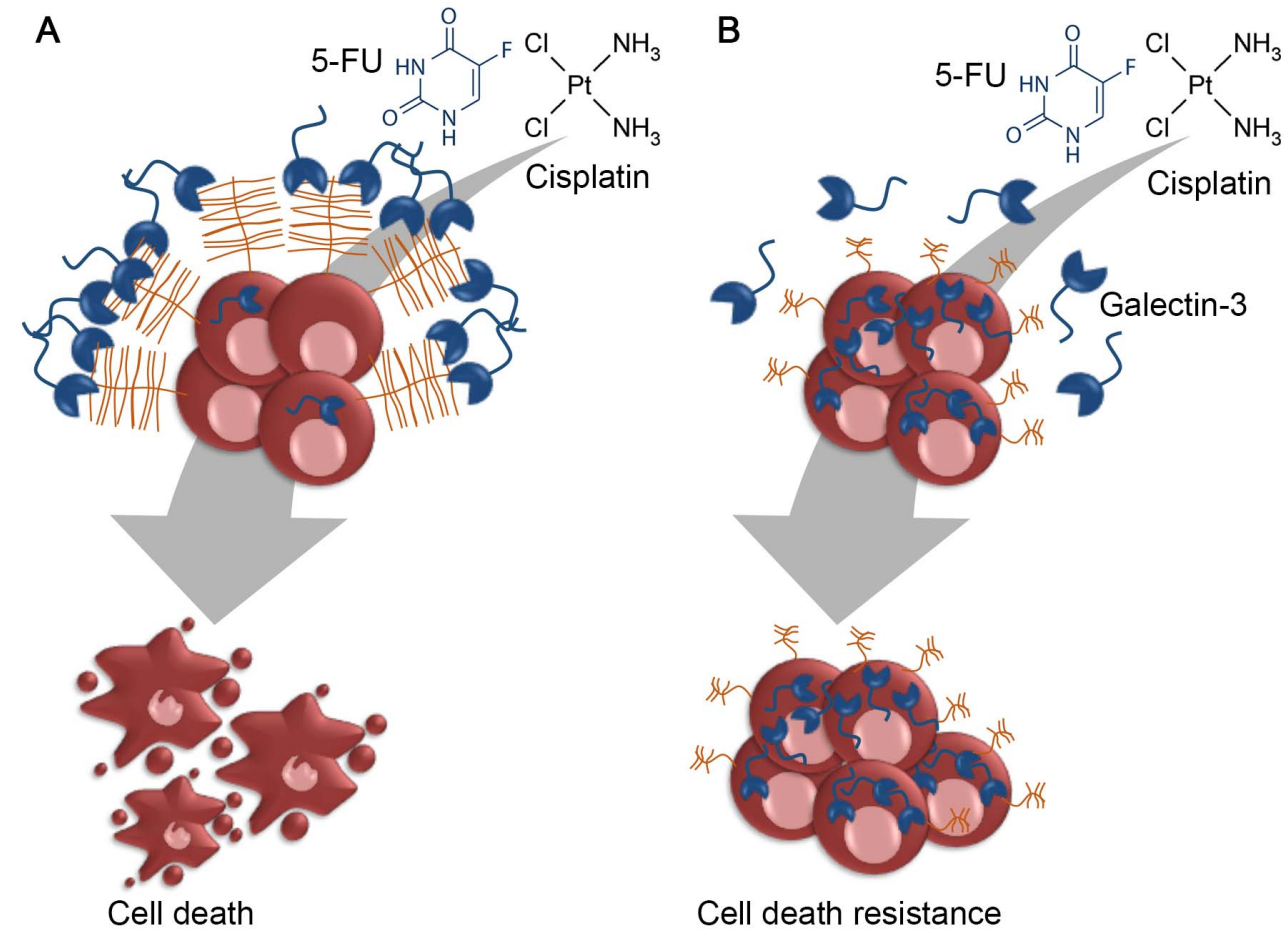

Figure 8. Proposed model for sialyl-Tn mediated resistance to cisplatin.

(A) Tumor cells expressing galectin-3 binding sites also express galectin- 3 at their cells surface. These cells are more susceptible to extracellular receptors clustering, caused by the action of extracellular galectin-3, thus increasing the sensitivity of tumor cells to cisplatin. (B) Given that the apoptotic function of gal-3 is related to its subcellular location, tumor cells expressing STn preferentially accumulate galectin-3 in the cytoplasm. As a consequence, STn expressing cells are more resistant to chemotherapy and can activate the intracellular anti-apoptotic machinery.

Our results suggest that galectin-3 inhibition could be a strategy to overcome STn-expressing cells resistance to chemotherapeutic drugs. Numerous studies have reported that galectin-3 inhibitors, such as Lac-I-Leu or modified citrus pectin (MCP), presented potential antimetastatic abilities $[43,44]$. Since galectin-3 has been shown to directly regulate the sensitivity of cancer cells to numerous chemotherapeutic 
agents [45-47], we could assume that galectin-3 inhibitors may hold the potential to enhance STn-expressing cancer cells sensitivity to cytotoxic drugs. However, these carbohydrate-based inhibitors only prevent extracellular $\beta$-galactoside-mediated interactions of galectin-3 and are not able to inhibit intracellular galectin-3. Therefore, future therapies targeting galectin-3 and/or ST6GalNAc-I enzyme may include the design of RNA interference and/or explore sialyl-Tn for a selective drug-delivery approach. 


\section{Experimental Procedures}

\section{Cell culture}

MKN45-Mock and ST6GalNAc-I cells (American Type Culture Collection, Manassas, VALLC [48]) were cultured in RPMI (Gibco, Life technologies, MD, USA) supplemented with $10 \%$ of fetal bovine serum (Gibco, Life technologies, MD, USA), $50 \mu \mathrm{g} / \mathrm{mL}$ of gentamicin (Gibco, Life technologies, MD, USA) and in the presence of geneticin $(300 \mu \mathrm{g} / \mathrm{mL})$ (Sigma). Mycoplasma contamination in cultured cells was excluded by using Lonza Mycoplasma Detection Kit.

\section{Flow cytometry}

For flow cytometry, cells were harvested and incubated with anti-sialyl-Tn (TKH2 antibody[49]) or anti-galectin-3 (M3/38, ATCC TIB166) followed by antimouse-Alexa488 or anti-rat-Alexa488 antibodies. Alternatively, cells were incubated with DyLigth488 labelled-hrGal-3. Analysis was made using the flow cytometer CyAn ${ }^{\mathrm{TM}}$ ADP Analyzer from Beckman Coulter. For detailed protocol see supplemental experimental procedures.

\section{Gene expression analysis}

Total RNA from cell cultures or tumor tissue was isolated with Tri-Reagent (Sigma) according to the manufacturer's instructions. Complementary DNA (cDNA) was synthesized using the High capacity cDNA RT kit (Applied Biosystems), according to the manufacturer's protocols. Quantitative PCR analysis was performed in triplicate using the SensiMix SYBR No-ROX kit (Bioline). Relative quantification was done using the $\Delta \Delta \mathrm{Ct}$ method normalizing to GAPDH gene expression (See Table S2 for primer detail). 


\section{Evaluation of cell death by propidium iodide}

Cells previously incubated with cisplatin $(12.5 \mu \mathrm{M}$ or $25 \mu \mathrm{M})$ and hrGal-3 $(2 \mu \mathrm{M})$ in the presence or absence of lactose $(50 \mathrm{mM})$ were harvested and stained with propidium iodide $20 \mu \mathrm{g} / \mathrm{mL}$ (Invitrogen). Analysis was made with flow cytometer CyAn ${ }^{\mathrm{TM}}$ ADP Analyzer from Beckman Coulter. For detailed protocol see supplemental experimental procedures.

\section{ELISA}

MKN45-Mock or -ST6GalNAc-I cells were cultured in the presence of cisplatin $(12.5 \mu \mathrm{M}$ or $25 \mu \mathrm{M})$ for $48 \mathrm{~h}$. After this period, the cellular medium was collected and galectin-3 was quantified by ELISA according to the manufacturer's procedure (ELISA galectin-3 Duo Set, R\&D Systems).

\section{Immunofluorescence}

Cells or gastric cancer tissues were incubated with anti-sialyl-Tn (TKH2 antibody[49]), anti-galectin-3 (M3/38, ATCC TIB166) or hrGal-3-DyLight488 and detected with anti-mouse-Alexa-546 (Invitrogen) or anti-rat-Alexa488 (Invitrogen), respectively. Nuclei were stained with DAPI (4',6-diamidino-2-phenylindole). Pictures were taken using a fluorescent inverted microscope (Zeiss Axiovert 200M). For detailed protocol see supplemental experimental procedures.

\section{Immunostaining}

Sections from cancer specimens were obtained from patients with muci- nous adenocarcinomas undergoing surgery at Hospital S. João, Medical Faculty (Porto, Portugal) between 1991 and 2009. Tissue fragments were fixed in $10 \%$ formaldehyde and embedded in paraffin. Serial sections of $3 \mu \mathrm{m}$ were cut and used for immunostaining with anti-sialyl-Tn antibody ((TKH2 antibody [49]), anti-galectin-3 (M3/38, ATCC TIB166) or incubated with hrGal-3/AP[50]. The tissue were classified 
using a 0 -to- 3 scale: 0 for $0-5 \%$ positive tumor cells, 1 for $6-50 \%$ positive tumor cells, 2 for $>50 \%$ positive tumor cells. For detailed protocol see supplemental experimental procedures.

\section{In vivo distribution of galectin-3}

Five Balb/c nude mice were implanted subcutaneously with $2 \times 10^{6}$ MKN45Mock cells. When tumors reached the size of $0.5-1 \mathrm{~cm}^{3}, 100 \mu \mathrm{g}$ of galectin-3-VivoTag $680 \mathrm{XL}$ were injected intravenously. After a period of $2 \mathrm{~h}, 48 \mathrm{~h}$ and $96 \mathrm{~h}$, mice were anesthetized with isoflurane gas and then imaged with a Xenogen IVIS Spectrum instrument with filter set of $640 \mathrm{~nm}$ excitation and $680 \mathrm{~nm}$ emission.

\section{Statistical Analysis}

All data are expressed as the mean \pm SEM of at least three independent experiments. Statistical analysis including t-test, one-way ANOVA and two-way ANOVA were done using GraphPad Prism 6.0 software. $p<0.05$ was considered statistically significant. 


\section{References}

1. Pinho SS, Carvalho S, Marcos-Pinto R, Magalhaes A, Oliveira C, Gu J, et al. Gastric cancer: adding glycosylation to the equation. Trends Mol Med. 2013 Nov;19(11):664-76.

2. Schultz MJ, Swindall AF, Bellis SL. Regulation of the metastatic cell phenotype by sialylated glycans. Cancer Metastasis Rev. 2012 Dec;31(3-4):501-18.

3. Pinho SS, Reis CA. Glycosylation in cancer: mechanisms and clinical implications. Nature reviews Cancer. 2015 Sep;15(9):540-55.

4. Kim YJ, Varki A. Perspectives on the significance of altered glycosylation of glycoproteins in cancer. Glycoconjugate journal. 1997 Aug;14(5):569-76.

5. Reis CA, Osorio H, Silva L, Gomes C, David L. Alterations in glycosylation as biomarkers for cancer detection. Journal of clinical pathology. 2010 Apr;63(4):322-9.

6. Harduin-Lepers A, Krzewinski-Recchi MA, Colomb F, Foulquier F, Groux-Degroote S, Delannoy P. Sialyltransferases functions in cancers. Frontiers in bioscience. 2012;4:499-515.

7. Marcos NT, Bennett EP, Gomes J, Magalhaes A, Gomes C, David L, et al. ST6GalNAc-I controls expression of sialyl-Tn antigen in gastrointestinal tissues. Frontiers in bioscience. 2011;3:144355.

8. Marcos NT, Pinho S, Grandela C, Cruz A, Samyn-Petit B, Harduin-Lepers A, et al. Role of the human ST6GalNAc-I and ST6GaINAc-II in the synthesis of the cancer-associated sialyl-Tn antigen. Cancer research. 2004 Oct 1;64(19):7050-7.

9. Pinho S, Marcos NT, Ferreira B, Carvalho AS, Oliveira MJ, Santos-Silva F, et al. Biological significance of cancer-associated sialyl-Tn antigen: modulation of malignant phenotype in gastric carcinoma cells. Cancer letters. 2007 May 8;249(2):157-70.

10. Vazquez-Martin C, Cuevas E, Gil-Martin E, Fernandez-Briera A. Correlation analysis between tumor-associated antigen sialyl-Tn expression and ST6GalNAc I activity in human colon adenocarcinoma. Oncology. 2004;67(2):159-65.

11. Akita K, Yoshida S, Ikehara Y, Shirakawa S, Toda M, Inoue M, et al. Different levels of sialylTn antigen expressed on MUC16 in patients with endometriosis and ovarian cancer. International journal of gynecological cancer : official journal of the International Gynecological Cancer Society. 2012 May;22(4):531-8.

12. Julien S, Adriaenssens E, Ottenberg K, Furlan A, Courtand G, Vercoutter-Edouart AS, et al. ST6GaINAc I expression in MDA-MB-231 breast cancer cells greatly modifies their O-glycosylation pattern and enhances their tumourigenicity. Glycobiology. 2006 Jan;16(1):54-64.

13. Kim GE, Bae HI, Park HU, Kuan SF, Crawley SC, Ho JJ, et al. Aberrant expression of MUC5AC and MUC6 gastric mucins and sialyl Tn antigen in intraepithelial neoplasms of the pancreas. Gastroenterology. 2002 Oct;123(4):1052-60.

14. Clement M, Rocher J, Loirand G, Le Pendu J. Expression of sialyl-Tn epitopes on beta1 integrin alters epithelial cell phenotype, proliferation and haptotaxis. Journal of cell science. 2004 Oct 1;117(Pt 21):5059-69.

15. Ozaki $\mathrm{H}$, Matsuzaki $\mathrm{H}$, Ando $\mathrm{H}$, Kaji $\mathrm{H}$, Nakanishi $\mathrm{H}$, Ikehara $\mathrm{Y}$, et al. Enhancement of metastatic ability by ectopic expression of ST6GalNAcl on a gastric cancer cell line in a mouse model. Clinical \& experimental metastasis. 2012 Mar;29(3):229-38.

16. Barondes SH, Castronovo V, Cooper DN, Cummings RD, Drickamer K, Feizi T, et al. Galectins: a family of animal beta-galactoside-binding lectins. Cell. 1994 Feb 25;76(4):597-8.

17. Mayoral MA, Mayoral C, Meneses A, Villalvazo L, Guzman A, Espinosa B, et al. Identification of galectin-3 and mucin-type O-glycans in breast cancer and its metastasis to brain. Cancer investigation. $2008 \mathrm{Jul} ; 26(6): 615-23$.

18. Zaia Povegliano L, Oshima CT, de Oliveira Lima F, Andrade Scherholz PL, Manoukian Forones N. Immunoexpression of galectin-3 in colorectal cancer and its relationship with survival. Journal of gastrointestinal cancer. 2011 Dec;42(4):217-21.

19. Xie L, Ni WK, Chen XD, Xiao MB, Chen BY, He S, et al. The expressions and clinical significances of tissue and serum galectin-3 in pancreatic carcinoma. Journal of cancer research and clinical oncology. 2012 Jun;138(6):1035-43.

20. Barut F, Onak Kandemir N, Bektas S, Bahadir B, Keser S, Ozdamar SO. Universal markers of thyroid malignancies: galectin-3, HBME-1, and cytokeratin-19. Endocrine pathology. 2010 Jun;21(2):809.

21. Cheng D, Liang B, Li Y. Serum galectin-3 as a potential marker for gastric cancer. Medical science monitor : international medical journal of experimental and clinical research. 2015;21:755-60.

22. Nakahara S, Oka N, Raz A. On the role of galectin-3 in cancer apoptosis. Apoptosis : an international journal on programmed cell death. 2005 Mar;10(2):267-75.

23. Zhuo Y, Chammas R, Bellis SL. Sialylation of beta1 integrins blocks cell adhesion to galectin-3 and protects cells against galectin-3-induced apoptosis. The Journal of biological chemistry. 2008 Aug 8;283(32):22177-85.

24. Nicol BM, Prasad SB. Sialic acid changes in Dalton's lymphoma-bearing mice after cyclophosphamide and cisplatin treatment. Brazilian journal of medical and biological research = 
Revista brasileira de pesquisas medicas e biologicas / Sociedade Brasileira de Biofisica [et al]. 2002 May;35(5):549-53.

25. Tamura F, Sato $Y$, Hirakawa M, Yoshida M, Ono M, Osuga T, et al. RNAi-mediated gene silencing of ST6GalNAc I suppresses the metastatic potential in gastric cancer cells. Gastric cancer : official journal of the International Gastric Cancer Association and the Japanese Gastric Cancer Association. 2014 Dec 23.

26. Ferreira JA, Videira PA, Lima L, Pereira S, Silva M, Carrascal M, et al. Overexpression of tumour-associated carbohydrate antigen sialyl-Tn in advanced bladder tumours. Molecular oncology. 2013 Jun;7(3):719-31.

27. Ren J, Agata N, Chen D, Li Y, Yu WH, Huang L, et al. Human MUC1 carcinoma-associated protein confers resistance to genotoxic anticancer agents. Cancer cell. 2004 Feb;5(2):163-75.

28. Sorensen BH, Rasmussen LJ, Broberg BS, Klausen TK, Sauter DP, Lambert IH, et al. Integrin beta1, Osmosensing, and Chemoresistance in Mouse Ehrlich Carcinoma Cells. Cellular physiology and biochemistry : international journal of experimental cellular physiology, biochemistry, and pharmacology. 2015;36(1):111-32.

29. Zhang H, Ozaki I, Mizuta T, Matsuhashi S, Yoshimura T, Hisatomi A, et al. Beta 1-integrin protects hepatoma cells from chemotherapy induced apoptosis via a mitogen-activated protein kinase dependent pathway. Cancer. 2002 Aug 15;95(4):896-906.

30. Cortes-Dericks L, Froment L, Boesch R, Schmid RA, Karoubi G. Cisplatin-resistant cells in malignant pleural mesothelioma cell lines show $\mathrm{ALDH}($ high)CD44(+) phenotype and sphere-forming capacity. BMC cancer. 2014;14:304.

31. Merlin J, Stechly L, de Beauce S, Monte D, Leteurtre E, van Seuningen I, et al. Galectin-3 regulates MUC1 and EGFR cellular distribution and EGFR downstream pathways in pancreatic cancer cells. Oncogene. 2011 Jun 2;30(22):2514-25.

32. Lakshminarayan R, Wunder C, Becken U, Howes MT, Benzing C, Arumugam S, et al. Galectin-3 drives glycosphingolipid-dependent biogenesis of clathrin-independent carriers. Nature cell biology. 2014 Jun;16(6):595-606.

33. Xue J, Gao X, Fu C, Cong Z, Jiang H, Wang W, et al. Regulation of galectin-3-induced apoptosis of Jurkat cells by both O-glycans and N-glycans on CD45. FEBS letters. 2013 Dec 11;587(24):3986-94.

34. Suzuki O, Abe M. Cell surface N-glycosylation and sialylation regulate galectin-3-induced apoptosis in human diffuse large B cell lymphoma. Oncology reports. 2008 Mar;19(3):743-8.

35. Fernandez GC, Ilarregui JM, Rubel CJ, Toscano MA, Gomez SA, Beigier Bompadre M, et al. Galectin-3 and soluble fibrinogen act in concert to modulate neutrophil activation and survival: involvement of alternative MAPK pathways. Glycobiology. 2005 May;15(5):519-27.

36. Mirandola L, Yu Y, Chui K, Jenkins MR, Cobos E, John CM, et al. Galectin-3C inhibits tumor growth and increases the anticancer activity of bortezomib in a murine model of human multiple myeloma. PloS one. 2011;6(7):e21811.

37. Liu FT, Patterson RJ, Wang JL. Intracellular functions of galectins. Biochimica et biophysica acta. 2002 Sep 19;1572(2-3):263-73.

38. Wang W, Guo H, Geng J, Zheng X, Wei H, Sun R, et al. Tumor-released Galectin-3, a soluble inhibitory ligand of human NKp30, plays an important role in tumor escape from NK cell attack. The Journal of biological chemistry. 2014 Nov 28;289(48):33311-9.

39. Jiang HR, Al Rasebi Z, Mensah-Brown E, Shahin A, Xu D, Goodyear CS, et al. Galectin-3 deficiency reduces the severity of experimental autoimmune encephalomyelitis. Journal of immunology. 2009 Jan 15;182(2):1167-73

40. Kouo T, Huang L, Pucsek AB, Cao M, Solt S, Armstrong T, et al. Galectin-3 Shapes Antitumor Immune Responses by Suppressing CD8+ T Cells via LAG-3 and Inhibiting Expansion of Plasmacytoid Dendritic Cells. Cancer immunology research. 2015 Apr;3(4):412-23.

41. Henderson NC, Mackinnon AC, Farnworth SL, Kipari T, Haslett C, Iredale JP, et al. Galectin-3 expression and secretion links macrophages to the promotion of renal fibrosis. The American journal of pathology. 2008 Feb;172(2):288-98.

42. van Stijn $C M$, van den Broek $M$, van de Weerd $R$, Visser $M$, Tasdelen I, Tefsen B, et al. Regulation of expression and secretion of galectin-3 in human monocyte-derived dendritic cells. Molecular immunology. 2009 Oct;46(16):3292-9.

43. Glinsky GV, Price JE, Glinsky VV, Mossine VV, Kiriakova G, Metcalf JB. Inhibition of human breast cancer metastasis in nude mice by synthetic glycoamines. Cancer research. 1996 Dec 1;56(23):5319-24.

44. Pienta KJ, Naik H, Akhtar A, Yamazaki K, Replogle TS, Lehr J, et al. Inhibition of spontaneous metastasis in a rat prostate cancer model by oral administration of modified citrus pectin. Journal of the National Cancer Institute. 1995 Mar 1;87(5):348-53.

45. Chauhan D, Li G, Podar K, Hideshima T, Neri P, He D, et al. A novel carbohydrate-based therapeutic GCS-100 overcomes bortezomib resistance and enhances dexamethasone-induced apoptosis in multiple myeloma cells. Cancer research. 2005 Sep 15;65(18):8350-8.

46. Fukumori T, Oka N, Takenaka Y, Nangia-Makker P, Elsamman E, Kasai T, et al. Galectin-3 regulates mitochondrial stability and antiapoptotic function in response to anticancer drug in prostate cancer. Cancer research. 2006 Mar 15;66(6):3114-9. 
47. Yu F, Finley RL, Jr., Raz A, Kim HR. Galectin-3 translocates to the perinuclear membranes and inhibits cytochrome $c$ release from the mitochondria. A role for synexin in galectin- 3 translocation. The Journal of biological chemistry. 2002 May 3;277(18):15819-27.

48. Tamura G, Sakata K, Nishizuka S, Maesawa C, Suzuki Y, Iwaya T, et al. Inactivation of the Ecadherin gene in primary gastric carcinomas and gastric carcinoma cell lines. Japanese journal of cancer research : Gann. 1996 Nov;87(11):1153-9.

49. Jass JR, Allison LM, Edgar S. Monoclonal antibody $\mathrm{TKH} 2$ to the cancer-associated epitope sialosyl Tn shows cross-reactivity with variants of normal colorectal goblet cell mucin. Pathology. 1994 Oct;26(4):418-22.

50. de Melo FH, Butera D, Medeiros RS, Andrade LN, Nonogaki S, Soares FA, et al. Biological applications of a chimeric probe for the assessment of galectin-3 ligands. The journal of histochemistry and cytochemistry : official journal of the Histochemistry Society. 2007 Oct;55(10):1015-26. 


\section{Supplemental information}

\section{Supplemental figures and legends}

A

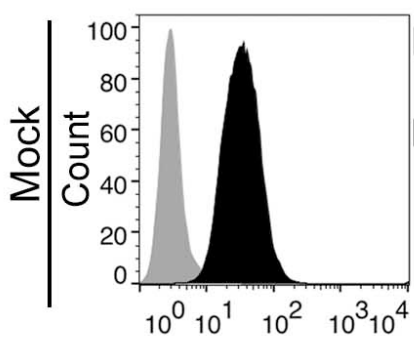

FLH-1

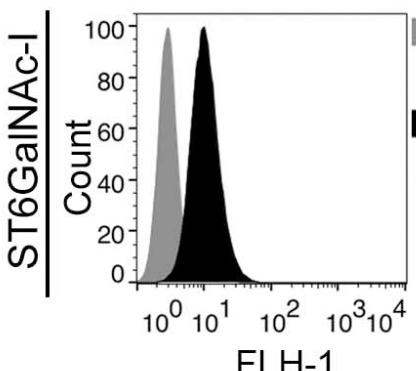

$\mathrm{FLH}-1$
Negative control

Cell surface

Gal-3

Negative control

Cell surface

Gal-3

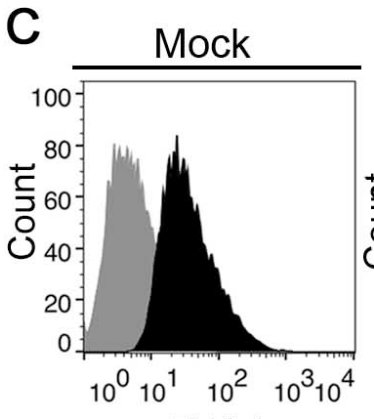

FLH-1

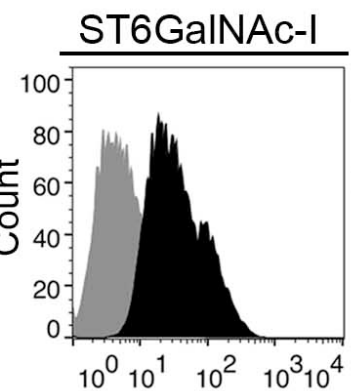

$\mathrm{FLH}-1$
B

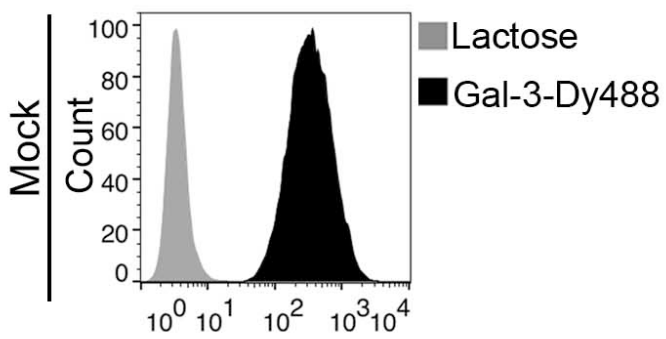

FLH-1

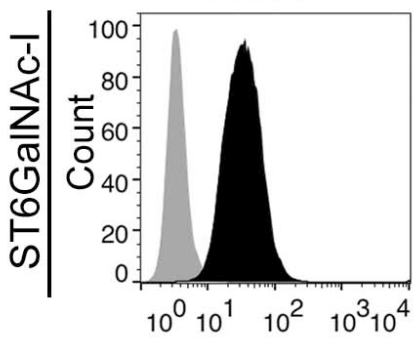

FLH-1
Lactose

aal-3-Dy488

Figure S1. Total levels of galectin-3 are not altered in Mock and ST6GaINAc-I cells.

(A-C) Flow cytometry histogram of $(A)$ cells surface galectin-3, $(B)$ galectin-3 binding site and (C) total galectin-3 in Mock and ST6GalNAc-I overexpressing cells.

(D) mRNA levels of galectin-3 in Mock and ST6GalNAc-I cells. Values are normalized to $\beta$-actin.

Data are representative images $(A)$ or are the mean \pm SEM, $n=3(B)$. 

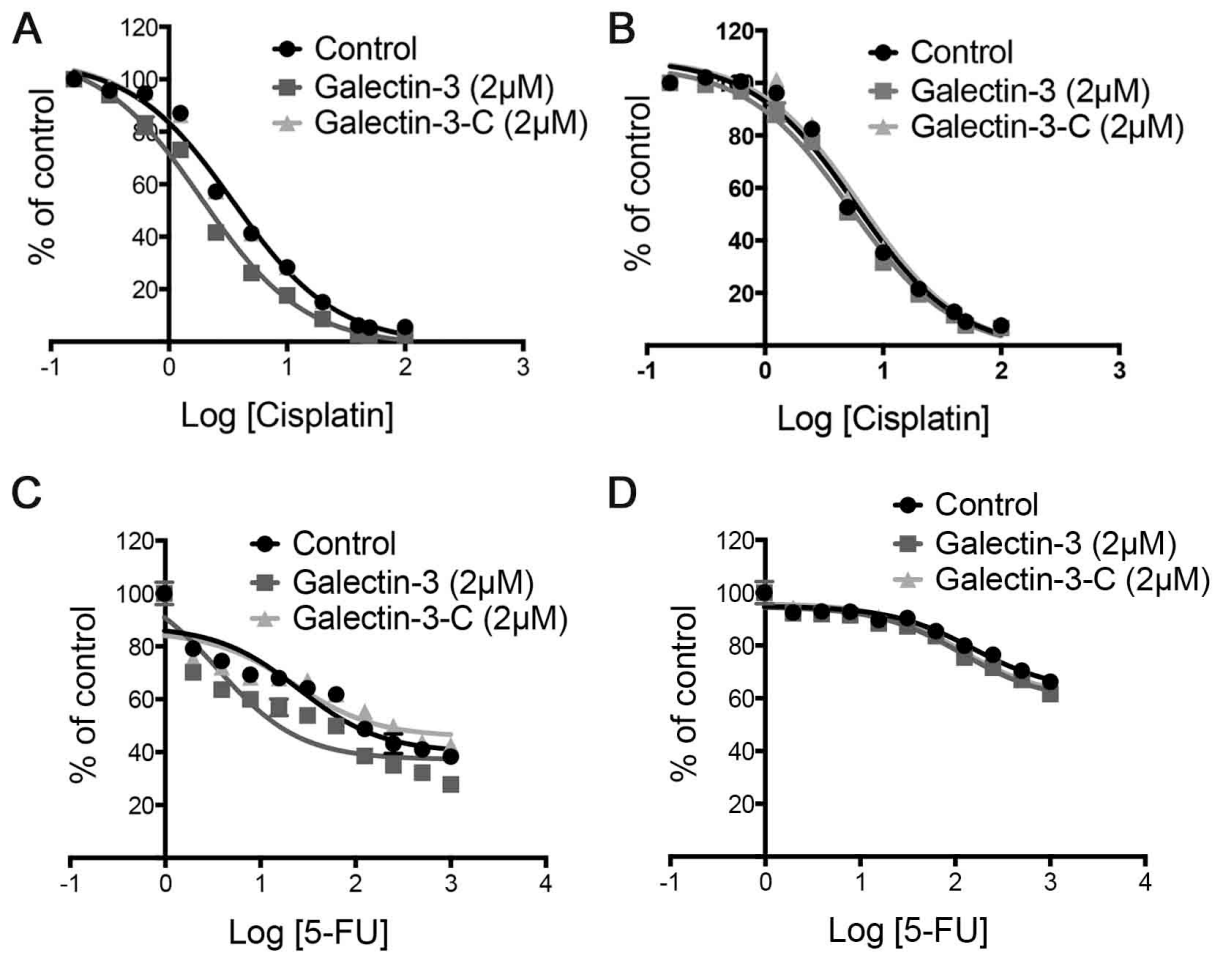

Figure S2. Galectin-3 increases cisplatin and 5-FU cytotoxicity in Mock cells.

(A-D) SRB assay showing Mock or STn-expressing cells viability under the treatment of cisplatin ( $\mathrm{A}$ and $\mathrm{B})$ or 5-FU $(\mathrm{C}$ and $\mathrm{D})$ and determined as a percentage of viable cells relative to control (cells with no drug treatment). Data are the mean \pm SEM, $n=3$. 
A

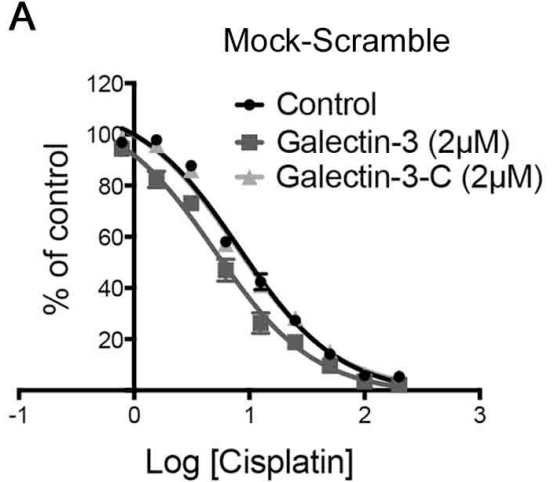

C

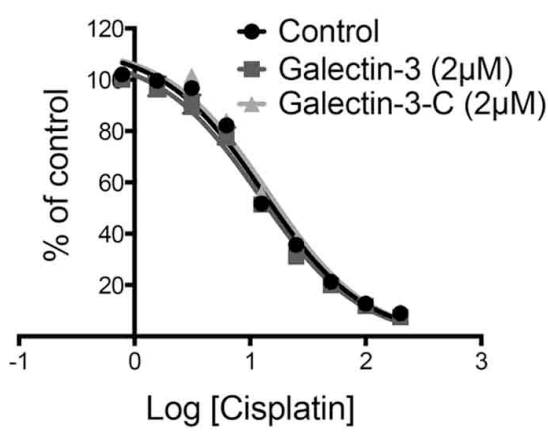

$\mathrm{E}$

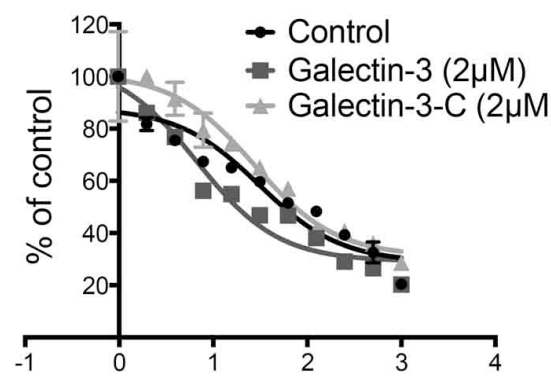

$\log [5-\mathrm{FU}]$

G ST6GalNAc-I-Scramble

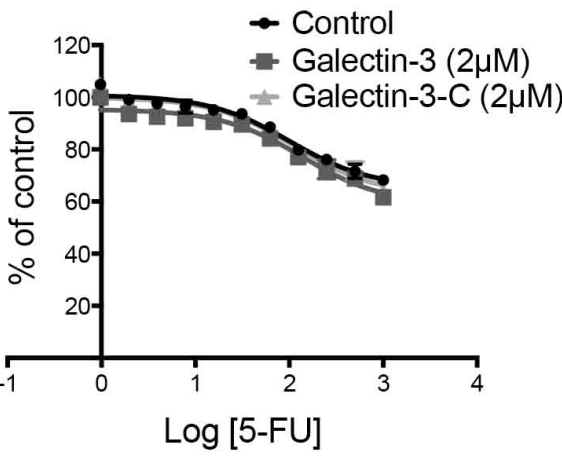

B

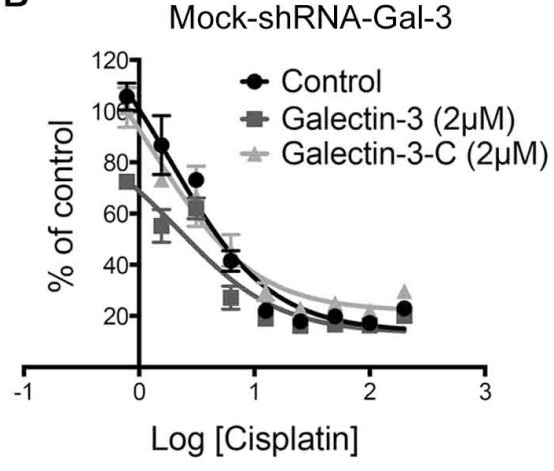

D ST6GalNAc-I-shRNA-Gal-3

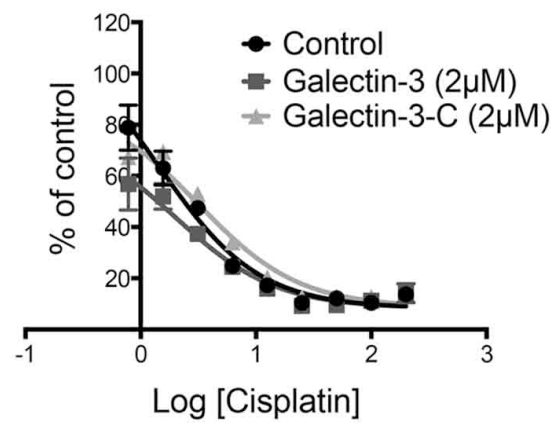

$\mathrm{F}$

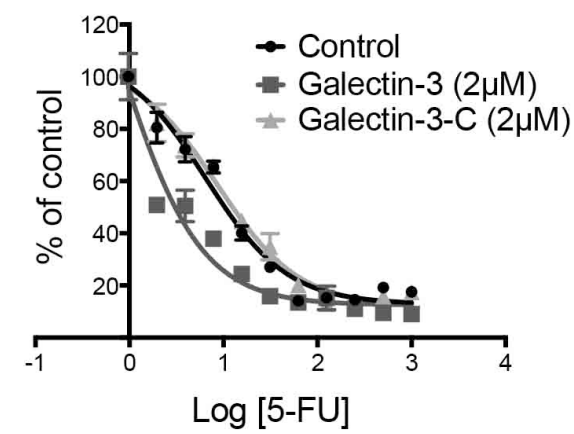

H ST6GaINAc-I-shRNA-Gal-3

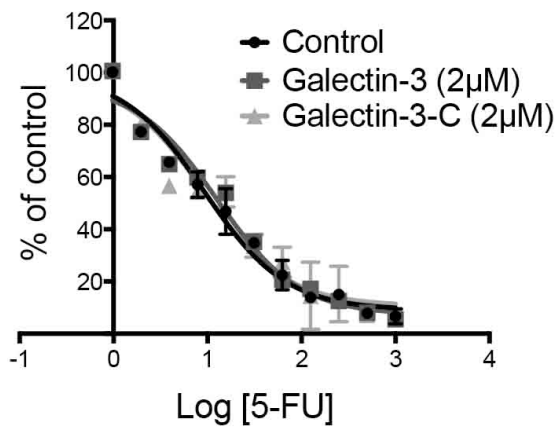

Figure S3. Intracellular galectin-3 protects cell from 5-FU induced cytotoxicity.

(A-H) SRB assay showing Mock-scramble, Mock-shRNA-Gal-3, ST6GalNAc-Iscramble or ST6GaINAc-I-shRNA-Gal-3 cells viability under the treatment of cisplatin $(A-D)$ or $5-\mathrm{FU}(\mathrm{E}-\mathrm{H})$ and in the presence of galectin-3 or galectin-3C. The indicated 
concentrations are presented in logarithmic scale and results determined as a percentage of viable cells relative to control (cells with no drug treatment). Data are the mean \pm SEM, $n=3$.
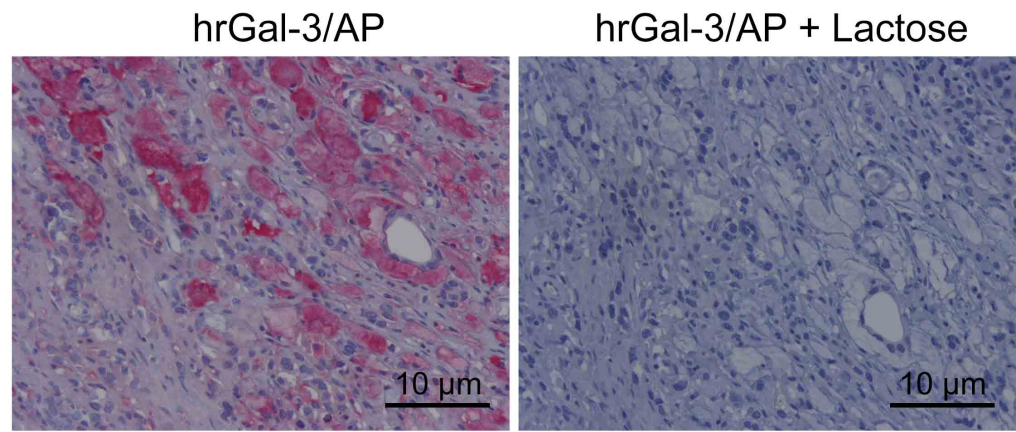

Figure S4. Lactose inhibits hrGal-3/AP binding.

Immunostaining of human gastric tumor with hrGal-3/AP in the presence or absence of lactose. Bar $=10 \mu \mathrm{m}$. Representative images are shown 


\section{Supplemental Tables}

Table S1. Immunohistochemical data.

\begin{tabular}{|c|c|}
\hline Histological type $(n=40)$ & Number of cases (\%) \\
\hline $\begin{array}{l}\text { Intestinal } \\
\text { Diffuse } \\
\text { Atypical }\end{array}$ & $\begin{array}{l}21(52.5 \%) \\
11(27.5) \\
8(20 \%)\end{array}$ \\
\hline \multicolumn{2}{|l|}{ Galectin-3 expression } \\
\hline $\begin{array}{l}\text { Negative } \\
<50 \% \text { of }+ \text { ve cells } \\
>50 \% \text { of }+ \text { ve cells }\end{array}$ & $\begin{array}{l}1(2.5 \%) \\
3(7.5 \%) \\
36(90 \%)\end{array}$ \\
\hline \multicolumn{2}{|c|}{ Galectin-3 binding sites (hrGal-3/AP) } \\
\hline $\begin{array}{l}\text { Negative } \\
<50 \% \text { of }+ \text { ve cells } \\
>50 \% \text { of }+ \text { ve cells }\end{array}$ & $\begin{array}{l}0(0 \%) \\
3(7.5 \%) \\
37(92.5 \%)\end{array}$ \\
\hline \multicolumn{2}{|l|}{ Sialyl-Tn expression } \\
\hline $\begin{array}{l}\text { Negative } \\
<50 \% \text { of }+ \text { ve cells } \\
>50 \% \text { of }+ \text { ve cells }\end{array}$ & $\begin{array}{l}9(22.5 \%) \\
20(50 \%) \\
11(27.5 \%)\end{array}$ \\
\hline
\end{tabular}

Table S2. Primers sequences.

\begin{tabular}{|c|c|c|}
\hline Primer & Forward 5' $\mathbf{- 3}$ ' & Reverse 5' $\mathbf{- 3}$ \\
\hline Galectin-3 & TGTTTGCAATACAAAGCTGGA & GCAACCTTGAAGTGGTCAGG \\
\hline$\beta$-actin & GCCAGGTCATCACCATTGG & GGTAGTTTCGTGGATGCCACA \\
\hline
\end{tabular}




\section{Supplemental experimental procedures}

\section{Cell culture}

MKN45 cells (American Type Culture Collection, Manassas, VALLC [1]) were cultured in RPMI (Gibco, Life technologies, MD, USA) supplemented with $10 \%$ of fetal bovine serum (Gibco, Life technologies, MD, USA) and $50 \mu \mathrm{g} / \mathrm{mL}$ of gentamicin (Gibco, Life technologies, MD, USA). Mock and ST6GalNAc-I transfected cells [2] were cultured on the same conditions but in the presence of the selective antibiotic geneticin $(300 \mu \mathrm{g} / \mathrm{mL})$ from Sigma. Mycoplasma contamination in cultured cells was excluded by using Lonza Mycoplasma Detection Kit.

\section{Recombinant human galectin-3 and galectin-3C preparation}

Galectin-3 and galectin-3C were produced in Escherichia coli BI21/DE3 containing the pET11a plasmid with the human galectin-3 (hrGal-3) coding DNA or the C-terminal domain fragment of galectin-3 (hrGal-3C) (gift from Dr. Nozomu Nishi, Kagawa University, Japan) and purified by affinity chromatography on lactosylSepharose (Sigma) as previously described [3]. Lactose was removed by gelfiltration chromatography on desalting columns and contaminating LPS was eliminated by affinity chromatography on detoxi-gel beads (Pierce). The endotoxin levels were less than $0,1 \mathrm{EU}$ per $\mu \mathrm{g}$ of protein as determined by the LAL method (Lonza). Conjugation of hrGal-3 with DyLight488 was performed accordingly to manufacturer's instructions (Thermo Fischer Scientific). Conjugation of hrGal-3 with VivoTag 680XL was performed according to manufacturer's instructions (Perkin Elmer, Boston, USA).

\section{Flow cytometry}

For flow cytometry, MKN45-Mock or MKN45-ST6GalNAc-I cells were harvested and $1 \times 10^{6}$ cells were incubated with $1 \% \mathrm{BSA} / \mathrm{PBS}$ for 1 hour in at $4^{\circ} \mathrm{C}$. 
Next, cells were incubated with $1 \mu \mathrm{g}$ of anti-sialyl-Tn (TKH2 antibody [4]) or antigalectin-3 (M3/38, ATCC TIB166) for 1 hour. Subsequently cells were washed with PBS, and primary antibodies were detected with anti-mouse-Alexa488 or anti-ratAlexa488 antibodies for $45 \mathrm{~min}$. After final washing, cells were fixed with $4 \%$ paraformaldehyde. For intracellular staining of galectin-3 after the steps described above, cells were permeabilized with saponin 0.5\%/PBS and incubated with antigalectin-3 and, subsequently, with anti-rat-Alexa488 antibodies. Alternatively, cells were incubated with different doses $10 \mu \mathrm{g}$ of DyLigth 488 labelled-hrGal-3 in the presence or absence of lactose $(50 \mathrm{mM})$ for 1 hour and fixed in $4 \%$ paraformaldeyde. Cleaved caspase $3 / 7$ assay was performed accordingly to manufacturer's instructions (Vybrant FAM Caspase-3 and -7 Assay kit, Life Technologies). Analysis was made using the flow cytometer CyAn ${ }^{\mathrm{TM}}$ ADP Analyzer from Beckman Coulter. Data were subsequently evaluated with FlowJo vX 0.7 software.

\section{Evaluation of cell death by propidium iodide}

$2 \times 10^{5}$ MKN45-Mock or MKN45-ST6GalNAc-I cells were seeded overnight in a 6 well plate and then incubated with cisplatin $(12.5 \mu \mathrm{M}$ or $25 \mu \mathrm{M})$ and hrGal-3 $(2 \mu \mathrm{M})$ in the presence or absence of lactose $(50 \mathrm{mM})$ for additional $48 \mathrm{~h}$. At the end of the experiment, cells were harvested and fixed in ethanol $70 \%$. Cells were then washed 2 times with PBS and incubated with $100 \mu$ L of PBS containing $0.1 \%$ Triton $\mathrm{X}-100$ (Sigma), $200 \mu \mathrm{g} / \mathrm{mL}$ RNAse (Sigma), propidium iodide $20 \mu \mathrm{g} / \mathrm{mL}$ (Invitrogen) for 30 min in the dark. The propidium iodide fluorescence was analyzed with the flow cytometer CyAn ${ }^{\mathrm{TM}}$ ADP Analyzer from Beckman Coulter. Data were subsequently evaluated with FlowJo vX 0.7 software.

\section{Gene expression analysis}

Total RNA from cell cultures or tumor tissue was isolated with Tri-Reagent (Sigma) according to the manufacturer's instructions. Complementary DNA (cDNA) 
was synthesized using the High capacity cDNA RT kit (Applied Biosystems), according to the manufacturer's protocols. Quantitative PCR analysis was performed in triplicate using the SensiMix SYBR No-ROX kit (Bioline). Relative quantification was done using the $\Delta \Delta \mathrm{Ct}$ method normalizing to GAPDH gene expression.

\section{Generation of MKN45 galectin-3 knockdown cells}

Stable shRNA Mock or ST6GalNAc-I cell line targeting galectin-3 (TRCN0000029305, Sigma) or the negative control (SHC016, Sigma) were generated after co-transfection of $30 \mu \mathrm{g}$ of shRNA-containing plasmids with $15 \mu \mathrm{g}$ pPAX2 and $5 \mu \mathrm{g}$ of pMDG.2 (Addgene) into HEK293t packaging cell line utilizing $\mathrm{CaCl}_{2}$ method. The viral supernatant was recovered and the transduced cells were generated by infection with $2 \mathrm{MOI}$ (multiplicity of infectious units) of shRNA lentiviral particles. On the next day, cells were replaced with fresh medium, and a day later, cells were selected with $1 \mu \mathrm{g} / \mathrm{mL}$ of puromycin for 1 week. Galectin-3 knockdown (shRNA-Gal-3) and negative control (scramble) cells were generated and subjected to Western blot to investigate galectin-3 expression.

\section{Western Blotting}

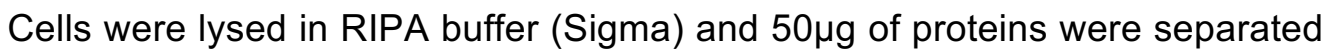
by Novex NuPAGE SDS-PAGE gel system (Invitrogen) and then transferred overnight to a PVDF membrane (Invitrogen). The membrane was incubated with antisialyl-Tn (TKH2 antibody [4]), anti-galectin-3 (M3/38, ATCC TIB166), anti-PARP (cell signaling), anti-p-AKT-ser139 (cell signaling) or anti- $\mathrm{-H}$-HXX (cell signaling). Anti- $\beta$ actin-peroxidase (Sigma) was used as a loading control. Horseradish peroxidase (HRP)-conjugated secondary antibodies (Dako) were detected using the enhanced chemiluminescence (ECL) reagent (GE Healthcare) and images were acquired using ImageQuant (GE HealthCare). 


\section{Cell viability assay}

2000 cells were seeded in a 96 -well plate for $24 \mathrm{~h}$. Next, cells were incubated with or without cisplatin (range from $0.09 \mu \mathrm{M}$ to $50 \mu \mathrm{M}$ ) or 5 -FU (range from $0.9 \mu \mathrm{M}$ to $1 \mathrm{mM}$ ) for a period of $72 \mathrm{~h}$. Cell mass was determined based on the SRB cell protein stain [5]. After this period, cells were fixed with $10 \%$ trichloroacetic acid at $4^{\circ} \mathrm{C}$ for $1 \mathrm{~h}$. The plates were then washed with distilled water and dried. SRB solution $(150 \mu \mathrm{L})$ at $0.4 \%(\mathrm{w} / \mathrm{v})$ in $1 \%$ acetic acid was added and incubated for $30 \mathrm{~min}$ at room temperature. The well plates were then washed with $1 \%$ acetic acid and dried. $100 \mu \mathrm{L}$ $10 \mathrm{mM}$ Tris base was added to the wells to solubilize the bound SRB, and absorbance was then read at $515 \mathrm{~nm}$ on an automated microplate reader (VERSAmax, Molecular Devices, Sunnyvale, CA, USA). Data were analyzed with GraphPad Prism 6.0 software. The experiments were performed at least three times, with each condition plated in triplicate.

\section{Colony Formation Assay}

Cells were plated 500 per well in complete media in six-well plates (Corning, Acton, MA, USA) and allowed to adhere for $24 \mathrm{~h}$. The next day cells were treated with cisplatin $(12.5 \mu \mathrm{M})$ in the presence or absence of galectin-3 $(2 \mu \mathrm{M})$. After $24 \mathrm{~h}$, cisplatin-containing media was removed, and cells were allowed to form colonies in complete media for 14 days. The colonies were then fixed and stained with methanol containing $1 \%$ crystal violet for 1 hour and counted manually.

\section{Sphere formation assay}

MKN45-Mock or -ST6GaINAc-I cells were harvested and $5 \times 10^{4}$ cells $/ \mathrm{mL}$ were ressuspended in ice-cold complete medium. Matrigel (reconstituted basement membrane, BD Bioscience Bedford, MA) was then added at a final concentration of $2.5 \%$ with ice-cold pipette tips to the cell suspension. A volume of $200 \mu \mathrm{L}$ of this suspension was added to each well of a Ultra Low Cluster 96-well plate (Costar 
Chapter 4

7007) with a round bottom. The spheroid formation was initiated by centrifugation of the plates at $1000 \mathrm{~g}$ for $10 \mathrm{~min}$. The plates were then incubated under standard cell culture conditions and at day $4,50 \mu \mathrm{M}$ of cisplatin was added to the culture medium and growth was monitored until day 9. Spheroid growth was photographed with an inverted microscope. The spheroid volume was calculated using the ImageJ software and applying the formula (volume $\left.\left(\mathrm{mm}^{3}\right)=\pi r^{3} 4 / 3\right)$.

\section{Immunofluorescence analysis of cells}

MKN45-Mock or MKN45-ST6GalNAc-I cells were plated in a 24 well glass bottom plate at a density of $5 \times 10^{4}$ overnight. The next day, cells were fixed with methanol. Fixed cells were hydrated with PBS and blocked with $1 \%$ of bovine serum albumin (BSA, Sigma) for 1 hour and incubated with anti-sialyl-Tn (TKH2 antibody [4]), anti-galectin-3 (M3/38, ATCC TIB166) or hrGal-3-DyLight488 for 1 hour. After washing, primary antibodies were detected with anti-mouse-Alexa-546 (Invitrogen) or anti-rat-Alexa488 (Invitrogen). Nucleus were stained with DAPI (4',6-diamidino-2phenylindole) and the coverslips were mounted with Aqua-Poly/Mount medium (Polysciences Inc., Warrington, PA). Pictures were taken using a fluorescent inverted microscope (Zeiss Axiovert 200M).

\section{Immunofluorescence analysis of gastric cancer tissue}

Tissue sections were deparaffinized in xylene and rehydrated in serial alcohol dilutions. Tissue sections were then blocked with $1 \%$ of bovine serum albumin (BSA, Sigma) for 1 hour and incubated with anti-sialyl-Tn (TKH2 antibody [4]), or hrGal-3DyLight488 for 1 hour. After washing, primary antibody were detected with antimouse-Alexa-546 (Invitrogen). Nucleus were stained with DAPI (4',6-diamidino-2phenylindole) and the coverslips were mounted with Aqua-Poly/Mount medium (Polysciences Inc., Warrington, PA). Pictures were taken using a fluorescent inverted microscope (Zeiss Axiovert 200M). 


\section{Immunostaining}

Tissue sections were deparaffinized in xylene and rehydrated in serial alcohol dilutions. Tissue sections were stained with anti-sialyl-Tn antibody ((TKH2 antibody [4]), anti-galectin-3 (M3/38, ATCC TIB166) followed by a secondary anti-mouse or anti-rat biotinylated antibodies (DAKO). Next, streptavidin-peroxidase (DAKO) was added and color development was done with DAB (DAKO). Nuclei were counterstained with hematoxylin. Tissue samples were washed in PBS and mounted in Vectashield (Vector Laboratories, Inc). Alternatively, tissue samples were incubated with hrGal-3/AP [6] for 2 hours and color development was done with Fast Red TR/Naphthol AS-MX and TR phosphate (Sigma), according to the manufacturer's instructions. Sections were counterstained with hematoxylin. The coverslips were mounted with Aqua-Poly/Mount medium (Polysciences Inc., Warrington, PA). As a negative control, an assay using lactose to inhibit the carbohydrate recognition domain of galectin-3 was performed. Representative areas of gastric adenocarcinomas were digitalized by digital camera (axioskop Plus, Zeiss, germany). The tissue were classified using a 0 -to-3 scale: 0 for $0-5 \%$ positive tumor cells, 1 for $6-50 \%$ positive tumor cells, 2 for $>50 \%$ positive tumor cells.

\section{In vivo studies}

Balb/c nude mice were bred at the animal facility of FMUSP and all experiments complied with the relevant laws and were approved by local animal ethics committees. Six- to 8-week-old male Balb/c nude mice were implanted subcutaneously with $2 \times 10^{6}$ MKN45-Mock or MKN45-ST6GalNAc-I cells. Each group consisted of five mice. When tumors reached the size of $1-1.5 \mathrm{~cm}^{3}$, mice were sacrificed, tumors were excised and fragmented for immunohistochemical staining and mRNA expression analysis. Each animal experiment was repeated at least 3 times. 


\section{Statistical Analysis}

All data are expressed as the mean \pm SEM of at least three independent experiments. Statistical analysis including t-test, one-way ANOVA and two-way ANOVA were done using GraphPad Prism 6.0 software. $p<0.05$ was considered statistically significant.

\section{Supplemental references}

1. Tamura G, Sakata K, Nishizuka S, Maesawa C, Suzuki Y, Iwaya T, Terashima M, Saito K and Satodate R. Inactivation of the E-cadherin gene in primary gastric carcinomas and gastric carcinoma cell lines. Japanese journal of cancer research : Gann. 1996; 87(11):1153-1159.

2. Marcos NT, Pinho S, Grandela C, Cruz A, Samyn-Petit B, Harduin-Lepers A, Almeida R, Silva F, Morais V, Costa J, Kihlberg J, Clausen $\mathrm{H}$ and Reis CA. Role of the human ST6GalNAc-I and ST6GalNAc-II in the synthesis of the cancer-associated sialyl-Tn antigen. Cancer research. 2004; 64(19):7050-7057.

3. Hsu DK, Zuberi RI and Liu FT. Biochemical and biophysical characterization of human recombinant IgE-binding protein, an S-type animal lectin. The Journal of biological chemistry. 1992; 267(20):14167-14174.

4. Jass JR, Allison LM and Edgar S. Monoclonal antibody TKH2 to the cancer-associated epitope sialosyl Tn shows cross-reactivity with variants of normal colorectal goblet cell mucin. Pathology. 1994; 26(4):418-422.

5. Voigt W. Sulforhodamine B assay and chemosensitivity. Methods in molecular medicine. 2005; 110:39-48.

6. de Melo FH, Butera D, Medeiros RS, Andrade LN, Nonogaki S, Soares FA, Alvarez RA, Moura da Silva AM and Chammas R. Biological applications of a chimeric probe for the assessment of galectin-3 ligands. The journal of histochemistry and cytochemistry : official journal of the Histochemistry Society. 2007; 55(10):1015-1026. 


\section{Chapter}

\section{General Discussion}

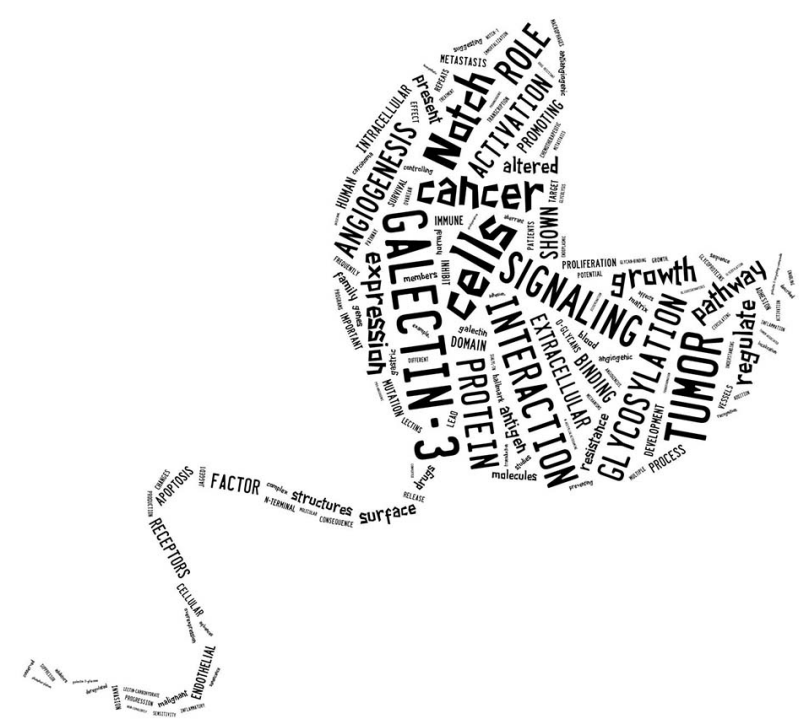



Over the past few years several studies have focused on the role of galectin3 in tumor biology, however future research is still needed to precisely determine which glycoproteins recognized by galectin-3 are responsible for its pro-tumoral functions, and the conditions under which galectin-3 can affect tumor progression. Several binding partners for galectin-3 have been identified so far, such as EGFR, VEGFR, MUC1 and integrins [1-3], but various other glycoproteins that may bind galectin-3 have not yet been discovered. In Chapter 2 of the present thesis, galectin3 was found to preferentially activate Jagged1/Notch signaling activation while galectin-1, another member of galectins family, preferentially activated DLL4/Notch signaling in tumor cells.

Notch receptors and ligands are frequently aberrantly expressed in a wide range of cancers such as breast, colorectal, pancreatic and melanoma [4]. Jagged1 ligand, expressed in several types of tumor cells lines and tumor samples, has proven to play roles in multiple aspects of cancer biology such as cell growth, proliferation, cancer stem cells, epithelial-mesenchymal transition (EMT), metastatic process, resistance to therapy and, more recently in angiogenesis [5]. Delta-like-4, usually expressed in endothelial cells, has been associated with tumor angiogenesis, metastasis and cancer stem cells $[6,7]$. Several strategies have been used to inhibit Notch signaling, such as small-molecule inhibitors of the $y$-secretase complex, which prevent the release of NICD [8], antisense Notch [9], RNA interference [10] and soluble receptor decoys that act by sequestering Notch ligands [11], though, they are still far from actual therapeutic application. Therefore, the identification of novel molecules that can control ligand-dependent Notch signaling activation may have a direct impact for the development of strategies aimed at controlling tumor progression.

In Chapter 3 we found that galectin-3 is a key protein in shifting normal resting blood vessel to a growth phase via activation of Jagged1/Notch signaling. To date, most antiangiogenic therapies are designed to disrupt VEGF-VEGFR 
interactions. Several angiogenesis inhibitors have already been approved by the U.S. Food and Drug Administration (FDA), like Bevacizumab, Sorafenib and Sunitinib, and are currently used to treat cancer treatment other diseases, such as macular degeneration [12-15]. However, most tumors develop mechanisms of resistance to antiangiogenic agents [16] probably because multiple signaling pathways are involved in angiogenesis, and more than one pathway is often dysregulated in human tumors. Therefore, blocking a specific pathway often induce tumor cells to develop other angiogenesis mechanisms that lead to antiangiogenic therapy resistance. In fact, the Notch signaling pathway has been associated with increased tumor angiogenesis. DLL4 expression was reported to be strongly express in the endothelium of tumor blood vessels with a decreased expression in normal blood vessels $[17,18]$. DLL4 expression seems to be regulated directly by VEGF in the context of tumor angiogenesis, and acts as a negative modulator of angiogenesis by downregulating excessive VEGF-induced sprouting [18]. Interestingly, although DLL4 inhibition leads to increase tumor vasculature density, this vascular network is essentially non-functional [18]. Several studies have reported that DLL4 inhibition decreases tumor growth in tumor models that are resistant to VEGF inhibitors [19, 20], suggesting that inhibition of this pathway is an attractive alternative for tumors resistant to VEGF inhibitors.

On the other hand, Jagged1 seems to be elicited by tumor microenvironmental stress and its overexpression both in tumor cells and endothelial cells, has been associated with increased tumor angiogenesis [21-23]. Inhibition of Jagged 1 by siRNA or using a soluble Notch decoy that prevented Jagged1 binding to Notch receptor, were found to inhibit angiogenesis both in vitro and in vivo in a human model of head and neck squamous cell carcinoma and in breast and neuroblastoma cancer models [24, 25]. Interestingly, activation of Jagged1/Notch1 signaling pathway was found to contribute to vessel stability when the VEGF/VEGFR2 pathway is inhibited [26]. Although targeting DLL4 or Jagged1, as 
well as the use of broad inhibitors of Notch receptor activation seem to be promising to inhibit angiogenesis in tumors, clinical development has encountered significant challenges with dose limiting intestinal adverse events [27]. Consequently, additional studies are still needed to understand the role that Notch individual components play in tumor angiogenesis before moving forward in Notch-directed therapies for clinical application.

Our results suggest that galectin-3 may limit the efficacy of anti-VEGF treatment by dysregulating the Jagged1/Notch signaling pathway. Thus, targeting galectin-3 may be an approach to indirectly inhibit Jagged1/Notch signaling and a way to overcome anti-VEGF resistance. Indeed, galectins are promising targets for antiangiogenic therapy. Galectin-1 binding to endothelial cells has already been associated with resistance to anti-VEGF therapy, and inhibiting galectin-1 could restore sensitivity to anti-VEGF therapy [27]. Since targeting Notch is still far from clinical application, the use of a combination treatment targeting both VEGF and galectin-3 may minimize side effects and provide a more efficient inhibition of tumor angiogenesis and tumor growth.

Future research on the role of galectin-3 in angiogenesis should address whether galectin-3 inhibitors, such as small molecules or antibodies can revert tumor resistance to anti-VEGF therapies. Moreover, a deeper understanding on the role of galectin-3 in Notch ligands regulation such as cell surface stabilization, endocytosis or turnover might be of great value to develop targeted antiangiogenic therapies.

Altered expression and localization of galectin-3 in cancer possibly reflect changes in the glycosylation machinery. Throughout this thesis (chapter 4), it was uncovered that galectin-3 intracellular accumulation caused be ST6GaINAc-I overexpression was responsible for platinum-drugs resistance in gastric cancer. These data illustrate a new mechanism of chemoresistance and demonstrate the importance of cellular glycosylation machinery in response to drugs. Since resistance to chemotherapy is the major obstacle to the clinical treatment of cancer, the findings 
of the present thesis suggest that a careful evaluation of STn expression and galectin-3 subcellular localization in tumors could help predict which patient will benefit from a platinum-based therapy. Moreover, our results suggest that future therapies targeting intracellular galectin-3 and/or ST6GalNAc-I enzyme could be a strategy to overcome STn-expressing cells resistance to chemotherapeutic drugs.

Galectin-3-specific low molecular weight inhibitors have been used as a strategy to block galectin-3 CRD. Indeed, lactulosyl-I-leucine (Lac-I-Leu), a synthetic low-molecular weight carbohydrate-based galectin-3 inhibitor, was found to reduce spontaneous human breast cancer metastasis in nude mice [28], and to increase susceptibility of the human metastatic cancer cell MDA-MB-435 to apoptosis induced by Taxol (paclitaxel) both in vitro and in vivo [29]. However, several galectin-3 intracellular functions do not involve lectin-carbohydrate interactions. Moreover, there are still several issues concerning the bioavailability of these compounds in vivo, mainly due to hydrolysis, metabolism and short half-lives. RNA interference strategy is another way to inhibit both the intra- and the extracellular galectin-3. Still, several obstacles need to be overcome before the design of preclinical and clinical studies based on RNAi therapeutics, such as validation of the delivery systems, careful evaluation of the target and safety of the delivery system [30].

Regarding sialyl-Tn, several anti-STn antibodies have been generated, such as $\mathrm{B} 72.3, \mathrm{TKH} 2, \mathrm{CC} 49$ and HB-STn1, and have been mainly used for diagnosis, imaging and radiotherapy [31-35]. More recently, LLU9B4 and 3P9 antibodies have been generated by immunization of mice with STn glycoproteins extracted from the human colon adenocarcinoma cell line LS174T and the human colorectal adenocarcinoma SW1116 cells, respectively [36, 37]. 3P9 antibody showed significant inhibitory effect on proliferation and migration of STn expressing cells and tumor growth, suggesting a potential application of this antibody for tumor therapy. While most of these antibodies are promising, their fine specificity is still unclear and the potential therapeutic effect on cancer cells and patient tissues needs to be 
carefully assessed prior to their use in clinic as therapeutic agents. Still, STn antigen is a good tumor marker and a few strategies have been developed to create an antiSTn vaccine, such as the Theratope immunotherapy (from Biomira Inc), which entered clinical trials and reached Phase III (NCT00046371) [38]. However, so far no vaccine has been approved for clinical use since vaccines failed to induce a protective immune response and no survival benefit was found in patients.

ST6GalNAc-I inhibition is also an attractive strategy to overcome STninduced resistance to chemotherapeutic drugs. However, to date, no specific inhibitor has been used to alter ST6GalNAc-I expression levels. Over the last few years, several sialyltransferase inhibitors based on the enzyme donor analog or receptor analog have been designed. For example, P-3F(ax)-Neu5Ac, a sialic acid analog, was found to be a competitive inhibitor of all sialyltransferases, blocking the synthesis of sialoglycans in murine melanoma cells and reducing cell adhesion, migration, and tumor growth [39]. In addition, a natural product such as Lith-O-Asp (a potential pan-sialyltransferase inhibitor), was found to reduce cell migration of various cancer cells and to have antimetastatic activity in an in vivo model of breast cancer [40]. However, all sialyltransferase inhibitors developed so far inhibit a broad range of sialyltransferases and their effectiveness does not appear to be promising for clinical applications. Further research should explore the inhibition of specific sialyltransferases in order to avoid disrupting the physiologically important sialylation.

\section{What future holds for galectin-3?}

Galectin-3 expression is increased in the serum of patients under several pathological conditions [41-43]. Therefore, a great challenge for the future will be to use inhibitors of galectin-3 for the treatment of different pathological conditions. Indeed, several larger glycans that are less subject to clearance and metabolism, have been developed to inhibit galectin-3 extracellular functions. Modified citrus pectins (MCP), a potential cancer therapeutic agent, act as competitive inhibitor of 
the carbohydrate-binding domain of galectin-3 and has been shown to inhibit galectin-3-mediated survival function [44]. Similarly, GCS-100 (La Jolla Pharmaceuticals; Prospect Therapeutics) is a large modified glycan $(\sim 1000 \mathrm{kDa})$, and has been shown to be effective in pre-clinical models of multiple myeloma, lymphoma, leukemia, and solid tumors [45-47]. Galectin Therapeutics, Inc. already has GM-CT-01, a carbohydrate complex that targets galectin-3 and galectin-1, in phase 2 clinical trial for the treatment of metastatic colorectal cancer (NCT00110721). Moreover, GR-MD-02, another carbohydrate-based complex targeting galectin-3, has also shown significant therapeutic effects on fibrosis regression and reversal of cirrhosis [48] and is currently in phase 2 clinical trial (NCT02421094). TD139 [49] (Galecto Biotech) was recently approved by the Food and Drugs Administration (FDA) for the treatment of patients with idiopathic pulmonary fibrosis and is currently in phase Ib/lla trial (NCT02257177). However, these promising therapeutics agents still need to be fully characterized regarding their binding and mechanism of action, since they are not specific for galectin-3 and can also recognize other galectins. Therefore, further research will still be needed to specifically inhibit extracellular galectin-3.

Since galectin-3 N-terminal domain is essential for full biological activity of galectin-3, an alternative approach to inhibit this protein could be the design of compounds that target galectin-3 at a site different from the canonical betagalactoside binding site. Indeed, N-terminally truncated galectin-3 (Gal-3C) has shown promising anticancer activity by inhibiting endogenous galectin-3. Gal-3C was found to reduce tumor growth and metastasis in an orthotopic xenograft mouse model of breast cancer [50]. Moreover, Gal-3C in combination with bortezomib produced a significant reduction in the tumor volume of a murine model of human multiple myeloma, compared to Gal-3C or bortezomib treatment alone [51]. However, one of the challenges in the development of Gal-3C for treatment of cancer has been 
the elucidation of the molecular mechanism under which Gal-3C exerts its anticancer activities.

For all the above-mentioned studies, one can imagine that the key to control the biological functions of the galectins is to find out how their secretion is regulated during physiological and pathological conditions. However, how galectins are secreted or shuttle between the nucleus and cytoplasm are still unanswered questions. Since the role of galectin-3 depends on its subcellular localization, an approach to control galectin-3 cellular localization could be an alternative way to inhibit a particular function of galectin-3. Indeed, using a new approach to manipulate the genome of mammalian cells (CRISPR/Cas) [52], we targeted an intronic region of the galectin-3 gene (Lgals3) and surprisingly found that gastric cancer cell MKN45 lost the extracellular expression of galectin-3 but kept their intracellular pool (total galectin-3, Figure 1A). Interestingly, cells that accumulated intracellular galectin-3 also displayed an enhanced Notch activation (Appendix A, Figure 1), suggesting a role for intracellular galectin-3 in modulating Notch activation. Therefore, future research should focus on the development of inhibitors that will differentiate intracellular from extracellular galectin-3. Moreover, understanding the mechanism by which extracellular/intracellular galectin-3 modulates Notch signaling pathway activation in endothelial and tumor cells, may help to develop better therapeutic strategies to inhibit Gal-3-Notch axis. Therefore, using CRISPr/Cas9 approach, future research should focus on understanding the biology of galectin-3 secretion. Since microRNAs may control protein exocytosis [53], our working hypothesis is that an intron-derided microRNA or intron-binding proteins may control galectin-3 cellular localization. This knowledge may open new perspectives on how galectin-3 compartmentalization (nuclear, cytoplasmic and cell surface) is regulated, and also how intracellular/extracellular galectin-3 affects Notch signaling pathway. Moreover, CRISPr/Cas9 could be a valuable tool for galectin-3-editing therapy. 
Elevated concentrations of galectin-3 are found in the bloodstream of patients with many types of cancers including breast, lung, gastrointestinal and ovarian. These levels are further increased in patients with metastatic disease [54]. Several studies have demonstrated that the increased circulation of galectin-3 may increase cell adhesion to vascular endothelium, cancer cell homotypic aggregation for the formation of tumor emboli and angiogenesis, facilitating the process of metastasis $[55,56]$. Therefore, targeting circulating galectin-3 in the bloodstream of cancer patients seems to be a very promising strategy to prevent metastasis formation and improve patient survival. However, several unanswered questions remain about what happens following the administration of galectin-3 inhibitors. Where are galectin-3 inhibitors acting? Do they inhibit serum galectin-3? Do they reach the tumor mass? Therefore, before galectin-3-based therapeutic agents can be fully recognized, a more comprehensive understanding of the mechanisms involved in their different cellular functions is required.

Indeed, galectin-3 inhibitors are not expected to be a miracle drug to cure cancer. In several types of cancer, such as ovarian and cervical, galectin-3 have proapoptotic effects in cancer cells and seems to be favorable for patients [57, 58]. Moreover, galectin-3 knockout mice have been shown to be perfectly healthy suggesting a strong redundancy in the galectins family in which, in the absence of one member, others are believed to restore its functions $[59,60]$. In fact, galectin- 9 was found to partially substitute the function of galectin-3 in galectin-3-null mice [60] and, our preliminary results suggest that galectin-9 have similar functions to the ones found for galectin-3. Indeed, galectin-9 was secreted during hypoxia by MDA-MB-231 and MCF7 breast cancer cells but not by endothelial cells (Appendix A, Figure 2A-C) and its mRNA levels were decreased in HUVECs under hypoxic conditions (Appendix A, Figure 2D). Galectin-9 consists of two carbohydrate-recognition domains (CRD) joined by a linker peptide, which is highly susceptible to proteolysis. To increase protease resistance, mutant proteins (Gal-9M, Gal-9S and Gal-9null) 
were prepared by serial truncation of the linker peptide and were found to be highly stable against proteolysis [61, 62]. Mutants recombinant galectin-9, a kind gift from Nishi Nozomu, Department of Endocrinology, Faculty of Medicine, Kagawa University, Japan, were produced accordingly to a previously established protocol $[61,62]$. Galectin-9 purity and biological activity was confirmed by SDS-PAGE (Appendix A, Figure 1E) and by galectin-9 ability to reduce prostate cancer cells (PC3) viability (Appendix A, Figure $2 F$ and $2 G$ ). Similar to galectin-3, exogenously added galectin- 9 was able to increase HUVECs sprout area and length in a carbohydrate dependent-manner (Appendix A, Figure 2H-2J). Consequently, an effective therapy against cancer may require the use of galectin inhibitors with a more broad specificity. 


\section{Conclusion}

While the knowledge of galectin-3 function in the tumor microenvironment is growing, there are still many unresolved questions. In recent years, it has become clear that combined targeting of different pathways could improve the efficacy of cancer therapies. Our results suggest that future therapeutic protocols using galectin3's inhibitors with conventional drugs may provide novel experimental strategies to overcome both platinum and antiangiogenic therapy resistance. However, understanding of cancer complexity depends on an elucidation of the underlying regulatory networks, both at the cellular and intercellular levels. Therefore, a better understanding of the glycosylation changes during tumor progression can help link altered galectin-3 expression to diagnosis and prognosis and may help to stay onestep ahead of cancer. 


\section{References}

1. Merlin J, Stechly L, de Beauce S, Monte D, Leteurtre E, van Seuningen I, et al. Galectin-3 regulates MUC1 and EGFR cellular distribution and EGFR downstream pathways in pancreatic cancer cells. Oncogene. 2011 Jun 2;30(22):2514-25.

2. Markowska AI, Liu FT, Panjwani N. Galectin-3 is an important mediator of VEGF- and bFGFmediated angiogenic response. The Journal of experimental medicine. 2010 Aug 30;207(9):1981-93.

3. Zhuo Y, Chammas R, Bellis SL. Sialylation of beta1 integrins blocks cell adhesion to galectin-3 and protects cells against galectin-3-induced apoptosis. The Journal of biological chemistry. 2008 Aug 8;283(32):22177-85.

4. Koch U, Radtke F. Notch and cancer: a double-edged sword. Cellular and molecular life sciences : CMLS. 2007 Nov;64(21):2746-62.

5. Li D, Masiero M, Banham AH, Harris AL. The notch ligand JAGGED1 as a target for anti-tumor therapy. Frontiers in oncology. 2014;4:254.

6. Hoey T, Yen WC, Axelrod F, Basi J, Donigian L, Dylla S, et al. DLL4 blockade inhibits tumor growth and reduces tumor-initiating cell frequency. Cell stem cell. 2009 Aug 7;5(2):168-77.

7. Huang QB, Ma X, Li HZ, Ai Q, Liu SW, Zhang Y, et al. Endothelial Delta-like 4 (DLL4) promotes renal cell carcinoma hematogenous metastasis. Oncotarget. 2014 May 30;5(10):3066-75.

8. Mizutani T, Taniguchi Y, Aoki T, Hashimoto N, Honjo T. Conservation of the biochemical mechanisms of signal transduction among mammalian Notch family members. Proceedings of the National Academy of Sciences of the United States of America. 2001 Jul 31;98(16):9026-31.

9. Garces C, Ruiz-Hidalgo MJ, Font de Mora J, Park C, Miele L, Goldstein J, et al. Notch-1 controls the expression of fatty acid-activated transcription factors and is required for adipogenesis. The Journal of biological chemistry. 1997 Nov 21;272(47):29729-34.

10. Nickoloff BJ, Qin JZ, Chaturvedi V, Denning MF, Bonish B, Miele L. Jagged-1 mediated activation of notch signaling induces complete maturation of human keratinocytes through NF-kappaB and PPARgamma. Cell death and differentiation. 2002 Aug;9(8):842-55.

11. Kangsamaksin T, Murtomaki A, Kofler NM, Cuervo H, Chaudhri RA, Tattersall IW, et al. NOTCH decoys that selectively block DLL/NOTCH or JAG/NOTCH disrupt angiogenesis by unique mechanisms to inhibit tumor growth. Cancer discovery. 2015 Feb;5(2):182-97.

12. Cook KM, Figg WD. Angiogenesis inhibitors: current strategies and future prospects. CA: a cancer journal for clinicians. 2010 Jul-Aug;60(4):222-43.

13. Santarelli M, Diplotti L, Samassa F, Veritti D, Kuppermann BD, Lanzetta P. Advances in pharmacotherapy for wet age-related macular degeneration. Expert opinion on pharmacotherapy. 2015;16(12):1769-81.

14. Shih T, Lindley C. Bevacizumab: an angiogenesis inhibitor for the treatment of solid malignancies. Clinical therapeutics. 2006 Nov;28(11):1779-802.

15. Siemann DW. The unique characteristics of tumor vasculature and preclinical evidence for its selective disruption by Tumor-Vascular Disrupting Agents. Cancer treatment reviews. 2011 Feb;37(1):63-74

16. Bergers G, Hanahan D. Modes of resistance to anti-angiogenic therapy. Nature reviews Cancer. 2008 Aug;8(8):592-603.

17. Mailhos C, Modlich U, Lewis J, Harris A, Bicknell R, Ish-Horowicz D. Delta4, an endothelial specific notch ligand expressed at sites of physiological and tumor angiogenesis. Differentiation; research in biological diversity. $2001 \mathrm{Dec} ; 69(2-3): 135-44$

18. Patel NS, Li JL, Generali D, Poulsom R, Cranston DW, Harris AL. Up-regulation of delta-like 4 ligand in human tumor vasculature and the role of basal expression in endothelial cell function. Cancer research. 2005 Oct 1;65(19):8690-7.

19. Noguera-Troise I, Daly C, Papadopoulos NJ, Coetzee S, Boland P, Gale NW, et al. Blockade of Dll4 inhibits tumour growth by promoting non-productive angiogenesis. Nature. 2006 Dec 21;444(7122):1032-7.

20. Ridgway J, Zhang G, Wu Y, Stawicki S, Liang WC, Chanthery Y, et al. Inhibition of DIl4 signalling inhibits tumour growth by deregulating angiogenesis. Nature. 2006 Dec 21;444(7122):1083-7.

21. Benedito R, Roca C, Sorensen I, Adams S, Gossler A, Fruttiger M, et al. The notch ligands DIl4 and Jagged1 have opposing effects on angiogenesis. Cell. 2009 Jun 12;137(6):1124-35.

22. Pedrosa AR, Trindade A, Fernandes AC, Carvalho C, Gigante J, Tavares AT, et al. Endothelial Jagged1 antagonizes DII4 regulation of endothelial branching and promotes vascular maturation downstream of DIl4/Notch1. Arteriosclerosis, thrombosis, and vascular biology. 2015 May;35(5):113446.

23. Steg AD, Katre AA, Goodman B, Han HD, Nick AM, Stone RL, et al. Targeting the notch ligand JAGGED1 in both tumor cells and stroma in ovarian cancer. Clinical cancer research : an official journal of the American Association for Cancer Research. 2011 Sep 1;17(17):5674-85.

24. Funahashi Y, Hernandez SL, Das I, Ahn A, Huang J, Vorontchikhina M, et al. A notch1 ectodomain construct inhibits endothelial notch signaling, tumor growth, and angiogenesis. Cancer research. 2008 Jun 15;68(12):4727-35. 
25. Zeng Q, Li S, Chepeha DB, Giordano TJ, Li J, Zhang H, et al. Crosstalk between tumor and endothelial cells promotes tumor angiogenesis by MAPK activation of Notch signaling. Cancer cell. 2005 Jul;8(1):13-23.

26. Zaghloul N, Hernandez SL, Bae JO, Huang J, Fisher JC, Lee A, et al. Vascular endothelial growth factor blockade rapidly elicits alternative proangiogenic pathways in neuroblastoma. International journal of oncology. $2009 \mathrm{Feb} ; 34(2)$ :401-7.

27. Croci DO, Cerliani JP, Dalotto-Moreno T, Mendez-Huergo SP, Mascanfroni ID, Dergan-Dylon $\mathrm{S}$, et al. Glycosylation-dependent lectin-receptor interactions preserve angiogenesis in anti-VEGF refractory tumors. Cell. 2014 Feb 13;156(4):744-58.

28. Glinsky GV, Price JE, Glinsky VV, Mossine VV, Kiriakova G, Metcalf JB. Inhibition of human breast cancer metastasis in nude mice by synthetic glycoamines. Cancer research. 1996 Dec 1;56(23):5319-24.

29. Glinsky VV, Kiriakova G, Glinskii OV, Mossine VV, Mawhinney TP, Turk JR, et al. Synthetic galectin-3 inhibitor increases metastatic cancer cell sensitivity to taxol-induced apoptosis in vitro and in vivo. Neoplasia. 2009 Sep;11(9):901-9.

30. Wu SY, Lopez-Berestein G, Calin GA, Sood AK. RNAi therapies: drugging the undruggable. Science translational medicine. 2014 Jun 11;6(240):240ps7.

31. Colcher D, Hand PH, Nuti M, Schlom J. A spectrum of monoclonal antibodies reactive with human mammary tumor cells. Proceedings of the National Academy of Sciences of the United States of America. 1981 May;78(5):3199-203.

32. Kjeldsen $\mathrm{T}$, Clausen $\mathrm{H}$, Hirohashi S, Ogawa T, lijima H, Hakomori S. Preparation and characterization of monoclonal antibodies directed to the tumor-associated O-linked sialosyl-2----6 alpha-N-acetylgalactosaminyl (sialosyl-Tn) epitope. Cancer research. 1988 Apr 15;48(8):2214-20.

33. Muraro R, Kuroki M, Wunderlich D, Poole DJ, Colcher D, Thor A, et al. Generation and characterization of B72.3 second generation monoclonal antibodies reactive with the tumor-associated glycoprotein 72 antigen. Cancer research. 1988 Aug 15;48(16):4588-96.

34. Rogers BE, Roberson PL, Shen S, Khazaeli MB, Carpenter M, Yokoyama S, et al. Intraperitoneal radioimmunotherapy with a humanized anti-TAG-72 (CC49) antibody with a deleted $\mathrm{CH} 2$ region. Cancer biotherapy \& radiopharmaceuticals. 2005 Oct;20(5):502-13.

35. Zhang S, Walberg LA, Ogata S, Itzkowitz SH, Koganty RR, Reddish M, et al. Immune sera and monoclonal antibodies define two configurations for the sialyl Tn tumor antigen. Cancer research. 1995 Aug 1;55(15):3364-8.

36. An Y, Han W, Chen X, Zhao X, Lu D, Feng J, et al. A novel anti-sTn monoclonal antibody 3P9 Inhibits human xenografted colorectal carcinomas. Journal of immunotherapy. 2013 Jan;36(1):20-8.

37. Pant KD, Jain A, McCracken JD, Thompson K. Immunohistochemical examination of anti-STn monoclonal antibodies LLU9B4, B72.3, and B35.2 for their potential use as tumor markers. Digestive diseases and sciences. 2008 Aug;53(8):2189-94.

38. Miles D, Roche H, Martin M, Perren TJ, Cameron DA, Glaspy J, et al. Phase III multicenter clinical trial of the sialyl-TN (STn)-keyhole limpet hemocyanin $(K L H)$ vaccine for metastatic breast cancer. The oncologist. 2011;16(8):1092-100.

39. Bull C, Boltje TJ, Wassink M, de Graaf AM, van Delft FL, den Brok MH, et al. Targeting aberrant sialylation in cancer cells using a fluorinated sialic acid analog impairs adhesion, migration, and in vivo tumor growth. Molecular cancer therapeutics. 2013 Oct;12(10):1935-46.

40. Chen JY, Tang YA, Huang SM, Juan HF, Wu LW, Sun YC, et al. A novel sialyltransferase inhibitor suppresses FAK/paxillin signaling and cancer angiogenesis and metastasis pathways. Cancer research. 2011 Jan 15;71(2):473-83.

41. Ozturk D, Celik O, Satilmis S, Aslan S, Erturk M, Cakmak HA, et al. Association between serum galectin-3 levels and coronary atherosclerosis and plaque burden/structure in patients with type 2 diabetes mellitus. Coronary artery disease. 2015 Aug;26(5):396-401.

42. Zhang R, Sun T, Song L, Zuo D, Xiao W. Increased levels of serum galectin-3 in patients with primary Sjogren's syndrome: associated with interstitial lung disease. Cytokine. 2014 Oct;69(2):289-93.

43. Balan V, Wang Y, Nangia-Makker P, Kho D, Bajaj M, Smith D, et al. Galectin-3: a possible complementary marker to the PSA blood test. Oncotarget. $2013 \mathrm{Apr} ; 4(4): 542-9$.

44. Glinsky VV, Raz A. Modified citrus pectin anti-metastatic properties: one bullet, multiple targets. Carbohydrate research. 2009 Sep 28;344(14):1788-91.

45. Demotte N, Wieers G, Van Der Smissen P, Moser M, Schmidt C, Thielemans K, et al. A galectin-3 ligand corrects the impaired function of human CD4 and CD8 tumor-infiltrating lymphocytes and favors tumor rejection in mice. Cancer research. 2010 Oct 1;70(19):7476-88.

46. Streetly MJ, Maharaj L, Joel S, Schey SA, Gribben JG, Cotter FE. GCS-100, a novel galectin-3 antagonist, modulates MCL-1, NOXA, and cell cycle to induce myeloma cell death. Blood. 2010 May 13;115(19):3939-48.

47. Thijssen VL, Heusschen R, Caers J, Griffioen AW. Galectin expression in cancer diagnosis and prognosis: A systematic review. Biochimica et biophysica acta. 2015 Apr;1855(2):235-47.

48. Traber PG, Chou H, Zomer E, Hong F, Klyosov A, Fiel MI, et al. Regression of fibrosis and reversal of cirrhosis in rats by galectin inhibitors in thioacetamide-induced liver disease. PloS one. 2013;8(10):e75361. 
49. Mackinnon AC, Gibbons MA, Farnworth SL, Leffler H, Nilsson UJ, Delaine T, et al. Regulation of transforming growth factor-beta1-driven lung fibrosis by galectin-3. American journal of respiratory and critical care medicine. 2012 Mar 1;185(5):537-46.

50. John CM, Leffler H, Kahl-Knutsson B, Svensson I, Jarvis GA. Truncated galectin-3 inhibits tumor growth and metastasis in orthotopic nude mouse model of human breast cancer. Clinical cancer research : an official journal of the American Association for Cancer Research. 2003 Jun;9(6):2374-83.

51. Mirandola L, Yu Y, Chui K, Jenkins MR, Cobos E, John CM, et al. Galectin-3C inhibits tumor growth and increases the anticancer activity of bortezomib in a murine model of human multiple myeloma. PloS one. 2011;6(7):e21811.

52. Savic N, Schwank G. Advances in therapeutic CRISPR/Cas9 genome editing. Translational research : the journal of laboratory and clinical medicine. 2015 Sep 26.

53. Poy MN, Eliasson L, Krutzfeldt J, Kuwajima S, Ma X, Macdonald PE, et al. A pancreatic isletspecific microRNA regulates insulin secretion. Nature. 2004 Nov 11;432(7014):226-30.

54. lurisci I, Tinari N, Natoli C, Angelucci D, Cianchetti E, lacobelli S. Concentrations of galectin-3 in the sera of normal controls and cancer patients. Clinical cancer research : an official journal of the American Association for Cancer Research. 2000 Apr;6(4):1389-93.

55. Chen C, Duckworth CA, Zhao Q, Pritchard DM, Rhodes JM, Yu LG. Increased circulation of galectin-3 in cancer induces secretion of metastasis-promoting cytokines from blood vascular endothelium. Clinical cancer research : an official journal of the American Association for Cancer Research. 2013 Apr 1;19(7):1693-704.

56. Fortuna-Costa A, Gomes AM, Kozlowski EO, Stelling MP, Pavao MS. Extracellular galectin-3 in tumor progression and metastasis. Frontiers in oncology. 2014;4:138.

57. Cortesi L, Rossi E, Della Casa L, Barchetti A, Nicoli A, Piana S, et al. Protein expression patterns associated with advanced stage ovarian cancer. Electrophoresis. 2011 Aug;32(15):1992-2003.

58. Lee JW, Song SY, Choi JJ, Choi CH, Kim TJ, Kim J, et al. Decreased galectin-3 expression during the progression of cervical neoplasia. Journal of cancer research and clinical oncology. 2006 Apr;132(4):241-7.

59. Colnot C, Fowlis D, Ripoche MA, Bouchaert I, Poirier F. Embryonic implantation in galectin 1/galectin 3 double mutant mice. Developmental dynamics : an official publication of the American Association of Anatomists. 1998 Apr;211(4):306-13.

60. Vijayakumar S, Peng H, Schwartz GJ. Galectin-3 mediates oligomerization of secreted hensin using its carbohydrate-recognition domain. American journal of physiology Renal physiology. 2013 Jul 1;305(1):F90-9.

61. Itoh A, Fukata Y, Miyanaka H, Nonaka Y, Ogawa T, Nakamura T, et al. Optimization of the inter-domain structure of galectin-9 for recombinant production. Glycobiology. 2013 Aug;23(8):920-5.

62. Nishi N, Itoh A, Fujiyama A, Yoshida N, Araya S, Hirashima M, et al. Development of highly stable galectins: truncation of the linker peptide confers protease-resistance on tandem-repeat type galectins. FEBS letters. 2005 Apr 11;579(10):2058-64. 


\section{Curriculum Vitae}

Name: Sofia Nascimento dos Santos

Nacionality: Portuguese

Address: Instituto de Pesquisas Energéticas e Nucleares, Centro de Radiofarmácia Av. Prof. Lineu Prestes, 2242, CEP: 05508-000, São Paulo, SP, Brazil

Email: snsantos@usp.br

\section{Academic qualifications}

2011 - present $\quad$ PhD student at Faculty of Medicie, University of São Paulo, Brazil.

2007-2009 Master degree in Human Molecular Biology, Faculty of Science, University of Lisbon, Portugal.

2004-2007 Graduation in Molecular and Cellular Biology, Faculty of Science and Technology, New University of Lisbon, Portugal

\section{Publications}

\section{Articles}

Oliveira FL, Bernardes ES, Brand C, Dos Santos SN, Cabanel MP, Arcanjo KD, Brito JM, Borojevic R, Chammas R, El-Cheikh MC. Lack of galectin-3 up-regulates IgA expression by peritoneal B1 lymphocytes during B cell differentiation. Cell Tissue Res. 2015.

Machado CM, Andrade LN, Teixeira VR, Costa FF, Melo CM, dos Santos SN, Nonogaki S, Liu FT, Bernardes ES, Camargo AA, Chammas R. Galectin-3 disruption impaired tumoral angiogenesis by reducing VEGF secretion from TGF $\beta 1$-induced macrophages. Cancer Med. 2014 Apr;3(2):201-14.

\section{Book Chapter}

Santos SN. Biologia Tumoral. Ademar Lopes, Roger Chammas, Hirofumi Yeyasu. (Org.). Oncologia para a graduação. 3ed.São Paulo: Le Mar, 2013, v. 1, p. 1-752. 


\section{Appendix}

Appendix A

Figures relative to Chapter 5 . 



\section{Appendix}

Figures relative to Chapter 5
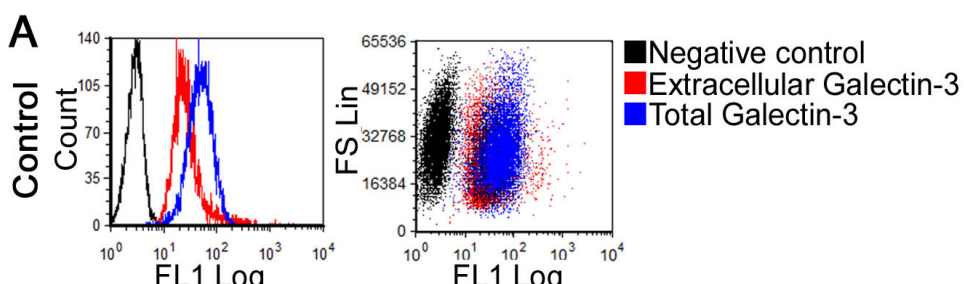

B
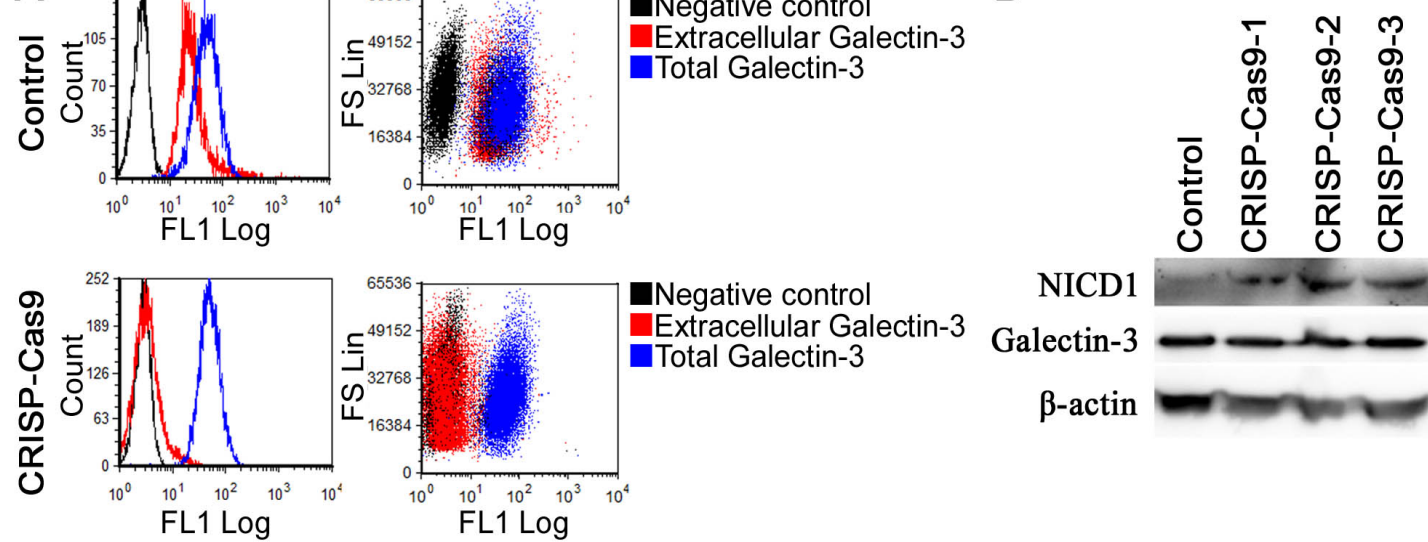

Galectin-3

$\beta$-actin

Figure 1. Intracellular galectin-3 modulate Notch activation.

(A) MKN45 cells were transfected with the plasmid pX330 (Addgene) containing 3 different oligo sequences targeting galectin-3 gene or with $\mathrm{pX} 330$ empty vector (control). After $72 \mathrm{~h}$ of transfection, cells were incubated with anti-galectin-3 antibody and anti-rat-Alexa488 antibody to assess galectin-3 extracellular expression. In addition, cells were permeabilized and incubated with anti-galectin-3 antibody to evaluate total galectin-3 expression. After staining, cells were analyzed by cytometry. Representative result for one oligo (CRISP-Cas9) is shown.

(B) Alternatively, total protein extract from MKN45 control cells or cells transfected with 3 different oligos that target galectin-3 were isolated and NICD1 and galectin-3 were evaluated by western blot. $\beta$-actin was used as a loading control. 


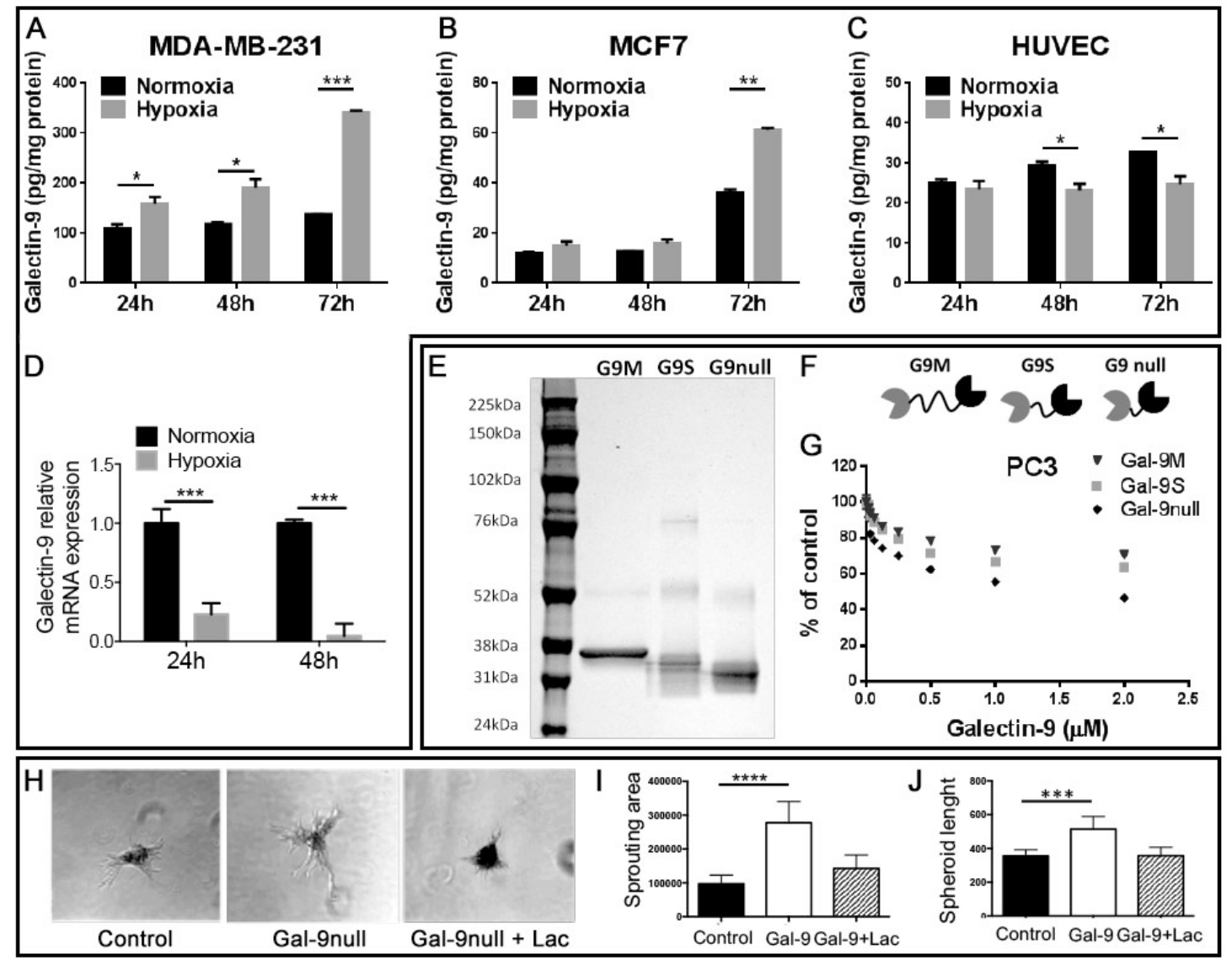

Figure 2. Galectin-9 modulates sprouting angiogenesis.

(A-C) Galectin-9 is secreted by cancer cells under hypoxic conditions, but not by endothelial cells. The concentration of galectin- 9 in supernatants was determined by ELISA following culture of breast cancer cells (A and B) and endothelial cells (C) cells under normoxic ( $21 \%$ O2) or hypoxic ( $1 \% \mathrm{O} 2)$ conditions for $24 \mathrm{~h}, 48 \mathrm{~h}$ and $72 \mathrm{~h}$. The data are expressed at $\mathrm{pg} / \mathrm{mg}$ protein, with total protein concentration determined using the method of Lowry.

(D) Total RNA was isolated from HUVECs under normoxic $(21 \%$ O2) or hypoxic $(1 \%$ O2) conditions for $24 \mathrm{~h}$ and $48 \mathrm{~h}$, and the expressions of galectin-9 mRNA was determined by realtime PCR. The relative level of expression was normalized to the level of $\beta$-actin.

(E) $10 \mu \mathrm{g}$ of recombinant galectin-9M, galectin-9S and galectin-9 null were run in an SDSPAGE and stained with commassie blue.

(F) Schematic overview of galectin-9 mutants form.

(G) Prostate cancer cell (PC3) were grown in a 96 well plate and incubated with a serial dilution of galectin-9M, galectin-9S or galectin-9null for $48 \mathrm{~h}$. Cellular viability was measured 
with SRB (sulforhodamine B) and data are presented as percentage of viable cells in comparison to the control.

(H-J) HUVEC were grown into spheroids and embed in growth factor reduced matrigel. Galectin-9 (Gal-9null) (+/- lactose) was added to the spheroids for 15 min prior to embedding. (H) Pictures were taken 48hrs after embedding. Quantification of assay with average area of spheroid $(\mathrm{I})$ and average length of longest sprout $(\mathrm{J})$.

${ }^{*} p<0,05 ;{ }^{* *} p<0,01 ;{ }^{* * *} p<0,001 ;{ }^{* * *} p<0,0001$ (bar=S.D, $\left.n=3\right)$. 